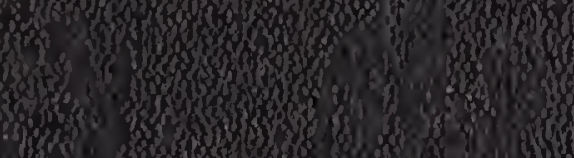




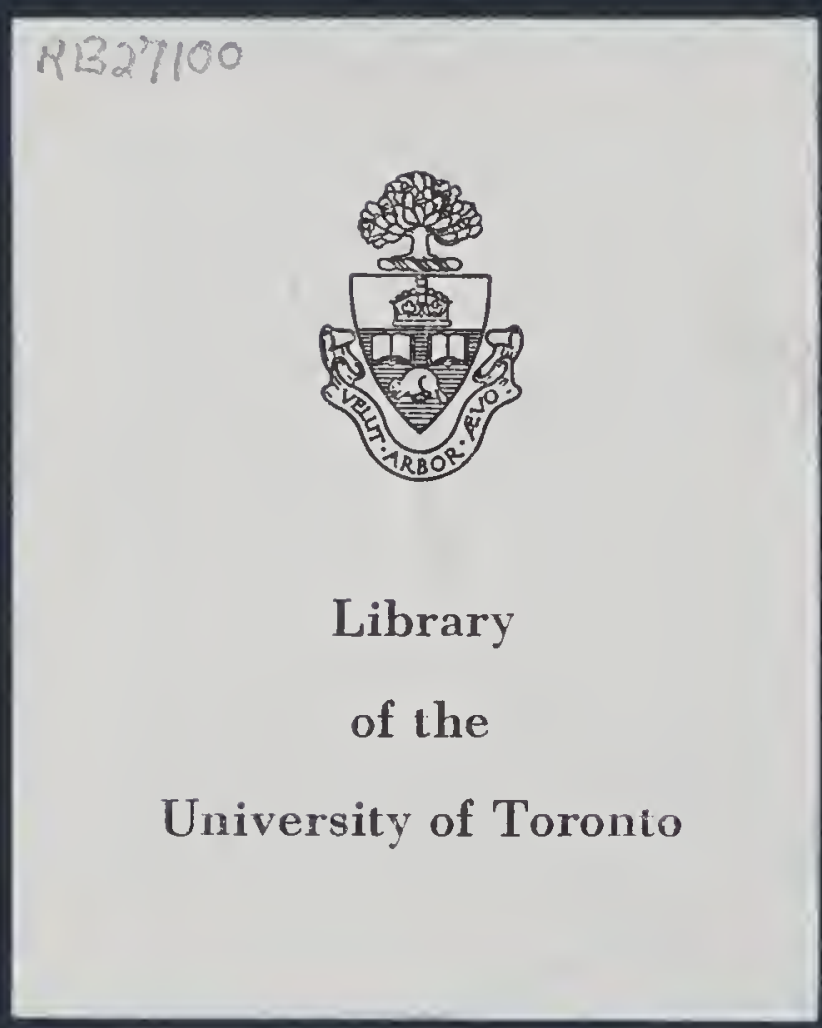




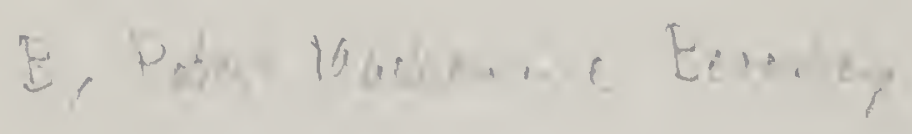

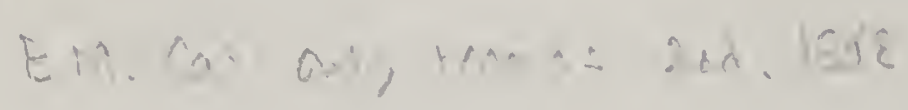

$$
1
$$


Sratle $\frac{112}{2 e}$

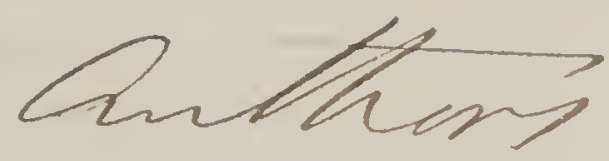

Conpliments

\section{TRANSHUTATION OF SPECIES}

EXAMINED. 
Digitized by the Internet Archive in 2020 with funding from University of Toronto 


\title{
THE DARWINIAN THEORY
}

\author{
OF TIIE
}

\section{TRANSMUTATION OF SPECIES}

EXAMINED BY

\section{A GRADUA'TE OF THE UNIVERSITY OH CAMBRIDGE.}

LONDON :

JAMES NISBET \& CO,, 21, BERNERS STREET. 1867.

[All Rights reserved.] 
JUHA CHILS AND SON, PRINTERS. 


\section{PREFACE.}

The following examination of Mr Darwin's 'Origin of Species' is intended as a 'common-sense answer to a Theory, which needs only to be carefully compared with itself to be completely confuted. By a common-sense answer is meant such a view as any person of ordinary understanding would take of the question of design, in any of the more striking instances of contrivance for a special object, in the works of Nature. In Mr Darwin's Theory the idea of design in every form of organic life is steadfastly denied, and it is asserted that all existing plants and animals have been produced by slow changes, without any plan or intention, from some antecedent forms.

To oppose this Theory the following pages have been written, in a full confidence that the common sense of mankind cannot be mistaken in this momentous question; and that it can only be by an artificial pressure on the reasoning faculties that any one can be induced to believe in the accidental evolution of organic beings.

As a more particular illustration of the meaning of a common-sense answer, take the following passage from Cicero: 'As soon as the animal is born, if it be one that 
is to be nourished by milk, almost all the food of the mother turns to milk, and the young animal, without any direction, by the pure instinct of nature, immediately seeks for the teat, and is therefore fed with plenty: That which makes it evidently appear that there is nothing in this fortuitous, but the work of a wise and foreseeing Nature, is that those females which bring forth many young, as sows and bitches, have many teats, and those which have a small number have few.'-(De Nat. Deorum, 52.)

This popular illustration of the argument of design is in fact as convincing as anything we could learn from a scientific disquisition of the highest order : it is one of the ten thousand cases to be found in Nature; and if any one of them be admitted to be true, it must be fatal to the 'Theory of 'Transmutation.

Should any one be disposed to object that it is presumptuons, without a panoply of science and ability, to confront a giant in the physiological kingdom, the answer would be that when great men leave the beaten track of acknowledged science to wander in the wilderness of fiction and paradox, they lose much of their redoubtable attributes, and come down to the level of meaner intellects; for, to use the words of Shakspeare, 'See now how wit may be made a Jack-a-lent, when 'tis upon ill employment.'-(Merry Wives of Windsor.)

At any rate such has been the conviction of the writcr of these pages, so that he has entertained a hope that if there be yet Goliatlis in the world, there may be still found some smooth stones of the brook adequate for the formidable duel.

Mr Darwin, in the legitimate walks of science, stands high among the chicf; for to say nothing of other pub- 
lications, who, in this generation, has given to the world a more instructive or a more beautiful book than 'the Researches of the Cruise of the Beagle'? A new edition of the work is advertised, and it is to be hoped that it will appear without any alterations or additions, to accommodate it to the author's new creed. A view of Nature taken as the production of the Creator's will, can never be made to harmonize with the blind force of cellular tissues sprouting by accident into all the phenomena of life.

M. Flourens has published a short answer to Mr Darwin, contenting himself chiefly with pointing out the abuse of terms, and the verbal inaccuracies with which the Origin of Species is argued. 'The answer, as far as it goes, is very effective, and successfully assails the foundation of the Theory; but it is to be regretted that a writer, so well qualified for the task, should have confined himself chiefly to one view of the subject.

The services of Professor Philipps in this cause have been considerable. Quotations from his valuable publication, 'Life, its Origin and Succession,' appear in the following chapters.

The whole of this controversy was indeed agitated more than thirty years ago, when Professor Sedgwick undertook to confute the author of the 'Vestiges of Creation' in a celebrated article in the Edinburgh Review, and in another examination of the Theory of Transmutation in the learned Professor's prolegomena to the Studies of the University of Cambridge. The Vestiges never recovered from that severe concussion; the book has ever since been considered an exploded romance by the scientific world.

Mr Darwin places himself in the old battle-field occupied by the Vestiges, maintaining in reality the very 
ground held by his predecessor. In the method of managing the argument there is a difference between the two writers, but in the object of the argument there is none; so that the force of proof urged by Professor Sedgwick against the Vestiges, applies in most points against Mr Darwin's Origin of Species.

In the Edinburgh Review there have been some able articles on Mr Darwin's Theory. In the April number of 1863, an article, of which the title is, 'Professor Huxley on Man's place in Nature,' is well worthy the careful attention of all those interested in this subject. 'The Review quotes an observation of Dugald Stewart: 'From those representations of human natme which tend to assimilate to each other the faculties of man and of the brutes, the transition to atheism is not very wide.' *

This transition is pointed out in the following pages, and it is shown how with some of the disciples of 'T'ransmutation there is no wish to conceal the atheistic import of the Theory.

'I'he Edinburgh Review remarks 'that it is necessary we should know to what this so-called Theory of Development is leading us. If it means that all the phenomena of the universe are the result of Nature's great progression from blind force to conscious intellect and will, to which alone we are to ascribe creative power, that is purely and simply the scientific form of the doctrine which denies a Creator altogether, or places the creative mind at an incalculable distance from its works' (p. 589).

* One of these articles is from the pen of the Duke of Argyll, for a part of it at least re-appears in 'the Reign of Law,' a book destined to celebrity for its successful opposition to Mr Darwin's Theory, as well as for its other intrinsic merits. 
The question of design in the phenomena of Nature compels an advocate of that view to assume a position on the very border's of theology in all the topics under discussion; it has however bcen the aim of the writer to speak with reserve on the higher aspect of the argument, and to keep for the latter part of the examination a direct reference to the atheism of Transmutation. There need be no apprehension of any serious damage likely to accrue to the received opinions from the disciples of this school, notwithstanding the positiveness of their doctrine, and its high pretensions. Common sense will, in the long run, be too strong for all their efforts, and civilized society will continue to entertain that indelible faith by which we believe "that the world was framed by the word of God, so that the things which are seen wore not made of the things which do appear ;' a formulary of words which precisely excludes Mr Darwin's Theory.

The interests of science may, however, suffer detriment for a season by the agitation of this controvcrsy, and we may fear that the partisans of Transmutation will be disputing about the interests of their hypothesis, and neglecting the higher pursuit of strict science. When we find learned men occupied about such questions as 'chains of linking forms taking a circuitous sweep, and extinct forms which geological research has not revealed' (Darwin, 324), this scems little better than the sterile occupation of blowing soap-bubbles of the imagination, to the neglect of all the more exact demands of science.

Cuvier has thus expressed himself on this subject: " "The

* 'L'échelle prétendue des êtres n'est qu'une application erronée à la totalité de la création, de ces observations partielles qui n'ont de justesse qu'autant qu'on les restreint dans les limites où elles ont été faites, et eette 
pretended chain of beings, as applied to the whole creation, is but an erroneous application of those partial observations, which are only true when confined to the limits within which they were made; and in my opinion it has in these modern times impeded, to a degree which can scarcely be imagined, the progress of natural science.'

All this will, however, at last come right; and certain stars that have shot madly from their spheres, after a temporary blaze, will pass into the darkness of oblivion. Mr Darwin's labours in the interests of Transmutation must either be triumphant, or there will be an end of that Theory for ever; for as no one with so good a chance of success will ever appear again, if he should fail of his object, Transmutation will have to be carted back to the family vault of Epicurus, from which it was exhumed, and which is its congenial and appropriate resting-place.

application, selon moi, a nui, à un degré que l'on aurait peine à imaginer, aux progrès de l'histoire naturelle dans ces dernier's temps.'-Règne Animal. Préface.

Cuvier, in the dedication of his 'Ossemens Fossiles' to Laplace, mentions it as a great advantage to himself in his earlier days that by associating with the geometricians and philosophers of the Institute, he was, to use his own words, 'penetrated with that severe spirit' of synthesis and method which regulated his thoughts in lis subsequent labours. It is greatly owing to that severe spirit that he became so illustrious in the scientific world. The imagination in him was held in firm restraint, without repressing the quickness of his sagacity and his innate genius. When the imagination is left at liberty in scientific pursuits, the result is almost always error and confusion.

'J'ai put surtout m'y pénétrer de cet esprit sévère, fruit de l'heureuse association établie dans son sein entre les mathématiciens et les naturalistes.' 


\section{CONTENTS.}

CIIAP.

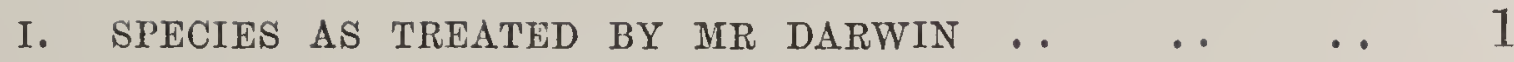

II. SPECIES AS DEFINED BY NATURALISTS . . $\quad \ldots \quad \ldots \quad \ldots 12$

III. MR DARWIN'S CENSURE OF SPECIES $\ldots \quad \ldots \quad \ldots \quad \ldots 23$

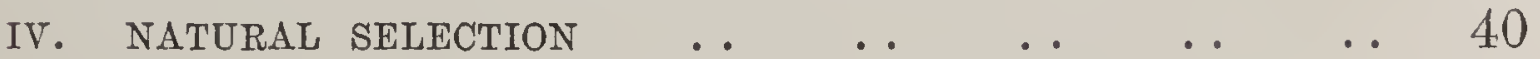

v. THE FUNCTIONS OF NATURAL SELECTION $\ldots \quad \ldots \quad 52$

VI. NATURAL SELECTION OPERATING IN INSTINCT . . . . 70

VII. NATURAL SELECTION IN THE ARCHITECTURE OF THE

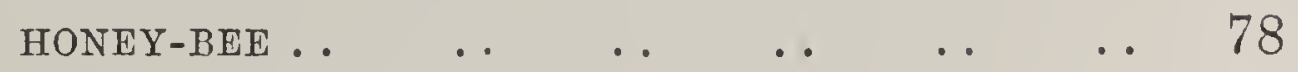

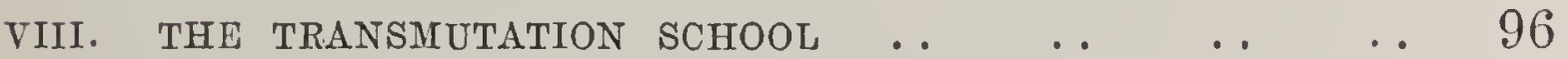

IX. M. TRÉMAUX'S THEORY . $\quad \ldots \quad \ldots \quad \ldots \quad \ldots \quad \ldots 118$

X. STRICTURES ON MR DARWIN'S THEORY . . $\quad \ldots \quad \ldots 135$

XI. THE GEOLOGICAL QUESTION $\ldots$.

XII. LYELL'S CONFUTATION OF TRANSMIUTATION $\ldots \ldots 198$

XIII. THE ORGANIC SIMILARITY OF ANIMALS .. . . . . 231

XIV. ORGANIC DISTINCTIONS $\ldots \quad \ldots \quad \ldots \quad \ldots \quad \ldots \quad \ldots 260$

XV. THE ARGUMENT OF DESIGN $\ldots \quad \ldots \quad \ldots 284$

XVI. THE CONCLUSION

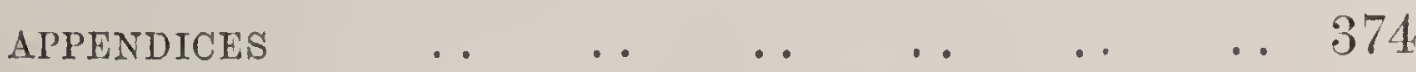





\section{TRANSMUTATION OF SPECILS EXAMINED.}

\section{CHAPTER I.}

\section{SPECIES AS TRFATED BY MR DARIIN.}

Mr Darwin begins his Introduction to the Origin of Species by the following words:-_ When on board H.M.S. Beagle as naturalist, I was much struck with certain facts in the distribution of the organic beings inhabiting South America, and in the geological relations of the present to the past inhabitants of that continent. These facts seemed to throw some light on the origin of Species ; that mystery of mysteries, as it has been called by one of our greatest philosophers.'

Thus are we enabled to fix a date for the first suggestion of that theory which appears in its full maturity in 'the Origin of Species.' The cruise of H.M.S. Beagle was from the year 1832 to 1836 , and Mr Darwin's publication of his researches in that cruise was in the year 1840 .

In the last pages of the Researches is an interesting passage recommending to young naturalists a journey in 
distant countries. After suggesting some reasons for undertaking such a journey, Mr Darwin adds, as a sort of warning, 'Moreover a number of isolated facts soon become uninteresting, the habit of comparison leads to generalization. On the other hand, as the traveller stays but a short space of time in each place, his descriptions must generally consist of mere sketches, instead of detailed observations. Hence arises, as I have found to my cost, a constant tendency to fill up the gaps of knowledge by inaccurate and superficial hypotheses' (608).

These very remarkable words show, by the Author's own confession, the tendency of his mind at that period; and though he has not informed us what those inaccurate and superficial hypotheses might be, yet as he has told us that at that time he was pondering on the origin of species, it seems obvious to connect the hypotheses with the lucubrations. Whether we should be justified in so doing may be determined after a careful examination of the whole subject.

In a discussion on the origin of species, the first requisite would have been a definition of Species by the author, that we might accurately understand his object, and be sure that we had not misunderstood his meaning. Never was there a term that more needed a careful definition than Species, for besides the deep importance of its true signification, many definitions of it have been propounded by many naturalists, so that unless Mr Darwin gives us his definition, we are left in the dark just in the point where light was most wanted. In this state the question commences. Mr Darwin not only has omitted to define what he intends by Species, but has made such contradictory statements on the subject (as we shall presently see), that we can only 
endeavour to guess at his meaning by collecting his various assertions and making as just a comparison of them as the case will admit,

This therefore must be our first task, to collect Mr Darwin's statements on the subject of Species, after which we may examine the deductions resulting from the statements.

'I look,' says Mr Darwin, ' on the term Species as one arbitrarily given for the sake of convenience to a set of individuals closely resembling each other, and that it does not essentially differ from the term Variety, which is given to less distinct and more fluctuating forms' (54).

This is the nearest approximation to a definition which Mr Darwin has given us, though it only amounts to a negative statement, ' that is, that Species and Variety do not essentially differ,' which, put in the positive form, will read, 'that Species and Variety are essentially the same,'-a start. ling proposition without doubt, and begging the whole question in limine; for if this be true, there is no such thing as Species, which indeed we are told is a term arbitrarily invented ; and then it will follow that nature's barrier against indefinite mutability is got rid of, and a clear stage made for $\mathrm{Mr}$ Darwin's theory. As this is, lowever, the only approach to a definition with which $\mathrm{Mr}$ Darwin has favoured us, we must observe, that there is enveloped in it a contradiction, concealed in artful words. 'The term Variety,' we are told, 'is given to less distinct and more fluctuating forms?' Therefore Species is more distinct and less fluctuating. If Species is distinct and does not fluctuate, then it does essentially differ from Variety, which, as Variety, is not distinct and does fluctuate. But what does fluctuate mean here? It means that varieties can interchange and cross, without barrier, and that species can not. It means, for example, 
that all the varieties of the dog can permanently fluctuate, inter se, making fertile crosses without limit, but that the species dog and the species fox can not.

Thus in fact Mr Darwin here confirms, as in other passages, the point he denies.

Take again this statement. 'I look at varieties which are in any degree more distinct and permanent as steps leading to more strongly marked and more permanent varieties, and these latter leading to a sub-species, and so to species' (54). 'Hence I believe a well-marked variety may be considered an incipient species.'

The argument is curious, Species does not essentially differ from Variety, and yet there are varieties of a marked character differing from their congeners, in having the quality of greater permanency - ' they are more permanent' - these more permanent varieties are gradually advancing to the higher dignity of sub-species, and so ultimately to species where their permanent character is fully established. Well, then, permanency is, by Mr Darwin's own showing, the attribute of Species, and it is not that of Variety. Variety changes by slow but steady gradations till it becomes Species, and then its mutation is arrested for a long period of time, and all this is stated to make us understand that Species and Variety do not essentially differ!

But surely varieties might save themselves all this trouble, for if they do not essentially differ from that towards which they are progressing, why make a stir for the change? and why persuade nature to make alterations for no conceivable object?

Again. 'It may be asked, how is it that varieties, which I have called incipient species, become ultimately converTED 
INTO GOOD AND DISTINCT SPECIES, which in most cases obviously differ from each other far more than do the varieties of the same species' (64).

Here then, after all, there is such a thing as a good and distinct species, and varieties differ so from them that a conversion, a change of character and quality, is to take place, and the fluctuating Variety is to become ' a good and distinct Species.' If this does not show an essential difference, how is it to be shown? and what more could we contend for who are fully convinced of the permanent and irrevocable laws of creation?

Again, in speaking of the difference between the primrose and the cowslip, Mr Darwin says: "We could hardly wish for better evidence of the two forms being specifically distinct. On the other hand, they are united by many intermediate links, and it is very doubtful whether these links are hybrids; and there is a large amount of experimental evidence, showing that they descend from common parents, and consequently must be ranked as varieties' (52).

Here, in fact, is a tacit acknowledgment of all that naturalists have usually advanced on the subject of species. Creatures that descend from common parents are varieties of a species. If experiments of a large amount prove this, it is proved that they are varieties. If the links that unite them are not hybrids, this is also a proof. Hybridity is the result of an artificial violation of species, non-hybridity means fecundity and fertility. The cross between the Newfoundland and the Greyhound is not hybrid, though the difference of form is great between them. The cross between the jackal and the dog is hybrid. All this, we shall find, has often been asserted, and has been held suf- 
ficient to establish the definite distinctions of nature. 'The vast majority of naturalists have agreed with $\mathrm{Mr}$ Darwin that there is such a thing as good and distinct species.

'The real difference between Mr Darwin and other writers is, that he puts the cart before the horse; and that when others say that Species has produced multiplied Variety, Mr Darwin affirms that Variety is on the way to produce Species. He takes a prophetical view of the subject, denying that Species differs from Variety at present, though believing that it will differ in 'ages to come ;' nevertheless, he also states that good and distinct species do already exist, and with this confusion and these contradictions we have to make out as well as we can what Mr Darwin means by Species.

After all this, it is curious to hear Mr Darwin make this remark: "To discuss whether such forms are rightly called species or varieties before any definition of these terms has been accepted, is vainly to beat the air' (51). There are more ways of beating the air than one, and this we think Mr Darwin has taught us ; but why then has not Mr Darwin himself given us a definition of the thing he is attacking? He is writing down Species as an 'arbitrarily invented term,' and yet he never explains to us what he understands himself by the term. It is with him a phantom indeed-now here, now there-in no tangible form, for he neither describes to us what it is that he is attacking, nor does he give the definition of it by any other writer. He may be contradicting Buffon, Cuvier, De Candolle, Von Baer, St Hilaire, Herder, or others; we cannot pretend to say what particular statement he may object to; only this we very clearly perceive, that he means by Species an established barrier of nature, ordained to prevent confusion, and this is the point 
on which we meet him. It is this point which will be dis. cussed in the next chapter.

Mr Darwin, however, finishes his book with a full confidence that he has got rid of Species. 'Hereafter', says he, 'we shall have to treat Species in the same manner' as those naturalists treat Genera, who admit that genera are merely artificial combinations made for convenience. This may not be a cheering prospect, but we shall at least be freed from the vain search for the undiscovered and undiscoverable essence of the term Species' (520).

And yet $\mathrm{Mr}$ Darwin has himself discovered that 'good and distinct Species' unquestionably exist! and more than this, he prophesies that Varieties are advancing in progress to be converted into Species; so that if the prospect is not cheering, it must be least of all so to the author of these predictions; we may have to lament the loss of that which is, and which Mr Darwin also slily admits, but in addition to this he will have to mourn over the loss of that which is to be. He that seeks to bereave himself of the present, and anticipates a privation of the future also, is certainly in a 'cheerless' plight.

We owe to the Duke of Argyll, in his valuable publication, 'The Reign of Law,' some deeply interesting remarks on Humming-birds, as illustrating the law of Species. For our present purpose it will be sufficient to state the facts as the noble author has given them from ' Gould's 'I'rochilidæe.'

Of the family of Humming Birds four hundred and thirty species are known, and all these belong to the great continent of America and its adjacent islands. Within these limits there is every range of climate, and there are particular species of Humming Birds adapted to every region where a flowering vegetation can exist. Mr Gould 
observes, on their beautiful appearance: 'That the member's of most of the genera have certain parts of their plumage fantastically decorated, and in many instances most resplendent in colour. My own opinion,' says he, 'is that this gorgeous colouring of the Humming Birds has been given for the mere purpose of ornament, and for no other purpose of their special adaptation in their mode of life; in other words, that ornament and beauty, merely as such, was the end proposed.'

This of course, if it be a right deduction, is 'absolutely fatal' to Mr Darwin's theory; for he has told us this in so many words.

Mr Gould proceeds: 'It might be thought by some persons that four hundred species of birds so diminutive in size, and of one family, could scarcely be distinguished from each other, but any one who studies the subject will soon perceive that such is not the case. Even the females, which assimilate more closely to each other than the males, can be separated with perfect certainty; nay, even a tailfeather will be sufficient for a person well versed in the subject, to say to what genus and species the bird from which it has been taken belongs. I mention this fact to show that what we designate a species has really distinctive and constant characters, and in the whole of my experience, with many thousands of Humming Birds passing through my hands, I have never observed an instance of any variation which would lead me to suppose that it was the result of a union of two species. I write this without bias, one way or the other, as to the question of species. I am desirous of representing nature in wonderful ways, as she presents herself to my attention, at the close of my work, after a period of twelve years of inces- 
sant labour, and not less than twenty years of interesting study.'

'The reader will please to observe, that whatever Mr Darwin may advance against Species, as a recognized distinction in nature, he, nevertheless, continually acknowledges it, and founds much of his reasoning on its existence, at the risk of the most manifest contradiction. Hence he says: 'It need not be supposed that all varieties, or incipient species, necessarily attain the rank of species' (54), an expression by which we clearly see that he means species as a resting-place for varieties, as the last step of their promotion. And again: 'On the view that species are only strongly marked and permanent varieties, and that each species existed as a variety we can see,'\&c., \&c. . . (503). Here Permanency is, without any circumlocution, made 'a characteristic of Species,' and coupling this with the other statement that varieties are acivanced to the rank of species, it is plain enough that Mr Darwin feels that to be a reality which it is the object of his whole book to disprove. How indeed would it be possible for a naturalist to compose a long treatise on the origin of Species, and not acknowledge the palpable fact that plants and animals are arranged in certain permanent partitions, and that owing to these partitions they always remain the same?

Now we have seen that Mr Darwin acknowledges both indirectly and directly that Permanency is a character of Species, an acknowledgment which of course would be fatal to his theory; but Mr Darwin so often deals fatal blows with his own hands against his own system, without any apparent suspicion of having done it any injury, thai we need not be surprised at his continuing the controversy as if nothing unusual had happened. 
It is not our business to reconcile but to state the contradictions we find in the Theory. Now though permanency is this attributed to species, it certainly is not the author's intention that we should understand this literally; for if so, how, according to his Theory, have all existing animals appeared on the scene? They are all altered forms of antecedent species, which have been swept away in the struggle for life. Species have been changed repeatedly in the millions of ages of geological time. The nearest approach therefore that we can make by conjecture to any elucidation of this confusion is, that species may be considered permanent in historical, but mutable in geological time. If the learned author has any other meaning than this, he has failed to make it intelligible; but even with this interpretation the contradiction does not disappear, and the general result amounts to this, that the grand principle of the system may be expressed as MUtabid PERnanenct.

In the mean while we may be amused as well as instructed with noticing Mr Darwin's opinions on the questions before us, at the time he wrote his Researches in the cruise of the Beagle. In speaking of certain birds found in Terra del Fuego, he says: 'When finding, as in this case, any animal which seems to play so insignificant a part in the great scheme of nature, one is apt to wonder why a distinct species should have been created; but it should always be recollected that in some other country perhaps it is an essential member of society, or at some former period may have been so' (354). And again: 'Unless we suppose the same species to have been created in two different countries, we ought not to expect any closer similarity between the organic beings on opposite sides of the Andes, than on shores separated by a broad strait of the sea' (400). And 
once more: 'We see the whole series of animals, which have been created with pecnliar kinds of organization, are confined to certain areas, and we can hardly suppose these structures are only adaptations to peculiarities of clinate or country, for otherwise animals belonging to a distinct type, and introduced by man, would not succeed so admirably even to the extermination of the aborigines. On such ground it does not seem a necessary conclusion that the extinction of species more than their creation should exclusively depend on the nature (altered by physical changes) of the country' (212).

Here we have passages acknowledging Species as an established distinction in animal life, and as created to be so, for on the subject of creation Mr Darwin speaks in his Researches with the utmost clearness. In describing the pit-fall of the lion-ant as seen in South America, he says, ' 'There can be no doubt but that this predacious larva belongs to the same genus with the European kind, though to a different species. Now what would the sceptic say to this? would any two workmen ever have hit upon so beautiful, so simple, and yet so artificial a contrivance? It cannot be thought SO, ONE HAND HAS SURELY WORKED THROUGH THE UNIVERSE' (527).

'These striking words we have ventured to place as the motto to our title-page. 


\section{CHAP'TER II.}

\section{SPECIES AS DEFINED BY NATURALISTS.}

THE theory which is here under consideration has this essential character, that it denies the fixedness of nature and invests all living organisms with inherent mutability. Alterations, transmutation, and 'conversion' into new states and forms of life, even into those most unlike previously existing states and forms, have been the destiny of all beings, and will-in degree at least-be yet their destiny. Every plant and every animal, and even man himself, have come to their present actual condition through multiplied transformations; and every creature is still progressing towards some 'improvement,' till, as it is believed, perfection will be ultimately attained. These changes, which have always an object of individual improvement, are effected by matter itself, without the intervention of any controlling Intellect or Power superior to matter; organisms can change themselves in the lapse of ages, when such a place is open for them in existence that it will be for the benefit of the individual organisms that change should take place. This change however is not the result of the will and intention of the animals, for even plants have acquired all their peculiarities and 'contrivances' in this way-the changes take place by the gradual accumulation of profit- 
able additions or diminutions of quality. It is a result in all cases, but never a design.

Such being the theory, we meet it with the fact that in nature there is an insurmountable obstacle to this mutability, and that in consequence of it no such changes can take place, nor ever have taken place--and this obstacle is usually known by the term 'Species.' It is however to be remembered that the term is an invention of the human intellect, an abstract idea based on long-continued observations of nature-but that the word Species has no natural existence. This is a point not to be forgotten, for I find that Mr_Darwin makes his attacks on Species as if we believed that this ideal classification had an independent and real existence, so that if he can invalidate the term Species he seems to think he has got rid of his most formidable antagonist, or at any rate he hopes that we may think so. The term may stand for all that it is worth-and certainly the day has not yet come for abandoning it; in the mean time this is an unalterable fact, that there is in nature a barrier preventing this imaginary mutability, by an arrangement which is known to exist in organized beings, and this arrangement, by general consent of physiologists, constitutes the divisions and boundaries of species.

This is the question now for our inquiry. We have seen what Mr Darwin has said on the subject; we will now adduce the opinions of other writers on Natural History.

M. Flourens says : 'Il y a deux caractères qui font juger de l'espèce, la forme, ou la ressemblance, et le fécondité. Mais il y a longtemps que j'ai fait voir que la ressemblance, la forme, n'est qu'un caractère accessoire. L'espèce est d'une fécondité continue, ce qui prouve qu'elles ne sont pas sorties de l'espèce, qu'elle ne sont quie l'espèce, qui s'est diverse- 
ment nuancée. Au contraire les espèces sont distinctes entre elles, par la raison décisive, qu'il n'y a entre elles qu'une fécondité bornée. J'ai déja dit cela, mais je ne saurais trop le redire' (34).

These very obvious truths M. Flourens confirms by a quotation from Buffon: "The comparison of the resemblance of individuals is but an accessory idea, and often independent of the first-the constant succession of individuals by generation - for the ass is more like the horse than the waterspaniel is to the greyhound, and nevertheless the waterspaniel and the greyhound are but one species, since they produce together individuals which can themselves produce others in the same way, whereas the ass and the horse are certainly of different species, since they produce together only faulty and sterile animals.*

'This brief explanation is to be found more at length in other passages of Buffon's Natural History, and one of these will be found in the note.t 'The whole subject is lucidiy stated in Müller's Elements of Physiology. We are compelled, for brevity's sake, to refer the reader to the work itself.

Thus then the matter stands; the mixture of species

* Buffon, Histoire de l'âne.

$\dagger$ 'D'ailleurs il y a encore inn avantage pour reconnoitre les espèces d'animaux, et pour les designer les uns des autres, c'est qu'on doit regarder comme la même espèce celle qui, au moyen de la copulation, se perpetue, et conserve la similitude de cette espèce, et comıne des espèces différentes celles qui par les mêmes moyens ne penvent rien produire ensemble; de sorte qu'un renard sera une espèce différente d'un chien, si en effet par la copulation d'un mâle et d'une femelle de ces deux espèces il ne resulte rien; et quand même il en résulterait un animal mi-parti, une espèce de mulet, comme ce mulet ne produirait rien, cela suffiroit pour établir que le renard et le chien ne seroient pas.de la même espèce, puisque nous avons supposé que pour constituer une espèce, il falloit une production continue, perpétuelle, invariable, semblable en un mot à cette des autres animaux' (x. 285).

+ Vol. II. p. 1661 . 
produces a hybrid progeny when there is any product at all, and this hybrid progeny cannot with its hybrid congeners have any descendants. The union of the dog and jackal, like that of the horse and ass, may produce a hybrid or mule, but these mule-animals united with other mules are sterile. The hybrid dog-jackal, with either dog or jackal, that is, with either side of the pure races, may have progeny; and, supposing the father to be a dog, the progeny of the second experiment will approach much nearer the dog than the progeny of the first experiment. This, repeated in the next generation by a dog-father, will produce an animal all but a dog, and in the fourth generation the result will be a pure dog, all trace of mixture having disappeared. Mules, amongst themselves, are always unproductive; and, as the mule is the attempt at a new animal, that attempt fails, for the artificial breed cammot be continued.

Animals of the same species, but distinguished as a race, however dissimilar in appearance, such as the bloodhound and water-dog, are prolific in their descendants, the descendants will be fertile mongrels, but not hybrids.

All the races of dogs are fertile with one another, and their fecundity continues in their descendants, whatever the mixture may have been. Yet these mongrels continue to be dogs; no new animal is formed, and the boundaries of this which we call species are not transgressed. We cannot make a race of new animals.

Cuvier has remarked: 'La nature a soin d'empêcher l'alteration des espèces, qui pourroit résulter de leur mélange, par l'aversion mutuelle qu'elle leur a donnée: il faut toutes les ruses, toute la contrainte de l'homme pour faire contracter ces unions, même anx espèces qui se 
ressemblent le plus ..... aussi ne voyons nous pas dans nos bois d'individus intermédiaires entre le lièvre et le lapin, entre le cerf et le daim, entre la marte et la fouine?' (Discours preliminaire, p. 76.)

'This is confirmed by Lyell, in an interesting passage specially in reference to the vegetable kingdom, in his Principles of Geology, third edition (ii. 390).

The celebrated John Hunter has observed that the true distinction of species must ultimately be gathered from their incapacity of propagating with each other, and producing offspring capable of again continuing itself; and Lyell, in adducing his testimony, observes that no proof has been obtained that a true hybrid race can be perpetuated.

De Candolle, after discussing the subject, concludes with these words: 'I see, then, that there exist in organized beings permanent differences which cannot be referred to any one of the actual causes of variation, and these differences are what constitute species.' (Essai elémentaire.)

The following passage in Lyell's Geology (at least in the earlier editions) is well worthy of observation; for though written against Lamarck, the true founder of Mr Darwin's theory, and several years before 'The Origin of Species' was published, it is, in fact, a home-thrust at $\mathrm{Mr}$ Darwin.

'I may remark that if it could be shown that a single permanent species had ever been produced by hybridity (of which there is no satisfactory proof), it might certainly have lent some countenance to the notions of the ancients respecting the gradual deterioration of created things, but none whatever to Lamarck's (Darwin's) theory of their progressive perfectibility, for observations have hitherto sliown that there is a tendency in mule animals and plants to degenerate in organization' (ii. 336). 
The sentiments uttered by other physiologists are repeated by Lawrence, ${ }^{*}$ who quotes in confirmation the words of Cuvier. 'I have carefully examined the figures of animals and birds engraven on the numerous obelisks brought from Egypt to ancient Rome. In the general character, which is all that can have been preserved, these representations perfectly resemble the originals, as we now see them. My learned colleague, M. Geoffroy St Hilaire, collected numerous mummies of animals from the sepulchres and temples of Upper and Lower Egypt. He brought away cats, ibises, birds of prey, dogs, monkeys, crocodiles, and an ox's head, embalmed. There is no more difference between these relics and the animals we are now acquainted with, than between the human mummies and the skeletons of the present day.' $\dagger$

Lawrence concludes his disquisition on the subject thus: 'We may conclude, then, from a general review of the preceding facts, that nature has provided, by the insurmountable barrier of instinctive aversion, of sterility in the hybrid offspring, and in the allotment of species to different parts of the earth, against any corruption or change of species in wild animals. We must therefore admit, for all the species which we know at present, as sufficiently distinct and constant, a distinct origin and common date' (200).

With all this evidence we are enabled to see that in the realities of nature the system of constant mutation can have no place, and that it must be restricted to the region of the imagination where it had its origin. We shall see ere long that Mr Darwin virtually accedes to the general

* See Lawrence's Lectures on Physiology (261), first edition.

+ Cuvier's Recherches sur les ossemens (Discours preliminaire, p. 71). 
deductions of other naturalists on this subject, by the concessions which he makes; indeed other writers, who are partially of his way of thinking, and who even more confidently reject the idea of creation, cannot but admit the actual fixedness of the forms of life upon the earth. M. Pouchet, a bold advocate of spontaneous generation for the origin of vertebrated life and a eulogist both of Lamarck and Darwin, acknowledges that it is only by supposing an immense period of time for the process that we can believe in a change of species. 'For us,' says he, 'if species be fixed, it is in the manner of the sun-that is to say, we cannot perceive the movement, so little are we in the account of time. It requires thousands of ages perhaps to establish a displacement of the sun or a transformation of a species' (193). In other words, there is no evidence to be had of such a transformation; we are to imagine therefore that it may be.

M. Pouchet lias established his position* by well-selected and convincing evidence of facts, and concludes his examination of the subject with these words :

'Du moins reste-t-il vrai et prouvé que, quand deux races très-differentes s'unissent, il ne faut esperer rien de bon non plus que rien de durable de leur union'. (156).

Now this we may say is the evidence of an opponent and therefore doubly valuable; for if an advocate of mutability of species can thus go out of the way to show the difficulty of mixing races, with any lope of a durable progeny, much less can he pretend to change species. As long as the learned author keeps within the region of facts and the known history of nature he tells us the real truth; but when he gets into solar cycles and manwantaras of * 'Un type moyen ne peut exister par lui'-même.' 
eastern mythical time, we then find ourselves amongst 'first organisms' coming into life by spontaneous genesis, and primary species arranging themselves for future adventures in multiplied transformations.

This then is the point we aim at, the existence of an ' insurmountable barrier' in nature to a system of indefinite change of form and character in organized beings. The continued fecundity of true species and the sterility of hybrids is this barrier, - a fact generally admitted by naturalists.

Such are the observations and deductions of learned physiologists; but the question is nevertheless one of common observation, and would be received in the commonly accepted view of the case by any one whose occupations led him to an ordinary acquaintance with plants or animals. The grazier and the market-gardener would confirm by their testimony the fact of the constancy of species, for the evidence to guide their judgment in the question is patent and notorious. That the popular view was also that of antiquity, we may see in Lucretius.

'Nam quod multa fuêre in terris semina serum Tempore quo primum tellus animalia fudit,

Nil tamen est signi mixtas potuisse creari

Inter se pecudes compactaque membra animantum, Propterea quia quæ de terris nunc quoque abundant Herbarum genera ac fruges arbustaque læata, Non tamen inter se possunt complexa creari, Sed res quæque suo ritu procedit, et omnes Fœdere naturæ certo discrimine servant.' (v. 916.)

A much more ancient testimony than that of Lucretius gires us the same information. 
'And God made the beast of the earth after lis kind, and cattle after their kind, and every living thing that creepeth upon the earth after his 7ind: and God saw that it was good.- And the earth brought forth grass, and herb yielding seed after his kind, and the tree yielding fruit, whose seed is in itself, after his lind: and God saw that it was good.'

This, in a more antique form of primitive simplicity, expresses, in substance, the doctrine which Cuvier, and Agassiz, and other celebrated naturalists have laboured to establish.

The following, in the 'Principles of Geology,' is Sir C. Lyell's recapitulation of his inquiry.

'For the reason therefore detailed in this and the two preceding chapters, we may draw the following inferences in regard to the reality of species in nature.

' 1 . That there is a capacity in all species to accommodate themselves, to a certain extent, to a change of external circumstances, this extent varying greatly, according to the species.

' 2 . When the change of situation which they can endure is great, it is usually attended by some modification of the form, colour, size, structure, or other particulars; but the mutations thus superinduced are governed by constant laws, and the capability of so varying form part of the specific character.

'3. Some acquired peculiarities of form, structure, and instinct are transmissible to the offspring ; but these consist of such qualities and attributes only as are intimately related to the natural wants and propensities of the species.

'4. The entire variation from the original type, which any given kind of change can produce, may usually be effected 
in a brief period of time, after which no further deviation can be attained by continuing to alter the circumstances, though ever so gradually: indefinite divergence, either in the way of improvement or deviation, being prevented, and the least possible excess beyond the definite limits being fatal to the existence of the individual.'

['This 4th article, is as perfect a denial of the theory of transmutation as words can express.]

' 5 . The intermixture of the distinct species is guarded against by the aversion of the individuals composing them to sexual union, or by the sterility of the male offspring. It does not appear that true hybrid races have ever been perpetuated for several generations, even by the assistance of man ; for the cases usually cited relate to the crossing of mules with individuals of pure species, and not to the intermixture of hybrid with hybrid.

' 6 . From the above considerations, it appears that species have a real existence in nature; and that each was endowed, at the time of its creation, with the attributes and organization by which it is now distinguished.' (iii. cap. 4.)

This deliberate decision on the important question of species, whilst it gives a correct and luminous exposition of the facts of nature, pronounces sentence of condemnation on the system of Lamarck, which is the same thing as passing censure on Mr Darwin's theory. These were the sentiments of Sir C. Lyell in the earlier editions of his Principles of Geology, but in the edition of that work now in the conrse of publication, and of which at present but one volume has appeared, it is to be presumed that other opinions will be expressed, and that the passage just quoted will be cancelled. 
As Sir C. Lyell has, in his Antiquity of Man, professed himself a disciple of 'Transmutation, his views in every question on which that theory depends must have undergone a change, and he must be considered now a teacher of a system opposite to that which he has hitherto upheld; and more than that, a champion of a cause which for more than thirty years of his life he vigorously opposed. Whatever may be the merit of his new opinions, the important point with those who might be disposed to listen to his instructions will be, that his present opinions are new, and that the renowned interpreter of Geology, to whom we have been accustomed to look for the soundest views of that noble bianch of science, has disappeared, to wander in pathis where we cannot follow him.

In the whole region of thought nothing can be further apart than the general doctrine of the Principles of Geology from the sentiments professed in the Antiquity of Man. That Sir C. Lyell should have passed over from the high vantage-ground he has so long enjoyed to the visionary school of Lamarck, is a mental metamorphosis as complete as the transition from one nature to another; so that the Transmutationists may boast; that however deficient may be their proofs of any corporeal transformation, they have, in this their illustrious convert, an undeniable specimen of intellectual transmutation. 


\section{CHAPTER III.}

MR DARWIN'S CENSURE OF SPECIES.

WE have seen Mr Darwin's statement of species, and have considered also the opinions of several celebrated naturalists on the same subject; we now have to examine Mr Darwin's arguments for opposing the received opinion.

His first exception to the acknowledgment of species is based on the great difficulty which he affirms there is in deternining correctly the species of several plants, 'there are genera in which the species present an inordinate amount of variation; and hardly two naturalists can agree which forms to rank as species, and which as varieties. We may instance Rubus, Rosa, and Hieracium among plants, and several genera of insects' (48). On this theme-the perplexity of the naturalists-he much enlarges : ' $\mathrm{Mr} \mathrm{H}$. C. Watson has marked for me 182 British plants, which are considered as varieties, but which nevertheless have been ranked by botanists as species. Under genera Mr Babington gives 251 species, whereas Mr Bentham gives only 112, a difference of 139 doubtful forms.' Well, let it be so. Let these learned gentlemen and a great many more puzzle themselves in framing their decrees about the species of plants; but are we then to come to this conclusion, that species has no real existence in nature because Messrs H. 
C. Watson and Babington have bewildered themselves in endeavouring to make proper distinctions? and in an abstruse subject, because there are many opinions and considerable disagreement, shall we get rid of the difficulty by boldly affirming that the subject itself is altogether ideal, and therefore may be dismissed as imaginary?

By this mode of argument we might clear the stage of many hard questions in physics, and many disputes in chemistry and geology might thus be very conveniently settled. Great is the difference of opinion that still exists in assigning the proper office to the pancreas in the internal structure of animals, and various have been the conjectures on the object of this organ and of the qualities of its secretion. It is a controversy not yet settled; and so much has been said on the subject by many English and continental anatomists, that the history of this discussion would fill a large volume. We might, however, compose all this learned agitation by denying that the pancreas had any functions to perform, and might even assign it a place in the animal economy amongst unoccupied appendages; and putting it on the shelf as 'an idle member,' might decree that it did once belong to some parent-form, from which other animals derived their origin, useful, and indeed necessary, to that parent-form, but no longer needed by its descendants. 'This would answer two purposes--it would furnish an analogy for the discarding of species, and serve as an auxiliary to the theory of transmutation.

Mr Darwin does not however fail to make the most of the ignorance of the naturalists, by again and again reminding us of it. 'It cannot be disputed that many forms, considered by highly competent judges as varieties, have so perfectly the character of species that they are ranked by 
other highly competent judges as good and true species (51). No clear line of demarcation has as yet been drawn between species and sub-species (53). The amount of difference considered necessary to give to two forms the rank of species is quite indefinite (61), \&c., \&c., \&c. But all such passages as these only prove that the naturalists have much to learn, that the art of accurate division is a very subtile and elaborate one, and that in the extremely delicate texture of plants (for it is to them that $\mathrm{Mr}$ Darwin refers) it requires an experienced eye, a long acquaintance with the subject, and much sagacity of observation, to come to a right decision - that these decisions in many cases are only designed to be temporary ; and as the field of botanical discovery enlarges, by a more perfect acquaintance with all regions of the earth, much yet will have to be re-cast and re-arranged, when the importation of additional knowledge into the hive of science shall call for the renewed labours of the workmen. Let, then, Mr Darwin manipulate the word 'species' as he likes, let him sometimes discard it and sometimes make use of it, and let him make the most he can of the perplexities of the physiologists, - we appeal from terms and words to nature itself, and there we say the great barrier to his system, insurmountable as the 'flammantia mœnia mundi,' is full before our eyes, and cannot be removed.

The substance of these remarks has been much better expressed by Lyell, who, in censuring Lamarck, has at the same time censured, by anticipation, Mr Darwin himself. 'Lamarck,' says he, 'has indeed attempted to raise an argument in favour of his system, out of the very confusion which has arisen in the study of some orders of animals and plants, in consequence of the slight shades of difference which 
separate the new species discovered within the last halfcentury.

'That the embarrassment of those who attempt to classify and distinguish the new acquisitions, poured in such multitudes into our museums, should increase, with the augmentation of their number, is quite natural; since to obviate this it is not enough that our powers of discrimination should keep pace with the increase of the objects, but we ought to possess greater opportunities of studying each animal and plant in all stages of its growth, and to know perfectly their history, their habits, and physiological characters, throughout several generations. For, in proportion as the series of known animals grows more complete, none can doubt that there is a nearer approximation to a graduated scale of being, and thus the most closely allied species will be found to possess a greater number of characters in common' '(ii. 348).

If, however, a longer time and further information should be required for a more correct classification, and if some licence for conjecture should be demanded, Mr Darwin has his objections: 'In very many cases one form is ranked as a variety of another, not because the intermediate links have actually been found, but because analogy leads the observer to suppose either that they do now somewhere exist, or may formerly have existed: and here a wide door for the entry of doubt and conjecture is opened " (49). Such an objection from this quarter is truly surprising, from one who for himself has opened so much wider a door for whole hosts of doubt and conjecture to pass through into the realms of chaos and primeval night. 'If my theory be true,' says Mr Darwin, 'it is inclisputable that before the lowest Silurian stratum was deposited, long. 
periods elapsed, as long as, or probably far longer than, the whole interval from the Silurian age to the present day; and that during these vast, yet quite unknown, periods of time, the world swarmed with living creatures' (333).

'This is 'indisputable,' that is, it cannot be disputed: though the learned author limself says that those periods of time are 'quite unknown,' swarms of living creatures of forms unknown, and beyond our imagination, for thousands of millions of ages have existed, though not a shred or a vestige of one of them is anywhere to be found-and yet, if a brother naturalist ventures to conjecture that there may have existed some missing links in a species of a flower, he is rebuked for opening a door to conjecture! Mr Darwin had better measure the width of his own door before lie complains of the doors of his neighbours.

In the eighth chapter we have the question of sterility discussed, and, as it will be seen, with ingenious management. First, lowever, it will be important to notice the concessions made to the question of sterility of hybrid animals : 'I doubt whether any case of a perfectly fertile hybrid animal can be considered as thoroughly well authenticated' (274). It is difficult, 'perhaps impossible, to bring forward one case of the hybrid offspring of two animals, clearly distinct, being itself perfectly fertile' (27). I do not know of any thoroughly well-authenticated case of a perfectly fertile liybrid animal' (:275). ' $\mathrm{Mr}$ Hewitt, who has liad great experience in hybridizing gallinaceons birds, informs me that the carly death of the cmbryo is a very frequent cause of sterility in first crosses' (286).

Here then a limit exists, and its existence is frankly acknowledged, beyond which the commixture of animals is 
found to be impossible. To many it would appear that these concessions render all further dispute unnecessary. By Mr Darwin's theory, all animals have sprung from one parent, they are all descended from one origin: how comes it then that the progeny of this one stock divided itself into thousands of different families, and with such rigorous excommunication of their brothers and cousins, that at last a union between their descendants, marked by constant sterility, rendered any confusion of the families impossible? We see an ordained law, and leave the matter there with the wisdom of the lawgiver; we, basing a deduction of common sense on a palpable fact, affirm that sterility is a visible proof of a foreordained separation, - a very manifest design, if ever there was one. Mr Darwin denies the design or the intention, but acknowledges the fact, without the least attempting to account for it, thereby fabricating for himself inexplicable difficulties; but till he can give us a satisfactory explanation of these difficulties, created by his own theory, we must decline to accept his exegesis of the mysteries of nature.

That he himself has but a faint confidence in his own exegesis, we may gather from the following words: 'It must be confessed that we cannot understand, except by vague hypothesis, several facts with respect to the sterility of hybrids. Nor do I pretend that the foregoing remarks go to the root of the matter: no explanation is offered why an organism, when placed under unnatural conditions, is rendered sterile (288).

If this explanation could have been given, Mr Darwin would indeed have achieved mighty things, for what would this be but to explain the profoundest of nature's mysteries, that secret, the key of which is with its Author, never to 
be committed to the hands of man. That this theory indeed is presented to us as if it were itself the key, we are well aware, and so it ought to be, if its pretensions of teacining 'the Origin of Species' could be sustained; but that it continually fails in doing this is manifest even by the acknowledgments of its inventor, of which the above sentence is a specimen; we shall presently see that there are other occasions in which he confesses himself hopelessly obstructed in the labyrinth of error.

'No explanation is offered,' says Mr Darwin, 'why an organism, when placed under unnatural conditions, is rendered sterile.' In these words lurks the unintended avowal that there are certain pre-existing conditions of nature, that nature has prescribed certain organisms to carry out certain functions, and that an attempt to divert the functions into another channel is a failure. This ought not to be aeknowledged by an exponent of the theory before us, which repudiates all idea of design, and holds that things are always on the move to better themselves, in a slow but sure advance towards perfection. We indeed $*$ hold that in varied schemes of life, and to realize them, organisms have been prepared, and fitted together in one harmonious whole, to carry out the object for which they were designed, and that they have thus been endowed with life. And this system of design and execution we call nature,

* 'Fixed forms, and which are perpetuated by generations, distinguish their species, determine the complication of secondary functions proper to each of them, and assign to them the part (le rôle) which they have to sustain in the harmony of the universe. These forms do not produce nor cliange theinselves. Life supposes their existence; it cannot be kindled except in organizations already prepared for it, and the most profound meditations, as well as the most delicate observations, only bring us at last to the mystery of pre-existent germs.'-Cuvier, Regne Animal, Introduction, p. 17. 
and when we talk of the laws of nature, we mean that law is the expression of prescience, intention, and power ; and we have therefore a very clear signification of our thoughts when we say that things are in a natural or unnatural position. But $\mathrm{Mr}$ Darwin entertains none of these views. His nature is Natural Selection, originating in no law, and owning no law; it is only a long-sustained experiment, an empirical condition of things trying all correctives, and testing all suggestions, to reach at last the clixir vite of a future perfection. If the learned author could always remember this, he would not so frequently make use of expressions which can have no logical standing in his system.

'On the theory of Natural Selection,' says our' author, 'sterility is especially important, inasmuch as the sterility of hybrids could not possibly be of any advantage to them, and therefore could not have been acquired by the continued preservation of successive profitable degrees of sterility' (267). This very whimsical decision, almost the strangest that erer has been offered as a tribute to science, is capable perhaps of more than one interpretation : but we would ask, if sterility did not originate by Natural Selection, by what other means has it been introduced? We have secn that $\mathrm{Mr}$ Darwin acknowledges the fact; but he here cuts off from himself the only explanation which he had to offer in his theory. For Natural Selection can do anything, and has indeed done almost everything that ever has been done in nature,-why then has it not been allowed to work in this particular instance? This, at first sight, might seem inexplicable; but when we remember that the rule of sterility is not for individuals alone, but for divisions, distinctions, and groups of animals, with an obvious intention to 
keep them apart, and therefore argues an intelligent design ; and that, on the contrary, Natural Selection acts only for individuals, caring nothing at all for the benefit of groups and classes, is essentially a selfish individual principle, and knows nothing, of a general plan, we can understand how it is that this grand functionary has kept clear of this business.

But again we ask, whence then originated sterility of unions not intended by nature? And again we ask, how did animals, all in the beginning one family, brother and sister, when separating themselves into different forms, and genera, and species, acquire this quality-that is, this quality of fecundity of the species and sterility out of the boundaries of the species? Natural Selection did not help them, because that wise one saw that sterility could not possibly be for their benefit-and yet sterility is the law! Perhaps the animals themselves acted on this occasion on their own view of the matter, and agreed to make the law, without consulting Natural Selection, and have thus adopted a system which has been of no service to them. It must, however, have been a very popular idea with both plants and animals, seeing how generally it has been adopted.

But how does Mr Darwin know that the sterility of hybrids could not possibly have been an advantage to the animals? The hybrid that is sterile has not made itself so, but is sterile as a joint-product of two parents. The hybrid can only take the nature he has, and the organization furnished by his parents. The mule has not made himself sterile, nor can le alter his condition-sterility originates not with the hybrid, but with the parents; hybridity is a negative state produced by the union of male and female not fitted for union-and it is of the utmost possible bene- 
fit to animals in general, that this sterility is the result of improper unions, as it averts general confusion, and sustains the unity of nature's design.

In this matter, however, Mr Darwin has forgotten himself; for though he thus affirms with such confidence that sterility 'could not possibly be of advantage to animals,' yet only a few pages earlier, in the 7th chapter, he had as plainly laid it down that the honey-bee workers* have made themselves sterile by Natural Selection, for the benefit of their society !!! If Natural Selection has acted thus in one conspicuous example-if sterility has in that case been produced by Natural Selection-how, we ask, is it quite impossible that it should not have been introduced by the same agency, wherever we see it prevail?

Surely this is a slip of the memory, and a very palpable one. We need not say that we happen to agree with $\mathrm{Mr}$ Darwin, and are quite of his opinion that Natural Selection has had nothing to do with the law of sterility : only we are both surprised and amused to see him turn the cold shoulder to his great auxiliary precisely at the time when its valuable assistance would be most serviceable.

But though Natural Selection has not produced sterility, it can cancel it, and has done so in the teeth of all that Mr Darwin has told us of the fixedness of this law. He gives us to understand that at some unknown time, and without any record or evidence to attest the fact, several

* A slight modification of structure or instinct, correlated with the sterile condition of certain members of the community, has been adrantageous to the community : consequently the fertile males and females of the same community flourished, and transmitted to their fertile offspring a tendency to produce sterile members having the same modification. And, $I$ believe, that this process has been repeated, until that prodigious amount of difference between the fertile and sterile females of the same species has been produced' (260). 
species of animals have become fertile amongst one another. Thus we are frequently informed that all varieties of dogs 'descended from several wild species' (20). How opposite this assertion is to the general opinion of naturalists need not to be stated, but Mr Darwin repeats the proposition in many* parts of his book, as if it were an established fact, resting it on the sole authority of his own conjecture. If, indeed, with a total deficiency of proof we should be disposed to accept this innovation in Natural History, the theory would advance a step, and the door would be opened for that mutation of Nature without which Natural Selection must be impotent; but with us Mr Darwin's creed carries no weight unless accompanied with rigorous proof. However, on the question of the varieties of the dog-species, Mr Darwin has much to say on the great difference between the races, but why should he refuse to this category that which he has so strongly urged as producing varieties in other species? He has told us, and told us truly, of the wonderful changes effected in cattle and other animals by breeding, why then make an exception in the case of the dog,- - the creature of all others most closely united to man, most constantly under his eye, and least at liberty to make its own choice? In another part of his work, Mr Darwin says, 'lastly-and this seems to me the

* ' I believe that our dogs have descended from several wild stocks, yet with perhaps the exception of certain indigenous domestic dogs of South America, all are quite fertile together,' and analogy makes me greatly doubt, whether the several aboriginal species would, at first, have freely bred together, and have produced quite fertile hybrids (266).

This passage involves the petitio principii more than once. First it is assumed that dogs spring from several aboriginal species, and then it is assumed that the crosses between them would, at first, be sterile hybrids. Those two words 'at first' assume the whole theory : for the meaning is, that in process of ages Natural Selection would alter this arrangement, and change the sterility into fertility. 
most important consideration-new races of animals and plants are produced under domestication by man's methodical and unconscious power of selection' (291); and yet the varieties of the dog are not to be accounted for in this way, but by having originally sprung from distinct species. To us, however, Buffon's reasoning on the subject is satisfactory, and he seems to have established the probability that the shepherd's dog is the 'vrai chien de la nature;' the dog that prevails in various parts of the world with the same character, and a similar form, and constitutes in fact 'the stock and the model of the entire species' - 'la souche et le modèle de l'espèce entière.'

What then is the general result of all that has been advanced to forward the theory? Truly, we may say, almost nothing. Much is urged about the contradictory evidence afforded us by plants - species that can be united with facility producing hybrids 'remarkably sterile' — species crossed with difficulty, but with a hybrid progeny when ' at last produced,' fertile. We are told that hybrids never have been raised between species ranked by systematists in distinct families; and a multitude of cases could be given of very closely allied species, which will not unite, or only with extreme difficulty (279); and all this we should have thought tends to prove the case against the theory. But the conclusion with $\mathrm{Mr}$ 'Darwin is in these words: 'Do these singular and complex rules indicate that species has been endowed with sterility simply to prevent their becoming confounded in nature? I thints not-to grant to species the special power of producing hybrids, and then to stop their further propagation by different degrees of sterility, not strictly related to the facility of the first 
union between their parents, seems to be a strange arrangement' (282).

What matters it if the rules be singular and complex; for, if in the end they secure the main object-the perpetuity of the existing plan of nature-if they obstruct Mr Darwin's scheme of fluctuation and mutation, and allow no scope to Natural Selection to alter plants and animals, then all is obtained that is wanted, and the theory has gained nothing.

This may be 'a very strange arrangement' to $\mathrm{Mr}$ Darwin, but it is a very efficient one; and if, when endeavouring to take a short cut across the country, we go over hedges and fences where we have no right to go, and push on trespassing till we come to a high wall, with the prohibitory words in large letters, 'No Road this way'what are we to do? It may be a very strange arrangement to balk us thus, but we have no alternative but to go back again, and plod on in the beaten path on the old High Road.

In the mean while we should remember, that all this voluntary perplexity about varieties and species of plant is the result of ${ }^{*}$ horticultural experiments, in which na-

* M. Naudin says: "There exist in the gardens two species of Petunias perfectly charaeterized. The one with white flowers (P. nyctaginiflora), the other with purple flowers (P. violacea), without any known varieties that have yet been reeognized, but crossing with faeility, and thereby produeing hybrids also fertile amongst one another. In the first generation, all the liybrids resemble one another; in the second, they are diversified in the most remarkable manner-the one returning to the white species, the other to the purple, and a large number marking shades between the two. If these varieties are fertilized artificially - as is praetised by some gardeners -they obtain a third generation more motley still (encore plus bigarrée), and in eontinuing this proeedure they arrive at extreme variations, sometimes monstrous, which the prevailing fashion eonsiders as perfection. That which is essential to remark liere, is that these variations are 
ture takes no part. We, from motives of curiosity, try our hand in crossing flowers, and produce some temporary innovations, but they are indeed ephemeral products; and all new varieties, whether hybrids or otherwise, if left to themselves, would speedily disappear, and be effaced from existence. As it is with our new plants, so is it with the varieties of our domestic animals,-by constantly watching and training them, and directing their sexual unions, we keep up or improve certain breeds; but all is artifice and contrivance, and has established no abiding novelty.

Let man be withdrawn from the scene, and at the end of two or three centuries, where would be our breeds, our varieties, our races amongst animals, and where our curiosities in the botanical world? The creatures would all have returned to the original wild type, the dainties of the garden and the grove would have merged in nature's original plan, and all our quibbles and mystifications about species and variety would be swept away in the undisturbed and majestic march of the Grand Design.

This chapter must not be dismissed without drawing attention to the fact that in the question of mutability of species, by which it is pretended that all forms of life have been brought into existence, the Theory of Transmutation stands confronted with creation, which Mr Darwin, to put on a level with his own system, calls 'a Theory'* also.

purely individual, and without any element of fixedness. From the sowing of their seeds new forms arise, which have as little resemblance to one another as they have to the forms which produced them.' On this, M. 'Trémaux, himself a transmutationist, observes: 'It is hereby evident that individual hybrid variations return to one or other of the species from which they sprung, when left to themselves.'

* 'How inexplicable on the Theory of Creation is the variable appearance of stripes on the shoulders and legs of the horse genus' (506, also $507)$. 
The whole question in dispute is simply this: have plants and animals been created with a suitable organization to occupy their places assigned to them in nature, or have they been progressively developed by accidental changes from antecedent forms, and do they exhibit their characters and their habits, and hold their position as chance has brought about, without any design?

In the ordinary way of thinking, it is held that the power and wisdom of the Creator designed and made organic beings for certain objects; and in the inimitable wisdom, skill, and beauty of the contrivances by which this has been effected, we see indisputable proofs of the high source of the general design. When the law of species is taken into the account, and the partitions of life are noted to be safe within a barrier which cannot be transgressed, we see so clearly an additional proof of the origin of the design, that we are disposed to look on this law as the very sceptre of the Creator - as visible evidence that the Supreme Intelligence which invented all the varieties of life, has resolved that the original plan should be maintained in all its purity, and that the boundary lines of separation should be perpetually respected. We see the result; organic beings do not change, the plan of creation is maintained.

This very plain and palpable fact, the Theory has to meet as well as it can; and therefore we have heard $\mathrm{Mr}$. Darwin say " that he does not think that these singular rules indicate that species has been endowed with sterility, simply to prevent their being confounded in nature.'

Nevertheless, almost all naturalists have thought so; and let them think as they like, the effect of sterility and the natural aversion to the mixture of species is indisputable. That these 'singular rules' have the effect of 
maintaining the order of nature is certain. For the corollary we need not be very solicitous, as it cannot be averted.

When, however, Mr Darwin thus meets the question of design, he is wont to object that we seek to hide our ignorance by taking refuge in something beyond our comprehension. Thus, in the case of sterility, he tells us that we 'slur it over-because we look on it as a special endowment beyond our reasoning powers' (268). After such a rebuke we naturally expect to receive a clear solution of the mystery from his superior reasoning powers, which disdain the acknowledgment of ignorance. What, then, is the explanation? He simply tells us what we knew before, and by many varied phrases iterates facts acknowledged already. He tells us there are 'constitutional differences incomprehensible to us, and confined to the reproductive system ' (280). That in pure species the sexual elements are perfect, and in hybrids imperfect' (268). That sterility, both of first crosses and of hybrids, is simply incidental, or dependent on unknown differences, chiefly in the reproductive system of the species which are crossed (283). That as the capacity of one species or variety of trees to take on another is incidental on generally unknown differences in their vegetable system, so, in crossing, the greater or less facility of one species to unite with another is incidental or unknown differences in their reproductive systems (299). That in hybridizing gallinaceous birds, the early death of the embryo in the egg is a frequent cause of sterility in first crosses; and this Mr Darwin says he was ' unvilling to believe' till convinced of the fact (2S6). That in unnatural crossings the organization has been dis- 
turbed by two different structures and constitutions having been blended in one (288).

And with these verbal solemnities, which add nothing to the stock of our information, $\mathrm{Mr}$ Darwin concludes in the passage which we have already seen: 'It must be confessed that we do not understand, except on vague hypotheses, several facts with respect to the sterility of hybrids' -- ' nor do I,' says he, 'pretend that the foregoing remarks go to the root of the matter: No EXPLANATION IS OFFERED WHY AN ORGANISI, WHEN PLACED UNDER UNATUURAL CONDITIONS, IS RENDERED STERILE' (288).

Surely after this most ample confession, Mr Darwin might have spared himself the pains of composing half a dozen pages of learned talk, all ending in the very point from which he had started, without advancing a hair's breadth towards an explanation of the mystery. We have no difficulty, then, in concluding that the law of sterility, with its 'singular rules,' is something beyond even Mr Darwin's reasoning powers. If we have slurred over this enigma, he, by his expansion, has largely exhibited his ignorance, and made it quite manifest that he is no more able to explain the subject than we who acknowledge our ignorance, and do not conceal that it is beyond our reasoning powers. 


\section{CHAPTER IV.}

NATURAL SELECTION.

Having thus gone through the question of species as we have seen it stated, we now come to the fundamental principle of the whole theory, Natural Selection, which it has become necessary occasionally to anticipate, as it is mixed up with Mr Darwin's statements and reasonings in every chapter of his book. It is now proposed to show at some length what the author means by Natural Selection, adducing his own words for authentic information.

In the general explanation of Natural Selection we may say, that it means that when plants or animals have been in circumstances wherein some modification of their existing organization would be for their benefit, the change has been effected by very slow degrees, gradually and imperceptibly advancing towards the beneficial point; and the changes, however minute, accumulating, in the long-protracted process of geological time, new forms of the animal or plant have at last been elaborated. It is not, however, to be supposed that these mutations have effected a permanent state of things, for though certain divisions of the families of animals and plants have thus been brought into existence, so as to be recognized as genera, and 'good and distinct species,' yet this is only temporary, for all varieties 
are to be considered as incipient species, and species itself differs not essentially or fundamentally from variety. All nature, then, is on the move; that which we call Creation is not effected and finished, but is working onwards to a finish, when all beings that have life will be in a state of perfection, and there will be no more change.

This, however, must be seen in the author's own words : 'The preservation of favourable variations and the rejection of injurious variations I call Natural Selection' (84). 'Nature grants vast periods of time for the work of Natural Selection' (107). 'No complex instinct can be produced through Natural Selection, except by slow and gradual accumulation of numerous slight but profitable variations' (260). "The chief cause of our natural unwillingness to admit that one species has given birth to another and distinct species is, that we are always slow in admitting any great change of which we have not seen the intermediate steps. The mind cannot possibly grasp the full meaning of a hundred million of years. It cannot add up and perceive the full effects of many slight variations, accumulated during almost an infinite series of generations' (516). 'By the theory of Natural Selection all living species have been connected with the parent species of each genus, by differences not greater than we see between the varieties of the same species in the present day; and these parent species, generally extinct, have in their turn been similarly connected with more ancient species, and so on, backwards, always converging to the common ancestor of each great class-so that the number of intermediate and transitional links between all living and extinct species must have been incomparably great: but assuredly, IF THIS THEORY BE TRUE, such have lived upon earth' (305). 'I see no difficulty, under 
changing conditions of life, in Natural Selection accumulating slight modifications of instinct to any extent in any useful direction' (265). 'Natural Selection, on the principle of qualities being inherited at corresponding ages, can modify the eggs, seed, or young as easily as the adult' ( 144 ). ' On the principle of Natural Selection, with divergence of character, it does not seem incredible that from some such low and intermediate form (the lower algce) both animals and plants may have been developed; and if we admit this, we must admit that all the organic beings which have ever lived on the earth may have descended from some one primordial form ' (519). 'The ultimate result will be that each creature will tend to become more and more improved in relation to its condition of life. This improvement will, I think, inevitably lead to the gradual advancement of the organization of the greater number of living beings throughout the world' (133).

This is the creed in the authentic words of the inventor of the theory. It is but fair, however, to add a corollary of the whole: 'If Natural Selection be a true principle, it will banish the belief of the continued creation of new organic beings, or of any great and sudden modification of their structure' (101). In other words, if Mr Darwin's theory be true, we have done with the Creator. Creation disappears as an obsolete idea, and Natural Selection takes its place.

Natural Selection has another principle to aid its operations, 'the Struggle for Life,' a competition for existence, by which the weak have to make way for the strong; so that those animals and vegetahles which can make most of their opportunities, and most improve their qualities, are sure to supersede their less fortunate or less provident rivals. The 
unimproved become extinct, whilst the accumulators of useful varieties remain masters of the field.

On this Mr Darwin has much to say. 'How do these groups of species, which constitute what are called distinct genera, and which differ from each other more than do the species of the same genus, arise? All these results follow from the struggle for life. Owing to this struggle for life, any variation, however slight, and from whatever cause proceeding, if it be in any degree profitable to an individual of any species, in its infinitely complex relations to other organic beings, and to its physical condition of life, will tend to the preservation of that individual, and will generally be inherited by its offspring' (64). 'I use the term struggle for existence in a large and metaphorical sense, including dependence of one being on another, and including (which is most important) not only life of the individual, but success in bearing progeny' (166). 'In looking at Nature it is most necessary never to forget that every single organic being around us may be said to be striving to the utmost to increase in number; that each lives by a struggle at some period of its life; that heavy destruction inevitably falls either on the young or the old, during each generation or at recurrent intervals. Lighten any check, mitigate the destruction ever so little, and the number of the species will almost instantaneously increase to any amount' (69).

With these quotations we have enough before us to comprehend the author's theory. We must now endeavour to ascertain what may be the precise meaning of the term 'Natural Selection,' which in itself contains substantially the whole of Mr Darwin's theory. An unknown power selects and makes choice; it adopts, repudiates, modifies, and changes certain qualities in animals and vegetables; it 
adds or diminishes attributes and endowments, and always with a beneficial tendency to the being on which it operates; in the great majority of instances it effects a change in the right direction, after numerous incomplete experiments indeed, but ultimately with success; for improvements in the universal struggle for life is the general result of its agency. Where does this power reside? is it in the animals and vegetables themselves? or is it something exterior to them that superintends and directs this process of amelioration? Is it nature that alters the structures and the organization? and if so, what is nature?

In not a few instances Mr Darwin speaks as if all this were accomplished by that metaphorical word, Nature. 'I see,' says he, 'no limit to the amount of change, to the beauty and infinite complexity of the co-adaptations between all organic beings, one with another, and with their physical conditions of life, which may be effected in the long course of time by Nature's power of selection' (115).

Here Nature is an intelligent agent, elaborating organized beings with beautiful and skilful art, adapting them for the new circumstances of their improving condition. Nature has the power, the knowledge, the skill, and the good taste to advance organized beings towards perfection, in designs of admirable wisdom and beauty. Nature, then, has all the attributes of the Creator, with only a different name; but is Nature an intelligent power, or is it a deity? is it a god or a goddess? Mr Darwin tells us, indeed, that he uses the term metaphorically; but why, in the first place, all through this grave and profound disquisition trifle with a metaphor, instead of using a reality? and why, in the next place, forget that it is a metaphor, and continually at- 
tribute to it acts of intelligence and designs of incomparable skill and science? That Mr Darwin does this beyond any other writer we shall presently see; indeed, he comprehensively informs us that "Natural Selection is a power incessantly ready for action, and is as immeasurably superior to man's feeble efforts, as the works of nature are to those of art' (65).

This, however, is not a very fortunate illustration; for, as Mr Darwin makes Nature, and Nature's power of selection, and Natural Selection all one, it only amounts to this, that Nature's works are as superior to man's works as Nature's works are.

But here Natural Selection is described as always ready to perform inconceivable acts of scientific skill, and is the same as Nature elsewhere described, an intelligent, vigilant, and energetic power, so that unless this language be watched, we might be induced to follow the illusion that Natural Selection has an independent existence, per se, a position often assumed in this theory, and that not only in passing, but enlarged on as an established fact.

In the fourth chapter, the case is stated thus. 'It has been often said that I speak of Natural Selection as an active power or deity, but who objects to an author speaking of the attraction of gravity as ruling the movements of the planets? Every one knows what is meant and is implied by such metaphorical expressions, and they are almost necessary for brevity. So, again, it is difficult to avoid personifying the word Nature, but I mean by Nature only the aggregate action and product of many laws, and by laws, the sequence of events as ascertained by us. With a little familiarity such superficial objection will be forgotten' (85). 
Mr Darwin will not, however, allow us to forget these objections, which so far from being 'superficial,' go very deep against his theory. But with this explanation before us, we shall have only to apply the definition in the place of the term, and we shall have some curious results.

But first it is to be observed that the two grand principles of the theory are avowedly metaphors. Natural Selection is a metaphorical expression, and the Struggle for Existence is used in 'a large and metaphorical sense.' These are the two pillars of the whole theory; Natural Selection and the Struggle for Existence represent and express everything that $\mathrm{Mr}$ Darwin has to urge; take them away and nothing remains, and yet they are both metaphors. If these terms are metaphors, they are not realities, but verbal pictures or shadows, and are, therefore, vicious terms in a scientific disquisition. Neither are they only now and then, and by way of illustration, introduced, though even that would scarcely be admissible in handling the great revelation of the existence and origin of beings; but they occur in almost every page, to the exclusion of other terms - so that from first to last we are led by a metaphor at every step, as the poor belated traveller is sometimes led by Will-o'-the-wisp into the fatal morass.

Next we should note that an intelligent preference and choice is attributed to Natural Selection, and this is pressed upon us by the analogy of our own preference in improving breeds. 'We may suppose that at an early period one man preferred swift horses; another, stronger and more bulky horses. How, it may be asked, can any analogous principle apply in Nature? I believe it can and does apply most efficiently, THOUGH IT WAS LONG BEFORe I SAW HOW, from the simple circumstance that the more diversified the de- 
scendents from any one species become in structure, consti. tution, and habits, by so much will they be better enabled to seize on many and widely diversified places in the polity of nature, and so be enabled to increase in numbers' (11S).

The argument, then, is thus: we prefer to breed certain horses with certain qualities; certain animals 'become' diversified, and the more they 'become' so, the better able will they be to seize on new positions, and to establish themselves in a new condition of life; in other words, to 'become' new animals. And this is called an analogy! Well, let it stand for as much, if $\mathrm{Mr}$ Darwin wants to endow his metaphor with power of preference and selection; let him make what he can out of the analogy of our using free choice in the breeding of animals; but if there be this preference, then some intellect favours, selects, and prefers, or else the analogy is worth nothing. For the rest, we may observe, that it is not surprising $\mathrm{Mr}$ Darwin should have been a long time in discovering the analogy : a longer meditation still might well have been conceded to the solution of the problem, for analogies and metaphors are shadowy substances, which, after the closest acquaintance, are not always worthy of our confidence.

After all that has been said on the subject, it is to be hoped that the eyes of the reader will not be blinded with the dust of ,words by which this theory is made to push its way. Natural Selection is, as a fact, absolutely nothing: there is no power or intellect to select anything, and nothing is selected. The whole matter is this : animals, as it is pretended, in the course of time manifest some slight beneficial variation in their organization,- - this they transmit to their progeny: the improved progeny has the best chance 
in the struggle for life, and takes the place occupied by the unimproved animals, which, unable to sustain their existence owing to the superior qualities of their competitors, are infallibly exterminated. The successful animals, or the survivors, Mr Darwin, by a figure of speech, calls the selected ones; but Selection in his system simply means not perishing. This most inaccurate use of words may be thus illustrated. Let us suppose that the following paragraph should appear in a newspaper, 'Yesterday a serious accident took place on the — line. The mail-train ran off the line, precipitating all the carriages down a steep bank. Three of the passengers were killed on the spot, and seven severely wounded; all the rest, we are happy to say, not less than a hundred and fifty in number, were* selected.'

Now that this is the real meaning of this mystery, $\mathrm{Mr}$ Darwin frankly acknowledges: 'I have called this principle, by which each slight variation, if useful, is preserved by the term Natural Selection, in order to mark its relation to man's power of selection' (64). This important passage reveals to us the motive which prompted Mr Darwin to invent the term, it was to introduce an imaginary resemblance between sentient beings making use of their reasoning faculties for preference and selection, and 'a series of events' incapable of making choice of anything. That the term has been successful, and flourishes splendidly in Mr Darwin's pages, we see at every turn; Mr Darwin himself tells us he has such*confidence in his figure of

* That Mr Darwin makes use of preservation as if it were a strict grammatical synonyme with selection, and vice versâ, we see in this passage :

'Under such circumstances, the swiftest and slimmest wolves would have the best chance of surviving, and so be preserved or selected ' (95). 
speech that he believes it can accomplish anything, even the most complicated, ingenious, and beautiful contrivances that it is possible to imagine in all the productions of nature; and yet when this effervescence of enthusiasm subsides, what is there to find? - that certain animals continue to exist!

Natural Selection, therefore, we affirm is a term to be utterly discarded. It is a verbal deception, and the only substance to be discovered, after the elimination of the metaphor, is that a certain series of events is said to have taken place, though those events are contested and denied.

This we shall have occasion to insist on again and again, and it is of the utmost consequence to the due understanding of the theory of transmutation.

It may perhaps surprise some of us to find Sir C. Lyell expressing himself in the highest terms of admiration in his estimate of this same figure of speech: "To many, this doctrine of Natural Selection, or the preservation of favoured races "in the struggle for life," scems so simple, when once clearly stated, and so consonant with known facts and received principles, that they have difficulty in conceiving how it can constitute a great step in the progress of science. Such is often the case with important discoveries, but in order to assure ourselves that the doctrine was by no means obvious, we have only to refer back to the writings of skilful naturalists who attempted in the earlier part of the nineteenth century to theorize on this subject, before the invention of this new method of explaining how certain forms are supplanted by new ones, and in what manner these last are selected out of innumerable varieties and rendered permanent.'-(Antiquity of Man, 417.) 
'Thus Sir C. Lyell seems to think that, owing to "this important discovery,' Mr Darwin is the Columbus of nature's hitherto undiscovered regions, and that now at last true light has dawned on physiology.

'deus ille fuit, deus, inclyte Memmi, Qui princeps vitæ rationem invenit eam quæ Nunc appellatur sapientia, quique per artem Fluctibus e tantis vitam tantisque tenebris In tam tranquillo et tam clarâ Juce locavit.'

This doctrine may perhaps appear too 'simple' to some of its admirers, who can scarcely believe that so great 'a discovery' can have been so easily made. Nevertheless, its simplicity all turns on this, that we are to believe that the slight advantageous variations, the result of accident, have appeared in animals, and that they have been accumulated till the changing animal, in the lapse of geological time, has, through innumerable mutations of antecedent animals now extinct, been ultimately transformed into some creature of different organization and character.

We have to believe that all these intermediate forms of extinct animals have really existed, and existed too for a very long time, as no new animal with advantageous variations sufficient to displace its congeners, can have been produced but in a long series of ages.

This we have to believe, and though geology ' does not reveal 'any of the evidences of this history, owing to the 'extreme imperfection of its records;' yet we are to believe that it ought to have revealed it.

Moreover, and that is the most important point of all, in believing that 'certain forms are supplanted by new ones,' we have to renounce our belief in the power and wisdom of the Creator, and to take out of his hands the production of all living things. 
All this is very simple, doubtless, to persons who have cmbraced the theory of transmutation, but it would seem indispensable that our understanding should be in a state of a corresponding simplicity before we could venture to launch after this Columbus in his newly-discovered world. 


\section{CHAPTER V.}

THE FUNCTIONS OF NATURAL SELEC'TION.

Having established the meaning of Natural Selection, we go on to consider the functions assigned to it in the theory.

' Natural Selection can only act through and for the good of each being;' and on this principle it chooses colours, makes leaf-eating insects green, and bark-feeders mottlegrey, the ptarmigan white in winter, the red grouse the colour of the heather, and the black grouse that of peaty earth. Grouse, if not destroyed at some period of their lives, would increase in countless numbers-hawks are guided by eyesight to their prey. 'Hence,' says the author, 'I can see no reason to doubt that Natural Selection might be most effective in giving the proper colour to each kind of grouse, and in keeping that colour, when once acquired, true and constant' (89).

Natural Selection, therefore, foresaw the proper colour for effecting concealment, gave the tint that would best answer the purpose, and has preserved it.

'We must believe,' says Mr Darwin, ' that these tints are of service to these birds and insects in preserving them from danger.' There is no difficulty in believing this, we always have believed it; but then the question arises, as these colours have been assigned to the animals to preserve 
them from danger, whose was the provident intellect that devised and predetermined this mode of defence, and then produced the means to render it efficacious? We have 110 difficulty in answering the question, but in this theory no providential design, no supreme creative will, can be admitted; so that, if we ask again how these protecting tints were produced, we learn by referring to the definition, that it was 'by the aggregate action and product of the sequence of events as ascertained by us.' 'That is, we see things in a certain form, and that is the reason of their being so. Colours are produced to defend animals from danger, and answer the purpose well, but they were not designed or devised to produce this beneficial effect, but they have become what they are by a sequence of events; the effect is the cause of the effect; events produce themselves, and that is the cause of their being produced.

Now, as the author of this profound theory frequently reminds us of the vast superiority of the achievements of Natural Selection over anything that man can devise or accomplish, we are at liberty to apply this sort of reasoning with much greater force to the productions of human skill, as it must be so much easier to make machinery, such as is produced by the hands of man, than to imitate the smallest of the works of nature. When therefore we see a superior watch, or a highly improved steam-engine, and are asked who made them, we may confidently affirm that they were not designed or made by any one, but are ' the result of the aggregate action, and the product of the sequence of events as ascertained by us.'

But to proceed with the functions of the great Improver. Natural Selection gave winged seeds to the dandelion. 'If it profit a plant to have its seeds more and more widely 
disseminated by the wind, I see no greater diffeculty in this being effected through Natural Selection than in the cotton-planter increasing and improving by selection the down in the pods of his cotton-trees' (91). Most people would say that it was not quite so easy to give wings to seeds as to improve cotton-plants by selecting the most downy pods. Mr Darwin seems to find no difficulty in it, but by what process he would enable a kidney-bean, a pea, or a mustard-seed to fly through the air he has not informed us. Wings however are a ready article in the theory, as we shall hereafter see.

In this particular case, it should be noted that the dandelion has not only improved itself, as every other being has in this theory, but it has had an eye to the benefit and settlement of its progeny. It has foreseen that it would 'profit' its family 'to be more and more widely disseminated,' and having therefore determined to make its descendants colonists, has invested its seeds with volant qualities, to find their fortunes, as aëronauts, far away from the parental station.

Manifold are the transformations which have been brought about in the process of time, for 'we may believe that the progenitor of the ostrich was the bustard, and that as $\mathrm{Na}$ tural Selection increased, in successive generations, the size and weight of the body, its legs were used more and its wings less, till they became incapable of flight' (152). In this authentic history of the feathered race we have the counterpart to the acquisition of wings, for it seems that animals may not only acquire wings but also get rid of the faculty of flying, though in this particular instance it is difficult to ascertain what the bustard has gained by turning himself into an ostrich. Considering the calamities that this 
change has brought on the ostrich, one of the most persecuted of animals, we suspect he would not be sorry to return to his bustard origin if only he knew how. Natural Selection always operates for the benefit of the changing animal, but whether when animals have got into a scrape by 'bettering themselves,' they can get out of it by retrogressive selection is perhaps a fact not yet determined.*

As however the breed of bustards still exists, it is clear that some only of that species were disposed to make the change: the more sober ones were content with the actual state of things, and thought it better to 'let well alone.'

As a general proposition we are to understand that wings may be acquired where they did not previously exist. 'It requires a long succession of ages to adapt an organism to some new and peculiar form of life, as for insiance to fly through the cir (328); and, indeed, it is essential to this theory that every existing bird should have acquired the faculty of flight, not by original constitution and appointment, but by gradual mutation, and accumulation of beneficial qualities, tending to the development of wings. $\mathrm{Mr}$ Darwin discusses this transformation with well-sustained gravity, and finishes with these words:-

'We do not see the transitional grade through which the wings of birds have passed; but what special difficulty is there in believing that it might profit the modified descendants of the penguin, first to become cnabled to flap along the surface of the sea, like the logger-headed duck, and ultimately to rise from its surface and glide through the air?' (329).

Such passages as these seem almost incredible in a

* Retrogressive Natural Selection seems to be admitted in the theory. On this subject more will be said hereafter. 
treatise having any pretensions to scientific standing; and truly may we say, that if such reasoning as this belongs to even the lowest and most rudimentary form of science, then Cuvier, Agassiz, Müller, Owen, Jones, Sedgwick, Phillips, and others, never understood its import, nor comprehended the true method of investigating nature. None of these prodigies of interpretation, lowever, seem to startle $\mathrm{Mr}$ Darwin. Having made up his mind to place the sceptre of creation in the hands of his Metaphor, he seems to rejoice in extravagant expressions which may in any way glorify the chief puppet of his theory. Hence he tells us 'She can act on every internal organ, on every shade of constitutional difference, on the whole machinery of life' (87). And with such a declaration, what may we not expect to be hazarded for its illustration?

In one of the author's most eccentric passages, we have the following curious information accompanied by reasoning equally curious. "The tail of the giraffe looks like an artificially constructed fly-flapper ; and it seems at first incredible that this should have been adapted for its present purpose by successive slight modifications, each better and better, for so trifling an object as driving away flics; yet we should pause before being too positive even in this case, for we know that the distribution and existence of cattle and other animals in South America absolutely depend on their power of resisting the attacks of insects; so that individuals, which could by any means defend themselves from these small enemies, would be able to range in new pastures, and thus gain a great advantage. A welldeveloped tail having been formed in an aquatic animal, it might subsequently come to be worked in for all sorts of 
purposes - as a fly-flapper, an organ of prchension, or as aid in turning, as with the dog' (215).

There are several points to notice in this statement: first, a well-developed tail 'had been formed' in an aquatic animal. How formed? By Natural Selection, of course, for the theory allows of no other formative power; but as this is always an exceedingly slow operation, requiring many ages, there must have been some thousands of ages when aquatic animals had no tails at all! They were forming in the waters by Natural Selection, but how, during the tailless period of their history, they directed their course in the water is not explained; fishes without tails would certainly be curiosities. However, such was their condition before 'their tails were formed.' After this, the fishes having in the process of long ages acquired a tail, that important appendage to their existence 'came to be worked in!' How worked in, and who was the artificer of the work? The Metaphor, of course,- the ever watchful and ingenious Natural Sclection. She 'worked in 'the fishes' tails into the postcrior extremities of the vertebral column of sundry land-animals. The meaning of which is, certain fishes 'came to be' converted into land-animals, and then their tails were adapted to their new forms which they had acquired. Some for flappers (horses, cows, \&c.), some as prehensile tails (monkeys), some as rudders in turning.

Thus, then, the tail of a horse may have been antecedently the caudal instrument of a shark, a cow may have derived her tail from the skate, and the giraffe owe his fly-flapper to a remote progenitor, the sturgeon.

Mr Darwin, solicitous to sustain the dignity of Natural Selection, fecls it but due to her character to apologize for 
the formation of a tail, through her instrumentality, for 'so trifling an object as driving away flies.' We are then gravely informed, as if we had never heard it before, that cattle in hot countries cannot dispense with a tail- the distribution and existence of cattle and other animals in South America depend upon their power of resisting insects.' The learned author need not have referred us to South America to prove his position; what we see in England is convincing enough on that head. Cattle deprived of their tails in a hot summer in this country would go wild, and would probably perish in the excess of irritation. We are fully convinced that this is not a trifling matter. Natural Selection has not at all demeaned herself in condescending to 'work in 'fishes' tails into the organization of cattle and other animals. Thus, then, $\mathrm{Mr}$ Darwin comes to the conclusion that it really has been for the benefit of animals that they should have tails for fly-flappers; only he must have the tail formed in his own peculiar way to suit his theory. The poor animals did not make their appenrance in life with this necessary provision, but in a million of years or so they very slowly acquired a tail. To use his own words, 'it was adapted for its present purpose, by successive slight modifications, each better and better'the tail always growing a little longer because it was more advantageous for the beast to have it lengthened-whilst the beasts that had no tail growing, died off by myriads in the struggle for life. Now this, be it observed, is seriously meant, though not so expressed, for in this very part of his disquisition, $\mathrm{Mr}$ Darwin is careful to remind us "that it certainly is not true that new organs appear suddenly in any class' (214). A memento to prevent us admitting a statement which might seem to imply a work of creation. We 
must therefore be very careful to remember that the tail of the horse, or the cow, or the giraffe, grew very slowly; and this of course means geological slowness. But a cow or horse with a tail only the hundred-thousandth part of its present length would not reap much benefit from the addition : it would only be appreciable by a powerful microscope, and would be of no advantage to its proprietor as far as we can see. Let us suppose that at the end of some thousand year's a cow's tail had grown an inch long, it would certainly avail nothing for the flagellation of insects, nor can we see any reason why this slowly-improving cow or horse should by this 'slight variation' gain the victory in the competition for existence; nevertheless, cows' tails grew by Natural Selection, till at last they came to be those instruments which we now see them to be, mutatis mutandis. This sort of history is applicable to every animal-to the trunk of the elephant, the horns of the decr, the hoof of the hor'se, \&c.

This, however, incidentally lets us into a secret, that in all these dreams of transformation a prospective advantage is always implied, as is obvious in this history of tails. No organ can be made suddenly, that is a fundamental rule in the theory; nevertheless, every remarkable organ has been slowly advancing in its formation, till it becomes the instrument requisite for some particular purpose, and then it advances no more. This implies, and means, that there is a design somewhere. Mr Darwin may shrink from this as he likes, but his slow growth of organs tending to an object, and that growth ceasing when the object is obtained, means only slow design. Mr Darwin may flatter himself that his millions of ages may conceal this, but it only makes apparent, that when any one tries to explain 
the productions of nature without a design he has an impossible task on his hands, and that it is impracticable to frame such a theory without occasionally admitting the principle which it is especially intended to exclude.

But this history of animals has greater marvels still, for' not only had many of these terrestrial creatures an 'aquatic origin' (21.5), but some land-animals have changed their original nature, and become aquatic. If we should be startled by hearing that a giraffe was once a fish, full as great must be our surprise to hear that a whale was once a bear. 'In North America,' we are informed, 'the black bear was seen by Hearne swimming for hours with widely open mouth, thus catching, like a whale, insects in the water, I see no diffculty in a race of bears being rendered by Natural Selection more and more aquatic in their structure and habits, with larger and larger mouths, till a creature was produced as monstrous as a whale.'* This appeared in the first edition of the Origin of Species, but has been suppressed in the subsequent editions, for no sufficient reason, as far as we can discern. It is in perfect harmony with all the rest of this wonderful creed, and is not one whit more ridiculous than many other statements reprinted in the last edition. The reader would be puzzled in endeavouring to strike the balance of absurdity between the origin of tails and the parentage

* In the third and subsequent editions the passage is thus given :-

'In North America the black bear was seen by Hearne swimming for hours with widely open mouth, thus catching, almost like a whale, insects in the water' (202).

The transformation is thus omitted. Nevertheless, the statement is left now as suggestive of the transformation, for it follows immediately a passage in which the author suggests the probable change of many birds. Indeed, if it does not convey this hint, the whole passage seems to want a purpose. 
of the whale. This, lowever, is not to be forgotten, that when the ursine-whale began his career, he must have had his tail to make: and this would be just the reverse of the other story. The land-animals derive their tails from the waters, having originally been fishes; but in this case, a land-animal goes into the water to procure a tail, and live like a fish.

But we must still for a while keep to our text :-

' In nova fert animus mutatas dicere formas Corpora-'

Thus we are told that the penguin, by natural selection, became a swift-flying bird (324); and we are assured, more than once, that the horse and tapir, the camel and the pig, are 'joined together by family-ties' (324); but whether the pig is descended from the horse or the camel, or the pig is progenitor of the tapirs, or the tapir of the horse, or vice versâ, or whether they all sprung from a common progenitor, is not certain. However, this is certain-according to the theory, that not only something of this sort has taken place, but that we are all of the same family, and that we have ties of descent with the elephant, the bat, the porpoise, the giraffe, and the crab-we all spring from one progenitor, and we are branches of one great family. "The frame-work of bones being similar, in the hands of a man, wing of a bat, fin of the porpoise, leg of the horse, the same number of vertebræ for the neck of the giruffe and elepliant, and innumerable other such facts 'at once explain themselves on the theory of descent, with slow and slight successive modifications. The similarity of pattern in the wing and leg of a bat, things used for such different purposes, and in the jaw and leg of a crab, and the petals, stamens, and pistils of a flower, is intelligible on the 
view of the gradual modifications of parts and organs, which were alike the progenitors of each class.'

Here is a curious assemblage !-men, bats, porpoises, giraffes, horses, crabs, elephants, and flowers all mixed up together. In this medley we may pick and choose our parents or first cousins, according to our inclination; or if the list should appear circumscribed, we may add the tapir and pig and camel-c closely joined together by family-ties' - with the horse; and with this handsome list of ancestors, we may be able perhaps to account for the different dispositions which we find in ourselves, our friends, and acquaintances.

That our origin is aquatic is an established point in the theory, so that when we thoroughly understand this, we need not be so much surprised to find ourselves, as well as giraffes and elephants, associated in genealogy with crabs and porpoises. 'All physiologists admit that the swimbladder is homologous, or ideally similar, with the lungs of the higher vertebrate animals;' hence there seems to me to be no extreme diffculty in belicving that Natural Selection has actually converted a swim-bladder into a lung: On this view it may be 'inferred that all vertebrate animals having true lungs have descended by ordinary generation from an ancient prototype, of WHICH We KNow NowIInG, fumished with a floating apparatus or swim-bladder" (210).

The proof drawn from an 'ideal similarity' leading to a progenitor, 'of which we know nothing,' and so endowing us all with lungs instead of swim-bladders, which our unknown progenitor possessed, is very convincing; and perhaps we might suggest as corroborating the proof of our aquatic origin, that we are disposed to call an ec- 
centric person 'an odd fish'-doubtless with reference to the ancient traditions of the family.

But if swim-bladders have been transformed into lungs ' in the higher vertebrata, the branchix (of the fishes and crustacea) have wholly disappeared .... and it is conccivable that the now utterly lost branchire might have been worked in for some quite distinct purpose . . it is probable that organs which at a very ancient period served for respiration, have been actually converted into organs of flight' (211).

All this, however, relates to anatomical structure and the adaptation of organizations. We now must turn our attention to outward form and comeliness, which has not originated in any design to produce the beautiful; for 'nature cares nothing for appearances' (87), but it is to be attributed to a cause which never would have been suspected. Beauty amongst birds and beasts, and I suppose fishes and insects too, originates in the preference of the females for handsome males! 'The birds of Paradise and some others congregate, and successive males display their gorgcous plumage, and perform antics before the females, which, standing by as spectators, at last choose the most attractive partner. Sir R. Heron has described how one pied peacock was eminently attractive to the hen birds. I can see no good reason to doubt that female birds by selecting, during thousands of generations, the most melodious or beautiful males, according to their standard of beauty, might produce a marked effect. Thus, then, I believe, that when males and females of any animal differ in structure, colour, or ornament, such difference has mainly been caused by sexual selection ; that is, individual males have had, in successive generations, some slight ad- 
vantages over other males in their weapons, means of defence, or cuARus, and have transmitted these advantages to their offspring' (94).

This romantic origin of beauty is however acknowledged not to be useful, except in ' a forced sense,' for ' the displaying of beauty to charm the females,' and thus producing. a beautiful progeny is of no real use (219), and yet it is effected according to the theory, so that Natural Selection does, after all, produce both the useful and the ornamental.

Here we must for a moment resume the serious tone, to draw attention to the flagrant abuse of words by which the theory is argned. It has already been noticed that both Natural Selection and the Struggle for Existence are avowed metaphors, and now when we have come to nature's most striking attribute, her beauty, we find it explained to us as originating in Natural Selection in 'a forced sense,' as if it had been selected for its utility, when the author candidly confesses that it is of no direct use. 'The effect of sexual selection, when cisplayed in beauty to charm the femates, can only be called useful in rather a forced sense' (219).

Now mark this, unless it be for the direct use of the animal or plant, nothing can be done by Natural Selection. This is the fundamental proposition on which the whole theory rests, repeated over and over again in many passages; everything is based on this,-take this away and the theory vanishes. Is not then this an instance in which the author has confuted himself? Has he not checkmated himself, and is not this manifest?

He has taken pains to show us, that by Natural Selection the female birds are instrumental in producing hand- 
some males. Now the ornament of the male bird is beauty in its stronghold: what can be thought of more exquisite than the plumage of many of these glorious creatures? This is no trifle in Nature, it is the frieze of her splendid temple, one of the most admirable expressions of beauty that she has selected for the decoration of her majestic fabric. Well, this dazzling attribute, said to be of no use, according to the theory, and produced only to please the eye of females, has been elaborated by Natural Selection, which spurns all ornament, and 'cares nothing for' appearances,' and never produces anything that is not strictly useful. If then this is not self-contradiction, and self-confutation, there must be an end of logic in the world.

Here the Theory ceases to be ridiculous, for it is truly melancholy to see a writer of such large information and superior intellect reduced to the necessity of making this avowal. 'Some naturalists believe that very many structures have been created for beauty in the eyes of man, or for mere variety. This doctrine, if TRUE, would BE ABSOLUTELY FATAL TO MY THEORY' (219).

Poor, miserable Theory! which, quarrelling with creation, will not allow that the decorations of this terrestrial scene have been sketched and executed by a supreme intelligence that sees beauty in its essence, and from that intuition has turned out myriad graceful forms tinted with refulgent colours, in well-considered contrast, or blended in perfect taste; and for all regions, and for every climate, has prepared endless varieties of elegance, attractiveness, and symmetry, - a theory that will not allow an artist to have executed the picture, though it acknowledges its 
beauty, and so betakes itself to cocks and hens as a refuge from creation, and seeks shelter under a Metaphor to escape from Omnipotence!

'Some naturalists believe'! all mankind believes it, all nations in all ages; not to believe it is to be stultified with the nepenthe of sophism, or drunken with the dregs of paradox. Our very nature is at war with such a delusion, and one of the first exercises of our awakened intellect is to confess in the words of the ancient days,

'He hath made all things beantiful in his time.'

But we resume the description of Natural Selection. We have seen that 'one pied peacock was eminently attractive to the hens,' to convince us that the splendid plumage of the males is due to the selecting admiration of the females. We must suppose therefore that the male and female, long before the Silurian era, differed very little in the external appearance, but one peacock having by some lucky accident acquired a feather of striking appearance, he became a favourite with the ladies, so that in the next hatching the eggs fecundated by the bean, predominated over those by the plain males. Young peacocks were hatched with the paternal feather, they of course were also favourites with the fair sex, and the ornamented males increased in number. Natural Selection after this helped them, in the revolution of ages, to the rest of their grand plumage, the purple, green, gold, and cinmamon, the gorgeous-eyed long feathers of the sweeping train, the graceful crest, and the large lustrous eye. Natural Selection, or nature which really does not care for appearances, took no interest in this change going on, but, to gratify the fair, lent a helping hand, and thus we have beauty in the male birds. 
In this way we may understand the moral qualities of birds by the appearance of the males. The dusky cocks, which differ little from the hens, have had quaker-eyed partners, fond of the drab colours and homely attire; the pea-hens, the pheasants, the birds of Paradise, the hummingbirds, and many more of the splendid species, descend from vain mothers, allured by gauds and garish show. The argus-pheasant, perhaps the most magnificent of male birds, is a sad instance of the frivolous disposition of his maternal ancestors. The crows and rooks spring from a grave and clerical lineage. The cock-sparrow argues the sobriety of taste that prevailed in his respectable family.

Mr Darwin, indeed, seems to have misgivings 'lest it should appear childish to attribute any effect to such weak means' (94); but after a little talking over the matter, concludes, as usual, that he 'sees no good ground to doubt,' and so inserts the article in his creed; for a creed it is, and continually presented to us as such, by the established formulary: 'I believe.'

To finish this picture with the last touch, the author informs us that 'he would not attribute all such sexual differences to this agency, for some of the peculiarities of the males he cannot believe are attractive to the females, particularly the tuft of hair on the breast of the turkeycock, which he considers neither as useful nor ornamental ' (95).

But has the learned author consulted the turkey-hens on this subject? de gustibus non disputandum: the fair ones may admire a strong tuft of hair on their husband's breasts, who knows? Philosophers and turkey-hens cannot be supposed always to see matters from one and the same point of view. 
To meet all this with serious argument would be a waste of time, but still we might inquire how it comes that the plumage of the male birds is generally fur superior to that of the females. In far the greater number of cases it is acknowledged to be so, when there is any material difference between the sexes. It is a rare case where the female surpasses the male in beauty. How is it then that admiration has all been on one side, and that the males, whose ardour of love seems to contrast with the coyness of the females, have been totally indifferent to the beauty of the fair sex? It is the male which generally seeks out and woos the female, as Mr Darwin notices; we should therefore have expected just the reverse of the established rule; for if the males had selected the improving females and neglected the others, this would have been 'selection,' and the females would have inherited the ornaments which we are disposed to consider as the proper attribute of that sex.

Before this sketch of the general functions of Natural Selection is dismissed, it should be noted that some animals - and especially some classed as domestic-seem to resist Natural Selection; in other words, they do not appear to manifest any tendency to transformation. 'Although I do not doubt that some domestic animals vary less than others, yet the rarity or absence of distinct breeds of the cat, the donkey, peacock, goose, \&c., may be attributed in main part to selection not having been brought into play' (43). 'This is a curious admission of the author, as if he had forgotten his millions of ages with which he usually meets the objection that we are not able to discern any change effecting in animals in the present day. Indeed, in another passage, he notices that some have urged against his theory that the mummy cats of Egypt differed not at all from those 
now in existence; to which he replies, 'What does this prove but that the cats of Egypt five thousand years ago resembled the present race?' - as if five thousand years were but a moment in his scale of time.

However, in the passage before us we see it acknowledged that Natural Selection has 'not been brought into play,' an expression which, when closely examined, means really that those animals have not begun to change themselves. 'Their limbs have not been 'plastic' - a favourite little word with the author, in which is slily condensed the power of self-creation-and so they have not brought Natural Selection into play.

The author finishes his remarks on this part of his subject with the following droll observation: "The goose seems to have a singularly inflexible organization.' Natural Selection, then, does not seem to be able to change a goose. That wise animal (for so we must esteem it) thinks it better to adhere to a conservative policy, and to be satisfied with things as they are, having no desire to lapsc into a giraffe, a crab, an elephant, or a philosopher. 


\section{CHAP'TER VI.}

NATUIRAL SELECTION OPERATING IN INSTINC'T.

In the Origin of Species there is a chapter dedicated to Instinct, and it is here that we now follow the author.

Instinct, even in its most striking examples, like every thing else in this theory, is to be traced to the operations of Natural Selection. 'Under changed conditions of life it is at least possible that slight modifications of Instinct might be profitable to a species;' and if it can be shown that instincts do vary ever so little, then I can see no diffeculty in Natural Selection preserving and continually accumulating variations of instinct to any extent that was profitable. It is thus, I believe, that all the most complex and wonderful instincts have originated' (229).

'Surely,' says M. Flourens, 'we cannot take this as meant to be serious: Natural Selection choosing an instinct!

.... la poésie a ses licences, mais

Celle-ci passe un peu les bornes que j'y mets.'

However, this we are to understand, that according to the theory no animals made their first appearance in the scene of life endowed with peculiar instincts, but acquired them 'by the slow and gradual accumulation of numerous slight, yet profitable, variations' (230). 'T'hus the-honey-bee was 
not the insect that it now is, with its peculiar polity; nor were the ants what we now know them to be; nor were the beavers distinguished by their architectural capacities; nor did the migratory birds ' know their seasons:' for in all those cases, and many more which are the theme of constant admiration, Natural Selection had not 'been brought into play.'

Of course, then, the animals in the days of their deficiency of instinct, were other creatures than they are now ; and as they must have had different habits, their organization must have been different. Take the instance of the spider, admired for the instinct which prompts it to construct its artful web, it could not, when it did not possess that instinct, exercise the faculty of capture, and therefore could not live as a destroyer of insects. It must have been altogether different. The glutinous fluid prepared for the spinners, with which the creature twists its thread of some thousand filaments, could not have existed, nor the sieve-like spinnarets pierced with numerous holes for the exudation of the liquid, which dries the moment it comes in contact with the air. And as the legs of the animal are adapted for its textile labours, these must have been different, and its disposition, appetite, and all its habits unlike what they now are. In other words, it was not then a spider. Neither is it possible to conceive how, through the instrumentality of Natural Selection, it ever could have become a spider, for as such a transformation would be a process requiring thousands of ages, and in the case of 'complex instincts' millions, the spider-to-be would have derived no benefit from the rudiments of a web, as the web must be what now it is to catch flies; and if we were to concede that by the accumulation of profitable modifications the spinnarets began to grow, 
and the viscous liquid to be secreted in the body, of what use would this be to the spider till furnished with the whole apparatus with which it might seize its prey? What advantage would it have been to the creature to have produced an infinitesimal portion of web, without the whole plan - the concentric circles, the radii, the foundation cables, and the whole apparatus?

Turn it then as you will, the spider must have been what it is, as soon as it came into existence ; it must have had its instincts, its organization, its habits, and its general character contemporaneously. It must have been called into being as a weaver and constructor of an implement to catch insects, or else it would not have been a Spider. It came into the scene fully prepared to sustain its part in nature for the object for which it had been designed: organs, secretion, disposition, and instinct were its dowry, all together, and with one object; and if any one can doubt that it was an animal ordained to repress the redundancy of the insect race, he must either by misfortune or the most resolute perverseness have lost or abandoned the right use of his reason.

And these remarks, mutatis mutandis, will apply to all cases of instinct.

As the stronghold of instinct is with the social animals, it is here that the theory has the boldest achievements to accomplish, and, as we shall see, has dared the most. With the ants and the honey-bee, the existence of neuters is a well-known part of the constitution of their society; and this peculiarity, the groundwork of much of their polity, is thus explained for us: 'Thus I believe it has been with social insects; a slight modification of structure, or instinct, correlated with the sterile condition of certain mem- 
bers of the community, has been advantageous to the community ; consequently, the fertile males and females of the same community flourished, and transmitted to their fertile offspring a tendency to produce sterile members, having the same modification. And I believe this process has been repeated, until that prodigious amount of difference between the fertile and sterile females of the same species has been produced, which we see in many social insects' (260).

If we apply this to the honey-bees, and this must be the most important application, we should remember that their polity and the constitution of their society have specific arrangements, which, if altered or made otherwise than they now are, 'the community,' as far as we know anything about it, would not exist at all.

If, therefore, at any times all the females were fertile, as the above explanation of the case informs us they once were, then 'the community' did not exist; and to pretend that it existed in some other form than that which now exists, is simply to insist on a fable, and may be dismissed as an idle dream, of which nothing like a proof can possibly be adduced.

Moreover, it is not sufficient to imagine that the neuters were once fertile, for we must also imagine that when the fertile females were transforming themselves into sterile neuters for the benefit of society, that one female was, by a long preconcerted scheme, at the same time prodigiously increasing her fertility in order to become the sole Mother and Queen of the whole hive. But it seens to be an easy matter not only for one individual to increase its fertility to any amount, but for fertile animals to agree to produce, and actually to produce, sterile offspring! 'the fertile 
males and females flourished,' we are told, ' and transmitted to their fertile offspring a tendency to produce sterile members!'

Surely this is the most marvellous of all the marvels which we have yet met with: fertile parents transmit through fertile progeny, a tendency to produce sterile members of society! Thus, then, sterility springs from fertility! and, because parents and children are fertile, therefore, and as a consequence, their grandchildren are sterile! Such is the logic of the theory.

But again : 'a slight modification of structure or instinct, correlated with the sterile condition of certain members of the community, has been advantageous to the community, - these gentle words carry with them a world of meaning, and yet they are so quietly introduced, that they might almost be supposed to express well-known facts which no one disputed. 'A slight modification of structure or instinct,' not only begs the whole question, but takes for granted that to change the structure or the instinct of an animal is as easy with them, as for us to change our shoes and stockings. Changing a structure is in fact a work of new creation, and changing an instinct is a feat never accomplished except in a fairy tale, if even a fairy tale has ever registered such an event. Perhaps in $\mathrm{Mr}$ 'ihackeray's History of the Ring and the Rose something like this is recorded, but that can scarcely be considered authority for the facts of Natural History.

These transformations, slowly working out by fertility producing sterility, were 'for the benefit of the community.' 'Certain members of the community' perceived this, and so they agreed to have sterile grandchildren, and thus on this public principle was the society at last established on 
a solid basis. The one female who was left fertile, whilst thousands and tens of thousands around her had become sterile, concentrated in her person the esteem and respect of the whole society, and thus has Natural Selection consolidated 'the Realm of Bees.'

Having thus given us the authentic history of bees, $\mathrm{Mr}$ Darwin goes on to the ants.

'But we have not as yet touched the climax of the difficulty; namely, the fact that the neuters of several ants differ, not only from the fertile females and males, but from each other, sometimes to an almost incredible degree, and are thus divided into two or three castes' (260). Details are then given of these striking differences, and in one case we have it described thus: "The difference between them is the same as if we were to see a set of workmen building a house, of whom many were five feet high, and many sixteen feet high-but we must further suppose, that the larger workmen had heads four times as big as those of the smaller rnen, and jaws nearly five times as big.' Here, indeed, is difference enough, but it is no obstacle to the theory, as we see by the following words: 'It will, indeed, be thought that I have" an overweening confidence in the principle of Natural Selection, when I do not admit that such wonderful and well-established facts at once annihilate my theory. In this case we may safoly conclude from the analogy of ordinary variations, that each successive, slight, profitable modification, did not probably at first appear in all the neuters in the same nest, but in a few alone! and that by the long-continued selection of the fertile parents which produced most neuters with the profitable modification, all the nenters ultimately came to have the desired character' (261). 
Surely we have an instance in this passage of the manner in which the author habitually deceives himself. We hear of 'the principle of Natural Selection,' when, in fact, it is no principle at all, but simply 'the sequence of events' according to the author's definition of the words. Let us, then, here again substitute the definition for the metaphor. 'It will be thought I have an overweening confidence in the Sequence of Events' - if put thus, the illusion vanishes, and the cloud of words is dissipated.

Here, however, the author personifies his metaphor more determinately than usual. "The long-continued selection of the fertile parents :' who selects them? Natural Selection: and what is Natural Selection? the Sequence of Events as observed by us. But by continual speaking of Natural Selection in this way, by constantly personifying the metaphor, the author presents it to us, and that repeatedly, as if it were an intelligent breeder of animals, exercising a clear judgment, and skilfully contriving to take advantage of every circumstance that might favour the object it had in view. A phantom of words sustains a character, and a figurative expression is turned into an omnipotent workman.

But why need $\mathrm{Mr}$ Darwin trouble himself about 'a climax of difficulty.' How can there be any climax in such a system as this? The theory that educes animated nature from the spore of a sea-weed, and that 'works in the tail of a fish for all sorts of purposes,' till it becomes the tail of a giraffe or a monkey; that turns swim-bladders into lungs, and branchiæ into wings, with many more such marvels, need not find a difficulty in any proposition. Natural Selection can do anything which the imagination can possibly suggest. It has brought fishes out of 
the water to become terrestrial animals, and has sent bears to live in the sea. Delphinum sitvis adpingit, fluctibus ursum.

There can be, therefore, no climax of difficulty for this thaumaturgic Metaphor. 


\section{CHAPTER VII.}

NATURAL SELECTION IN THE ARCHITECTURE OF THE HONET-BEF.

THe received opinion of all ages as to the principle of Instinct is in direct opposition with the dogmas of the theory. What that theory teaches us on this subject we have now seen; and, as the aim of it is to get rid of the idea of a preordaining wisdom, arranging beforehand certain habits of life for animals, either in a social or a solitary condition, and adapting their organization for their pre-determined habits, here it is we take our stand, and boldly affirm that instinct is the result of pre-ordaining wisdom, and that certain creatures act in a certain way for their own benefit, not because the Sequence of Events has brought them to act in that way, but because they have been brought into existence so to act, and liave no alternative but to act as they do.

Certain species have appeared on the scene for a certain object, and without their will or power of altering the arrangement, certain germs of life derived from themselves are developed, which inherit the qualities, faculties, and dispositions of the species, handing down to all ages the unalterable traditions of their race.

No animal can escape from the instinct of its species, 
nor can modify it ; the honey-bee always makes its honey and the comb to contain it by one invariable rule, and the bird always constructs its nest after one pattern; the plan and pattern of the garden-spider's web is always the same.

'The polity of the honey-bee is the same that it was in the days of Aristotle and of Homer, the same as in the age of the Vedas, the same as in the most ancient figure of the insect in the Egyptian Hieroglyphs, and the same as it was ages before any intelligible record could refer to its existence.

To animals, whose habits are not stationary, and whose life is exposed to numberless vicissitudes, instinct has been given that by various provisions and contrivances they may be enabled to guard their species from danger; and by its careful reproduction, accomplish the place in nature assigned to them. They are actors of a drama which they must perform, and they come into the scene invested with the qualities and the talents requisite for the part which they must sustain.

In other words, instinct is creative power transmitted to created beings, and it is for this reason and in consequence of this origin of instinct that its manifestations remain unexplained. Creatures act in a certain wonderful way by an impulse which we cannot understand. It is one of those mysteries exhibited in nature which we must be content to accept as an uninterpreted fact, just as we see the magnetic needle turn to the pole, and cannot explain it.*

The stronger animals, which are well-armed and have

* When a bee makes its nest geometrically, the geometry is not in the bee, but in that great Geometrician who made the bee, and made all things in number, weight, and measure.-Reid on the Active Powers, III. p. 1 , cap. 2 . 
little to fear from other animals, have comparatively a small heritage of instinct; but when animals, which are weak as individuals, have a great work to perform in social compact, they are endowed with manifold instinct, and are sometimes formidable from their numbers.

Some animals, such as the rabbits, have a character of sociability, but the work assigned to them is little more than reproduction of their species. Their instinct, therefore, is insignificant.

The work chalked out for the ants, the vespidæ, and the bee is very great. They have to build a city, to sustail a large society in perfect order, to rear a numerous population, and to procure, by foraging, abundant provisions for the community. Each insect viewed as an individual is weak; but when a multitude of them act in concert for attack or defence, they are very formidable: and the instinct that prevails amongst all, constitutes the safeguard and welfare of all.

This instinct compels them to follow certain habits for certain objects; there is a distinct design in their polity, resulting in a constitution of their state as clearly defined as that of the demos of Athens, or the more complicated government of Sparta, and far more fixed and certain than our vaunted constitution, now unhappily in a state of transition from a moderated monarchy to an immoderate democracy.

It is probable that a principal object of the existence of the honey-bee, is for the fructification of flowers; and starting from this supposition, all the design would appear to be harmonious. In order to produce the effect, an insect would be required whose sole food would be the nectar of flowers; the nectar so gathered is in the insect's 
stomach changed into honey, and regurgitated in its new form in the store-houses. The store-house must be a very numerous aggregate of chambers for the numerous society; the material for constructing the store-chambers is extracted from the food itself, elaborated by an act of secret chemistry. No chemist can produce wax out of honey, but this the bee accomplishes, and thus the insects in procuring their food, find also the material for their building. The building is always progressing in warm climates, and in temperate latitudes always during the summer months, both to enlarge the city for the reception of its increasing wealth, and for the wants of its increasing population.

The production of eggs, from which the whole population springs, is confined to one female, the fountain of life to the community.

Her sole occupation is reproduction of her species; the workers, therefore, imperfect females, are not burthened with gestation, and are free for all the multiplied labours of the city. They are labourers, builders, nurses, purveyors, soldiers, sentinels. They are also scavengers and ventilators of the city. The population is exceedingly dense in prosperous circumstances and favourable seasons, and the plan of the city is complicated, and the streets and passages narrow, but all proceeds with order, decorum, and regularity.

Even in the nests of wasps-a lair of free-booters-courtesy and consideration prevail amongst the population, and there is neither strife nor disorder within the precincts of their abode. The laws of the community are sustained in perfect harmony, and in all the bustle and crowding of a dense hive there is a perfect plan of general action, though the labours may be various, and many different objects 
require their attention. It would be well for our cities and towns if a numerous police and vigilant magistracy could secure the public order as perfectly as in a bee-hive.

In the bee-hive there is no police, because every individual of the community keeps the peace by keeping itself in its proper place and attending to its duties. A strong impression of duty is one of the most striking manifestations of the instinct of the bee. There is no idleness, no robbery, no infraction of law, no resistance of authority. Each citizen contributes to the harmony of the whole, and all the community respect the queen-mother with most loyal attachment and devotedness.

The more there is to be done, the happier the bees are; industry is the joy of their existence, and that industry is exercised not for individual gratification, excepting as far as the contributing to the general welfare may be considered their reward.

At such a scene as this, Natural Selection must look with a malignant eye, for if it cannot calumniate and depreciate the realm of bees, the occupation of the Metaphor is gone, and it must betake itself to that limbo, large and broad, whither all things transitory and vain mount up as to their proper home.

We have seen how in the history furnished us by the theory, the bees have come to be divided into their actual ranks, and how the neuters have been brought into their present form by Natural Selection. We have now to consider the explanation offered us of the architecture of the honey-bee.

$\mathrm{Mr}$ Darwin's statement on this subject is given at great length, but the following may be taken as a correct epitome of what he says. He divides the architectural tendencies 
of the bees into three classes; the lowest that of the humble-bee, the next in advance the structure of the Mexican Mellipona, and the highest and most perfect the cells of the bee-hive. The humble-bee makes use of its old cocoons, adding thereto irregular rounded cells of wax. The Mellipona forms a regular waxen comb of cylindrical cells, in which the young are hatched, and in addition, some large cells of wax for holding honey. These latter cells are nearly spherical, and of nearly equal sizes, and aggregated together in an irregular mass. The spherical walls, when they come in contact, do not intersect, for the bees build perfectly flat walls of wax between the spheres, which thus 'tend' to intersect.

On this state of the case it occurred to Mr Darwin, '(1) that If the Mellipona had made its spheres at some given distance from each other, and (2) had made them of equal sizes, and (3) had arranged them symmetrically, and in (4) a double layer, the resulting structure would probably have been as perfect as the comb of the hive-bee.' This proposition (containing four assumptions), he sent to Professor Miller, of Cambridge, who returned him an answer, in regular algebraic and geometric language, that the result would be a structure, both in form and accuracy, identical with the cells of the hive-bee.

When we state our own case to a lawyer, in our own point of view and according to our wishes, it is very probable that we may have a formal opinion, highly encouraging for our law-suit. We have seen the statement of the case,- the comment of the author on it is characteristic.

'Hence we may safely conclude, if we could shignitly modify the instincts already possessed by the Mellipona, and in themselves not very wonderful, the bees would make 
a structure as wonderfully perfect as that of the hivebee. We must suppose the Mellipona to make her cells truly spherical, and of equal sizes (two assumptions), and this would not be very surprising, seeing that she does so already to a certain extent, and seeing what perfectly cylindrical burrows in wood many insects can make, ap. parently, by turning round on a fixed point. We must suppose the Mellipona to arrange her cells in level layers (another assumption), as she already does her cylindrical cells; and we must further suppose (fourth assumption) that she CAN SOMEHOW ACCURATLLY JUDGE at what distance to stand from her fellow-labourers when several are making their spheres, -we have further to suppose (fifth assumption) - but this is no difficulty --that after hexagonal prisms have been formed by the intersection of adjoining spheres in the same layer, she can prolong the hexagon to any length requisite to hold the stock of honey. By such modifications of instinct, in themselves not very wonder.. ful, hardly more wonderful than those which guide a bird to make its nest, I believe that the hive-bee has acquired, through Natural Selection, her inimitable architectural powers.'

To leave nothing unexplained, Mr Darwin remarks : 'The work of construction seems to be a sort of balance struck between many bees, all instinctively standing at the same relative distance from each other, all trying to sweep equal spheres, and then building up, or leaving unguarded the planes of intersection between the spheres' (247).

The Honey-bee then by this statement is, in fact, a Mexican Mellipona performing pirouettes, and trying to sweep equal spheres. Natural Selection has brought the Mellipona, after changing the whole constitution of the com- 
munity, to become a skilful architect by striking imaginary circles; and in order to simplify the making of a hexagon, has taught it to execute the plan by intersecting circles, and building up the planes of intersection, which seems a strange way of making her problem more simple. It certainly presupposes no small degree of geometrical knowledge to hit on such a plan, to say nothing of other difficulties.

But here, as usual, a magical transformation of an animal is taken for granted as most easy to be effected. 'We may safely suppose,' says the author, 'that if we could slightly modify the instincts of the Mellipona, that insect would produce a structure as perfect and beautiful as the comb of the hive.' Certainly, if we could effect this, we could perform wonders; we could then be able to change the whole economy of nature, and should surpass in skill the wizards of Egypt, or the magicians of the Arabian Nights Entertainments. Slightly modify the instincts of a sheep, and that modification by giving it more courage would be for its benefit, and put this modification into the hands of Natural Selection, and in due time the sheep might become a wolf.

But observe, it is deemed nothing wonderful in this theory, that a Mellipona should make sucl cells as she does, which, though inferior to those of the hive-bee, would ordinarily be considered as marvellously skilful contrivances for an insect; and the instinct which prompts the birds to build their curious and beautiful nests, is spoken of with a sort of contempt, as if it were easily to be explained, and more easy to be accomplished, though it is very doubtful whether all the skill of man could exactly imitate some nests of the more refined and complex fabrics. 
To some minds such passages as the above will appear perfectly amazing; that, especially in a scientific disquisition, in which one naturally expects a rigorous attention to facts, such preposterous suppositions and dreams should be brought forward, as the foundation of a systematic exegesis of nature; and that on a long series of assumptions, all purely imaginary and incapable of proof, an argument should be built up for cancelling creation.

It is, however, the impatience of a supreme Intellect, 'ordering all things well,' which manifestly has prompted the above explanation, for the author introduces the subject thus: "We hear from mathematicians that bees have practically solved a recondite problem, and have made the cells of the proper shape to hold the greatest possible amount of honey, with the least possible consumption of precious wax in their construction-... Grant whatever instincts you please, and it seems at first quite inconceivable how they can make all the necessary planes and angles, or even perceive when they are correctly made-but the difficulty is not nearly so great as it first appears,'-and then follows what we have already seen.

Just so, it is quite inconceivable how the bees can make all the necessary planes and angles. It is quite inconceivable how the spider should know how to construct his web; it is quite inconceivable how the tailor-bird should have learned to sew together leaves for her nest with the regular seamstress' art, it is quite inconceivable how the beavers should have learned to build their houses, and make their dams, should have acquired the art of cutting down timber for architectural purposes-and so of a thousand other such instances. We affirm that we cannot know how all this is effected, instinct is a mystery emanat- 
ing from the supreme Geometrician, the supreme Intellect; certain animals are instruments for executing a certain plan assigned to them, and that is all we can say on the subject. We see their work, and can only admire it,-in many instances we never can equal it, in some we cannot imitate it, and in no case can we explain how the animal is guided by that instinct which is the object of our admiration.

There are certain barriers to our knowledge which we never can surmount, there are questions in which we must be content to be always ignorant. In the legitimate path of science, by patient investigation, immense wealth of knowledge is to be obtained; but if we attempt to break forth into regions unfitted for our mental faculties, discomfiture and shame will be all that we shall obtain.

We have, moreover, to make serious objections to the imaginary series of experimental architecture amongst bees, as if the first sketch of it began with rude cells of the humble-bee, and had gone on by progressive perfection to the hive-bee. This of course is part of the theory which supposes that nature has always been changing, and is still undergoing mutation, in ceaseless instability, as if nothing had yet been settled by any definite arrangement. To that supposition we offer an answer in the general arguments of these pages, but in the mean time we affirm that it is a great mistake to suppose that all the varieties of the bees, each* in its proper sphere, are not fulfilling the

Linnæus has enumerated 35 speeies of the genus Apis. Mr Kirby, in his Monographia Apium Anglia, has deseribed above 220, natives of England. In Guadaloupe the bees are without stings, and form no eombs; they enclose their honey in waxen cells of the figure and size of pigeon's eggs, but more pointed. If the hollow of the tree in whieh they fix themselves should be too large for their purposes, they form a dome of wax, and work under the structure. 
duties assigned to them. The designs of Nature are often beyond our comprehension for their number alone, and it is astonishing to observe what multitudes of species have been placed in existence, with a similar purpose, to be obtained by various methods. The infinitely varied, and often infinitely minute, operations of the great workshop of Nature are apportioned to myriads of workers, each capable of performing its task with accuracy and perfection, and adapted by organization and instinct to obtain complete success in the line of its prescribed duty. To execute every idea of Nature, vast multitudes of able-bodied labourers are put on her lists, and there is not one of them that does more or less than was intended. She has armies of builders and armies of destroyers; for to repress the redundancy of production is as much her object as to encourage the multiplication of life. The entomologist Ratzeburg enumerates 650 species of insects injurious to the forests of Germany alone, and each of these species would be a study for a careful physiologist.*

We must not, therefore, despise the humble-bee, nor ' hear with a disdainful smile the annals' of her simple life. She has a sphere of existence assigned, and if she does all required of her, she may be as much respected as the cottager of her race, as the hive-bee is admired as the architect and burgess of a stately city. The Mellipona and the hive-bee have their mission to perform, and a range of obligation which they never exceed; and we may be quite sure that the Mellipona has as little chance of rising superior

* An innumerable army of dung-beetles and stercoraceous flies, of ants and termites, is constantly at work removing the decaying substances which otherwise would pollute the atmosphere.-Homes without Hands. 
to its present condition, as the African negro has of taking precedence of European intellect.

But we must return awhile to the details of the architecture of the hive-bee. We have seen that geometricians of repute have been consulted on a problem of intersecting spheres producing hexagons at the intersection, \&c.; and we have, also, seen how that problem was stated, so as to be applicable to an imaginary state of things, having no real existence, and to be found only in the surmises and suppositions of the Theory. This is not the first time that the bees have had this compliment paid them, that their architecture has been tested by the rules of geometry, and examined by the ablest mathematicians of the day. The result has always been, that geometry has confirmed the calculations on which their architecture has been executed, to whatever quarter those calculations have been traced. But in this case Mr Darwin seems, unwittingly, to pay them a higher compliment than usual, for he either supposes that the bees intend to make hexagons by striking imaginary intersecting circles, or that the hexagon is produced by that exercise of their imagination. 'It suffices,' says he, "that bees should be enabled to stand at the proper relative distances, and form the walls of the last completed cells, and then by striking imaginary spheres,' \&c. (253). We have also seen that 'they are somehow to know the proper distance,' and all the rest will follow.

Now to us it appears, that if carpenters or bricklayers were about to construct hexagonal chambers, and were for that purpose to go into the dark and strike imaginary spheres, at the proper distances, which they were somehow to ascertain without measuring, they would be a very curi- 
ous race of Laputan builders, acting on abstract principles to begin with, and still more marvellous if their unusual plan should turn out successful.

If $\mathrm{Mr}$ Darwin should urge, that the hexagon is not an intention but a result, that the intention is the circle, and the accidental production a hexagon, then the bee imagines the circles, which it never really sweeps, knows when to stop where an imaginary circle meets an imaginary circle, and builds its walls on the points of contact of two or more dreams.

But let the case be put still more clearly. The bees work in ignorance of what they are doing; at least, $\mathrm{Mr}$ Darwin says so; at any rate, they do not understand geometry, in this we should all agree. But philosophers, men of science, are adepts in geometry, and by algebraic calculations can make great discoveries. To test, therefore, the value of the comprehensive 'sovishow' of this supposition, let us suppose that six scientific Transmutationists are locked up in a room perfectly dark; to each is to be given a piece of chalk, and they are to arrange themselves as they like by striking imaginary (not real) circles in order to draw a superficial hexagon on the floor. As soon as they are satisfied with their exploit, the figure they have drawn is to be sent to Professor Miller, of Cambridge, who will measure the angles aud report thereon. What sort of a figure should we have by the joint-labours of the six learned gentlemen? Who will venture to describe its exquisite and accurate proportions?

Though this is but a partial illustration of the work of the bees, which with them is much more than a superficial hexagon, it may serve to show the value of this part of the theory. 
We might here inquire if Mr Darwin is disposed to extend this explanation of the hexagonal architecture to the wasps also, for with them there is no Mellipona Mexicana to suggest a transition of architectural skill : neither would the Cambridge problem apply to their case, as their cells are in simple rows, and not placed base to base as with the bees. The wasps, however, construct accurate hexagons for their cells, and of another material : do they also sweep imaginary circles, and build up the planes of intersection of their dreams?

It would be extending this discussion to an unreasonable length, to enter into a full explanation of the real mode of operation observed by the bees in constructing their cells. This is to be seen in Reaumer, Huber, and Kirby and Spence. We may generally state that the bees begin their labours of cell-making by forming the bases of the cells first, and that when a pyramidal base of three lozenges is finished, they then build up the walls from its edges. This shows their intention - they know what they have to do before they begin ; but how they know, and how they construct the bases according to the proper angles, will never be explained. They accomplish the work, and we must be content with the fact.

In particular circumstances, however, they are able to diversify the work according to the need, and the bees then introduce such variations of the general rule as the case seems to demand. Thus the first rows of cells of the comb, affixed to the top of the hives, are made, not as hexagons, but in the form of a pentagon, and for this there is a good reason. This we learn from Huber. 'It is evident,' says he, "that the hexagonal figure of cells admits of this application by only one angle to the surface of the roof, 
where many are ranged laterally, but there must be large vacuities between the angles. But a more solid fixture becomes the marked solicitation of nature in the formation of the combs. The first row of cells, that by which the whole comb is attached to the roof of the hive, differs from all the rest, instead of hexagon, the orifice is a pentagon. The cell consists of four sides, with the roof of the hive in the plane of the fifth. The bottom, also, is different from that of common cells; only one of these picces is a lozenge, the other two is of an irregular quadrilateral figure. By the simple dispositions preserved here, the stability of the comb is completely secured, for it touches 'the interior' surface of support in the hive in the greatest possible number of points.'

Here, then, there is no ideal intersection of spheres; the pentagon dissipates all that vision, and it is clear that the bees intend to introduce the hexagon, as soon as, in their judgment, they can do so with safety. We need only to inspect a large comb to see how the theory of imaginary circles is confuted, by the management of the cells in case of any obstruction to the work, or even in the introduction of the larger cells of the drones. Cells with larger dimensions for the drones have to be worked into the general plan, and this is done by gradual change of the dimensions of the neighbouring cells, till at last the symmetrical measurement of the general design is perfectly restored.

In cases of obstruction by intervening obstacles, sometimes placed to test their skill, they find themselves compelled to alter the hexagonal regularity in order to work round the obstacle, hence some of the cells are of irregular form, but always returning by'gradations to the regular symmetry and correct shape of the normal design. 
This again is proof of their object, to adhere to the correct hexagonal pattern and the rhomboidal base. The plan is imprinted in their minds, so to speak; the pattern is in mysterious vision before them, and they build according to the plan they have received, by a necessity of their nature.

This is their instinct, and it is as admirable as it is inexplicable.

These remarks should not be closed without noticing that though $\mathrm{Mr}$ Darwin makes the bees execute a very hard problem, and for a direct purpose, to secure the greatest economy of wax, he neither allows this to be the result of an instinct, nor will he permit it to be a design or intention of the bees themselves. In what quarter then is the motive or the calculation? It is, as usual, with the great Pan, Natural Selection, the true Antitheos of the author's system. 'The bees, of course, no more know that they swept their spheres (imaginary, be it observed) at one particular distance from each other, than they know what are the several angles of the hexagonal prisms and of the basal rhombic plates. The motive-power of the process of Natural Selection (sequence of events) having been economy of wax, together with cells of due strength, and of the proper size and shape for the larvæ; that individual swarm which made the best cells, and wasted least loney in the secretion of wax, having succeeded best, and having trausmitted by inheritance their newly-acquired econonomical instincts to new swarms, these in their turn will have had the best chance of succeeding in the struggle for existence.

'Beyond this stage of perfection in architecture, Natural Selection could not lead; for the comb of the hive-bee, as far as we can see, is absolutely perfect in economizing wax' (255). 
Natural Selection, therefore--a perfect geometrician-led the bees to adopt a perfect design of architectural skill. Doubtless, long before the Silurian era, Sequence of Events was Senior Wrangler in the year that the primal Spore took its degree.

But is all this really written in earnest? and is the author not trifling with us? Does he soberly and seriously mean us to believe this fantastic fable? A swarm starting with a new batch of instincts! A queen, producing, some day, twenty thousand eggs issuing in bees inclined to strike imaginary spheres! and then the new pirouette breed sustained by queens with the new faculty to produce the new instincts! and thus at last economy triumphing over all obstacles.

Certain it is, that if Natural Selection can 'lead' to the striking of imaginary spheres, it can also lead learned men to strike out into the wildest freaks of imagination that ever yet were heard of.

But on what facts is based this theory of the struggle for existence? who or what struggles for life with the bees? Each bee, of each variety, gets on very well in its line of life: the Mellipona does not fail, and as far as we know, wants nothing; and the Humble-bee, the constructor of rude cells, and of rough unsymmetrical architecture, prospers everywhere, as we have an opportunity of observing ; why then was it requisite to concoct the new order of architects? If the old varietes were well to do in the world, where was this struggle for their existence; where was the need to introduce any improvement in order to enable them to live and to surmount the obstacles to their existence?

This struggle for existence, which the author has in- 
formed us, is to be taken in a large metaphorical sense, is in fact a mere jingle of words; it comes in to round the paragraphs and to help its brother metaphor, Natural Selection, in any of its great achievements. Twin brothers they are, of one family and one disposition.

Arcades ambo,

Et cantare pares, et respondere parati.

How wise, then, after these portentous speculations, appear the words of a great philosopher !

'The main business of natural philosophy is to argue from phenomena without feigning hypotheses, and to deduce causes from effects, till we come to the First Cause, which is certainly not mechanical.'-(Newton.) 


\section{CHAPTER VIII.}

\section{THE TRANSMUTATION SCHOOL.}

The attempt has frequently been made to describe or explain the origin of life on our globe, but in every instance the result has been a signal failure. In nature's first labours no midwife was present, and they who could persuade us that they know the mysteries of her secret chamber, are all sooner or later detected as vain pretenders. History has here no information to give us; science can afford us no help; but rather, by enlarging our knowledge of the complexities of organization, and the multiplicity of their relations, increase our astonishment at the vastness of the subjects which have to be explained. We can only hope to describe things as they actually are, and to interpret their design; and in doing this, scrupulously and faithfully, we shall always have our hands full; but if we would go on to explain by what method and by what particular adaptations of matter animated beings were first endowed with form and life, we descend to the low level of the charlatan, and return to the obsolete pretensions of the alchemist and magician. Whenever the attempt is seriously made, we perceive that it is mainly by the instrumentality of verbal inaccuracies, by the free use of expressions of a large and indefinite meaning, by analogical and metaphori- 
cal appliances to establish facts, by bold inventions of phenomena which have no existence in nature, and by frequently taking for granted the proposition to be proved.

These are the expedients of the modern school; but in remoter days the exposition was by mythos, presented as a sacred tradition for the acceptance of faith, and not meant as a physiological system for examination and approbation.

One of the most ancient and most popular theories taught that all creatures were formed out of the earth, by itself, and that in dying they returned to their parent, as is well expressed in a verse of Lucretius.

Omniparens eadem rerum commune sepulchrum.

The Epicureans spoke as if they thought that the earth had originally created animals; Lucretius, the interpreter of that school, says of the earth that it has grown effete, and that she who first created all races, and gave forth the great beasts, now scarcely creates very little animals.

Jamque adeo fracta est æetas, effoetaque Tellus

Vix animalia parva creat, quæ cuncta creavit

Srcla, deditque ferarum ingentia corpora partu (ii. 1150).

He also attributes to the earth the creation of the human race, and says that all terrestrial animals, as well as the birds, owe their birth to her, who therefore justly receives the title * of mother.

In the infancy of knowledge this opinion could scarcely be avoided: the earth seems to produce all trees and plants, and some animals also; moreover, as no other solid substance but the earth seemed at hand, out of which solid

* Quare etiam atque etiam maternum nomen adepta Terra tenet merito, quonian genus ipsa creavit Humanum, atque animal prope certo tempore fudit Onne, quod in magnis bacchatur montibu' passim, Aërias que simul volucres variantibu' formis (v. 820). 
bodies could be made, they extended this obvious principle of creation to all animated nature. Hence animals and men were made out of the soil; and yet, as no creation of an animal had ever been witnessed, and as all the known races were of an antiquity vastly beyond any record or tradition, they supposed that the earth had now grown old, and having ceased to produce anything new, had lost her original fecundity.

This simple creed was not presented with any logical finesse. There was no disquisition about the meaning of creation, no subtle disputes about canse and effect, no perplexities about mind and matter, no chemical research into first elements, and no attempt to account for the modus operandi. It was the act of Tellus, or of Nature, and there they left it.

In these days the word 'creation' has become suspicions to the scientific world, and is scarcely tolerated; but in the classical age, and even in a sceptical school, it was freely used. The motive of this modern sensitiveness is obvious; it originates in a desire to assume 'a free position,' as it is called, that is, independent of the least suspicion of biblical influence.

Long, however, before the Scriptures had any footing in Europe, very long, indeed, before they had ever been heard of out of the boundaries of Syria, many believed that a supreme intellect had effected the great work of creation.

Anaxagoras, in the fifth century before the Christian era, is said to have been the first of the Greek philosophers who distinctly taught this. He was the first who introduced Mind for the distribution of matter ; for in the begimning of his work, which is beautifully and magnificently composed, he says: 'All things were' commingled, then 
came in Mind, and separated and arranged them.' ${ }^{*}$ And Aristotle tells us $\uparrow$ that 'he made Mind, the beginning of all things, saying that it alone, of all things, was simple, uncompounded, and pure. And to this beginning he attributes both knowledge and action, or the first movement, saying that Mind moved everything.'

This was the next step in advance: design argued a designer, and as they saw many excellent contrivances, many wonderful calculations, and proofs of surpassing knowledge in the works of nature, they came to the conclusion that a presiding Intellect was the author of all things. And to these limits, the question at issue may now be restrained. It is not requisite in disputing with the Transmutationists to go beyond the ancient battle-field, where the Stoics contended with the Epicureans, and where of old they fought the battle of mind against matter. The whole question is whether there be a design and a designer in the works of nature. I have no wish to push the inquiry beyond these limits.

In Cicero's admirable book on the nature of the gods, we find that the Epicureans held precisely the fundamental principle of the 'Transmutationists. In that work, Cotta, speaking to Velleius the Epicurean, says: "You deny that reason had any share in the formation of things,'-(nihil enim in rerum naturâ ratione factum esse vultis, i. 32).

We have seen how carefully this doctrine is insisted on by $\mathrm{Mr}$ Darwin in his Origin of Species, and it is obvious that this must be sustained as the foundation for the whole superstructure of the theory.

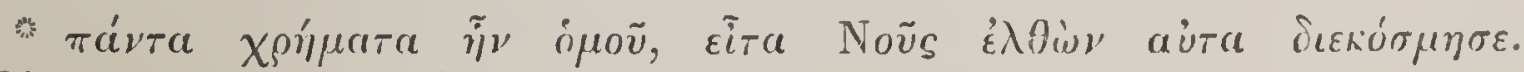
(Diogenes Laert. ii. 6.)

$\dagger$ Aristot. de Animâ, i. 2. 
The Stoics had various thoughts about the creative power, but they all held that it was intellectual and divine. Zeno held * that the law of nature was divine, and that it had the power to force us to what is right, and to restrain us from what is wrong-and the words of Seneca, the famous exponent of stoical morality, show us exactly the thoughts of shis school on this subject. 'Whosoever,' says he, "was the former of the universe, whether it is that all-powerful Deity, or incorporeal Reason, that is the artificer of the great works, or the Divine Spirit diffused through all the greatest and the least of things, with an equal intention.'

The whole question, therefore, with the ancients, was the same as that which is now the subject of debate, whether Mind has invented and organized all things, or whether the autoplastic actions of irrational matter have elaborated the universe and its contents.

Now the Stoical side of the question is that of common scnse, by the simple argument that a machine must have

Z Zeno naturalem legem divinam esse censet, eamque vim obtinere recta imperantem prohibentemque contraria. De Nat. Deorum, 14.

$\uparrow$ Quisquis formator universi fuit, sive ille deus est potens omnium, sive incorporalis Ratio ingentium operum artifex, sive divinus spiritus per omnia maxima ninima aquali intentione diffusus. (Consolat. ad Helv. 8.)

Enough has been said in the text to explain the different tenets of the two ancient schools on the origin of things; it may, nevertheless, be interesting to hear Cicero's more extended account of the Stoic Doctrine, 'that universal nature, which embraces all things, is said by Zeno to be not only artificial, but absolutely the artificer, ever thinking and providing all things useful and proper; and as every particular nature owes its rise and increase to its own proper seed, so universal Nature has all her motions voluntary, has affections and desires, productive of actions agreeable to them, like us, who have sense and understanding to direct us. Such is the intelligence of the universe.' (Nat. Deorm. xxii.) Here universal Nature and the Intelligence of the universe are obviously the divinity, approximating to Pantheism-

Mens agitat molem, et magno se corpore miscet. 
been designed by a mechanician, that a watch must have been made by a watch-maker ; though, at the same time, it is possible to avoid this conclusion, as regards the productions of nature, by having recourse to the system of Buddhism, which ignores Creation and a Creator by a Pantheistic creed, considering Nature itself and everything that is in Nature divine and eternal, and therefore without commencement as identified with the Deity itself. To some it might appear that this* is the most skilful contrivance to avoid the idea of a creation, for though it is not tenable in close reasoning, yet it is the most plausible of all the plans that deny creation, and is considered satisfactory by many millions of the human race. It is however very far from the European mode of thought, being strictly characteristic of the oriental sphere of philosophy, and can never be made to approximate to our physiological inquiries.

With such mysterious speculations modern science has no sympathy; the current tends in the opposite direction, to find in irrational matter the power of self-creation without reason, and to ignore every possible phase of a demiurgic existence.

Writers of this class must frequently be reduced to the necessity of using a language that contradicts their theory, for in treating of the apparatus of nature it is impossible to repudiate the idea of design altogether, as the intention of certain contrivances is so manifest as to be beyond the possibility of doubt. No one therefore ever did, or ever

* I have somewhere read, that in the kingdom of Burmah within the last twenty years some learned men-six I think in number-were put to death by the king for teaching the impious doctrine of a Creator. To us this seems a strange use of the word 'impiety' - but in the Pantheistic creed the idea of a Creator will appear impious, for if it be accepted as certain that the Universe and the Deity are identical, it must scem impious to talk of creating such a universe. 
could discourse at length of nature without admitting occasionally the idea of intention, and of certain objects obtained by certain expedients; but in the strictly Material School this ought not to be, as the first proposition of the sect is that all things are made without design, and are as we see them to be simply because they are so. Nevertheless all the disciples of all the Material Schools are continually lapsing into the language of their opponents, and though they are always 'driving out "Nature" with a fork,' yet is she always returning upon them again, and 'her object,' 'her designs,' \&c., aggain and again make their appearance, with an occasional protest that no real meaning is to be attached to such expressions, which are used in ' a wide metaphorical sense' easily understood.

'I consider,' said Cabanis, in speaking of the provisions for the reproduction of animals, - ' I consider, with the great Bacon, the philosophy of final causes is sterile, but I have elsewhere acknowledged that it was extremely diffcult for the most cautious man never to have recourse to them in his explanations.' And Dr Whewell has well observed, 'though the physiologist may persuade himself that he ought never to refer to final causes, we find that practically he cannot help it, and that the event shows that his practical habit is right and well-founded.'

Saint Hilaire, a celebrated authority of the Antitheistic School, has said: 'I ascribe no intention to God, for I mistrust the feeble powers of my reason; I observe facts merely, and go no farther; I only pretend to the character of what is; I cannot make Nature as an intelligent beingwho does nothing in vain, who acts by the shortest mode, who does all for the best.'

A testimony which is well worth remembering, for we 
see that Saint Hilaire considers those who thus speak of Nature as virtually giving her the attributes of God; this, however, is precisely the language used by some French writers, his successors, and disciples too of the School of 'Transmutation; they make Nature an Intelligent being, with an object or intention, which they so expressly designate. Of this we shall ere long see an example. .

Neither is this prohibited language avoided by Mr Darwin, as the antecedent pages have already shown. Other more striking examples will hereafter be adduced.

The term Nature with many of the ancient philosophers, and especially with those of the Stoical School, was simply intended as another designation of God; and we ourselves profess to use the word in that sense too, out of respect to the Aiuthor of Nature whom we do not name, as Cuvier has wcll expressed it. Nature with us means an Intelligent Agent : it is not a figure of speech only 'difficult to avoid,' but a reverential expression cheerfully embraced.

Until the eighteenth century the Mosaic Economy was the undisputed authority in Europe for all discussions on the Origin of Life on our globe. Biology was a revelation, and when the science of geology began, it first started from a revelation. About the beginning of the last century, a French author, De Maillet, composed a work to explain the Origin of Life without any regard to the established opinions. His first proposition was, that at one time the earth had been entirely covered with water, and that, therefore, the first animals must have been aquatic-must have been fishes. When the waters retired, the fishes underwent metamorphoses. (We should suggest that they died, as is the manner of fishes when left on dry land.) The fishes which kcep to the bottom of the waters, creeping anongst 
the mud, became reptiles; those which occasionally rise above the waters became flying animals, their fins were turned into wings, their scales into feathers; and, in one word, mammifers, and man himself, came into existence from this aquatic origin. De Maillet's work was published about the year 1748, shortly after the author's death. 'Twenty years later, Robinet published a book entitled 'Essais de la Nature qui apprend à faire l'homme.' Robinet makes Nature his agent, which he freely personifies. Nature, according to him, commenced with creating worms, then insects. Later, she made a bold step, and fabricated the crustaceans. Then she placed inwards the external plates of the crustaceans, and made vertebræ of them-thence came the serpent. After the serpent the lizard; the front part of the lizard was transformed into wings-from thence the bird. And thus, progressively, Nature formed the quadrupeds, the quadrumanous animals, and last of all man.

I know not that any other writer followed in this track till M. Lamarck* appeared, who, with a greatly superior genius and much scientific knowledge, stood forth as the great exponent of the Theory of Transmutation.

M. Lamarck derives all animals from a monad, though what might be the nature of the monad we do not learn. From the monad the next step was to the Polypus: 'int

* Jean Baptiste Monnet de Lamarck was born in Picardie, 1744, and died at Paris, 1829. Appointed professor of Zoology during the Revolution, he developed in the course of his lectures his curious system. This he published, 'Extrait du cours de Zoologie du muséum d'histoire naturelle' in 1812 ; and also in his 'Histoire des animaux sans vertèbres,' 1815 , in seven volumes. Towards the end of his life, this learned man became quite blind.

† Au moyen des efforts qu'il s'impose, et des habitudes qu'il prend, le polype se donna successivement toutes les formes jusqu'aux plus élevées. 
consequence of the efforts which the Polypus imposed on itself, and the habits which it assumed,' the Polypus gave itself, successively, all forms of life even the most elevated.

The exercise of habit, and the effort at action, is the transforming power in Lamarck's system; animals have aimed at certain faculties and functions, and thus have obtained them-a process by which they have gradually become new animals. He has, however, other agents for his system of Transmutation-' efforts of internal sentiment;' 'influence of subtile fluids,' and 'acts of organization :' the usual cloud of words with which an empirical writer surrounds himself, when treating of the essence of his system. Lyell well observes, that in using these phrases 'he substitutes names for things, and with a disregard to the strict rules of induction, resorts to fictions as ideal as the plastic virtue, and other phantoms of the geologists of the middle ages.'

But to proceed with the system. It being assumed as an undoubted fact, that a change of external circumstances may cause one organ to become entirely obsolete, and a new one to be developed, such as never before belonged to the species, the following proposition is announced, which, however absurd it may seem, is logically deduced from the assumed premises. ${ }^{*}$ It is not the organs, or, in other words, the nature and form of the parts of the body of an animal, which have given rise to its habits and its particular faculties; but on the contrary, its habits, its manner of

* This fundamental principle of his system, Lamarck expressed in these words :-

'L'habitude d'exercer un organe, lui fait acquérir des développements et des dimensions qui le ehangent insensiblement, en sorte qu'avec le temps elle le rend fort différent. Au eontraire le défaut constant d'exercise d'un organe l'appauvrit graduellement et finit par l'anćantir.' 
living, and those of its progenitors have, in the course of time, determined the form of its body, the number and condition of its organs-in short, the faculties which it enjoys. The otters, beavers, water-fowl, turtles and frogs were not made web-footed in order that they might swim; but their wants having attracted them to the water in search of prey, they stretched ont the toes of their feet to strike the water and move rapidly along the surface. By the repeated stretching of their toes, the skin which united them at the base acquired a habit of extension, until, in the course of time, the broad membranes which now connect their extremities were formed.

In like manner, the antelopes and gazelles, in order to escape from the carnivorous animals, were compelled to exert themselves in running with greater speed; a habit which in the course of ages gave rise to the slenderness of their legs, and the agility and elegance of their forms.

The camelopard was not gifted with a long flexible neck because it was destined to live in the interior of Africa, where the soil was devoid of herbage; but being reduced to live on the foliage of lofty trees, it contracted a habit of stretching itself to reach the higher boughs, until its neck was elongated, and its fore legs became much longer than the hinder, so that at last it could raise its head twenty feet from the ground.*

Nature, we are told, is not an Intelligence, nor the Deity, but a delegated power ; a mere instrument-a piece of mechanism acting by necessity - an order of things constituted by the Supreme Being, and subject to laws which are the expression of his will. This Nature is obliged to proceed gradually in all her operations-she cannot produce

$$
\text { * Lyell's Analysis of Lamarck. }
$$


animals and plants of all classes all at once, but must always begin by the formation of the most simple kinds, and out of them elaborate the more complex, adding different systems of organs as they may be needed.

Nature is daily engaged in the formation of rudimentary sketches of animals and vegetables, by a process which the ancients termed spontaneous generation. She is always beginning anew, day by day, the work of creation, by forming monads, which are the only living things she gives birth to directly.

Such is the system which, though of great celebrity in its day, made very few converts, and would, perhaps, by this time have been shelved with other literary curiosities, had not Mr Darwin come forward, an jllustrious disciple to retouch the Theory, to recast some of its parts, to supply its deficiencies, and to give the last finish to the genesis of nutation.

The main difference between the plan of the master and of the disciple is in the machinery by which the required transformations have been effected. In the general principle of Transmutation there is a perfect accordance, but each proposes a method of his own to accomplish the alleged phenomenon. According to Lamarck, it has been mainly by effort and by continued attempts to bring about a change, that the change has been realized; with Mr Darwin the agent has been a metaphor, or, dropping the metaphorical term, 'the Sequence of Events,' which can be the cause of nothing, as it is itself a series of effects. Lamarck's agent, though a ridiculous absurdity, is something intelligible and tangible. Mr Darwin's is a phantom always eluding the grasp. We might, if criticising the Limarckian system, inquire what became of the animals 
before the change, so requisite for their new character in the drama of life, was fully accomplished? How did the once thick-legged and slow animals, the pre-gazelles and the pre-antelopes, continue to escape the carnivorous animals, all the time that their legs were lengthening and refining, and their powers of speed accumulating? And how did the progenitors of the giraffe ward off starvation, in deserts without herbage, before their necks and tongues and front legs were prolonged to enable them to reach the foliage of the trees? and so on in every other case. These questions of course would be quite as puzzling if applied to the Darwinian system, and perhaps more so, as $\mathrm{Mr}$ Darwin demands an immensity of time for his mutations. His dogs, with 'slightly plastic limbs,' improving in the lapse of thousands of ages to enable them to catch hares, when all other food had failed them, would, it is to be feared, have long ago joined 'the people of dreams,' before the day of their improvement dawned on them.

The pictures of Lamarck's otter acquiring web-feet and an amphibious existence by frequenting the sides of streams in search of its prey, immediately suggests the more magnificent transformation of the bear into the whale. Lamarck's otter must surely have been first cousin to Darwin's bear.

When two great wizards, like Jannes and Jambres, descend to the water-side for the exercise of their art, there is no limit to the wonderful achievements which they may accomplish with their transforming rods.

After this the theory of Transmutation seems to have been dormant, at least in this country, till an anonymous author published 'The Vestiges of the Natural History of Creation.' 'The date of the fifth edition of this work now 
before me is 184.5 , the first edition was probably published two or three years earlier. It met with great success, soon became a popular book, and is still enjoying a measure of popularity. This is to be attributed in part to the pleasant style of its composition, and to the lucid and intelligible tone of the statements it contains. It is an easy book to read, and the novelty of its subject made it an entertaining one. The scientific world is disposed to speak slightingly of the work as deficient in information, but the author does not seem to put forth the pretensions of a man of science, and he offers his statement simply as the result of his reading-he gathers from other writers his materials, and proposes his deductions on them with simplicity and modesty. There may be mistakes in the statements, or a deficiency of knowledge may here and there betray itself, but on the whole the book may be considered the least offensive of any that have yet appeared to advocate the theory of Transmutation.

It may be interesting to see the opinion of this author on Lamarck's system, as showing the disagreenent amongst the advocates of the same cause. The author of the Vestiges, in making the following strictures, explains, in measure, his own views: 'Early in this century, M. Lamarck, a naturalist of the highest character, suggested a hypothesis of organic progress which has incurred much ridicule, and scarcely ever had a single defender. He surmised, and endeavoured, with a great deal of ingenuity, to prove, that one being advanced in the course of generations to another, in consequence merely of its experience of wants calling for the exercise of its faculties in a particular direction, by which exercise new developments of organs took place, ending in variations sufficient to constitute a species. 
It is hardly necessary to remark how inadequate does the view of Lamarck appear to account for the rise of the organic kingdoms. If he had suggested a law of development for advancing the fundamental or internal organization in a succession of stages, like those of the individual ovum of the highest animal, and pointed to some abnormal and not yet understood tendency in organic beings to give rise, through the medium of generation, to modifications of external structure fitting the progeny for new conditions; and if, to these ideas, he had added a more explicit acknowledgment of the whole being the evolution of a divine will, which was present in it all, he would, in my opinion, have come much nearer to fact, and obtained more patient hearing from mankind' (241).

The author of the Vestiges tells us that at first the earth presented only seas and sea-animals. Afterwards shores were formed, and animals fitted for living in such a field were produced by an advance of development from certain of the marine tribes. In time there was dry land and vegetation, and then the shore-animals gave birth to families fitted for that superior theatre of existence (258).

There is much reason to believe that 'certain large and important mammals, if not the whale,' have proceeded directly from the reptiles (263). The marine Saurians were progenitors of aquatic mammalia, whales, \&c. (267). Elephants were derived from herbaceous cetacea (267). Birds sprung from fishes (263). The rhinoceros was the progenitor of the hog, and the horse was fined down from the elephant (a startling pedigree for the Racing Calendar). 'In the prehensile upper lip of the horse we see the last relic of the proboscis of the elephant and tapir; the clumping of the extremities into one shield or hoof, serving to 
support the body of the animal in soft, dry soil, sufficiently shows what kind of hubitat determined the production of this interesting and useful genus' (269).

The walrus or morse furnished the origin to ruminating animals (269), and the family of bears (Ursidx) came from the seals (271).

Man's parentage is not directly stated, but suggested, apparently in a hint: 'Last of all issued from the woods a being erect, majestic, and with many traits of external grace and beauty, to overspread the whole earth with his race,' \&c., \&c. (274).

As the system requires a parentage from an antecedent form for every 'newly-developed ' life, we cannot suppose that 'the majestic creature' is exempt from the general rule, and we must therefore understand that when man 'issued from the woods' he had been there for ages with his progenitors-the Gorilla, the Oran-Otang or Chimpanzee, that he had gradually got rid of the lower pair of hands, that his legs and muscles had been 'developed' into those of the human form, that his foot and heel had become adapted for walking, that his face and brain had mightily improved, that he had acquired the power of speech; and endowed now with a conscience and imagination, and with a capacity for the abstract sciences, was able to produce from his Species a Homer, a Mitton, a Newton, or a Laplace.

Such in a few words is this system. The origin of all life is to be traced to the waters; water is the general

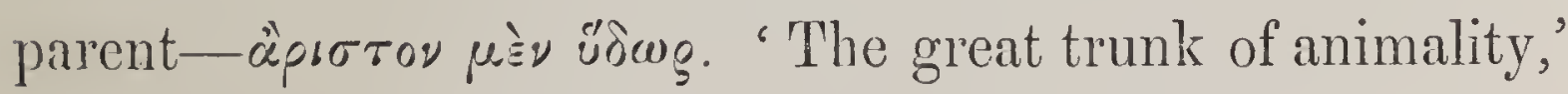
says the anthor, "lies in the ocean, up even to the mammalia.' A curious contradiction of the old creed which made earth ' the great trunk of animality.' 
As usual with all the School, we have the modus operandi of Transmutation propounded to us in an enigma. In the Vestiges, it is ' the Law of Development' - it is ' an abnormal, and not yet understood, tendency in organic beings' - the first and simplest of beings advanced upon the several lines of development, till at length they became creatures of complicated and extensively-adapted structure.'

They were developed - they became! What is development? It is an addition of matter to existing forms to produce this augmentation; but let us suppose matter added to a hog for an indefinite period, till it had grown twenty feet high, it would still only be a huge hog-it would not have become more like an elephant in its constitution than when it was only a foot high. Do they mean change* by

* This is, in fact, the real meaning of the dainty word 'development,' as used in this school. The word 'change' would secm to be begging the question, so they substitute another term which seems to be indefinite, though they do not at all intend it to be so. This peeps out in the following sentence of Professor Powell : 'Some scientific inquirers reject the idea of development or transmutation, because, as they allege, they find no evidence or existing instances of such a thing to produce.'-(Unity of Worlds, 431.) We see then what the school intend by 'development;' it is in plain English Transinutation: and if this were substituted for the other word, in all passages where it occurs, much ambiguity would disappear.

'The original and strict meaning of 'development' is the disengaging from somcthing that infolds, and thence, the disclosure of bodies by growtl. I find it defined thus in a French exposition of tcrins :-

'Accroisement naturel des corps solides, liquides, ou gazeuses, des végétaux, des corps organisés ou inorganiques de terrain, des rochers, de l'homme lui-même, specialement considéré dans les êtres vivants.'

Buffon says: 'L'homme croît en liauteur jusqu'ì seize ou dix-huit ans, et cependant le développement entier de toutes les parties de son corps en grosseur n'cst achevé qu'à trente ans.'

In cvery instance whicre this word is lcgitimately used, it means augmentation, extension, or improvement of something already existing. It never has the meaning of Transmutation.

Barthelemi uscs it in this passage in the strict sense: 'Je pensc, que de temps en temps, peut-être même à chaque génération, la nature répand sur la terre un ccrtain nombre de talents qui restent ensevelis, lorsque rien ne contribue à les développer.' 
development? if so, then animals have been changed by 'the Law of Change '- a mystery of words of great depth. When a walrus was developing into a cow, how did the development begin? whence did the new particles of matter come for the new form and habits? and how did they begin to assume the new form?

The answer probably would be, that it was by the operation of a Law not yet understood. Then if you do not understand your Law, and have no means of explaining or proving it,-if it is merely a gratuitous invention, a mist of words to conceal your ignorance,--why pretend to be an exponent of that which you do not understand, and which after all your trouble is not explained at all? How easy it is to deceive oneself with a word! Lamarck had his words, 'efforts of internal sentiment' - 'acts of organization,' 'influence of subtile fluids.' Then in another quarter we have Natural Selection, all expedients to conceal a deep chasm of the unknown with a thin veil of pretension; but the chasm is there still, deep as eternity, and no verbal expedients will ever succeed in making us forget its existence.

The next English writer who adopted the theory of 'Transmutation was Professor Baden Powell, and this, but briefly, in his notes on 'The Order of Nature,' published in 1859.

The position assumed by the learned Professor is, as far as I understand it, to admit ' a Universal Reason and Supreme Intelligence' in the mechanism of the universe (233), but wholly to repudiate the idea of creation, and especially in the production of the various forms of life.

In noticing a suggestion of Playfair, that it might be worthy of consideration whether the original constitution of the planetary system might not be referable to a me- 
chanical cause, he observes (147), "If the arrangements alluded to could be shown to be the results of still ligher mechanical causes, it would but furnish a still higher proof of Intelligence, instead of being antagonistic to it ; mechanism is the very exponent of mind,' and yet he objects to any inference of design or purpose - 'for the structure of the universe we can infer no final design or purpose whatever, which is perpetual in its adjustments, offering no evidence of beginning or end' (237); though he adds these remarkable words, 'however, the limited evidence in some of its parts, of adjustment of means to ends, may warrant the conjecture of other higher unknown purposes.'

In the notes appended to 'The Order of Nature,' the Professor very plainly takes his place in the School of Transmutation, objecting to the idea of creation," as derived from religion, and 'therefore having no place in science.' That all Species were derived from older ones seems to him a necessity by the universal Law of Continuity ; and if there is an absence of evidence to prove this by geological records, it is because the evidence has not yet been found (467). This point he takes up with some asperity, calling it 'a trite objection,' which he thinks he has 'disposed of ' in some previous publication.

He then quotes Professor Brown of Heidelberg, who

* It has been already shown that Creation is not necessarily connected with any religious idea, and that Lucretius, of all writers most adverse to religious impressions, freely uses the term ; take this instance, in which he says that things may be created without the intervention of the Deity :Quas ob res, ubi viderimus nihil posse creari

De nihilo, tum, quod sequimur, jam rectius inde

Perspiciemus; et unde queat res quaque creari,

Et quo quæque modo fiant operâ sine Divûm.-(i. 155.)

Lucretius more than once gives the title of creatrix to Nature:-

Donicum ad extremum crescendi perfica finem

Omnia perduxit rerum Natura creatrix.-(ii. 1115.) 
lays down two laws by which, as he avers, the sequence of organic beings has been regulated.

1. By an independent productive power constantly advancing in an intensive as well as extensive direction or degree.

2. By the nature and change of the outward condition of existence under which the organic beings to be called forth were to live. Both these laws are in the closest connection with each other, although we cannot understand the productive power.*

Here, again, the Transmutationist brings up his system to a blank wall in the labyrinth of error. We have here ' an independent productive power which we cannot understand.' This by the ancients would be termed Nature, or God; and all indeed that we seem to gain by the various teachers of this school is a choice of new words. We say that a supreme Mind, whose actions are inscrutable, performed the acts of creation which we do not even hope to explain ; the new school, after preaching against creation, presents us with ' an independent productive power which they cannot understand,'- ' or an abnormal tendency not yet understood.' What have we gained by these new terms? what has been proved or advanced by them? are not the old words as good? and are they not far more respectable?

'There is one peculiarity in Professor Powell's views-that he speaks with a sort of magisterial certainty of our ultimately understanding all these mysteries; that we shall, in

* It is remarkable that though these laws are quoted by Powell with approbation, Brown himself does not seem to have been a Transmutationist, for he distinctly says, ' no experience proves that any one species or' genus, or even an order or a class, has really been transformed into another' (465): and for this Professor Powell reproves him, as not having sufficiently considered the subject. 
due time, be able to interpret this unknown power; and that, if 'life is unknown, it only remains to be made known.' He seems to think that the day is not far distant when the mysteries of life and generation will be as thoroughly understood as any chemical problem that science has mastered. We shall see: some persons, however, will doubt this.

As Professor Powell wisely abstained from entering into any details, contenting himself with advocating the general principle, he has escaped the ridicule which must be the lot of all those who undertake to furnish us with the pedigree of animals, evolving from one another. Thus he is able, not having committed himself, to speak slightingly of Lamarck, and to call the Vestiges of Creation 'a philosophical romance' (173). An unkind cut at a fellow-labourer and associate in that school of which both are teachers.

Mr Darwin has, in 'The Historical Sketch of the recent Progress of Opinion on the Origin of Species,' which is a sort of preface to his book, given a brief notice of writers whom he considers, either directly or indirectly, as favourable to the theory of Transmutation.

Most of those names have been mentioned in this chapter, but he also reckons as his coadjutor the Hon. and Rev. W. Herbert, Dean of Manchester, who, in a work on Amaryllidaceæ, 1837, advanced the proposition 'that botanical species are only a higher and more permanent class of varieties :' the precise language used by Mr Darwin. He also believed that the single Species of each animal was created in an originally highly plastic condition (i. e. with capacities for metamorphose), and that these have produced by intercrossing, all our existing Species. This statement we take 
from Mr Darwin, having never met with any of the publications of the Reverend Author.

In this 'Historical Sketch,' Mr Darwin says of the Vestiges: 'The work, from its powerful and brilliant style, though displaying in the earlier editions little accurate knowledge, and a great want of scientific caution, immediately had a very wide circulation. In my opinion it has done excellent service in calling, in this country, attention to the subject, in removing prejudice, and in thus preparing the ground for analogous views.'

Thus Mr Darwin considers the author of Vestiges as his pioneer, and the husbandman who has prepared the soil for the Darwinian harvest. But it is open to suspicion, and by some persons asserted that we owe 'The Origin of Species' to the influence which the Vestiges exercised on $\mathrm{Mr}$ Darwin's mind: and that in the general argument of that publication, Mr Darwin found suggestions for a more perfect system of Transmutation, which it has been his business to elaborate. 


\section{CHAP'TER IX.}

M. 'TRÉMAUX'S THEORY.

M. Trémaux, the last who has entered the lists as the champion of Transmutation, has made his appearance even after Mr Darwin. His work ' Origine et Transformations de l'homme et des autres êtres,' was published in $\mathbf{1 8 6 5}$.

As his system is carefully considered, and differs, in its main principle, from the other writers of this school, with whom indeed he finds much fault for not having discovered the great secret of the sect, a separate chapter may be assigned to an analysis of his Theory. Unlike his predecessors, who trace the Origin of Life to the waters, M. Trémaux assures us that the soil has created or produced all animals, and has been the cause of their various transmutations. He commences at once with a sentence which enunciates his leading principle :-

'La perfection des êtres est ou devient proportionelle au degré d'élaboration du sol sur lequel ils vivent; et, le sol est en général d'autant plus élaboré, qu’il appartient à une formation géologique plus récente' (17).

This is printed in capital letters in the text. This he calls his 'grand simple law,' though many supplementary clauses are appended to it in the progress of his inquiry. To the action of the soil he adds also, though apparently with reluctance, the difference of temperature of different 
climates, as a sort of secondary instrument, "which has a certain action on plants, but has very little effect on man, who knows how to preserve himself from the excesses of temperature.'

Here, of course, the objection would be obvious, first, that very many animals depend altogether on a very high temperature for their existence, as others do on a cold one; and that apes and monkeys, and many other creatures, if placed on the very best 'recent' soil, in a cold, or even temperate climate, would speedily perish. A high temperature has also produced, or is inseparably connected with, a considerable division of the human race, the Negroes and their kindred tribes. 'But colour,' says M. Trémanx, 'with men, as with many animals, is only the little side of the question.' 'La coloration, chez l'homme, comme chez beaucoup d'animaux, n'est que le petit coté de la question; chez l'homme le teint est le résultat d'une très faible modification de la peau ... et n'a aucune influence sur la constitution et les facultés' (23). Still, this distinction of colour is sufficient to make a broad division of the human race, and is not such a trifle as M. Trémaux would have us believe. It is a very evident and unquestioned result of temperature, and has produced a marked character, which all mankind has always acknowledged, though they have been slow to perceive in the effect of any soil any mark of diversity, at all comparable to such a distinction.

The general law has, moreover, to be qualified with ' the effect of frequent crossings, and a change of alimentary productions, which takes place in a sensible degree (assez sensible) between neighbouring countries.'

These two qualifications invalidate the theory; for the 
instances would be few indeed, where these crossings did not take place, and where neighbouring tribes did not interchange the productions of the soil. All this, moreover, involves a history of mankind, to be worked out of the imagination; for how did the first stock of men (educed out of a previous stock of superior apes) separate from the first family so as to avoid neighbourhood, crossings, and interchange of food? For it is one part of this Theory, that a Species, to become such truly, must have been long isolated, and have lived long on one soil. When this process has been continued a sufficient time, then the Species is formed, with law of fecundity.

But man sprung from a very superior quadrumanous animal, very far superior to the gorilla. His history, therefore, and that of his predecessors, with the soil they lived on, \&c., \&c., have all to be sketched by the imagination-it cannot be a history of facts.

M. Trémaux attributes to the soil some undefined mysterious action, which he does not explain ; that it is something more than the difference of the food which it produces, is evident from the following passage.

'L'homme se nourrit de différentes espèces végétales et animales particulières à chacune des grandes divisions continentales. De la parait resulter un ensemble de physiononics propre à chacune de ces divisions, et même une certaine corrélation de forme, mais elle n'empêche nullement l'action du sol de se dessiner nettement sous cette influence particulière' (24).

'The 'action of the soil,' then, is something over and above the action of the food it produces. A principle of transmutation exists in the soil: in the recent soils, the tendency of its action is towards perfection; in the primi- 
tive soil, it is towards degeneration and debasement. What may be the nature of this action, is not unfolded to us ; it is, in fact, the mystery of M. Trémaux's system, and is analogous to 'the law of development,' and the 'independent productive power,' of the other writers of this school.

Like the rest of his fellow-labourers, M. Trémaux personifies Nature, and talks of her objects and intentions, as if the various forms of life had all been projected in an antecedent plan.

'Si l'on cherche à créer une nouvelle espèce par le croisement, on échoue; ce qui est bien naturel, puisque, dans la Nature, son but est contraire, c'est à dire qu'il unifie les êtres qui y sont soumis au lieu de les diversifier; en d'autres termes son but est de grouper les êtres en espèces distinctes.... la Nature se refuse à faire une nouvelle espèce' (189).

Now this is remarkable language, as it is precisely that which, as we have seen, Saint Hilaire said he could not use - 'I cannot make Nature as an intelligent being,' and yet M. Trémaux is strictly of the Material School, no writer can be more so.

All the perfect types of animals have been produced on recent soils. The primitive soil of the first geological ages was composed of disintegrations, effected at one epoch only ; the recent soil of our epoch is made of disintegrations, effected during all the geological epochs,-the disintegration of the ancient rocks mingled in the soil renders it completely unfit for man (119-20).

Man reaches perfection, or degenerates according to the recent or ancient soil on which he lives; and as soon as he reaches the type proper to the conditions in which he is 
existing, he changes no more, as long as the conditions remain the same (121).

In all modifications of the established order of things, Species, fixed till then, may be, and often have been, changed.- ' Let us go back to the epoch, when one of those grand movements took place, of which geology shows us the traces; by means of that law, of which we have established the bases, nothing can be more simple than to comprehend the effect of that new condition.'

'Les êtres les plus parfaits jusqu'alors se transformeront en jouissant de ce nouveau sol; ils acquerront un nouveau degré de perfection, supérieur à ce qui existait antérieurement; nouveau sol, nouveaux êtres' (122).

Of course, if M. Trémaux has laid it down as the 'basis of his law,' that the soil does transform animals, thus, when the soil is changed, new transformations may be expected. But, 'the basis' is simply assuming the proposition to be proved.

When Species are once formed, it requires particular conditions to bring to perfection the formation of a new Species; it is requisite that not only should the race, which is about to be formed, be isolated from the surplus of its Species; but that it should abide on one sort of soil only, and, moreover, that it should not be of a middle quality, as it would then tend to make the middle type (140).

If beings, which the soil tends to transform and ameliorate, continue to cross with those which belong to soils of less favoured nature, then it will only be able to effect a difference of variety.

If the crossings with the original Species are in any way prevented, the favoured Variety necessarily becomes Species, by continuing to transform itself (141). 
'To account for the lack of intermediate beings, which the records of geology cannot afford us, M. Trémaux affirms that "the relative epoch of transformation was * short [long, says Mr Darwin], that the grouping of distinct Species was soon effected, that the conditions for their geological preservation were unfavourable, because they were on a recent soil, or one subject to elevations and movements-these are the multiplied causes which render so difficult, and almost impossible, the discovery of the intermediate beings between the Species' (147).

And of these multiplied causes, we may safely say, that they are all visionary, and that every one of these 'conditions' is deduced from the imagination alone, without the support of any known fact. From anything that can appear to the contrary, conditions totally dissimilar are quite as probable, and, as some would say, much more probable. How does M. Trénaux know that the epoch of transformation was short, and that the grouping of distinct Species was soon effected? Mr Darwin would tell a very different story; though it must be freely confessed, that neither of these learned gentlemen can know anything at all about the matter.

'The original Species (l'espèce mèrc) of mian was, in the favoured regions, of a greater superiority relatively to the gorilla, than the white man is relatively to the negro: but that Species has disappeared before man, as the red skins of America disappear before the European colonies (258).

It is only in the regions the most favourable for him that the primitive man could exist, more perfect than that

* Mr Darwin says, "the process of Natural Selection is always cxtremely slow' (114). The disagreement of the Transmutationists on many essential points is very instructive. 
which is now called ' the man of the woods.' M. Trémaux seems to think that it is not impossible to discover, in some regions of the earth, the being who may be considered as having been the most advanced during the epoch which preceded that of man (290).

This disappearance of anthropomorphous Species, proper to each soil, has made a wide gap between men and the quadrumanous animals. It has established that which is now called the human Species (290).

Men and apes resemble one another in their anatomical composition, which is in effect the only point which makes us recognize the common origin of these beings, since the difference of intellectual faculty is only the result of their different degrees of advancement and perfection, which are only secondary considerations (308).

The negro is a degenerate man, not an advanced ape : in the same way that the apes are degenerated from a more advanced Species, which, some time or other, occupied more favourable regions of the earth, and in the end gave birth to more perfect beings, which have formed the stock from which we have sprung (310).

On the whole, beings from their lowest point of separation, up to man, liave been perfected by means of transformation from one Species to another (472).

It may, perhaps, be amusing to learn by what means the intelligence of apes was evoked, preparatory to their assuming the human form. "The intelligence of the quadrumanes, which live in the trees, is kept on the watch; with their eyes they follow their enemies-they calculatethey reckon in a more continued and sustained manner the chances which are for or against them. They have even to foresee the strength of the branch which is to sus- 
tain them, and to take into consideration its elasticity which aids them in springing from one bough to another. One may conceive that this difference of state must induce a greater exercise of the mental faculties, than with some powerful animal which has less to fear, or with the burrowing animals which find their security in that concealment which deprives them of exercise ${ }^{\prime *}$ (280).

In this way our intellect began, our sylvan ancestors watched their enemies from the tops of the trees, and calculated the strength of the boughs on which they were about to leap. This was the commencement of 'calculation;' these faculties were more and more 'developed,' as the breed of anthropoidal animals improved with the soil, till 'the scale of being arrived at man, with whom every thing is done by calculation. He does not content himself with necessary speculations, he desires to know everything that surrounds him, even the stars, the past, the future, the infinite.' So, then, from the bough of a tree we leaped to the stars and the infinite! Who ever would have suspected that algebra and astronomy spring from an ape's lucubrations on the length of his leaps? But why such an origin of intellect should be confined to the anthropoidal animals is not apparent, seeing that the squirrel is equally watchful of his enemies, and equally sagacious in his leaps, and lives also on the trees. Who knows, but that squirrels may be developing into geometricians in some undiscovered forests of 'the favoured regions'!

An incidental argument introduced by M. Trémaux,

* 'Ces seules observations nous montrent quelles voies a dû prendre le règne de l'intelligenee.

'Lorsque l'on arrive à l'homme, chez lequel tout se fait par calcul. Il ne se contente pas des speculations neeessaires, il veut connaitre tout ce qui l'entoure, les astres mêmes, le passé, l'avenir, l'infini.' 
when discussing our relationship with apes should not be omitted. 'Why should we be astonished that the hand of an ape which serves him continually for seizing the branches, in leaping from one to the other, should differ in some degree from that of a nian, which is used for such different purposes?' (319) So, then, the ape's hand was not invented and made for him to enable him to live a sylvan life amongst the trees, but by endeavouring to make use of it in leaping, it became what it is, and the ape himself became a quadrumanous animal! Our hands, also, have become human by applying them to multifarious purposes!

Here we have Lamarck again, animals making themselves what they are, by effort. But is not this, also, forgetting the great instrument of all changes, the soil? If a superior soil could make an ape of any sort, of course it could make it complete. If the soil has been the cause of the production of all species of animals, why create any difficulty about so small a matter as the formation of an ape's hand?

M. Trémaux has been more cantious than some of his school in giving the pedigree of animals; nevertheless, he has favoured us with a slight sketch, in such points as he says are very easy to be recognized (très-saisissable). The articulated animals descend by regular series to the worms, which are themselves intimately connected with the infusoria, the vertebrated are united by unmistakable connections with the fishes and the reptiles, and with these and the mammifers. To pass from these to birds, the degree of union is not so well sustained; nevertheless, we see it in the bats, and also in the penguins, which with their rudimentary wings serve as examples. These are pretty nearly all the details with which we are furnished, 
the rest is hinted in general expressions, left for the imagination to supply whatever may be deficient: and, indeed, in this matter M. Trémaux has not ventured on more than any physiologist would assert, that there is a sort of analogy or resemblance, and a chain of similitude traceable in degree, throughout the Animal Kingdom.

In his system, however, we might inquire, if, as it is pretended, there is a union between mammifers and fish, how the soil elaborated the fish? as the soil is the creator it must have produced the mammifers first, and from them the fish must have sprung. M. Trémaux says nothing about the power of water on aquatic animals, nor does he notice that which would be obvious to any one, that if it be true that the soil has produced land-animals, then it must be considered that the water has produced the aquatic tribes. This would, however, break into his system of transmutation of every Species of animal from antecedent Species - and of the "unity of all animals. In his system there cannot be two producers : and it will be remembered that he has distinctly told us 'that all beings from the lowest point of separation, up to man, have been perfected by means of transformation from one Species to another!' There is this curious proposition of the Theory, common indeed with most of the school, that animals in the position in which they first appeared on the scene, were not perfect in their grade of life and the position which they occupied, but have become perfect by a long process of transmutation subsequently. The worm was not perfect but improved into some higher form, the reptile was not perfect, the mammifer was not perfect, the ape improved through many gradations of ameliorating Species up to man-and so of every other animal. M. 'Trémaux thinks, indeed, that all animals are 
perfect now, and that they have reached their resting point, at least this scems to him probable, though it is by no means apparent why the inferior forms should now rest content with their inferiority, or why the soil should cease to exercise its powers of mutation. In this point, as in many others, he disagrees with Mr Darwin, who looks forward to an immense improvement in all forms of life, for with him Nature has by no means reached its Sabbath, but is progressing onwards towards perfection.

If it were worth while to sift such a system with question, we might ask how the soil could have influenced the existence of most of the carnivorous animals? The wolf, for instance, cares nothing for the nature of the soil: primitive or recent, elaborated or simple, are all one to him. He abounds in all soils, very frequently amongst the rocky solitudes of the primary mountains, as well as in the forests or ' the recent' plains, and in the great steppes of wild and sterile lands. What, again, has the sôil had to do in forming migratory birds, which continually pass over in long journeys to distant lands, and settle on soils of the most varying qualities? But a system like this may claim immunity from questions, its existence is in the realm of the imagination, and therefore it is free from the test of logic.

The work of M. Trémaux is certainly a curiosity in literature. It is written in a grave, philosophical tone, well sustained, and with dignity of style. Pages follow pages full of ideal statements and positions of circumstances, to account for the formation of Species; laws and rules are laid down for the events of ancient epochs; and geological combinations* and distributions of life are described, as if all

* As a striking instance of these visionary speculations take the following passage:- 
this had really happened, and were as authentic as the history of France; and the whole system is built up with as much care as if it were a solid and substantial fabric, based on a careful induction from known and acknowledged facts.

The general view of M. Trémaux on Nature will be best seen in these words, which need no comment:- Quoi de plus admirableque cette incommensurable Nature, où tout s'enchaine tellement bien, qu'il suffit d'un seul acte de condensation d'atomes, de rien, pour que des astres immenses, des milliers de soleils, puis chaque planète, chaque être animal, végétal ou autre, en découle à son tour' (486).

We have only now to show M. Trémaux in the character of an opponent of Mr Darwin. These two writers have indeed the same cause to advocate, but it is by such a different principle, that M. Trémaux frequently reproves $\mathrm{Mr}$ Darwin for his statements, and, in some instances, with success; though it must be borne in mind that M. Trémaux's true ground of quarrel with his confederate is, that he does not make any use of M. Trémaux's fundamental principle.

'T'he principle of Selection has been long known, although it has only been seriously put into practice in our epoch. This principle is considered by $\mathrm{Mr}$ Darwin as the great motive power of perfection. 'The employment of it, in fact, by suppressing artificially the procreative action of the inferior beings of each species, gives an advantageous result which elevates the average specimen of this type; only that

'Let us suppose that, from one cause or another, a Species is nearly entirely destroyed; if a feeble remnant of it should find itself in a favourable geological condition, it may be transformed many times in succession (elle peut se transformer plusieurs fois de suite), and so much the more casily the smaller the remnant shall be, and the more isolated, and that without leaving scarcely any traces of its mutations' (226). 
this result, being artificial, disappears with the attention which has produced it.

'When a horticulturist chooses his best specimens for reproduction, or simply suppresses the worst, it is evident that the descendants obtained by this process will present, on an average, a higher degree of improvement. But if this process of careful selection is relaxed, the new race falls back into its state of anterior equilibrium.

' $M r$ Darwin, it is true, imagines an effect of a struggle for life, which would fulfil, in an unconscious and permanent manner, this function of Observer, adequate to destroy the inferior creatures. In this view of the question, Mr Darwin seems to us to be greatly in error, for a struggle for life is injurious to all that are subject to it, good as well as bad.

'When two plants or two animals press upon one another and dispute for existence, they injure one another mutually much more than they make a difference between two slibjects of the same Species; if one triumplis over the other, it is simply that the one which has been less injured gains the victory.

'Supposing ten trees should fix their roots where one only could have successfully grown without this struggle or competition, the ten, in spite of this competition, or rather on account of it, will grow miserably stunted. Nevertheless competition has played its part in hindering the development of many seeds and off-sets.

'If ill-fed animals fall upon a meagre pasture, the more insufficient it is, the more do they devour it with an eager competition. Nevertheless the most favoured is far from being satisfied, as he might have been if he had been alone, that is to say, without this struggle for food. 
'If a tribe of people is expelled from a good soil to a miscrable one, as the Irish of Armagh and Down, who were driven into the barony of Mlews, the struggle for life becomes indeed serious, but they nevertheless all degencrate. It does not terminate in some of them improving, and becoming greatly superior to the others.

'In one word, the struggle for life only keeps the productive power of beings, the germs of which are always superabundant, in an equilibrium with the resources of the soil; and nothing authorizes $\mathrm{Mr}$ Darwin to suppose that the very feeble difference of action with which it bears on individuals of the same species, is superior to the injurious competition with which it acts on all of them.

' Mr Dầrwin, like many others, wanted an explanation for' the phenomena which surround us, and he has not perceived that everywhere and in all times beings were developed in proportion to the qualities of the soil to which they belong. The augmentation of these qualities must therefore determine the qualities of the beings themselves ' (228).

....... According to Mr Darwin, this law of progress by Selection only takes account of cases of perfection; and cannot, as he himself acknowledges, account for cases of degeneracy, which are nevertheless so very numerous. Thus is he driven by his system to deny every instance of the sort. Nevertheless no one will admit that the white man has made progress in assuming the negro type, although Mr Darwin can say with reason that the constitution of the negro agrees better than ours with the contions of life in Central Africa-in the same way that the constitution of the earth-worm agrees better with its condition than ours. Moreover, in explaining how it is that the island and the little continents have fewer species than 
the great ones, he is greatly embarrassed, and can only give reasons more or less contradictory. The same situation presents itself when he endeavours to explain why the animals of Egypt which have not changed their soil nor other conditions of life for three or four thousand years, have not also changed their character, for nothing prevented the animals of that region to continue Selection, as all of them are not exactly alike.

'If this combination of Natural Selection and struggle for life were the cause of the perfecting of beings, it would act as well on bad soil as on good, which is not the case. $\mathrm{Mr}$ Darwin recognizes this indirectly when he tells us "that which I have said, I repeat, I do not believe in any nccessary law of development... the varicty of each species is an independent faculty, and very variable in degree." In fact, in his system he is obliged to recognize that variability is independent, but independent of this system only, since it is overruled by the soil and by crossings. He is obliged also to recognize that it is very variable considering that it often acts in a sense contrary to his theory.

'Nevertheless he makes this Theory the cause of the distinction of Species. In speaking of the absence of intermediate varieties which results so distinctly from the limit to which fecundity extends, he says: "If we cammot always and everywhere meet with the innumerable forms of 'Transition, that depends chiefly on the action of Natural Selection, by virtue of which new varieties constantly tend to supplant and exterminate their original stock." That explains continued extinctions, but not the degrees. Besides this we suppose that geological documents have only kept imperfect register of these transformations. That could not explain those general and regular gaps in the 
evidence, and the apparent phase of stability which characterizes the Species. Moreover, these two explanations of the same phenomenon do not agree; is it the one, or is it the other, that is really the agent?

'The struggle for life brings about a general destruction of the inferior beings by the superiors. But as this action operates from one end to the other of the scale of beings, there would be no means of distinguishing the Species. This would be the result, that only the advanced being, less influenced by that condition, would have more advantages to injure the being which would be immediately beneath it.

'Notwithstanding all these contradictions which Mr Darwin's Theory receives from the facts which we have placed under the eyes of the reader, his book contains a number of interesting remarks. His ideas of conformation and appropriation of beings, with regard to the functions which they have to fulfil, and the circumstances in which they live, had already been indicated by Lamarck, who himself only gave an explanation of more ancient ideas. The merit * *f $\mathrm{Mr}$ Darwin is that he has given them more development and more consistence.

'In another passage Mr Darwin himself recognizes, if not the error of his Theory, at least the limits of its effects, which amounts almost to the same thing. These are his

* 'Le mérite de Mr. Darvin est de leur avoir donné plus de développement, plus de consistence' (236).

It is by no means certain that Mr Darwin will relish this compliment. M. Pouchet also says : 'M. Darwin est le continuateur direct de Lamar'ck.' - (Pluralité des Races, 173.)

M. Flourens confirms all this: "Le fait est que Lamarck est le père de MI. Darwin. Il a commencé son systìme. Toutes les idées de Lamarck sont, au fond, celles de M. Darwin. M. Darwin ne le dit pas d'abord; il a trop d'art pour cela' (15). 
words: "Natural Selection can render each organized being only as perfect as or a little more perfect than the other inhabitants of the same country; and against which they must continually struggle for existence. Now such is in effect the degree of perfection attained by Nature. The aboriginal productions of New Zealand, for example, are perfect if we compare them among one another, but they are on the way to disappear before the continually increasing number of plants and animals introduced by the Europeans. Natural Selection cannot produce absolute perfection - it can only produce a relative superiority; that is, a degree of perfection measured by the local re. sources."

'This quotation establishes very clearly, and in a double way, the limit of the effects as we have laid it down. It points out even the true cause of perfection, in affirming that it is measured by the local resources' (237).

Thus does M. Trémaux censure Mr Darwin, and in his remarks on the struggle for life, with convincing arguments. Even when he confronts his own Theory with that of Mr Darwin, it is with some degree of success, for M. Trémaux has something substantial to present to the reader, as every one acknowledges that soil can improve, thongh scarcely any one but $M$. Trémaux would affirm that it can form or transform organized beings. The soil can do something, Natural Selection nothing; and it is amusing to find that Mr Darwin occasionally invokes the assistance of the soil to eke out the deficiencies of Natural Selection. 


\section{CHAPTER X.}

STRICTURES ON MR DARWIN'S THEORY.

WE have now to return to Mr Darwin's Theory, and still further to examine its claims to our acknowledgment of its authority as an interpreter of Nature.

M. Flourens has well said," "Natural Selection is only Nature under another name' (31); and again, 'Either Natural Selection is nothing, or it is Nature, but Nature endowed with the attribute of Selection-NATURE PERSONIFIED, which is the last error of the last century; the nineteenth century has done with personifications' (53).

This is indeed an exact analysis of Mr Darwin's metaphor. Natural Selection is organization, and selects itself.

Now that Natural Selection is indeed Nature, in this Theory, and nothing more, is evident not only from the general course of the argument, and the statements with which it is supported, but from some passages of the author which leave no doubt on the subject. Having spoken of Nature in the previous sentence, he goes on to say, 'she can act

* 'L'élection naturelle n'est sous un autre nom que la nature. Pour un être organisé, la nature n'est que l'organisation, ni plus, ni moins. Il faudra donc aussi personnifier l'organisation, et dire que l'organisation choisit l'organisation. L'élection naturelle est eette forme substantielle dont ou jouait autrefois avec tant de faeilité. Aristote disait que "si l'art de batir était dans le bois, cet art agirait eornme la nature." A la plaee de l'art cle batir M. Darwin met l'élection naturclle, et e'est tout un : l'un n'est pas plus eliinérique que l'autre' (p. 31). 
on every internal organ, on every shade of constitutional difference, on the whole machinery of life. Man selects only for his own good, Nature only for that of the being: which she tends. Every selected character is fully examined by her, and the being is placed under well-suited conditions of life.'

Could studied language, seeking to express the personality of Nature, and to endow her with discrimination and accurate judgment, go further than this? Take again this statement :-

'Slow though the process of selection may be, if feeble man can do much by his powers of artificial selection, I can see no limit to the amount of change, to the beauty and infinite complexity of the co-adaptations between all organic beings, one with another, and with their physical conditions of life, which may be effected in the long course of time by Nature's power of Selection' (115).

Here the personification rises in intensity: if 'feeble man' can do much in improving domestic animals and plants, how much more can powerful Nature do in the way of mutation, having so great a measure of time for her operations. Observe, that 'powerful' is implied in the contrast to 'feeble man;' and observe, also, that the argument also urges that if man selects, and by selection produces improved and beautiful varieties, much more can Nature do in this way; implying that she is much more intelligent, and wise, and has a more refined eye for beauty, than the artificer man. But whence comes this 'beauty?' We have already seen that Natural Selection spurns beauty, that beauty is no part of the design of Nature, and that if it were so, it would be fatal to the Author's 'Theory, by his own confassion. How then 
comes it that there would be 'no limit to the beauty' of organized beings? On such a system we should rather have expected that there would be "no limit to the ugliness.' And how comes it that we, the most exalted and improved of apes, have come to appreciate beauty and to admire it, and to be fascinated with it in form, colour, larmony, contrivance, and adaptation? who gave us this faculty to admire beauty? Natural Selection was our maker, and yet Natural Selection takes no account of beauty; how can we have got any faculty but as we derived it by improvement from our forefathers, the anthropoidal patriarchs of the tropical forests? Is it an improvement to comprehend and admire beauty? It either is or is not an improvement; if it is, then Natural Selection, which disregards beauty, improved us by enabling us to value it! Our creatrix, therefore, improved us by making us esteem that which she disapproves! Surely this must be regarded as a mistake. Or if it be not a mistake, then it is no improvement to have an eye and a taste for beauty; and the blue-tailed baboons, and the howling monkeys, and the hideous gorillas are superior to us in the satisfaction they feel in their fiendlike females.

But this is not all: "if feeble man can do much by his porrers of selection, - what does man do? He makes varieties, and cannot make anything more, and if he withlolds his hand the varieties disappear; but Nature, according to the Theory, makes new species. Here then is implied, that which is implied throughout the whole Theory, that variety and mutation are the same. When we produce by cultivation a new variety of a rose, we know how far we have gone, and we know that we have not made a new species, and cannot do so; but if a rose 
were to be gradually transformed into some new flower, never yet heard of or seen, and to become a new species of a new plant - a very possible and probable event in this Theory-then a transformation would have been accomplished; though to improve and to change are two opposite propositions. When therefore Man and Natural Selection are thus brought together in comparison, the comparison fails: Man varies and can do no more; Natural Selection changes the Nature and quality of organized beings; she has her department (in the 'Theory), and to this we can never approach.

We must take another instance of this abuse of language: 'It has been asserted, that of the best shortbeaked tumbler pigeons more perish in the egg than are able to get out of it, so that fanciers assist in the act of hatching. Now if Nature had to make the beak of a fullgrown pigeon very short for the bird's own advantage, the process of modification would be very slow, and there would be simultaneously the most rigorous selection of the young birds within the egg, which had the most powerful and hardest beaks, for all with weak beaks would inevitably perish, or more delicate and more easily broken shells might be selected, the thickness of the shell being known to vary like every other structure' (92).

If Nature liad to make! that is, if it were her inclination so to do, she would 'rigorously select' hard-beaked young birds or weak shells. Can personification go beyond this? and yet, after all, we must remember both here and in all other passages, that Natural Selection is only 'the sequence of events as ascertained by us.' So then we have the sequence of events setting about to make pigeons 
with short beaks, and 'rigorously selecting' strong beaks or weak egg-shells! We may, however, in passing, observe, that in this "very slow' process it is obvious that the whole breed would be dead and gone some ten thousand years, perhaps, before one beak had been made strong enough. If the greater part perish at present under existing arrangements, Natural Selection must accelerate her movements, or her plan will fail.

Here then is the illusion: Natural Selection is continually, and many times in every chapter, spoken of as if it were something exterior to the organized being, a power inspecting* and watching opportunities, when in reality it is nothing but the organization of the being itself; and it is quite apparent that $\mathrm{Mr}$ Darwin by repeatedly using this language has felt the reaction of it upon himself, and has been overpowered by it; we need not therefore wonder if many an incautious Reader should be misled, when the Author misleads himself.

' Unless favourable variations be inherited by some at least of the offspring, nothing can be effected by Natural Selection' (107). Now we have seen that the true sense of Natural Selection is Nature in the organized being, or organization. Let us read the above sentence then as thus corrected, and we shall have it: 'Unless favourable variations be inherited by some at least of the offspring, nothing can be effected by organization,' or, unless organization be varied, organization cannot vary.

To this sapless sentence something however much more significant is added. 'Non-inheritance of any new character is, in fact, the same thing as reversion to the character

"Mr Darwin defines it 'a power incessantly ready for action' (64). 
of the grand parents or more remote ancestors, and no doubt this tendency to reversion may often have checked or prevented the action of Natural Selection.'

No doubt at all about it. 'This tendency to revert to ancestors is that principle which extinguishes the whole 'Theory, and has always checked and prevented the vagaries of Natural Selection. It is owing to this that we all continue as we are, and that all animals are as they were since the day they were first created; it is owing to this that crabs, giraffes, elephants, horses, tapirs, and pigs do not change into one another'; it is owing to this that no new species can be anywhere found, either that has been made since any record could exist, or that is now in the process of formation; and though $\mathrm{Mr}$ Darwin assures us frequently that varieties are now in the act of making new and well. defined species, yet we laugh at the assertion, and believe it no more than we do the existence of the Centaurs and Cyclopes; and our reason for this is that the tendency to revert to the character of ancestors shuts the door effectually against all the clever schemes of Natural Selection.

We must not however pass over lightly the confusion of terms introduced by $\mathrm{Mr}$. Darwin in the use he makes of varieties, for with him, as we have already said, varieties and mutations are identical, - a very important postulate for the Theory.

'Plus j’y réfléchie,' says M. Flourens, 'plus je me persuade que M. Darwin confond la variabitité avec la mutabilité. Ce sont deux mots, ou plutôt deux phénomènes qu’on ne peut séparer assez. La variabilité, ce sont les variations,

* It is curious to observe how quietly $\mathrm{Mr}$ Darwin takes this for granted, as if it were an unquestioned fact of physiology, "It inevitably follows that as new speeies are formed through Natural Selection, others will become rarer, and finally extinct' (116). 
les nuances plus ou moins tranchées, des variétés d'une même espèce. La mutabilité c'est tout autre chose ; c'est le changement radical d'une espèce en une autre, et ce changement ne s'est jamais vu' (32):

Many passages from Mr Darwin's book might be adduced fully justifying these strictures of M. Flourens; the following sentence involves this confusion of terms:

"If the tendency to reversion has not prevented man from creating innumerable hereditary races in the animal and vegetable world, why should it have stopped the process of Natural Selection?' (107). Man has cultivated, for instance, the breed of dogs, and has successfully produced hereditary races - the greyhound, the foxhound, \&c.; he has also produced varieties of plants, some of which are fertile : but in neither of these cases has he broken through the barrier of species, he has produced varicties only; but Natural Selection radically changes, according to the Thieory, the Species_changes a bustard into an ostrich, a horse into a tapir, \&c. When, therefore, we 'create innumcrable hereditary races,' we do nothing at all like Natural Selection, we keep within the limits of Nature. Natural Selection spurns those barriers, and makes new creations altogether. "The tendency to reversion to ancestors' does not prevent us accomplishing our object of producing varieties, but if we were to attempt to form a new Species (that which Natural Selection makes her principal business), we should be prevented immediately. The alleged attribute of Natural Selection is mutation, transformation, change; we confine ourselves to vary existing forms, but never pretend to change their nature. Our operations therefore cannot in any way be compared to those of Natural Selection. Now this is no triffing matter in an 
examination of the Theory, for if it were allowed to pass that our artificial variations are equivalent to the mutations effected by Natural Selection, then the Theory would be proved at once. This certainly is assumed by Mr Darwin, but the assumption must be utterly repudiated; nothing can be further apart in intrinsic meaning than our artificial variations and the transformations of Natural Selection.

Neither should the wording of the passage before us be allowed to pass unnoticed: 'man creates innumerable hereditary races.' Creation in this discussion is a term that would awaken all the suspicious sensibilities of a Transmutationist. Mr Darwin would not allow us to say that an animal is created, we therefore cannot permit him to make us creators in order that he may turn round upon us and claim as much for his Natural Selection. We are suspicious of metaphorical language in this discussion, and we have good reason to be so, for it is no secret to us that a metaphor is in Mr Darwin's hands a Trojan horse, which, if once admitted, 'monstrum sacratâ sistimus arce.'

But there is a still deeper mystery in Natural Selection, which, if nothing else, is certainly a mystery of words. 'The action of Natural Selection will depend on some of the inhabitants becoming slowly modified, the mutual relations of many of the other inhabitants being thus disturbed. Nothing can be effected unless favourable variations occur, and variation itself is always a slow process' (114). The real meaning of this is that unless animals or plants begin to change they never will be changed, a proposition not very hazardous. But low do these clianges*

* Perhaps Mr Darwin has provided for these occurrences of variations by the following new law of nature:-

'I am strongly inclined to suspect that both in the vegetab]e and animal kingdom, an occasional intercross with a distinct inclividual is a law 
begin? They are called variations, modifications, sometimes plastic tendencies: they may have many more names which ingenuity might invent, but, let them be called what they may, they are supposed to be accidental occurrences, laid hold of by keen-eyed Natural Selection, who is always on the watch to turn to the best account any 'modifications' that may occur. The pre-elephant, whatever sort of animal that might be, had no proboscis, but 'some slight modification' in the nasal regions 'occurred,' and they were worked out slowly, by Natural Selection, till at last the proboscis with its many thousand muscles was duly formed. These accidental occurrences must indeed have been numerous, for they have been the exciting cause of every species of every organized being that exists, or ever has existed: unless some modification had occurred in a fish it never would have had a tail; unless some variation had appeared in the predecessor of a nettle it never could have had a sting; and so on throughout the whole realm of nature. Many myriads of these 'variations' must have occurred, and must indeed at present be at work, for Mr Darwin assures us that varieties are incipient species, and yet not one single instance of these advancing modifications has ever been detected, whilst on the contrary everything seems to prove the fixedness of the plan of Nature. If ever there was a case in which the rule "de

of nature. I am well aware that there are, on this view, many cases of difficulty, some of which I am trying to investigate' (106).

Would it not have been better if the learned author had thoroughly investigated, and satisfactorily parried, all these difficulties (not some of them only), before he ventured to publish, on suspicion, a new law of nature? An occasional intercross with a 'distinct' individual means an intercross with an individual of another species. What a wonderful law this must be which brings about these exceptional cases only occasionally! It is not difficult to understand the object of this 'law,'-it is, in fact, to allow free scope to Natural Selection. 
non apparentibus et non existentibus eadem est ratio,' it surely is in this dispute of Natural Selection.

There is in this system another difficulty which seems to puzzle its author, and to lead him into contradictory statements. 'It is obvious,' says he, 'that the several species of the same genus, though inhabiting the most distinct quarters of the world, must have originally proceeded from the same source, as they had descended from the same progenitor' (3S1). This is intelligible enough, and is plainly required by the Theory. But then comes the question, which Mr Darwin agitates, whether species has been produced on one or more points of the earth's surface. ' Undoubtedly there are very many causes of extreme difficulty in understanding how the same species could possibly have migrated from some one point to the several distant and isolated points where now found. Nevertheless, the simplicity of the view that each species was produced within a single region captivates the mind. He who rejects it rejects the vera causa of ordinary generation, with subsequent migration, and calls in the agency of a miracle.'

Before we proceed, it may be as well to understand this accurately. The argument is this, if you do not believe that Natural Selection has formed each Species in some single region, and that they all subsequently migrated into all parts of the earth wherever they are found, then you do not believe that they sprung from one common progenitor, and therefore you must believe in a Divine creation, here called a miracle. 'But,' says Mr Darwin, 'if the same species can be produced (i. e. created) at two separate points, why do we not find a single mammal commòn to Europe and Australia and South America?-- l'he conditions of life are the same, and sonie of the aboriginal 
plants are identically the same at these distant points of the Northern and Southern Hemispheres? The answer I believe is, that mammals have not been able to migrate, whereas some plants, from their varied means of disposal, have migrated across the vast and broken interspace' (383).

The argument thus carried on urges that, if creation could produce two species, exactly similar, in two separate points, why has it failed to do so in South America and Australia, where all the mammals differ from those of the old world? With this inquiry we are not concerned; but it is obvious that it has another aspect, and bears with equal force against Mr Darwin's theory, for how comes it that these mammals of the same genus as those in the old world, the jaguar, the puma, the ocelot (all felidæ), the llama of the camel family, \&c.; and which, according to the Theory, must have descended 'from the same progenitor,' should be found in South America, when Mr Darwin expressly tells us that they have not been able to migrate thither? There they are, nevertheless; no independent and separate creation can have produced them, and migration is out of the question.

Who shall unravel this perplexity?

If in this desperate state of the Theory it should be suggested that the continents in past ages may have been united, even that would avail nothing here, for Mr Darwin himself has laid it down that 'the mammals have not becn able to migrate,' and therefore that as well as every other' means of migration is inadmissible. Moreover, he himself is averse to admit 'that continents which are now quite separate, have been continuously, or almost cortinuously, united with each other, and with the many oceanic 
islands' (358). So that the door is shut, and there we must leave it.

For the rest of the argument the result is equally infelicitous, as these confessions indicate-'undoubtedly many cases occur in which we cannot explain how the same species has passed from one point to another.' 'It would be hopelessly tedious to discuss all the exceptional cases of the same species now living at distant and separated points; nor do I for a moment pretend that any explanation could be ofjered of many such cases' (383-4).

The Theory therefore fails to explain the very point which it undertook to interpret; and if the alternative really be 'a miracle,' then certainly Natural Selection has not, in this case, averted that alternative. In his anxiety to exclude a miracle, Mr Darwin has locked himself in, and cannot get out.

But there is still another point for consideration in this system, of which Mr Darwin has said something, and on which we shall venture to add a few remarks, first placing his words before the reader. "When cases of diversified and changed habits occur, it would be easy for Natural Selection to fit the animal for its changed habits, or exclusively for one of its several different habits. But it is difficult to tell, and immaterial for us, whether habits generally change first, and structure afterwards; or whether slight modifications of structure lead to changed habits; both probably often change almost simultaneously. Of cases of changed habits it will suffice merely to allude to that of the many British insects which now feed on exotic plants, or exclusively on artificial substances. Of diversified habits, innumerable instances could be given. I have often watched a tymant fy-catcher (samrophagus sulphur- 
atus) in South America, hovering over one spot and then proceeding to another, like a kestrel, and at other times standing stationary on the margin of the water, and then darting like a kingfisher on a fish. In our own country the larger titmouse may be seen climbing branches, almost like a creeper; it often, like a shrike, kills small birds by blows on the head; and I have many times seen and heard it hammering the seeds of the yew on the branch, and thus breaking them like a nuthatch. In North* America the black bear was seen by Hearne swimming for hours with widely open mouth, thus catching, almost like a whale, insects in the water' (202).

We quite agree with the Author in acknowledging the difficulty of this question, but that it is immaterial we cannot at all concede. If transformations are to take place in Nature, and animals are to become new creatures, it must be a very important point to determine whether the change first takes place in the structure of the animal, or in its habits. If a land-animal is about to turn into a fish, or a fish into a land-animal, or if a wingless animal is about to assume wings (all cases considered quite possible in the 'Theory, if indeed they are not more properly speaking historical facts), it must be deeply interesting to know whether the inclination to change precedes the altered structure, or vice versâ.

If a bear were determined to live in the depths of the sea, before his new structure enabled him to do so, he would

"This is the celebrated passage which in the first edition had an additional sentence now suppressed: "I see no difficulty in a race of bears being rendered by Natural Selection, more and more aquatic in their structure and habits, with larger and larger mouths, till a creature was produced as monstrous as a whale.' In truth the passage without this conclusion is incomplete; for in the commencement it is stated that it is easy for Natural Selection to fit the animal for its changed habits. 
find he had made a very serious mistake, and that Natural Selection had induced him to make a change, not at all to his advantage. But if, on the other hand, he were to wait till his new marine organization, sufficiently developed, might enable him to frequent 'the deep unfathomed caves of ocean,' then he would get on very scurvily as a bear, and be reduced to short commons in the mountains and forests. An animal half a bear and half a whale would be a curious sight, or one-third bear and two-thirds whale, or any other proportion you choose, would be beyond our powers of imagination; and the middle state of change for all transforming animals must be their 'struggle for life,' indeed, though not in the sense that $\mathrm{Mr}$ Darwin intends it. This difficulty indeed is supposed to be lessened by imagining a very long series of new animals intermediate between the bear and the whale, and each new generation, in a vast length of time, gradually becoming more and more aquatic in tastes and habits, till from an amphibious animal a true whale was at last elaborated. This hypothesis, nearly as respectable as an ordinary Fairy tale, must be left as it is, for it needs no comment, but still the question would remain to be answered, does 'modification of structure' precede habit, or habit go before modification. Who shall answer this question? Lamarck gives the precedence to habit; and according to his theory, effort and inclination produce a change in organization : but with either, or with all the expositors of this school, this is certain, that there never was a design on the part of the Creator to produce a whale or any other animal, in order to sustain any predetermined character in Nature; no land-animal ever schemed to become a whale, nor did any fish devise the means of living in the water, nor did any Creative Intel- 
lect ever imagine the form, life, and attributes of any animal-organized beings are as they are by accidental modifications, of which Natural Selection has taken arlvantage.

But in the passage before us $\mathrm{Mr}$ Darwin intimates that if an animal has more than one habit, if it allows itself two or more occupations, or indulges in more than one amusement, this is to be considered as indicative of an approaching change of organization : thus the tyrant fly-catcher is probably advancing to the kingfisher, and it is doubtful whether the titmouse will be changed into a creeper, a shrike, or a nuthatch.

We could suggest similar suspicions circumstances: the reindeer is known occasionally to devour the hamser, an intelligible indication of his change some day into a carnivorous animal; and the dog now and then eats grass, a not improbable hint that he in due time may become a graminivorous animal, and take his place in some new development of the ovine race, when the struggle for existence will simultaneously exterminate all the existing breeds of sheep.

We ourselves have seen buffalos immersed in the water, and keeping their muzzles just above the stream, for hours together; and though this did not suggest to us the probability of their transformation into any great fish, yet, possibly, Natural Selection had her eye upon them, and was slowly bringing about the change that is to be!

Perhaps this interesting question has been already settled for us by Shakespeare, who, as he rarely missed any subject, seems not to have overlooked the possibilities of Natural Selection. In the Midsummer's Night's Dream he first gives the ass's head to Bottom, and then represents Bottom as 
manifesting asinine inclinations. 'Methinks I have a great desire for a pottle of hay; good hay, sweet hay hath no fellow.' The rule then, after all, seems to be that when a man is turned into an ass he then begins to have asinine thoughts. In other words, the structure precedes the habit.

Now, in discussing all these wonders, it is to be remembered that the whole system is proposed as a creed, and that belief, and the necessity of belief in things which do not appear, is very frequently urged by the learned author. How often, how very often, does he make use of the expression, 'I see no difficulty in believing,' and almost always when the thing to be believed is most startling, and we may add too, impossible: 'credo quia impossibile est' is a maxim greatly needed in this Theory, and we are again and again reminded that we must believe certain propositions, without expecting any proof.

In the great principle of all, Transformation, this is insisted on as a sine quâ non. 'In order that any great amount of modification should in the course of time be produced, it is necessary to believe that when a variety has once arisen, it again varies, after perhaps a long interval of time, and that its varieties, if favourable, are again produced, and so onwards' (89).

This, in fact, amounts to taking the whole Theory on credit. If we believe this, we believe, of course, all the rest; proofs we cannot have, and therefore we must accept that which is offered us, assertion as a substitute for proof; a very easy method, doubtless, of establishing a new system, but quite unique in a scientific inquiry.

But this method is again and again proposed to us : 'We may account for the distinctness of birds from all other 
vertebrate animals by the belief that many ancient forms of life have been utterly lost' (4.63).

If utterly lost they never can be found; they never have been found, and they exist only in the pages of Mr Darwin's book. But the demands of this creed sometimes place the author in a very awkward predicament, as for instance, when he says, "we may readily believe that the unknown progenitor of the vertebrata possessed many vertebræ' (4.69). Now the context requires that the 'many' vertebræ should mean many more than are now formd in the vertebrata: so then, vertebræ began all at once! ' the unknown progenitor,' the first of this class, did not acquire his vertebræ by the slow process of Natural Selcetion, through untold ages, but had all his vertebræ, per saltum, and more too than his descendants.' We should have expected to hear, as in harmony with the rest of the system, that vertebræ began from a rudiment-a rudiment worked into a sketch of a vertebra; and after some million of years a series of vertebræ produced for the benefit of the animal-but no, a whole series of vertebræ all started into being for 'the unknown progenitor.' Here, then, surely was a creation! here was a miracle! the animal made at once for the needs of his life, the very thing which Mr Darwin abominates, and tells us would be fatal to his system.

But in these strictures on Natural Selection we must not forget the co-ordinate principle of Strnggle for Life. These two agents have, according to the 'Theory, produced all the phenomena of living beings. Natural Selection does not, in any instance, work alone; in proportion as she produces, the Struggle for Life destroys. It is the object of the one to improve organizcd beings, and of the other to 
remove those which show no tendency to improvement: a plant or animal relatively unimproved is infallibly exterminated; all progressive beings destroy the stationary members of their family.

These two principles are, as we have seen, two personifications, two metaphors, two figures of speech. It is, however, an error and a deception of language to represent them as distinct, as the real meaning of one is an accidental change of organization, and of the other the advantages resulting from that change. There must be some agent to struggle, and this can only be the 'modified organization.' Non-change is relatively nothing, an unimproved animal or plant is simply passive. Non-change is non-improvement, according to the Theory, and the unimproved perish.

'In looking at Nature,' says Mr Darwin, 'it is most necessary to keep in mind that every single organic being around us lives by a struggle at some period of its life' (70). 'Battle with battle must ever be recurring with varying success, and yet in the long run the forces are so nearly balanced, that the face of nature remains uniform for long periods of time, though assuredly the merest trifle would often give the victory to one organic being over another' (76). 'All organic beings are striving to seize on each place in the economy of nature; if any one species does not become modified and improved in a corresponding degree with its competitor it will soon be exterminated' (107).

Surely this statement is a strange perversion of the realities of nature. It is indeed certain that the destructive principle, the Shevah mystery of creation, is actively at work to repress the redundancy of existence, and that an 
immense amount of animal life is sacrificed every hour of every day, on the earth, and in the waters, and in the air, to say nothing of trees and plants continually consumed by various animals; but this is very different from the demands of the Theory, different in principle and different in action.

On the principle of course we cannot agree; according to our view, destruction is as much a plan of Nature as existence; it is indeed one convincing proof amongst many of the design apparent in Nature. Life has been given in infinite forms, and with it a check to the excess of life; though the very check is, in another view, a predetermined method of sustaining life, for the animal that perishes is the food of the animal that destroys it. In one sense we may say that all animal life is sustained by destruction, by the consumption of vegetables or animals. But the destruction is not a blind accident without a design, but a well-calculated plan, or, if ever apparently not answering the object of the design, failing in temporary and exceptional instances rather from its want of energy than from its too great activity--as for instance in the occasional overwhelming increase of locusts.**

* The principle of struggle for life, supposed by Mr Darwin, is not destruction acting as a well-considered balance to keep down the excess of life, but an accidental circumstance out of which come forth new forms of life. His system of extermination is invented merely to account for the appearance of new species in the way of transformation, by getting out of the way the pretended predecessors of the last-formed species. The real struggle for existence which in some cases may be observed in nature, produces a totally different result, as M. Trémaux las well observed; it does not evoke new forms of life, but is equally and impartially injurious to all the beings engaged in the struggle. Any one may see the phenomenon in a thickly planted wood. There a struggle for existence really does take place, that is, each tree does its best to reach the light and air, and find an expanse for its ramification. The result is not the formation of a new tree, with improvements enabling it to take the place of its com- 
It is probable that there is scarcely an organized being that has not some antagonist to its prosperity; but, nevertheless, the weakest as well as the strongest thrive and prosper; the lion and the hare, the eagle and the wren, the shark and the pilchard keep their ancient positions in the ranks of life; accidents, disappointments, and dangers may sometimes be their lot, but extermination of their species is wholly improbable.

In the sea where a vast majority of the inhabitants are carnivorous, the principle of destruction is most active, one species preying on another in a series of slaughters; but slaughter is not extermination, and though it may go on at a frightful rate, if numbers are counted, yet in the end the balance of life will remain the same. Few animals can suffer so largely from numerous enemies as the herring,hundreds of millions are devoured by other fishes and by the birds, and hundreds of millions are captured by man. This, if called a struggle for existence, (a struggle in which there is no resistance or effort of any sort,) will always have a certain termination. The herring will be victorious, and the race will not be exterminated.

And how is this? the animal has not been improved in any wonderful way to enable it to confront its dangerous destiny, it has no defensive or offensive apparatus, it is easily captured, and in certain seasons is apparently indifferent to its pursuers, allowing them to approach, without any effort to escape; it is a simple unarmed animal, neg.

petitors, but an injury mutually inflicted by all the trees on one another. In all the vast woods of Nature's domain, or in those planted by man, who ever heard of this struggle issuing in a newly-invented tree qualified to master all its competitors? Hyriads of trees perish, after a hard and precarious existence, for want of space, but no new rival springs up to exterminate them. 
lected by Natural Selection, and left to take its chance, and yet it flourishes amazingly, and will flourish.

Mr Darwin does indeed himself acknowledge that the forces are so nearly balanced that the face of Nature remains uniform for a long period of time, i.e. till it is changed. But how could this balance be sustained for a 'long period of time,' that is, for all the time we know anything of, if all were left to a blind accident, and there had been no calculation in contriving the antagonistic principles of life and destruction?

If there is a balance that has, for unknown ages, preserved the order of Nature in its just proportions, surely this must be the result of some profound calculation which could grapple with the whole abstruse problem, the un. known number of which was to be found only in futurity; for if Natural Selection, which is in fact identical with chance, be supposed to have produced the destroyers, how is it possible to imagine that at the end of thousands of years, there should be no mistake, and that the face of Nature should remain uniform. This is believing in the old story of the atoms of Epicurus, and their accidental wisdom. Natural Selection acts for the benefit of individuals only, and has no general plan for the good of all, of this we are frequently reminded, but here is a system of events at any rate, if plán it may not be called, which has, in spite of infinite combinations and contrarieties, and circumstances which no ordinary foresight could take into calculation, brought out undiminished and unimpaired, through all the hazards of time, the original harmony of Nature.

If for a moment we think of all destructive genera of 
animals, all of which, according to the theory, have been produced fortuitously by Natural Selection, the chances would be almost infinite against all these creatures having been turned out loose into Nature by mere accident, to live by destruction, and yet at the end of ages appearing: to be neither too many nor too few.

Here then again we say, and we shall still have to repeat it, that $\mathrm{Mr}$ Darwin proposes an intelligent and sagacious scheme without an intellect that could have devised it; we are told that the balance is well-poised, but there is no mind to inspect or maintain the balance; and a wonderful problem has been solved without calculation.

We are told that 'the modified offspring from the more highly improved branches in the line of descent will, it is probable, often take the place of, and so destroy, the earlier and less improved branches' (125); but how can $\mathrm{Nr}$ Darwin undertake to say that any animal is "less improved' than it ought to be; and what does he mean by improving animals? Is there any animal not rightly and adequately organized for the position it occupies in Nature? What animal will Mr Darwin name which needs improvement, in what respect is it deficient, and what improvement would he suggest? Nay, has he not himself said, when pressed by another argument, "Who will pretend that he knows the natural history of any organic being sufficiently well to say whether any particular change would be to its advantage?' (139); and in another passage, where he is still harder pressed, he, for the occasion, abandons his 'Theory, and comes round to our side of the question: "What advantage would it be to an intestinal wor'm, or even to an earth-worm, to be highly organized?' (135). This is just what we ask, and applying this ques- 
tion to the whole scale of being, we ask what advantage would it be to improve the organization of a tapir, a pig, a camel, a bustard, an ostrich, or any of those animals which we have seen transformed in this theory?

But mark the inconsistency! Though Mr Darwin can ask these questions of common sense when it suits his purpose, yet he tells us, in plain contradiction to these sentiments, that 'the ultimate result will be that each creature will tend to become more and more improved in relation to its condition of life.' 'This improvement will inevitably lead to the gradual advancement of the organization of the greater number of beings throughout the world' (1.33).

If this general improvement should ever take place, when all creatures will thus be advanced to the limits of perfectibility, there will be no more Natural Selection, for she will have done her work, and consequently there will be no more Struggle for Life. Creatures will not be waging battle within battle to maintain their position, and in fact all the destroyers will disappcar, and they will be transformed into some superior position 'by an advancement of the brain for intellectual purposes' (134), and even the intestinal worm will perhaps be in a fair way to study logic and propound theories.

Such are the bright prospects which this system holds out to us!

We have then enough before us to understand that the whole system is based on the progressive improvement of organization, and that without this, the ingeniously constructed fabric would fall immediately into ruins. 'The basis however rests on three assumptions.

1. 'That the phenomena of life are accidental. 
2. That organization has needed improvement.

3. That improvement has really taken place.

Not one of these propositions falls within the compass of scientific physiology; they all belong rather to the speculative theories of ancient philosophy, and to such disquisitions and dogmas as we see in the Timæus of Plato. They are not capable of proof by induction from experience, and are simply dogmas, to be dismissed to that department of literature to which they properly appertain.

In the mean time it is instructive to observe that $\mathrm{Mr}$ Darwin not only confesses that there is a great difficulty in determining the direction which future improvement is to take, but that he himself, who so confidently assures us that it is to be, speaks with hesitation of the nature of this improvement, only he inclines to think it will be in the direction of human intellect, by an improvement of the brain. Now, if it is difficult to guess, and impossible to assert, the future destinies of inmprovement, surely it must be not less difficult to point out the line that it has taken. If we could be absolutely certain of the direction it has taken, we might speak with some confidence of the direction it will take; if we knew one we might plausibly speculate on the other, the knowledge of either end of this supposed scale would help us to reason on the other; but in all this great agitation about continually advancing improvement by accidental 'modifications,' Mr Darwin has not given us one single instance of real improvement in any species. He has told us of transformations many, but of improvements nothing. A transformed animal is not an improved one. A tapir changed into a horse (a favourite metamorphose in the Theory), is not an improved animal, 
but a new one. If an elephant were changed into an Arabian steed, it would not be an improved elephant, it would have lost a large measure of its intellect and almost all its strength, and would simply be a horse, neither more nor less.

A horse endowed even with the gift of speech and with human reason to direct that speech, would not be improved-it would be an importunate monster; no longer a laborious servant, but an irksome and offensive prodigy. It is impossible to entertain seriously the idea of improving any animal, or adding to the advantages of its existing organization: it is as misplaced and audacious as to undertake the task of its creation. No mental aberration can be greater than to indulge the imagination with an improvement of Nature. We ask then, has the improvement hitherto advanced in the direction of human intellect? and if it really is to advance steadily in that path, what will become of all living creatures when all are as intellectual as man? They either must all become men in form as well as in brain, or with improved brains must continue to be quadrupeds, birds, fishes, and insects. What a preposterous and outrageous dream have we got into! either man the only animal on the face of the earth; or all animals intellectual and rational as man, and endowed also with language, their unquestionable heritage if they are to enjoy human reason. Can nonsense go beyond this? and yet is not this a legitimate, nay, an inevitable deduction from the antecedent propositions?

It may perhaps be a matter of surprise that the l'heory should have tacked to it this strange appendage, which at first sight might seem superfluous, and not demanded by the argument. It might be thought (quite enongh to insist 
on that which has been, to be satisfied with the wonderful transactions of unknown and unwitnessed ages, but why launch out into the depths of futurity, that dark ocean for which there is no card? But in truth the Theory imperatively demands an imagined future, as much as it has insisted on an imagined past. Without this prospect of advancing improvement terminating in perfection, we should have a system teaching us that all beings have for millions of ages been steadily improving, but that now the process has entirely ceased-that the Sabbath has been reached, and now at last 'all is very good.' Or, if things are not now perfect, we must be content with Nature as it is, with myriads of species all distinct from one another, innumerable multitudes lingering in the lowest grades, and life rising up by gradations in distinct phases of superior exhibitions. What then has the system done for us, if it has progressed thus far, and now stands still? What has been gained if tapirs and elephants have been turned into horses, bears into whales, bustards into ostriches, logger-headed ducks into sea-swallows; if still the tapirs, the elephants, the horses, the bears, the whales, and the others exist apart, just as if nothing had been accomplished in the way of metamorphose? If we are now in a state of rest, and there is to be no more change, then all the transmutations hitherto effected have been merely separate feats of magic in individual cases, and, for aught we can see to the contrary, things would have been just as well, if none of these alleged changes had taken place.

The Theory therefore imperatively requires that nature should be on the move, and continually advancing. The Theory must have this corollary tacked to it, and though it may be as incommodious as can well be imagined, 
there is no way of escaping from it. 'Each creature will tend to become more and more improved in life, and this improvement will lead to the gradual advancement of the organization of beings throughout the world,' and the direction of this improvement will be, "by an advancement of the brain for intellectual purposes.'

Let not Mr Darwin's disciples then wince at the conclusion of this their system. It may take a long time to effect it, a period perhaps as long or longer than that which has elapsed from the Silurian era to the present day, but in the end all creatures will be rational as men: the volvox globator may, after an incalculable series of changes, finish his career by taking the chair of mental and moral philosophy, a sponge may become a professor of geology, and even a gander, that * animal of whose aptitude to mutability $\mathrm{Mr}$ Darwin most despairs, may nib his own quills, and sit down to write a learned volume of a new exposition of nature.

But the Theory has its exigencies, and as is often the case in a deviation from probability, a further advance into the improbable becomes unavoidable. Thus Natural Selection has been compelled to take into association the Struggle for Life, which sone might be disposed to think could be dispensed with: for it would be argued, why in the case of the improvement of a plant or animal does it follow as a necessary consequence that all the unimproved beings of the cognate species must perish? Supposing that Natural Selection were to produce a new species of violet, why must all the old-fashioned violets be forthwith exterminated? would not the world be large enough for the two sorts of flowers? or granting the formation of a

* 'The groose scems to have a singularly inflexible organization' (43). 
new animal, by transmutation, and a great improvement on the species nearest allied to it, why must its unimproved neighbour be swept out of existence?

Now the reason of this apparent non-sequitur is, that in the Theory it is requisite to account for all the intermediate animals which 'we are to believe' have existed between two creatures now apparently unlike, but which, we are told, have sprung from one progenitor. In connecting the tapir with the horse there may have been thousands (in some cases Mr Darwin says tens of thousands) of intermediate animals, connecting the two extremes by slow approximations. Now all these have disappeared (that is, they cannot be found), they have been 'exterminated,' and this has been effected by the Struggle for Life, and so of all the missing links between all animals. In such a scheme the Struggle for Life has had enough to do, and as the system of nature continues as it was, and as varieties now existing are commencing species, and as all beings are on the high road of improvement, in which very great changes have yet to be accomplished, and as Natural Selection and the Struggle for Life have worked together inseparably from the beginning of things, they cannot now be separated, and thus it is that the Struggle still continues, and that the battle for life is going on as vigorously as ever, even in cases where not the slightest sign of it can be discovered, and where all seems tranquil, peaceful, and secure.

'If my 'Theory be true,' says Mr Darwin, 'numberless intermediate varieties, linking closely all the species of the same group together, must assuredly have existed; but the very process of Natural Selection constantly tends, as has been often remarked, to exterminate the parent forms 
and the intermediate links' (197). And, again, 'all the intermediate forms between the earlier and later states, as well as the original parent-species itself, will generally tend to become extinct' (127).

In a few words, then, all this is devised, to answer the question, what has become of all the links of your chain, the progenitor, and all the intermediate forms?-They have been exterminated. There is a principle in Nature which effects this, and it is called the 'Struggle for Life.' 


\section{CHAPTER XI.}

THE GEOLOGICAL QUESTION.

IF the lofty title to Mr Darwin's book, 'The Origin of Species,' could be sustained, we should indeed be favoured with a revelation, which has hitherto been supposed to be beyond the reach of human cognizance. We should be introduced to the beginning of things, and behold all the secrets of the primordial laboratory disclosed to our gaze, beyond the utmost dreams of our curiosity, and the farthest aspirations of our hope.

Mr Darwin does indeed profess to take us very far back into the night of antiquity, before the dawn began, vastly beyond all other exponents of science, even to ages long before the formation of the lowest Silurian rocks, an era of which geology knows nothing. Under his guidance we suppose that we shall in these hitherto undiscovered regions reach the very beginning of life, and see the first organic creature constructed, and assume the properties and actions of life-be made acquainted, in fact, with its 'origin.' But we are disappointed, we advance, as we suppose, to reach the origin, but when we have gone as far as our learned guide can lead us, we only find a blank wall; an insuperable barrier blocks up our path, and we are not permitted to find the origin. 'In all organic 
beings,' says Mr Darwin, 'as far as is at present known, the germinal vescicle is the same, so that every individual organic being starts from a common origin. Professor Asa Grey has remarked, the spores and other jeproductive bodies of many of the lower algæ may claim to have first a characteristically animal, and then an unequivocal vegetable, existence. Therefore, on the principle of Natural Selection with divergence of character, it does not secm increctible, that from some such low and intermediate form both animals and plants may have been developed, AND IF WE ADMIT THIS, we must admit that all the organized beings which have ever lived upon earth; may have descended from some one primordial form?

Certainly, if we admit that animals and plants may have been 'developed' from a spore of the lowest seaweed, we must admit that all of them may have descended from a similar form; there can be no difficulty in the proposition after the first admission; but after all, this is not the Origin of Species, for we have to learn the origin and the formation of this primordial spore. It may be "first characteristically animal,' and 'then unequivocally vegetable,' but whence did it derive these double qualities? It was the most marvellous of all beings to have within itself the potential existences of all animals and all vegetables that ever were to be; to possess qualities which by 'development' were ultimately to expand into an elephant, a whale, a palm-tree, an eagle, a crab, a butterfly, and a man, and therefore we anxiously inquire whence came this spore? Who or what were its parents? How was it made? How did it acquire the double quality of animal and vegetable? In all ordinary discussions of such subjects we should say that the spore of the lowest algx sprung from 
an alga, or from the sea-weed to which it belongs: but whence did that alga come-from another spore, and so on, either ad infuitum, or from some first cause of its existence?

Obviously, then, this is the origin of nothing, for $\mathrm{Mr}$ Darwin's 'prinordial form' as much needs an origin, which he has not explained to us, as any of the animals that may have sprung from the primordial form.

Creation he cannot introduce, for it is the object of his book to exclude creation. Neither can he invoke Natural Selection, for there was nothing to select, when there was no life; neither' can he, as a last resource, betake himself to Lamarck's convenient cloud of 'Spontaneous generation,' for against that Theory Mr Darwin has protested; therefore nothing remains for him but to say that the first primordial form WAS, - to confess his ignorance of its origin, and to be content to say that it came into existence in a way that he is utterly unable to explain.

In this position we meet him and shake hands. This is exactly what we say: we are convinced that this was the origin of the primordial sea-weed, it came into existence in a way that we cannot explain. We have not the most distant idea of the process, it is utterly inconceivable to us, only we are sure that there is a Power which could and did effect that which we are unable to comprehend.

But all animals and vegetables spring from this one primordial form. In what way did the first springing commence; did the animal quality start first, or the vegetable? How did the movement commence, and in what direction? The first step in this process, we are told, was 'on the principle of Natural Selection, with divergence of character;' easy words these to pronounce, but not so 
easy to explain. However, there was some ' divergence of character' in the first spore: that is, it began to change its character,--some 'modification,' some 'development,' some 'plastic' propensity appeared in our great Ancestor, and he produced-what? an improved spore certainly,-it could not be beyond that. But how could Natural Selection work here? where was the competition, where was the Struggle for Life? The new spore had to struggle with itself, or perhaps we can imagine that the great Ancestor produced (how we will not say) 'several modified,' spores, and thus the struggle began amongst the family, the unimproved ones were exterminated, and an advanced race began. A race of what? what new vegetable or what first animal? that history does not reveal. Then male and female had to be developed, Natural Selection formed the two sexes, made some male and some female, invented all the mysteries of reproduction, and set the world a-going till the process finished in man.

Now Mr Darwin has told us that all this does 'not appear incredible,' and nevertheless he soon contradicts himself in these words: ' a difficulty has been advanced, that, looking on the dawn of life, when all organic beings, as we may imagine, presented the simplest structure, how - could the first steps in advancement, or in the differentiation and specialization of parts have arisen? I can make no sufficient answer, and can only say that as we have no facts to guide us, all speculation on the subject would be baseless and useless' (137).

If Mr Darwin presents us with a history of the beginning of life which he frankly acknowledges he cannot explain, and for which he has no facts to guide him, how can he tell us that such a history is 'not incredible?' what 
can this mean but that he requires us to believe an invention of his own imagination, and that we are to accept on trust that which he plainly tells us is inexplicable?

Now in the above passage we see the failure of the system, and its ingenious author check-mated by his own acknowledgment. 'No one ought to feel surprise,' he adds, 'at much remaining uncxplained in the Origin of Species, if due allowance be made for our profound ignorance of the mutual relation of the inhabitants of the world during the many past epochs of its history' (137).

If much remain unexplained about the Origin of Species, then Mr Darwin has given a false title to his book, 'On the Origin of Species by* Natural Selecticn, and the preservation of favoured races in the Struggle for Life;' for when we approach to the origin we cannot learn what it is; and when, after that, we seek for information in the first steps in advancement, Natural Selection is fairly abandoned, and Mr Dawwin tells us he can give no answer to our inquiries, for he has no facts to guide him, and all speculation on the subject would be baseless and useless!

Now when the Origin of Species is the question, and we come to such a confession as this, can we help concluding that the author acknowledges his own defeat? the ingenious helmsman has steered the Theory on the rocks, and there it must await its destiny.

In this most important part of the discussion it is deeply interesting to find not only an acknowledgment of the failure of the 'Theory, but to meet with a profession of that

The title chosen by the author for his book does not avoid the metaphor, and in that respect is in kceping with the rest of the volume- 'favoured races, - who favours them? or who has shown them favour? They are the clect of Mr Darwin's system ; Natural Selection, another metaphor, educates the clect and preserves them. 
principle which, if duly attended to, would have saved the author from this dilemma? "when we have no facts to guide us, and when we are profoundly ignorant of the mutual relation of the inhabitants of the world, during the many past epochs of its history, all speculation on the Origin of Species would be baseless and useless.'

This is precisely the true state of the case, and with this conclusion we heartily agree-only, be it observed, that this principle contradicts the author's practice, as that which he attempts all through, from the first page to the last, is to give us a clear sketch of the mutual relation of the inhabitants of the earth during the many past epochs of its history. He tells us of their transformations, he describes to us how animals have been changed into other forms, he talks of their improvement, of their plastic qualitics, of their modifications, of the changes of varieties into new species; he says that transformation has been going on from the dawn of life, is now going on, and will go on to ultimate perfection; he intimates the classes of animals which have been transformed 'in ten 'thousand generations ;' in short, he professes a perfect acquaintance with their general history in the past cpochs of geological formation, and insists on the achievements of Natural Selection in bringing on animated nature from the beginning of things to the present hour; is this "profound ignorance of the mutual relations of the inhabitants of the earth during the many past epochs of its history?' Let the reader judge.

It is however pleasant to find that there are occasions when the force of truth can bring the author to admit those sober reflections which common sense demands, which must be the basis of all truth, and which onght to 
guide the most powerful as well as the most ordinary intellect.

But the approach to the dawn of life, and the search for the primordial form, bring us to a position where we can discover something real; for whither can we turn to investigate the early appearance of organic beings but to the records of geology? The earth, as it has been well said, has left us her autobiography, and this we must study to search as far as we can the epochs of her ancient formations. All the successive records of this great work it is our business carefully to consult, that we may understand the story of life, by a patient and cautious research. This labour has been undertaken by many an able student, and the story is now so well understood that the general outline of it will scarcely require any farther emendation. On the grand plan, and most of the details, there is a general harmony of sentiment. Geology is an established and consistent science.

We shall now see how Mr Darwin confronts the testimony of geology. 'If my Theory be true,' says he, 'it is inclisputable that before the lowest Silurian stratum was deposited, long periods elapsed, as long as, or probably far longer than the whole interval from the Silurian age to the present day; and that during these vast, yet quite unknown periods of time, the world swarmed with living creatures' (333). This surely is casting the whole system on the hazard of a die, it is a bold defiance and brow-beating of the evidence of nature, and is the most desperate and daring proposition ever yet risked in all the amnals of science. 'My Theory must be true,' it affirms, 'and therefore it is beyond dispute that the records of geology are of no account. The cvidence that I want is not to be had 
in the existing records, and therefore I affirm that there was another world before the lowest Silurian, and that in that unknown epoch the world was swarming with animals according to my system.'

This passage one would think must be sufficient to open the eyes of any votary of Natural Selection, and to convince the most ardent zealot of the hopelessuess of the Theory. Even the author himself has his misgivings, we may almost say his despair, after this reckless declaration. "To the question why we do not find records of these vast primordial periods, I can give no satisfactory answer - the difficulty of understanding the absence of vast piles of fossiliferous strata, which, on my Theory, no doubt were somewhere* accumulated before the Silurian epoch, is very great. The case at present must remain inexplicable, and may be truly urged as a valid argument against the views here entertained' (334).

The absence then of evidence in the geological record is by the author's acknowledgment an argument so adverse to his 'Theory that 'he can give no satisfactory' answer to it-it is a very great difficulty-it is inexplicable-the objection is a valid argument against the vicws he has entertained.'

What more could we wish than this, even in a formal recantation? the author acknowledges that the existing evidences of Nature's records are against him, and that he cannot get over the difficulty. But if the present state of things is unmanageable, time to come may bring some

* This is repeated, p. $497:$ 'Why do we not find great piles of strata beneath the Silurian system, stored with the remains of the progenitors of the Silurian groups of fossils? for on my Theory such strata must somewhere hare been cieposited at these ancient and utterly unknown epochs of the world's history.' 
relief-' hereafter the difficulty may receive some explanation.' The learned author conjectures that 'at a period immeasurably antecedent to the Silurian epoch continents may have existed where oceans are now spread out, and clcar and open oceans may have existed where our continents now stand' (335). He suggests that palæontological researches modify antccedent decisions; that fossil animals have becn discovered lower down in the rocks than was supposed in the time of Cuvier; that we have not cxamined all the formations in the world; that we have no right to expect to find an infinite number of thesc fine transitional forms which have connected all the past and present specics, we ought only to look for a few links (327); that we falsely infer becausc certain genera have not been found beneath a certain stage, that they did not cxist before that stage-negative evidence is worthless; and, lastly, we should look on the geological record as a history of the world imperfectly kept, and written in a changing dialect. Of this history we possess the last volume only, relating only to two or three countrics. Of this volume only here and there a short chapter has been preserved, and of each page only here and there a few lincs. On this view the difficulties above discussed are greatly diminished, or even disappear (337).

So then, notwithstanding the above acknowledgments, the author at last talks himself into the pleasant belicf that the difficulties have disappeared! This indeed is characteristic of _Mr Darwin's mode of reasoning. He not unfrequently begins a proposition with stating the inexplicable difficulties which accompany it, but finishes by saying that he sees no great difficulty in believing in some solution of the problem. But if all these difficulties dis- 
appear by the metaphor of a damaged volume, the only one to be found of a large work, why did we not hear of this before the author had reduced himself to the necessity of confessing his total discomfiture? He might have spared himself that humiliation, and might thus have brilliantly surmounted his greatest difficulty. Here $\mathrm{Mr}$ Darwin reminds us of a person who, having been checkmated in the game of chess, asks permission to take back his piece as he sees a much better move on the board. Let him take back his piece, we shall see what good it will do liim.

We must not however leave this last quoted passage without a remark. When Mr Darwin says, that 'of this history we possess the last volume only,' he very dexterously begs the whole question. We affirm that the whole series of volumes is in existence, and that the last concludes with the Tertiary formation; Mr Darwin means that a vast number of other volumes relating to the preSilurian epoch have been lost, and that the only one remaining is the present record of geology, which he lumps together as one volume, and calls it the last. His library, as well as his pre-Silurian world, exists in the land of dreams-our library is complete, and is in existence on the solid earth that now is. This is the difference between us in this matter. Our first volume is in the Silurian rocks, and this he calls his last; if he will produce only a few pages of an earlier volume, we shall be very glad to add them to our collection.

But what then, we may ask, is the use of geology, that science hitherto so much admired for the accuracy of its proofs and the certainty of its progress, if we do not accept the records that it offers as they are, but insist 
upon others as they ought to be? If we appeal from what we see and know to that which can neither be seen nor known? if we set aside the evidence of the senses and substitute that of the imagination? If this be permitted within the precincts of science, what can be the limit to idle and profitless speculations? who after this need despair of advancing any theory however childish or preposterous? Supposing that some learned man felt it incumbent on himself to prove that 'there were giants in those days,' in the days near the beginning of things, and that he were to write a learned and ingenious book on the subject (such as an ingenious man might write on any theme), investing his hypothesis with an air of plausibility till he came to the evidence of geology. Here a barrier stops his progress; how does he summount it? He tells us that if his Theory be true, it is indisputable, that in unknown ages long before the lowest Silurian formation, the earth swarmed with giants thirty feet high, and that their remains are to be found in those rocks which 'somewhere, were formed' in that most distant epoch; but that we are not to be astonished at the actual deficiency of the proof, for we do but possess the last volume of geological record, all the previous ones having been irretrievably lost.

In what does this differ from Mr Darwin's process of reasoning? Surcly in nothing but the Theory itself, which is far more difficult to be digested than the pre-Silurian giants.

There are occasions nevertheless when $M r$ Darwin can refer to the records of geology as affording most ample proof for any particular point he may have in hand. 'Geology,' says he, "plainly tells us that small genera have in the lapse 
of time often increased greatly in size, and that larger gencra have often come to their maxima, declined and disappeared ' (59).

Here a great deal is revealed to us in the few lines of the few pages of the only remaining volume; it is in fact a history of the past epochs of life, in a certain aspect; but it does not seem to have occurred to the learned author that if we learn so much as this from geology, if we are thus correctly instructed in the rise and fall of the large and small genera, it is inconceivable that we should not at the same time have been favoured with some evidence of the existence of those infinite gradations of species required by his Theory. If there were ten thousand or one thousand intermediate forms connecting the tapir and the horse, both of which we know first appear in the Tertiary formation, how comes it that we find none of these connecting links? Let not $\mathrm{Mr}$ Darwin betake himself to his pre-Silurian world, and to his 'rocks somewhere to be found,' for the tapir and the horse are harmoniously together in the Tertiary; they certainly did not exist previously, they were not in the cretaccous system, still less amongst the terrific reptiles of the Oolite, but they were where they are found to have been, in circumstances which suited their existence. 'There we find them amongst their congeners in the T'rtiary, but we do not find the many thousand links which the 'Theory requires to unite them; "what geological research has not revealed us,' says the author, 'is the former existence of infinitely mumerous gradations, as fine as existing varieties, connecting all known species; and this not being effected by geology is the most obvious of the many objections which may be urged against niny views' (324). 
Surely these two passages have a curious aspect when thus placed in juxta-position, the first affirming that geology tells us truly the history of small and large genera, the second that it has told us nothing of the infinitely numerous gradations connecting all known species. It would tax the ingenuity of the learned Author to reconcile these discordant propositions.

In the mean time let it be observed and not forgotten, that Mr Darwin here fully acknowledges that he has no geological evidence wherewith to prove his Theory.

Let us now examine the few lines of the remaining volume and see what it tells us. As it is beyond the Silurian era that Mr Darwin would take us, but as thither it is impossible to follow him, we will go as far as we can, down to the Silurian rocks, and there gather such evidence as can be collected.

The oldest Silurian strata, the first which contain any fossil remnants, rest on older rocks still, and of them Professor Owen thus speaks: "There is an enormous series of sub-aqueous sediment, originally composed of mud, sand, or pebble, the successive bottom of a former sea, derived from pre-existing rocks, which has not undergone any change from heat, and in which no trace of organic life has yet been detected. These non-fossiliferous, non-crystalline sedimentary beds form, in all countries where they have yet been examined, the base rocks, on which the Cambrian and the oldest Silurian strata rest-whether they be significative of ocean abysses never reached by the remains of coeval living beings, or whether they truly indicate the period antecedent to the beginning of life on this planet, are questions of the deepest significance, and demanding much further observation before they can be authoritatively answered' (Palo- 
ont. 116). The first evidence therefore that is offered to us is, as far as is known by observation in all parts of the world, an absence of organized beings in the basal rocks of the Silurian system. "No trace of organic life has as yet been detected,' - and it is owing to this circumstance that it has been proposed to name the base-formation, azoic, or destitute of life, in contra-distinction to the upper systems, which are all more or less fossiliferous.

The question therefore when we come to these lowest rocks is, not whether they swarm with fossils of extinct life or follow still older rocks, not discovered, swarming with fossils of plants and animals, according to the Theory, but whether we are justified in affirming that they truly indicate a period antecedent to the beginning of life in this planet. The evidence, as far as it is now known, would justify us in affirming that life had not begun during the formation of those rocks; and though it is strictly in keeping within the rules of investigation which science demands, not to affirm as much without more direct proof; yet how far apart is this from affirming on the other hand, without a tittle of evidence, and indeed with the whole evidence the other way, that before the lowest Silurian stratum was deposited, long periods elapsed, as long as, or possibly far longer than, the whole interval from the Silurian age to the present day; and that during that vast and unknown period of time, the world swarmed with living creatures.

The evidence therefore now to be obtained does not favour Mr Darwin; it bars out his Theory at the very beginning, inexorably excludes Natural Selection, which has no chance of ever passing these first non-fossiliferous rocks.

The sober language of true science affirms that it cannot 
be authoritatively answered whether the base-rocks of the Silurian system were antecedent to life in our planet.

Mr Darwin, on the contrary, authoritatively affirms that it is indubitable that life swarmed in eras immensely more ancient than the lowest Silurian strata.

Between two such statements reconciliation is impossible. After the basal rocks in ascending order we come to the lower Silurian, and there we find the protozoa, the fucoids, the first form of sponges, palæospongia, graptolites, supposed to be compound animals of the Zoophyte order, and some mollusca, Of these ancient forms, some of which 'scarcely deserve the name of animal,' the Trilobite is the most interesting, a crustacean of tripartite form, and interesting for its nicely jointed and curious shell, and its elaborate eye.

All the fossils of the Silurian* system are "eminently marine, and consist of species and genera of Zoophytes, radiata, mollusca, annilids, and crustacea. It is only towards the close of the Silurian era that any fishes appear, the first vertebratcd animats. They are found in the uppermost verge of the system, or in beds which are by some considered as the basis of the Old Red Sandstone.

* 'As yet we have no indication whatever of a terrestrial fauna in the Silurian system; and the accumulating evidence of recent research rather tends to dispel the hope of ever finding, in true Silurian strata, any of the higher manifestations of vertebrate existence.'-Advanced 'Text Book of Geology, p. 159.

'It is a remarkable fact that the most sedulous research in many parts of the world has failed to discover the trace of any vertebrate animal in the lower division of the Silurian system. All the marine animals from Zoophytes to crustaceans, and which probably amount to more than 1000 species, already known, belong to invertebrated classes, and no true fish has yet been discovered. The name Silurian marks, therefore, the first series of fossiliferous deposits, throughout the great mass of which no vertebrated animals have been anywhere discovered.'--Murchison. Siluria, $205-40$. 
'The earliest good evidence which has been obtained of a vertebrate animal in the earth's crust is a spine of the nature of the dorsal spine of the dog-fish, and a buckler like that of a placoganoid fish, in the most recent deposits of the Silurian period, in the formation called the upper Ludlow Rocks' (Owen, 119).

We have then the predominance of the sea proved to us by this evidence, and of a sea sustaining life, though that life was dissimilar to that which now prevails in the ocean; and below that we have the exhibition of a period in which no life has been discovered; and if geology teaches us any commencement it is here we must seek it. We cannot go beyond the evidence.

'The fossiliferous strata occupying the lowest place in the geological sequence, have been observed to pass, in almost every instance, by gradual and imperceptible changes into non-fossiliferous rocks, and for this reason, in addition to others, it has been thought probable either that the lowest strata were in reality the first beds deposited upon the earth, and that the animals whose remains are found in them were its first inhabitants, or at least that no fossiliferous rocks of an older date, if such exist, exhibit any important zoological changes, or contain species different from those with which we are already acquainted' (Ansted, 87.)

Now if the suspicion of some of our chicf geologists should be correct, that the dawn of life begins with the lowest Silurian formation, or even near it (in the nearness of geological time), it is obvious that the Theory is confuted, and that its confutation is complete; for in these rocks we find several animal forms of independent existence, of different genera and different species, and there- 
fore it is impossible that so early in the appearances of life all these separate phases should have been produced by Natural Selection; they must be, according to that system, the remnants and traditionary representatives of eras almost infinitely distant from that time-or else they must have come into existence by sone other method. But if all these preceding eras and preceding rocks be a dream, then those animals have come into existence not by Natural Selection, but by other means.

This of course Mr Darwin has foreseen and provided for. 'I camnot doubt that all the Silurian Trilobites have descended from some one crustacean, which must have lived long before the Silurian age, and which probably differed from any known aninal' (332). Less than this could not be propounded in so critical a position of the 'Theory, for if the author had 'doubted' in this emergency, there wonld have been an end of the question. Here, however, we are again referred for proof to the invisible world, which no traveller can reach. 'There must have been, we are told, an ancestral crustacean long before the Silurian age, differing from all known animals, and from this the 'T'ilobite must have descended! But what slaall we say about this indescribable monster-unlike all known animals on land, or in sea, or in the regions of the air? It must indeed have been most wonderful, a chimera beyond the imagination of the poets, and of the same genus perliaps as the animal described by the showman, as having come 'from the undiscovered islands.' But, seriously, is not this abasing rather than elevating science to comnect it with such speculations, which do not amount to the dignity of a conjecture, but must be ranked with those 
fictions which have all the wildness without any of the inspîtration of poetry.

'But,' says the Author, 'some of the most ancicnt, Silurian animals, as the Nautilus, Lingula, \&c., do not differ much from the living species, and it cannot, on my theory, be supposed that these old species were the progenitors of all the species and the order to which they belong, for they do not present characters in any degree intermediate between them. If, moreover, they had been the progenitors of these orders, they would almost entirely have been long ago supplanted and exterminated by their numerous and improved descendants' (id.). 'This, it will be observed, is a sort of private conversation of the author with himself, for what have we to do with the perplexities and exigencies of his 'Theory? Certainly according to that Theory, here is a sad trouble and discouragement, and the author tells us what it is. But it is only with the escape out of the difficulty that we are concerned, the breaks in the genealogy and the non-extermination of the improved families are his affair, not ours-on these deficiencies we only look on and smile, but again we beg leave to assure him that his appeal to a pre-Silurian world is no escape at all, and that he must on the battle-field of the lowest rocks yet discovered, either beat us or be beaten himself.

We have been told that the series of rocks which were antecedent to the Silurian, and took a longer time for their formation than all the rocks that have been subsequently deposited up to the present day, were 'somiwhere accumulated.' Somewhere! did ever one word yet do service for so much as this 'somewhere?' It contains an unknown world, and ages incalculable. It expresses the ex- 
istence of 'swarms of animals,' of forms with which we are unacquainted, and it assures us of the evidence of their existence in fossiliferous rocks many miles thick, if only we could find them. But what will Mr Darwin place below the basis of the Silurian rocks? after the clay-slate system, the mica-schist system, and the gneiss system, what other formation shall we name? where between these and the granite will be room for his 'somewhere?' If the granite be not the general floor on which all the oldest formations rest, it is somehow or other very inconveniently near them, and by its position and appearance in all parts of the world has frequently suggested the suspicion that it is the ubiquitous substratum. 'Thus speaks Humboldt on this subject.

'What we call the older Silurian strata are only the upper portions of the solid crust of the earth. The eruptive rocks which we see breaking through, pushing aside, and heaving up these, arise from depths that are ininaccessible to us; they exist, consequently, under the Silurian strata, composed of the same association of minerals which are familiar to us under the name of granite, augite, and quartz porphyry, at the points where, by breaking through, they become visible. Resting on analogies, we may safely assume that that which at one and the same time fills exclusive fissures in the name of veins, and bursts through the sedimentary strata, can only be an offset from an inferior bed. The active volcanoes of the present day carry on their processes at the greatest depths; and from the strange fragments which I have found included in streams of lava, in different quarters of the globe, I also hold it as more than probable that a primordial 
granite-rock is the foundation of the great systems of stratification which are filled with such varicty of organic remains' (Cosmos, i. 305).

How great would have been the surprise of Humboldt to hear of this other additional crust of the earth which had been 'accumulated somewhere,' between the earliest non-fossiliferous rocks and the granite.

But the Theory has other difficulties to surmount in confronting geology, and these the author has himself stated: "The abrupt manner in which whole 'groups of species suddenly appear in certain formations has been urged by several palæontologists, Agassiz, Pictet, Sedgwick, \&c., as a fatal objection to the belief in the transmutation of species. If numerous species, belonging to the same genera or families, have really started into life at once, the fact would be fatal to the Theory of descent with slow modification through Natural Selection. But we continually overrate the perfection of the geological record, and falsely infer, because certain genera or families have not been found beneath a certain stage, that they did not exist before that stage. In all cases positive palæontological evidence may be implicitly trusted, negative evidence is worthless, as experience has so often shown' (327).

Now this passage, as it clearly states the antagonism of geological science to Mr Darwin's system, is of the highest importance, for it amounts to this, that if that system is true, geology, as now established, is false, and that the deductions of palæontologists must be cancelled. If we overrate the evidence of geology, then the estimate of its value as a teacher is erroneous, and we must, according to this proposition, consider that the information obtained by 
it is not trustworthy. 'The science, in other' words, has to be re-cast and re-moulded, and it will not be a true science till it is made to agree with the Theory.

But if, as we are assured, negative evidence in palæontology is worthless, what a violence must be done to common sense to make of it a positive one. The geologists tell us that certain animals cannot be found in any geological formation before certain periods, and therefore there is no evidence that they existed before those periods, tantamount to a high probability that they did not previously exist. Mr Darwin tells us that certain animals cannot be found before certain periods, but it is, nevertheless, certain that they did previously exist. With him negative evidence is the main stay of his Theory; and strange it is that he who confronts us with a visionary preSilurian world, for which there is only negative evidence, and on which he bases his whole system, should turn round on us and tell us that negative evidence in palæontology is worthless.

If our negative evidence is worthless, his is not less so; but if his negative evidence is worthless, as it is all that he has to show, his Theory is confuted.

But if negative evidence is inadmissible in palæontology, if it be 'worthless,' how could it ever have made one step towards any definite deduction? By it we are instructed when certain organic beings existed, and when they did not exist; but if we do not choose to believe the negative evidence, all is at a stand-still. How do we know that the mammalia in the Gypsum of the Paris Basin did not exist in the era of the Old Red Sandstone? by negative evidence. How do we know that the ruminantia and carnivora did not exist in the carboniferous period? by negative evi- 
dence. Who, of the most daring speculators, would venture to affirm that man existed in the Eocene era? For anything we can show to the contrary, man might have been an inhabitant of the earth at that period, but we are all satisfied that he was not, and we are convinced by negative evidence alone. Let, then, Mr Darwin say what he likes, when animals cannot anywhere be discovered before a certain point in the geological series, it will be believed that their non-appearance is owing to their non-existence; and it will also be believed that when we first find them in a certain geological formation, that then, they first began to exist. This is the opinion of a crowd of * able geologists, and it is the deduction of common sense.

But $\mathrm{Mr}$ Darwin instinctively feels that geology is his worst enemy, and therefore, like an able tactician, he endeavours to damage its value and undermine its authority. 'If we admit,' says he, 'that the geological record is imperfect in an extreme degree, then such facts as the record gives, support the 'Theory of descent with modification' (508).

This in plain English means thus much: 'if you can bring yourself to disbelieve the testimony of geology, then

* Take as an instance of the use made of negative evidence in geology, the following remarks of Lyell on the secondary formations :-

'It is certainly a startling proposition to suppose that a continent covered with vegetation, which had its forests of palm-trees and tree-ferns, which was inlabited by large Saurians and by birds, was, nevertheless, entirely devoid of land quadrupeds. If the proofs were confined to the Wealden, we might hesitate to lay mucl stress on mere negative evidence, since extensive deposits of the Eocene period, such as the London clay, have as yet yielded no mammiferous fossils, and the coal-slate of Great Britain, after having been studied for so many years, are now only beginning to produce the bones of Saurians; but when we find the same general absence of Mammalia in strata of the Oolitic and Liassic eras, we can hardly refuse to adinit, that the highest order of quadrupeds was very feebly represented in those ages, when the small didelphis of Stoncsfield was chtombed' (iv. 235). 
you may believe that animals have come to their present forms by transmutation from previous ones.' When a record is imperfect in ' an extreme degree,' who could trust it? This is the point to which Mr Darwin would bring us.

And then again, 'the noble science of geology loses glory from the extreme imperfection of the record. The crust of the earth, with its embedded remains, must not be looked at as a well-filled museum, but as a poor collection made at hazard and at rare intervals' (522).

But we must now more closely examine these statements. "We falsely infer because certain genera or families have not been found beneath a certain stage, that they did not cxist before that stage;' which also reads that if we were to state the truth, we should say that those genera did exist before that stage. This goes a step further, we have had the benefit of negative evidence denied us, now it is turned against us to prove the exact opposite of that which had hitherto been deduced from it.

If, however, there be anything clear in geology it is this, that there has been a succession of organic beings, not descending genealogically one from another, but appearing successively in order of time; and that there are definite epochs where they can be first traced as existing, and also where they disappear. Now we have the ruminants in the miocene division of the tertiary formation, and the felidx first appearing in the more ancient division of the tertiary, but the most careful search has never succeeded in discovering the slightest trace of them in the chalk formation. Did they exist in the chalk era? certainly, according to Mr Darwin, because it would be impossible that Natural Selection could have had time to produce them in the 'lertiary epoch, and the antecedent links from 
some progenitor are wanting, therefore we must seek for them in periods infinitely more remote; but by no means must we suppose that they came into being in the era when they first appear.

In this way there must always be disagreement between the records of geology and the exigencies of the Theory. The Theory will constantly be demanding that which geology denies, and denying that which geology affirms. It is impossible that they ever should be reconciled.

The testimony however of physiologists on the succession of organic beings is very clear. Buffon says: 'Qu'il y a eu des espèces, maintenant anéanties, dont l'existence a précédé celle de tous les êtres actuellement vivants ou végétans-qu'on peut determiner des époques dans la succession des existences qui nous ont précédés-que les empreintes de poissons, de crustacés, et de végétaux (qu’on ne trouve qu'à de grandes profondeurs) semblent nous indiquer que leur existence a précédé, même de fort loin, celle des animaux terrestres.'

Cuvier observes: 'Ce qui est certain, c'est que nous sommes maintenant au moins au milieu d'une quatrième succession d'animaux terrestres, et qu'après l'âge des reptiles, après celui des palæothériums, après celui des mammouths, des mastodontes, et des mégathériums, est venu l'âge où l'espèce humaine, aidée des quelques animaux domestiques, domine et féconde paisiblement la terre.'

M. Flourens * has well expressed this: "That which is the essential object, the important point, is, in effect, the relation of strata and species, and that which that relation demonstrates to us is that the reptiles have appeared before the mammifers, since the reptiles are found in strata where

$$
\text { * Ontologie (303). }
$$


the mammifers are never found-that the marine mammifers have appeared before the terrestrial, because the marine mammifers are found in strata, where the terrestrial mammifers are never found, and that is not all, this relation between strata and species proves to us, that even with the terrestrial mammifers there has been a succession of species, and a very remarkable succession.'

This latter remark may be best explained in the words of Cuvier': 'First of all, all the genera now unknown, the palreotheriums, the anoplotheriums, \&c., belong to the most ancient soils of which we are speaking, to those which rest on the Calcaire* grossiel-in the second place, the most celebrated of the unknown species, which are connected with known genera, or to genera very nearly allied to those which are known, as the elephants, the rhinoceros, the hippopotamus, the fossil mastodons, are not found together with the most ancient genera-it is only in the soils of transport that they are found. In fine, the bones of species which seem to be the same as ours, are not met with except in the last deposits of the alluvium.'

We have here established by the testimony of geology distinct deposits and distinct genera belonging to them, they are not found previously, and in most instances they are not found afterwards in the succeeding deposits.

Let us hear the testimony of another celebrated + geologist. 'Every plant and animal that now lives upon earth began to be during the great Tertiary period, and had no place among the plants and animals of the great secondary

* Calcaire grossier is a formation of the Paris basin, take the chalk system (secondary) as the base, then we have resting on it the plastic clay, next in ascending scale the Calcaire grossier, and then the Gypsum of Montmartre-after which upper marine, \&c.

$\uparrow$ Hugh Miller, 'Testimony of the Rocks (195). 
division. We can trace several of our existing quadrupeds, sucl as the badger, the hare, the fox, the reindeer, and the wild cat up to the earlier times of the Pleistocene, and not a few of our existing shells, such as the great pecten, the edible oyster, \&c., up to the greatly earlier times of the coralline crag. But at certain definite lines in the deposits of the past, representative of certain points in the course of time, the existing mammals and molluscs cease to appear, and we find their places occupied by other mammals and molluscs; even such of our British shells as seem to have enjoyed as species the longest term of life cannot be traced beyond the times of the Pleiocene deposits. . . . . . We thus know that in certain periods, nearer or more remote, all our existing mollusca began to exist, and that they had no existence during the previous periods, which were, however, richer in animals of the same great molluscan group than the present time-a great number of still older shells have been detected in a single deposit of the Paris Basin, the Calcaire grossier, and a good many more in a more ancient formation still, the London clay. On entering the chalk, we find a yet older group of shells, wholly unlike any of the preceding ones, and in the Oolite and Lias yet other and different groups,' \&c.

Thus testimonies to the same effect might be multiplied from almost every respectable book on geology. All writers agree on the subject that certain genera or species have made their appcarance for the first time in certain deposits ; and as this is fatal to the Theory, we need not be surprised to hear Mr Darwin stoutly declaring that this evidence is false; this is his own word, "why do whole groups of allied species appear, though certainly they often falsely appear, to come in suddenly on the several geological 
stages? (497). So their sudden appearance is acknowledged, only we are to understand that they had also existed in antecedent formations, though they cannot be found. Before, however, we hear the explanation offered to us of these sudden appearances, we must yet more closely press the evidence before us.

We clearly understand then that the last great formation of the Tertiary, with its classification of ages in chronological succession, introduces us to the fauna and flora that now exist; for though there is a manifest difference, if we compare the organic beings of the lower divisions with those of the Pleistocene, and of the present era, called sometimes the post-Tertiary, yet there is still a similitude and a connection, and everything seems in this formation, taken as a whole, to be preparing for the present state of things, and the.introduction of the actual inhabitants of the earth. 'When we reflect,' says Lyell, 'on the tranquil state of the earth, implied by some of the lacustine and marine deposits of this age, and consider the fulness of all the different classes of the animal kingdom, as deduced from the study of the fossil remains, we are naturally led to conclude, that the earth at that period was in a perfectly settled state, and already fitted for the habitation of man' (iv. 129).

The Tertiary formation is separated from the preceding chalk formation with such marked difference, the character of the two eras is so wide apart, the biological chasm is so vast between them, that palæontologists speak of them as if they were distinct worlds. The 'Tertiary is, as it were, severed and walled off from the next formation beneath it, and by this strong separation the argument too is hemmed in and confined to a comparatively small compass. 
M. Deshayes first pointed out that which Lyell fully confirms: that 'no species of fossil shell has yet been found common to the Secondary and Tertiary formations. 'This marked discordance in the organic remains of the two series is not confined to the testacea, but extends; as far as careful comparison has yet been instituted, to all other departments of the animal kingdom, and to the plants. I am informed by M. Agassiz that after examining about 500 species of that class, in formations of all ages, he could discover no one common to the Secondary and Tertiary rocks-nay, all the Secondary species hitherto known to him, belong to the genera distinct from those established for the classification of the Tertiary and recent fishes. There appears to be a greater chasm between the remains of the Eocene and Maestrecht beds (Secondary) than between the Eocene and recent strata; for there are some living shells in the Eocene formations, whilst there are no Eocene fossils in the newest Secondary group' (iv. 2li $)$ ).

Similar are the statements of Professor Ansted.

'At the close of the Secondary period (that is, the commencement of the T'ertiary) all these older forms appear to have becn completely destroyed, the newer forms becoming much more abundant and widely distributed, and not one species remaining identical with anything that exists in the Secondary rocks' (ii. 71).

By all this then we see that the Eocene formation of the Tertiary begins the grand drama of the existing state of things. The curtain of creation rises, and Nature is seen earnestly occupied in her grand laboratory, introducing in well-considered pauses the animated scale which is to terminate in man. We find in the Eocene, carnivorous land-animals unknown before, and by their pre- 
sence alone assuring us of the existence of other animals destined to be their prey. In the Meiocene ${ }^{*}$ there lias been discovered a peculiarly destructive feline quadruped, with the upper canines much elongated, trenchant, sharppointed-sabre-edged, whence the name Machirodus has been proposed for this feline sub-genus. It was represented by species as large as a lion, and by others of the size of a leopard. Then later on there was a large Pleistocene lion, found in England and Belgium; and the gigantic bear, wolves, foxes, wolverines, marten cats, hyæenas, \&c. The herbivorous class prospered, the redundancy of their increase required repression, and hence this large provision of their enemies.

I'hen we come to the celebrated animals of the Paris Basin, the palæotherium, amplotherium, dinotherium, \&c., and the fossils of the Tertiary of Northern India, a prodigious display of a by-gone age: new and singular forms of the Carnivora, Felidx, and Canidæ; colossal bears, and genus allied to the otter, but large as panthers; two species of mastodons, two new species of elephants, new species of rhinoceros, $\uparrow$ hippopotamus, new species of

* Owen, p. 418.

t 'Of the fossil speeies, that which was the earliest known, and which is the most frequently met with in the niddle and northern parts of Europe, as well as in Asia, is distinguished from the living species by a very remarkable eircumstance. What partieularly attraets our attention in the rhinoeeros is the situation of the bulky horn which it carries; and when we examine its skeleton to examine what basc has been furnished by nature, to sustain so weighty an organ, we perceive with surprise that it is placed upon the extremity of the bones of the nose, which form a very thick arch it is true, but without any suppoit from the rest of the skull. The specics which seems to have been the most common in the ancient world, would appcar to have been, in this respect, much more advantageously organized than the existing species. It was, in fact, provided with a kind of bony partition in the nostrils, which, scrving as a prop to the arch that supported the horn, gave greater solidity to it. Add to this favourable circumstance that the arch formed by the bones of the nose is, in the fossil species, 
the horse, of the camclopard, and then, in all countries, the Elephas primigenius, in prodigious herds: Nature in that era rejoicing in her gigantic productions, and in creatures of colossal frame.

Such at a glance was the scene of those days; the giant quadrupeds have for the most part disappeared, but the branches of their families, in smaller or altered form, are recognized amongst living creatures. But now the question comes, whence spring those huge pachydermata? we find the great creatures in the 'Tertiary, 'there were giants in those days,' but we do not find any trace of them in the antecedent formations. We have already seen that there is a broad gulf between the Tertiary and Secondary, that life was altogether different, if we compare the two eras; but here in the Tertiary a prodigious aggregate of unusually large animals crowds upon us, they march into the scene in solemn grandeur from some unknown birth-place, and who shall tell us of their birth and the secret of their first appearance?

What is Natural Selection to do here? She has not time enough to produce a tooth of one of these creatures, and as for a proboscis she would require some myriads of

less elevated, and more depressed towards the lower jaw. The immense majority of fossil bones belong to this species, which, until within these few years, was the only one known.'-Bertrand's Revolution of the Globe, page 155 .

In this statement we see that the ancient rhinoceros was mueh more advantageously organized than the existing species; that a 'favourable eireumstanee' appeared in its organization, the very phrases used by $\mathrm{Mr}$ Darwin, passim. Now, aceording to his Theory, Natural Seleetion ought to have made these advantageous and favourable organizations a means of advaneing the favoured species above all its eompetitors. All other unimproved ereatures of its kindred ought to have been "infallibly exterminated ;' but it so turns out that the rhinoceros with the advantageous organization has perished, and the rhinoeeros with the inferior organization is triumphant. 
ages beyond the Tertiary. Where are the progenitors of the Mastodon, of the Palæotherium, of the Sevatherium? where is the head of the elephant's family? the first sketch of the elephantoid genus, where? Now we can find in the Secondary rocks, in the chalk, numbers of shells, some of them exceedingly minute and of most delicate texture, yet with all their parts complete! but an elephant or a mammoth is larger than a shell, and if their progenitor existed, with infinite number of intermediate forms, there must be enormous remnants of their fossil appearances somewhere; certainly some of them ought to be in the Secondary formation, if the Theory is of any value, but not a fragment is to be found.

It is in this corner of creation, moreover, that all those animals are seen for the first time which Mr Darwin is so fond of connecting together by family descent, the tapir, the horse, elephant, giraffe, pig, \&c. 'The same number' of vertebræ forming the neck of the giraffe and the elephant, at once explains itself or the theory of descent with slow and successive modifications' (513). Well, we have the elephant and we have a species of the camelopardus in the Tertiary, and we have the horse and pig, and very true it is that they all have seven vertebræ in their necks (as also man has, and the dogs and cats as well as the rats and mice); but where are the scattered members of this strange family to be found; the intermediate animals, in 'ten thousand generations,' connecting them in successive links?

And here too in this page of the earth's history we are too far off to appeal to the pre-Silurian world, for between the Tertiary and the Silurian are all the other formations of the earth's crust; so that in the search for all these lost 
links Mr Darwin has to run the gauntlet of all the rocks from the Cretacean down to the Cambrian, thence to the basal rocks of the Silurian, and thence to "Chaos and old Night.'

So then in all this immense series, in all these 'millions of ages' required for forming the rocks, between the Tertiary and the Silurian, there is not a particle of evidence to be adduced for the help of Natural Sclection. Why then appeal to a pre-Silurian imaginary formation? here is space enough to find what is wanted, how comes it that nothing which is wanted can be found?

$\mathrm{Mr}$ Darwin has told us that 'species very rarely endured for more than a geological period' (171), an admission which, though true, is startling from this quarter, as it is a clear acknowledgment of the negative evidence in palæontology, which $\mathrm{Mr}$ Darwin has declared to be worthless. It is obvious that this his rule can only stand on negative evidence; a species that has existed in one formation, is not found in the next. Therefore, argues Mr Darwin, it has ceased to exist, convinced of the fact simply because he cannot find the species. In this case the negative evidence in palæontology satisfics $\mathrm{Mr}$ Darwin, as it does us also.

But now we ask why, if the negative evidence is admitted as a proof in one instance, is it rejected in another? We say that the clephant, \&c., did not cxist, or that its antecedent link did not exist, in the Secondary, because there is no trace of them to be found in that formation; and this we urge against the existence of an animal which has only a theoretical standing, and whose real cxistence is the thing to be proved. Negative evidence against a creature that cannot be produced, is inevitable. 
Produce us your cretacean mastodon, or your giraffe, in the Old Red Sandstone, and we will believe that they then existed, but this you cannot do, and therefore we do not believe your theory.

In the mean time it will be observed that negative evidence is admitted in the theory when wanted, and repudiated when it is found to be inconvenient.

The conclusion then is this:-

All the great creatures, of which we have been speaking, first make their appearance in the first Tertiary formation.

They do not appear in the antecedent or Secondary formation, nor in any other geological epoch, though the other strata contain abundant fossils of the organic beings which existed during their formation, and which are considered peculiar to them.

The animals that existed in the Secondary formation are not found in the 'lertiary, from whence it is concluded that they did not exist in the Tertiary.

The animals that existed in the Tertiary formation are not found in the Secondary, from whence it is also conchuded that they did not exist in the Secondary.

* Sir C. Lyell observes: 'It seems impossible to account for our not having yet found any bones of fish in the Silurian rocks, except by supposing that they were not yet in being, or that they occupied only a limited area.'-Principles of Geology, 10th edition, p. 145, 1866.

Here the negative evidence is admitted às full proof of an important fact in palaontology-we apply this principle in arguing on the Tertiary formation. Nevertheless, in his Antiquity of Man, Sir C. Lyell protests against the negative evidence, just as Mr Darwin docs; and thus does he make the Silurian rocks echo to his master's voice. 'It would be a waste of time to speculate on the number of original monads or germs from which all plants and animals were subsequently evolved; moreover as the oldest fossiliferous strata known to us (the Silurian), may be the last of a long series of antecedent formations, which once contained organic beings' (p. 470). 
The Tertiary formation then is the era of the first appearance of the animals in question; they began to exist in that epoch, and not sooner.

This is sufficient; all the rest must follow as an inevitable corollary.

The evidence of geology entirely confutes Mr Darwin's Theory of the Transmutation of Species. 


\section{CHAPTER XII.}

LYELL'S CONEUTATION OF TRANSMUTATION.

Tre reader will already have perceived that Sir Charles Lyell entered the lists as an opponent of Transmutation many years ago. This appears in all the earlier editions of the Principles of Geology; ours is the third, of the year 1834. It is from this erlition that extracts will be given of his confutation of Lamarck, and it will soon be perceived that every point in that confutation is direct against Mr Darwin, and we may add against Sir C. Lyell himself also. Subsequent to the publication of Mr Darwin's Origin of Species, Sir C. Lyell went over to the opinions which he had so ably confuted; and in his publication on 'The Antiquity of Man' has advocated the dogma of 'l'ransmutation, even in its most extravagant form. That volume was published in the year 1861 .

In the third edition of the Principles of Geology, the learned anthor has no scruple in expressing himself as a believer in a Creator, he speaks of the Divine Author of all things, and considers the phenomena of Nature as his work. Thirty years ago this was not unusual in the language of scientific writers, but now the fashion is changed, and in the School of 'Transmutation it would be inappropriate and misplaced. Mr Darwin has candidly told us that 'Natural 
Selection, if it be a true principle, will banish the belief of the continued creation of new organic beings, or of any great and sudden modification of their structure' (101). 'Transmutation is in fact the antitheos of their system; they that believe in Natural Selection, logically cease to believe in a Creator.

In the third edition, already referred to, Sir C. Lyell says: "We must suppose that when the author of Nature creates* an animal or plant, all the possible circumstances in which its descendants are destined to live are foreseen, and that an organization is conferred upon it which will enable the species to perpetuate itself, and survive under all the varying circumstances to which it must be inevitably exposed' (ii. 35l). Sentiments such as these were in harmony with the opinions which the learned writer entertained at that time,-we proceed now to lay some of those opinions before the reader.

Lamarck's statements are first given: 'Every considerable alteration in the local circumstances in which each race of animals exists, causes a change in their wants, and these new wants excite them to new actions and habits. 'These actions require the more frequent employment of some parts before but slightly exercised, and then greater development follows as a consequence of their more frequent use. Other organs no longer in use are impoverished and diminished in size, nay, are sometimes annihilated, while in their place new parts are insensibly produced for the discharge of new functions.' This is Lamarck's doctrine, and on this Lyell thus comments: 'I must observe

* In other passages similar language is used, as for instance: 'Trom the above considerations, it appears that species have a real existence in nature, and that each was endower, at the time of its creation, with the attributes and organization by which it is now distinguished ' (ii. 403). 
that no positive fact is cited to exemplify the substitution of some entirely new sense, faculty, or organ, in the room of some other suppressed as useless. All the instances adduced go only to prove that the dimensions and strength of members, and the perfection of certain attributes, may, in a long succession of generations, be lessened and enfeebled by disuse, or on the contrary be matured and augmented by active exertion; just as we know that the power of the scent is feeble in the greyhound, while its swiftness of pace and its acuteness of sight are remarkable; that the harrier and staghound, on the contrary, are comparatively slow in their movements, but excel in the sense of smelling. . . . It is evident that, if some well-authenticated facts could have been adduced to cstablish one complete step in the process of transformation, such as the appearance, in individuals descending from a common stock, of a sense or organ entirely new, and a complete disappearance of some other enjoyed by their progenitors, time alone might then be supposed sufficient to bring about any amount of metamorphosis.

'The gratuitous assumption, therefore, of a point so vital in the Theory of Transmutation, was unpardonable on the part of its advocate' (ii. 332).

Lamarck's picture of the supposed change of animals on the principle of appetence is then introduced: 'The camelopard was not at first gifted with a long and flexible neck, but when reduced by want, made great efforts to reach the leaves of the tree, and so by degrees its neck became lengthened,' \&c. On this his critic remarks: 'But if the soundness of all these arguments and inferences be admitted, we are next to inquire, what were the original types of form, organization, and instinct, from which the 
diversities of character, as now exhibited by animals and plants, have been derived? We know that individuals which are mere varieties of the same species would, if their pedigree could be traced back far enough, terminate in a single stock; so, according to the train of reasoning before clescribed, the species of a genus, and even the genera of the great family, must have had a common point of departure. What, then, was the single stem from which so many varieties of form have ramified? were there many of these, or are we to refer the origin of the whole animate creation, as the Egyptian priests did that of the universe, to a single egg' (335).

Here the learned writer, in a style most unusual to him, indulges in a little irony against the disciples of Transmutation, and, by anticipation, hits Mr Darwin very hard, who, as we have seen, deduces all animal life from one primordial form-the spore of one of the lowest algæ. It is instructive to note these prophetic thrusts.

We are then reminded that in the Theory of the ancient philosophers it had been assumed, that created things were always more perfect when they came from the hands of their maker, and that there was a tendency to progressive deterioration in all sublunary things, "but when the possibility of the indefinite modification of individuals descending from common parents was once assumed, as also the geological inference respecting the progressive development of organic life, it was natural that the ancient dogma should be rejected, or rather reversed; and that the most simple and imperfect forms and faculties should be conceived to have been the originals whence all others were developed. Accordingly, in conformity to these views, inert matter was supposed to have been first endowed 
with life; until, in the course of ages, sensation was superadded to mere vitality; sight, hearing, and the other senses were afterwards acquired; then instinct and the mental faculties; until, finally, by virtue of the tendency of things to progressive improvement, the irrational was developed into the rational.

'The reader, however, will immediately perceive, that when all the higher orders of plants and animals were thus supposed to be comparatively modern, and to have been derived in a long series of generations from those of more modern conformation, some further hypothesis became indispcnsable, in order to explain why, after an indefinite lapse of ages, there were still so many beings of the simplest structure. Why have the majority of existing creatures remained stationary through this long succession of epochs, while others have made such prodigious advances? why are there such multitudes of infusoria and polyps, or of confervæ and other cryptogamic plants? Why, moreover, has the process of development acted with such unequal and irregular force on those classes of beings which have been greatly perfected, so that there are wide chasms in the serics; gaps so enormous, that Lamarck fairly admits we can never expect to fill them up by further discoveries?' (\$37).

The Transmutationists avail theinselves of the striking difference of character in the races of dogs to show the way in which a new species may begin. Mr Darwin has said much on this subject. Sir C. Lyell remarks on it: 'But if we look for some of those essential changes which would be required to lend even the semblance of a foundation for the theory of Lamarck, respecting the growth of new organs and the gradual obliteration of others, we find 
nothing of the kind: for in these varieties of the dog, says Cuvier, the relation of the bones with each other remain essentially the same; the form of the teeth never changes in any perceptible degree, except that in some individuals one additional false grinder occasionally appears, sometimes on one side, and sometimes on the other' (356).

'Lamarck has thrown out a conjecture that the wolf may be the original of the dog, but he has adduced no data to bear out such an hypothesis. Dogs have become wild in Cuba, Hayti, and in all the Caribbean islands. In the course of the seventeenth century, they hunted in packs from twelve to fifty or more in number, and fearlessly attacked herds of wild boars and other animals. It is natural, therefore, to inquire to what form they reverted? Now they are said by many travellers to have resembled very nearly the shepherd's dog, but it is certain they were never turned into wolves' (357).

We have seen that the marvcls of instinct are no barrier to Mr Darwin's theory of Natural Selection, as little as they were to Lamarck's system. These physiologists agree. that all species have proceeded from varicties, forming themselves into species, and on the same principle preparing again for the formation of other species. 'We might ask,' says the critic of Lamarck, 'if a few generic types alone have been created among insects, and the intermediate species have proceeded from hybridity, where are those original types, combining, as they ought to do, the elements of all the instincts which have made their appeaiance in the numerous derivative races? So, also, in regard to animals of all classes, and of plants, if species in general are of hybrid origin, where are the stocks which combine in themselves 'the habits, properties, and organs, of which 
all the intervening species ought to afford us mere modifications' (395).

We now come to a subject requiring some attention, as it is one in which Sir Charles Lyell has exhibited pre-eminently the versatility of his opinions. In his strictures on Lamarck, he enters on the subject of embryology: 'There is yet,' says he, 'another department of anatomical discovery to which I must allude, because it has appeared to some persons to afford a distant analogy, at least, to that progressive development by which some of the inferior species may have been gradually perfected into those of more complex organization.

'Tiedemann found-and his discoveries have been most fully confirmed by M. Serres - that the brain of the foetus, in the highest class of vertebrated animals, assumes, in succession, forms analogous to those which belong to fishes, reptiles, and birds, before it acquires the additions and modifications which are peculiar to the mammiferous tribe. So that, in the passage from the embryo to the perfect mammifer, there is a typical representation, as it were, of all those transformations which the primitive species are supposed to have undergone, during a long series of generations, between the present period and the remotest geological era.' After some further discussion of this theory, the ingenious critic concludes: 'It will be observed, that these curious phenomena disclose, in a highly interesting manner, the unity of plan that runs through the organization of the whole series of vertebrated animals; but they lend no sup. port whatever to the notion of a gradual transmutation of one specics to another; least of all of the passage, in the course of many generations, from an animal of a more simple to one of a more complex structure' $(402)$. 
This theory thus confuted by Sir Charles Lyell is warmly adopted by Darwin: he considers it a most important auxiliary to his general argument. "In two groups of animals,' he says, 'however much they may at present differ from each other in structure and habits, if they pass through the same or similar embryonic stages, we may feel assured that they have both descended from the same or similar paients, and are therefore in that degree nearly related. Thus community in embryonic structure reveals community of descent, however much the structure of the adult may have been modified' (Origin of Species).

Here then we see Darwin, in express terms, contradicted by Lyell - ' this theory,' he says, 'lends no support whatever to the notion of gradual transmutation from one species to another'-but in his volume, of which the title is 'The Geological Evidences of the Antiquity of Man,' he has turned round to the opposite point of the compass, and argues strongly for that which , he had vehemently repudiated. In this last publication he says, "if there had been a system of progressive development, the successive changes through which the embryo of the species of a high class, a mammifer, for example, now passes may be expected to present us with a picture of the stages through which, in the course of ages, that class of animals has successively passed in advancing from a lower to a higher grade.

'Hence the embryonic states exhibited one after the other by the human individual, bear' a certain amount of resemblance to those of the fish, reptile, and bird before assuming those of the highest division of the vertebrata' (Antiquity of Man, 416).

The result then is this, that our parentage is first from a fish, next through a reptile, and last from a bird! In 
this genealogy Sir Charles Lyell and Mr Darwin are now perfectly agreed. It is proved by the human embryo, there is 'a certain degree of resemblance' to the embryo of the fish, reptile, and bird, and a certain degree of resemblance is a clear proof of family identity. We are, as Mr Darwin says, 'nearly related.' It is to be regretted that these learned physiologists have not been more accurate in describing our near relations, for 'a fish' is a wide term-we have all the depths of the ocean to search for our progenitor-from a shark to a herring, from a tunny to a mackerel. We may therefore suppose that a tunny was the progenitor of a crocodile, a crocodile of an ostrich, an ostrich of an ape, and an ape of a man. By this branch of the science of Transmutation, we learn at least one point with some degree of certainty, that a bird hatched a mammifer-perhaps a gorilla; the next "step of 'improvement' to the 'human face divine' would be comparatively easy.

But we must return to our author. After describing the difficulty which attends the formation of an accurate definition of Species, Sir C. Lyell traces the next step to the dream of 'Transmutation,-he is speaking here in his Principles of Geology, not in his Antiquity of Man: 'These views seem to confirm all his doubts as to the stability of the specific character, and he begins to think there may exist an inseparable connection between a series of changes in the inanimate world, and the capability of species to be indefinitely modified by the influence of extinct circumstances. Heneeforth his speeulations linow no definite bounds, he gives the rein to conjecture, and fancies that the outward form, internal structure, instinctive faculties, nay, that reason itself may have been gradually 
developed, from some of the simplest states of existencethat all animals, that man himself, and the irrational beings, may have had one common origin; that all may be parts of one continuous and progressive scheme of development, from the most imperfect to the most complex; in fine, he renounces his belief in the high genealogy of his Species, and looks forward, as if in compensation, to the future perfectibility of man in his physical, intellectual, and moral attributes' (ii. 347).

This able and eloquent description of the mental hallucination exhibited in a belief of the doctrine of Transmutation, should not be forgotten. It is traced, and most justly, to an unrestrained imagination indulging in wild conjecture. Reasoning from facts is discarded, assumption becomes the basis of argument, and the deficiencies of proof are compensated by the ingenuities of special pleading. In the above passage Sir Charles Lyell has not only, in writing against Lamarck, given a correct analysis of Mr Darwin's Origin of Species, but has touched a striking part of that system, the future perfectibility of man. This we have seen in the preceding pages. We spring from fishes, birds, and apes, but we shall, in the course of geological time, advance to a high grade of improvement through the instrumentality of Natural Selection.

But we now come to the culminating point in 'Transmutation, the formation of man out of the quadrumanous animal. This a few years since appeared to Sir C. Lyell the climax of absurdity, as he expresses it in his calm and dignified language.

'Such is the machinery of the Lamarckian system; but the reader will hardly, perhaps, be able to form a perfect conception of so complicated a piece of mechanism, unless it 
is exhibited in motion, so that we may see in what manner it can work out, under the author's guidance, all the extraordinary effects which we behold in the present state of the animate creation. I have only space for exhibiting a small part of the eatire process by which a complete metamorphosis is achieved, and shall therefore omit the mode whereby, after a countless succession of generations, a small gelatinous body is transformed into an oak or an ape; passing on at once to the last grand step in the progressive scheme, by which the orang-outang, having been already evolved out of a monad, is made slowly to attain the attributes and dignity of man.

'One of the races of quadrumanous animals which had reached the highest state of perfection, lost, by constraint of circumstances (concerning the exact nature of which tradition is unfortunately silent), the habit of climbing trees, and of hanging on by grasping the boughs with their feet as well as their hands. The individuals of this race being obliged, for a long series of generations, to use their feet exclusively for walking, and ceasing to employ their hands as feet, were transformed into bimanous animals, and what before were thumbs became toes, no separation being required when their feet were used solely for walking. Having acquired a habit of holding themselves upright, their legs and feet assumed, insensibly, a conformation fitted to support them in an erect attitude, till at last these animals could no longer go on all fours without much inconvenience. . . . . . Now, when so much progress had been made by the quadrumanous animals before mentioned, that they could hold themselves habitually in an erect attitude, and were accustomed to a wide range of vision, and ceased to use their jaws for fighting 
and tearing, or for clipping herbs for food, their snout became gradually shorter, their incisor teeth became vertical, and the facial angle grew more open. Among other ideas which the natural tendency to perfection engendered, the desire of ruling suggested itself, and this race succeeded at length in getting the better of other animals, and made themselves masters of all those spots on the surface of the globe which best suited them. They drove out the animals which approached nearest to them in organization and intelligence, and which were in a condition to dispute with them the good things of this world, forcing them to take refuge in deserts, woods, and wildernesses.' ..... 'The individuals of the ascendant race, animated with a desire of interchanging their ideas, which became more and more numerous, were prompted to multiply the means of communication, and were no longer satisfied with mere pantow mimic signs, nor even with all possible inflexions of the voice, but made continual efforts to acquire the power of nttering articulate sounds. The habitual exercise of their throat, tongue, and lips, insensibly modified the conformation of their organs, until they became fitted for the faculty of speech. Hence, in this peculiar race, the origin of the admirable faculty of speech; hence also the diversity of languages, since the distance of places where the individuals composing the race established themselves, soon favoured the corruption of conventional signs' (ii. $34.0-4.3)$.

Such is the doctrine of Transmutation in its full-blown beauty, for we see but the buds, as it were, of the genealogical tree, till we are favoured at last with the consummate flower of an ape ripened into a man. The learned critic of Lamarck has taken pains in the portraiture, and by his 
well-sustained gravity and measured sentences has deepened the irony of his description of the metamorphose. A little further on he gives us his own undisguised sentiments.

'The orang-outang, which, for its resemblance in form to man, and apparently for no other good reason, has been selected by Lamarck to be the most perfect of the inferior animals, has been tamed by the savages of Borneo, and made to climb lofty trees, and to bring down the fruit. But it is said to yield to his masters an unwilling obedience, and to be held in subjection only by severe discipline. We know nothing of the faculties of this animal which can suggest the idea that it rivals the elephant in intelligence, much less anything which can countenance the dreams of those who have fancied that it might have been transformed into the dominant race.'

We have now to listen to Sir Charles Lyell-quantum mutatus ab illo Hectore !-pleading earnestly, from the opposite point of the compass, for this 'dream' of Lamalek, and advancing many arguments for the transmutation of an ape into a man.

Mr Darwin's Theory of Natural Selection, as the grand agent of metamorphose, has found favour with Sir C. Lyell, rather than the principle of appetency or tentative action suggested by Lamarck; though to us, if compelled to make a selection between these 'dreams,' that of Lamarck would seem a degree less absurd than the other. Following therefore $\mathrm{Mr}$ Darwin, Sir C. Lyell considers that this transformation has taken place by many grades of progressive improvement, through Natural Selection. He expressly names the orang-outang as the animal on which this improvement may have taken place; and feeling, like $\mathrm{Mr}$ 
Darwin, the necessity of some geological evidence to prove this chain of improvement, he is obliged to abandon all the existing evidence that the earth's strata can offer, and to appeal to a future day, 'auspicio melioris ævi,' when the missing links of this valuable chain of anthropoidal transformations may possibly be discovered. 'At some future day, when many hundred species of extinct quadrumana may have been brought to light, the naturalist may speculate with advantage on this subject; at present we must be content to wait patiently, and not to allow our judgments respecting transmutation to be influcneed by the want of evidence which it would be contrary to analogy to look for in post-Pleiocene deposits in any district, which, as yet, we have carefully examined. For as we meet with extinct kangaroos and wombats in Australia, extinct llamas and sloths in South America, so in equatorial Africa, and in ccrtain islands of the East Indian Archipelago, may we hope to meet hereafter with types of the anthropoid primates, allied to the gorilla, chimpanzee, and orang-outang. Europe, during the Pleiocene period, seems to have enjoyed a climate fitting it to be the habitation of the quadrumanous mammalia; but we no sooner carry back our researches into the Miocene times, where the plants, insects, and shells imply a warmer temperature both of sea and land, than we begin to discover fossil apes and monkeys north of the Alps and Pyrenees. But according to the doctrine of progression it is not in these Miocene strata, but in those of Pleiocene and post-Pleiocene date, in more equatorial regions, that there will be the greatest chance of discovering hereafter, some species more highly organized than the gorilla and chimpanzee' (Antiquity of Man, 4.99).

Of course we shall have to wait a good long time for 
these discoveries, before 'many hundred species of extinct quadrumana' can be brought to light by researches in equatorial Africa and islands of the East India Archipelago. It is not quite apparent why these discoveries are restricted to these parts of the world, seeing that the Tertiary deposits of northern India, rich in the evidence of ancient animals, have produced species of the quadrumana; but certain it is that researches in equatorial Africa have least chance of being prosecuted, and delay in this question is a point gained. In the mean while, however, as Sir C. Lyell has fixed his 'hopes' most on the discoveries to be made in the Pleiocene and post-Pleiocene deposits, it seems to have occurred to him that this will hardly allow time enough for the series of improved progenitors of the human race to have got rid of their handfeet, to walk upright, to abandon the branches of trees, and to acquire the faculty of speech, with reasoning faculties, a conscience, and an acknowledgment of a moral law. Mr Darwin, his master, requires immense periods of time for his transformations, and as the post-Pleiocene brings things close to our own age, it is obvious that here is too scanty an allowance of ages to effect the great metamorphose according to the doctrine of the school.

Sir C. Lyell, therefore, has a plan of his own to get over this difficulty, it is by 'a rapid stride,' as he explains to us $n$ the following passage: "We may almost demur to the assumption that the hypothesis of variation and Natural Selection obliges us to assume that there was an absolutely insensible passage from the highest intelligence of the inferior animals to the improvable reason of man. The birth of an individual of transcendent genius, of parents who have never displayed any intellectual capacity 
above the average standard of their age or race, is a phenomenon not to be lost sight of, when we are conjecturing whether the successive steps in advance, by which a progressive scheme has been developed, may not admit of OCCASIONAI STRIDES, constituting breaks in an otherwise continuous series of psychical changes. .... If, in conformity with the theory of progression, we believe mankind to have risen slowly from a rude and humble starting-point, such leaps may have successively introduced not only higher and higher forms and grades of intellect, but at a much remoter period may have cleared at one bound the space which separated the highest stage of the unprogressive intelligence of the inferior animals from the first and lowest form of improvable reason manifested by man' (id. 504).

In this passage, which exhibits the scholar fully equal to the master in the art of conjecture, we have Natural Selection put aside for the nonce-we do not hear of a minute modification appearing accidentally to the advantage of the ape, millions of ages carrying on the improvement, and all the stationary apes exterminated-but the great chasm between the instinct of animals and the reason of man is cleared by onc bound-(and a greater leap never yet was taken, of that thcre can be no doubt) - and thus ingeniously is the difficulty surmounted. Now, as Lamarck has his principle of appetency, and Mr Darwin his principle of Natural Selection, this new principle of 'occasional strides' or long leaps, may be designated the Saltatory Principle, for it may turn out to be of even more importance in the Theory than even Natural Selection, and ought therefore to have a name in the annals of science. When time and space hem in too closely the disciples of this 
school, the Saltatory Principle may liberate them at once; and with this convenient auxiliary it will no longer be needful to search too precisely in equatorial Africa for the missing myriads of quadrumana, but by four bold leaps, from the fish to the reptile, from the reptile to the bird, from the bird to the baboon, and from the baboon to man, to carry Transmutation triumphantly over all obstacles,-

'And show a Newton as we show an ape.'

Let us, however, reflect a little on this interesting process: for what can be more interesting to us than this great leap of the first man? We will suppose that 'an individual of transcendent genius' sprang up by chance amongst the apes, and that he found himself one day, in fact, a man in reasoning faculties and mental endowments-he would naturally wish to separate himself from his kindred, and to follow the suggestions of his new nature. How did he contrive to do this with his animal form, his nether hands, or prehensile feet, his inability to walk, and his whole frame constructed for the mode of life to which he had hitherto been accustomed? 'Then where was the female for him to perpetuate his 'transcendent genius:' did a female ape about the same time 'clear in one bold bound' the immeasurable chasm betwecn the intelligence of the animal and the reason of man? did she from the beast leap into the lady? and was our first parent thus enabled to transmit to future ages that race to which we belong? An ape turned man in mind, consorting with a female ape imimproved, and nothing but an ape, would not find much felicity in his conmubial life; and it is more than doubtful if the progeny of such a union would exhibit the intellect of the father. It is much to be feared that 'the young barbarians when at play,' would skip from the branches with 
their mother, would howl and grin in the palm trees, and exhibit their usual dexterity in hunting after parasitic insects.

But seriously, this is a difficulty either not considered or purposely omitted by the Transmutationists, that in their fables of modified animals, it must be requisite to find male and female contemporaneously and similarly modified; and that too in several successive generations, otherwise it is certain that these casual variations of very minute difference, would forthwith disappear, and thus the modification would soon be absorbed in a return to the normal condition of the species.

The Transmutationists, before they storm the citadel of Reason, to establish there the rights of their kindred ape, liave a fierce battle at the outworks. Sharp is the controversy about the terms 'bimanous' and 'quadrumanous,' two-lianded and four-handed; for if it be conceded that man is specifically a two-linnded animal, then it would follow, that in this respect he is proved to be in an order apart, by himself-and is not to be classed as one of the primates of the animal kingdom. Now as it is of essential interest to the Lamarckians to make out a close family connection between man and the ape, and as they cannot deny that man has only two hands, they vehemently insist that the ape has not four hands, but that the hind limb is terminated by a good and proper foot. Professor Huxley is quoted by Sir C. Lyell as authority for the tarsal and metatarsal bones, and avers that their number and form resemble those of a man's foot. He adds, however, some damaging acknowledgments: 'the metatarsals and digits, on the other hand, are proportionally longer and slenderer, while the great toe is not only proportionally shorter and weaker, 
but its metatarsal bone is united by a far more movable joint with the tarsus; at the same time the foot is set more obliquely upon the leg than in man. The hind limb of the gorilla, therefore, ends in a true foot with a very movable great toe. It is a prehensile foot, if you will, but is in no sense a hand: it is a foot which differs from that of a man in no fundamental character, but in mere proportions, degree of mobility, and secondary arrangement of parts.'

No slight differences these, whatever special-pleading may pretend to the contrary. Professor Huxley, indeed, himself adds, 'it must not be supposed that because I speak of these differences as not fundamental, that I wish to underrate their value. They are important enough in their way, the structure of the foot being in strict correlation with that of the rest of the organism of the ape.'

Let us here see what we have got, by the acknowledgment of the school, that the gorilla has a prehensile foot; but man has not a prehensile foot; let the tarsal and metatarsal bones be as they may, man has not a prehensile foot. Moreover, the foot of the ape is set more obliquely on the leg than ours, and therefore cannot be used as ours, except very imperfectly. The ape cannot walk, ${ }^{*}$ according to our

* Cuvier, in his 'Conformation particulière de l'Homme,' has thus spoken of the foot:- -

'Le pied de l'honme est très différent de eelui des singes : il est large ; la jambe porte verticalement sur lui; le talon est renflé en dessous; ses doigts son eourts, et ne peuvent presque se ployer ; le pouce, plus long, plus gros que les autres, est plaeé sur la même ligne, et ne leur est point opposable; ce pied est donc propre a supporter le corps, mais il ne peut servir, ni à saisir, ni à grimper, et eomme de leur eoté les mains ne servent point à la marehe, l'hornme est le senl animal vraiment bimane et bipede.

It is not easy to answer this argment, or deny this deduction, if the use to which the nember is put is to determine the real meaning of the liand and foot.

'The foot of man is distinguisherl from that of the apes by its power of 
ideas of walking - he has need of support, owing to the inclined position of his body, when in a standing position, and it would be impossible for him to walk upright, more lumano, for a hundred yards.

Well then, if a foot is for walking, our progenitors can only by courtesy be said to have a foot: it is ' a prehensile foot'-a foot for seizing and carrying objects, for which purpose it is our custom to use our hands. If in the place of our present feet we had the apparatus that terminates the lower limbs of the gorilla, what should we do with it? should we with it run in the Olympian games, or should we lay hold of the branches of the first tree, and swing ourselves aloft on the high places of the forest?

The gorilla has been made for the woods and forests; we have been made that we might run and walk. Away, then, with all this special pleading and finesse of a perverted physiology. Look at the facts of Nature, and let them settle the question.

Or if that should be preferred, let us set a foot of a gorilla before us for inspection, and with that the foot of the Apollo Belvidere: look at them, compare them-are they similar instruments? were they designed for similar objects? are they intended for similar purposes?

But the T'ransmutationists will remind us that there is

being planted flat upon the ground, and thus of affording a firm basis of support. Even the ehimpanzee and the orang, when they attempt to walk erect, rest upon the side of the foot; and the absenee of a projeeting heel eauses them to be very deficient in the power of keeping the leg upright upon it. For it is to this projection, that the strong museles of the ealf of the leg are fixed, by which the heel is drawn upwards, or the leg drawn back upon it.'-Carpenter.

This is a sorry description of a foot, but in truth the foot of the ape is as little intended for walking as our feet are for seizing objects. By long practice persons have been known to make a prehensile instrument of the foot, but no long practice would enable an ape to walk with lis foot-it could never be beyond a liobble. 
no design in Nature, and that nothing has been created for a particular object, but that a series of events has produced what we see. Well, then, is the foot of man the same instrument as the foot of the ape, and does it, as a fact, perform similar functions?

It seems, however, that in this discussion the learned physiologists incline to the opinion that the gorilla is more nearly related to us in family-ties than the orang-outang, ' for the carpus of the orang-outang, like those of most apes, contains nine bones, while in the gorilla, as in man, they are only eight.' We are, then, one bone nearer the gorilla than we are to the orang-outang. He is bone of our bone. It is to be feared that it was the gorilla which took the long leap, and became the first gentlemran.

Then we and the apes have the same number of teeth, though the canines of the apes have an awkward habit of projecting, like tusks in the upper and lower jaw, two inches and a half long. Those that wish to study the teeth of their great ancestor', may see the whole matter well explained, and with admirable illustrations, in Todd's Cyclopædia of Anatomy and Physiology (iv. 918). In that page and the next, are well executed wood-cuts of the jaws of the gorilla, natural size; and so formidable do they look, that a person unacquainted with odontology might well suppose that they belonged to a bear, or some other dreadful beast of destruction. If the first lady-gorilla, the great grandmother of our race, had such a set of teeth as those, we, her descendants, may well say to her, 'Oh, grandmamma, what great teeth you have got!'

When we come to the brain, the supposed sent of intellect, the School of Transmutation musters all its powers to bring in their Theory triumphant; and we are assured that 
the apes have the three characters of the brain peculiar to man, the occipital or posterior lobe, the hippocampus minor, and the posterior cornu. We are also told that the posterior lobe of the cerebrum of the chimpanzee is prolonged backwards, so as more than to cover the cerebellum. In short, it is declared as an established fact, that the brain of the ape has the hippocampus minor. Be it so. In the moan while, it is conceded that the human cranium has not yet been obscrved with a less capacity than 63 cubic inches, whilst the most capacious gorilla skull has not more than 34 cubic inches. The largest 'human skull contains 114. cubic inches, the smallest, 63 ; the largest adult gorilla, 34 , the smallest adult, 24 .

Comparative volume of brain, if the brain be worth anything, must be of some value, and whatever that worth may be, man has twice as much of it as the gorilla. But besides the comparative volume, there is probably very much depending on the peculiar convolutions of the brain, in which mysterious labyrinth perhaps the inscrutable secret of intellect may be hid. Sir C. Lyell, who here argues with more than usual warmth for the Transmutationists, gives us what he calls a correct side-view of the chimpanzee brain, and a correct side-view of the human brain (Antiquity of Man, 4.82). They are, lowever', but indifferent woodcuts, and deficient in that clearness and neatness which the subject requires; such as they are, the reader may consult them, and it will at once be perceived how wide is the difference between the convolutions; so different, indeed, are they, that if mental power depends in any way on the form of the brain, the mental faculties depending on such different convolutions must indeed be wide apart.

But it never seems to strike the advocates of Transmut- 
ation, that the more they can make the ape to approximate to man by anatomical comparison, the more striking and wonderful is the real difference between them. The character of man, his habits, temper, disposition, inclination, and intellect, are much further apart from the ape than from any other animals. It is in the intellect and affections that we see the real meaning of man; his bones and his brain may resemble those of the ape, but to what sort of a creature, viewed generally in his disposition, do those bones and brains belong? Talk as you will of improved apes, and of the unquestionable existence of the hippocampus minor in their cerebral apparatus, yet where was there ever an ape since the world began that could construct a bow and arrow, or light a fire, and cook its food? Acts such as these are certainly no proof of a highly cultivated intellect, as they are the elementary contrivances of the lowest savages; but such as they are, no ape ever attempted them, nor ever imitated them, though they are disposed to a sort of mimickry when they have an opportunity of observing the actions of man. The more you praise and magnify the structure of the ape, the more abject and vile does the animal appear. It is because lie is so near us, in a sort of odious caricature, that the difference is so astonishing. The character of the ape is very far less human than that of the dog or the tame elephant. There can be no communion between man and the ape, no hope of friendship - the ape never can be made useful to man, or be trusted by him. The gorilla, whose bones, it is said, most closely resemble ours, and therefore by Transmutation is most closely allied to us, is a ferccious demon of the wilderness, as fierce and dangerous as the worst carnivorous animals; the mandril, though not so near, is 
still of the same family, and therefore our kinsman-but of all beasts he is the most foul, violent, and repulsive. If we turn from these loathsome creatures to the dog, the elephant, the horse, what virtues, what intelligence, what nobility of character do we find! There is friendship between us and them, there is mutual love-and if the moral character determines the worth of the animal, how vastly do they excel those darlings of the 'Transmutationists that howl in the African forests, and have their cerebrum prolonged backwards so as more than to cover their cerebellum.

Nay, we may venture still further, and aver, if similitude of character and action may be a just claim to bring an animal in near relationship to man, that even amongst the insects, the ever-celebrated honey-bee is of nearer kindred to us by far than the ape. The honey-bee has its polity, its government, its laws, its order, its civic architecture, its public zeal, its interest of community, and its loyalty - and in all these things it closely resembles us--Mens cuJusque Is EST QUIsque. By this famous rule the bee is one with us; and by this rule the ape is as far from man as the east is from the west, which is an infinite distance.

But as it is to the outward form that the Transmutationists refer as an evidence of their system, we willingly meet them there, and put aside for a moment weightier considerations. As they appeal to the bones, to the bones we will go, and we will place side by side the human skeleton and that of the ape. The skeleton of man, usually a distressing object, owing to its gloomy associntions, then becomes, by comparison, an object of admiration, so that the bones of even a negro are comely compared with those of the chimpanzee or gorilla. The mere carpentry and frame-work of the human form exhibit a 
majestic dignity of design and a symmetry of construction that might prepare us to expect, in the finished edifice, a being of superior grade. But look at the Simian skeleton, examine its proportions and general contour, and then say if it is not equally well adapted for a structure of uncouth and disgusting appearance. Then from the outward sketch of the two, turn to the full development of the living form, and place an adult gorilla or chimpanzee in juxta-position with a man of comely figure-not merely a handsone European, but, if you choose, a Caffre of South Africa-and then make your comparison, and draw your conclusion. The human form, when of finished mould, myriads of which could any day be produced, is an object of transcendent beauty, far surpassing the comeliness of all other animals; and as being the last production of the Great Artist, it manifests the perfection of his skill in the highest degree. *

Now tum to our fabled progenitor, the ape; and where is there an animal more appalling to look at than the gorilla, more loathsome and detestable in ugliness? Strength, malignity, and beastliness are the expression of his person; and amongst his other hideous peculiarities, perhaps the most so are his legs, terminating in a gummy

* 'It is one of the master-results of creation, and one of the peculiar' marks of creative genius, that perfection and beauty are presented together. As truth is the soul of eloquence, so is perfection the sonl of beanty. The works of nature are beautiful because there is so much excellence in thein, such admirable adaptation to their purpose; and we find the works of man beautiful only so far as they are correct imitations of their great originals in nature, or show some approach to Nature's excellence. And man is the most beautiful object in Nature because he is the most perfect, that is, because the purpose of his existence is the higliest, and because his physique exhibits the most marvellous mouldings to adapt it to its high purpose; bccause, in short, in him the material is wrought to such a pitch of refinement as to he the receptacle and minister of the "inmaterial." -Dr Iumphrey on the Human Foot and Hand (41). 
ankle, thick with unusual sinews, to enable his prehensile foot (hand it is not to be called) to strangle the animal or the man with whom he contends. The chimpanzee, a much gentler creature, is unsightly, ungainly, and of most base aspect, concentrating in its form all that we think ungraceful; and added to this, a ridiculous and grotesque appearance makes the poor animal look as despicable as it is unlovely.

How comes it then that with such similarity of anatomy there should be such dissimilarity of appearance, as well as of character? how comes it that perfection of form should, in certain respects, be so near to hideousness of appearance; and that the perfection of beauty should be genealogically allied to the perfection of ugliness?

This surely seems to suggest to us the finishing touch of the mașter's hand, as if lie had produced these uncoutl creatures as a puzzling preface to what he next would do; as if the attempt at producing grace and elegance so triumphant in the formation of a multitude of animals had now at last signally failed, and the art were lost, in order that by the next form creation might be anazed, and as it were dazzled, on beholding such a blaze of beauty shining out of such a sketch of antecedent deformity.

But then we are reminded by the school, that if man has a voice and can talk, he is not to boast, for so have animals, birds, and beasts their tones, which they make intelligible to one another; and that our speech, therefore, has its rudimental form in the tones of animals.

Be it so; but genealogically we spring from apes, and not from nightingales, and therefore we must listen to the voice of our progenitors, the most ancient primutes of our race, 
to trace the origin of our voice. Let us then go to the Equatorial forests of Africa and hearken to our progenitors - ' the linked sweetness long drawn out' of the yelling and roaring gorilla, the howls and the screams and the grunts of all the rest of the noble family-and then we shall be convinced that the musical modulations and harmonious varieties of the human voice are justly to be traced to our forefathers of the woods.

But at last, man, such as he is, came forth, having got rid of the last resemblance of the last improved ape, and standing on the scene, a perfect man. We will not inquire into the history of the transitions; it may have been, according to $\mathrm{Mr}$ Darwin, through thousands of intermediate and improving species, or it may have been by the Saltatory principle proposed by Sir C. Lyell, by which an individual of transcendent genius may have 'cleared at one bound the space which separated the highest stage of unprogressive intelligence of the inferior animals from the first and lowest form of improvable reason manifested by man.' In other words, the unprogressive ape leaped into the improvable man. We might indeed here ask if, in this long: leap, he lost his prehensile feet, his projecting snout, and his formidable jaws; we might ask if the shape of his pelvis was changed during that happy jump, and if the capacity of his skull was doubled, and the convolutions of his brain were altered; and if he left behind him his demon figure and aspect; but these are questions of comparatively small import; for he became a man with 'an improvable reason,' and that is a thousandfold of higher import than these anatomical considerations. With his reason he became as the Gods, knowing good and evil-the moral sense was awakened in him-conscience set up its tribunal 
in his breast; virtue became desirable to him, justice, mercy, benevolence, forbearance, honour, courtesy, sacrifice of self, and a long train of other beautiful spirits came to lodge with him; and he learned that to do unto others as he would desire that others should do unto himself, was a rule of conduct fulfilling all righteousness.

He had an eye now for beauty, and he found it everywhere on the earth, in the waters, and in the sky. He admired the ordinances of the seasons and the arrangements that pervade all Nature. He saw, or fancied that he saw, (poor deluded creature that he was!) a design of a great Artificer in every existing thing on the face of the earth, and the more he studied them the more did the proofs of design and skill crowd on his understanding. The Religious sentiment now kindled in his bosom, and he bowed down in lowly reverence to his Maker and his God. Religious light rose upon him more and more unto the perfect day, and he considered himself a responsible being in a probation for futurity. This may have been a delusion in him, but we know very well as a fact that it was so, for man had not yet learned the hylology of Natural Selection. Then with the gift of Reason and Imagination he rose on the wings of intellect as a poet, an orator, a philosopher. Then was there a Homer, a Milton, a Shakespeare, a Demosthenes, a Newton, a Laplace in the world. Then did minds plunge into the Infinite, and then did they continually advance and mount upwards in the mountain regions of science, ascending higher, and yet finding still greater heights beyond.

Well, then, at last we come to this point, was man with reason and a conscience made to be man by the progress of events, taking their natural course-and was he by 
gradual improvement without design elaborated out of an ape; or did that Supreme Power, which all nations believe to be God, make him to be what he is, by intention, design, and creation? If this former supposition be true, then the Metaphor of Natural Selection is omniscient and ommipotent, then must it be acquainted with all the sciences in their very essence, and be able to do all things; for unless we concede that wonderful and elaborate machines can make themselves, then certain it is that some other power must both contrive and construct them. Now this power in the Theory is Natural Selection. It is distinctly called so by Mr Darwin, for he tells us, in speaking: of the formation of the eye as an optical instrument, that we are to 'suppose there is a power, Natural Selection, always intently watching each slight accidental alteration in the transparent layers, and carefully selecting each alteration which may in any way produce a distinctive image,' \&c. (208). 'This power, therefore, is to all intents and purposes his God; and as he does not allow an act of creation by the interference of divine power, he sets up another to do the work by metaphorical agency.

Now all this is clearly perceived by Sir C. Lyell, and thus acknowledged:-

'In our attempts to account for the origin of Species, we find ourselves face to face with the working of a law of development of so high an order as to stand nearly in the same relation as the Deity himself to man's finite understanding, a law capable of adding new and powerful causes, such as the moral and intellectual faculties of the human race, to a system of nature which had gone on for millions of years without the intervention of any analogous cause. If we confirm Variation or Natural Selection with such 
creational laws, we deify Secondary causes, or immeasurably exaggerate their influence.'

This is plainly stated, and would lead one to suppose that after such an acknowledgment Natural Selection was to be discarded as inadmissible: not so, however, for the learned author goes on to sáy :-

'Yet we ought by no means to undervalue the importance of the step which will have been made, should it ever become highly probable that the past changes of the organic world have been brought about by the subordinate agency of such causes as Variation and Natural Selection. All our advances in the knowledge of Nature have consisted of such steps as these, and we must not be discouraged because greater mysteries remain behind wholly inscrutable to us' (Antiquity, 469).

In other words, if Natural Selection should appear as the probable agent of the changes of the organic world, we must accept it as a great mystery. Now, as the whole bearing of Sir C. Lyell's book on the Antiquity of Man, is to show the reasonableness of Natural Selection, and to speak of it as a marvellous discovery in science, we come to the conclusion that Natural Selection 'stands in the same relation as the Deity himself to man's finite understanding.'

Thus, then, we are taught that Natural Selection, or " the sequence of events as observed by us,' is the substitute for' the Creator, and that 'the progress of events, without direction or plan,' is the cause of the existence of all organic beings: or, to condense the whole mystery in one comprehensive formulary, - THE ORGANIC WORID IS $\Lambda$ S IT IS, BECAUSE IT IS SO.

In the above passage, however, of Sir C. Lyell, we have 
two exceptions to make. First, to his statement that our 'advances in the knowledge of Nature have been by such steps as these.' This cannot be admitted for a moment. True Knowledge never made a single step like this; of the Saltatory principle she knows nothing-from close and rigid induction she never leapt to metaphorical language, as a substitute for facts. Bacon never admitted anything like Natural Selection as an augment of science; Kepler, Newton, Herschel, Laplace, Cuvier, Davy, never reasoned through such instrumentality; every branch of science repudiates a method like this; it must seek its restingplace in the realm of the imagination to which it properly belongs.

Secondly. We object to Variation and Natural Selection being represented as 'subordinate agents.' To what power are they subordinate? The expression obviously insinuates that they are subordinate to that higher power, which must be God. But what God is this? not the Deity of whom we have heard. - The deity that created a spore of a sea-weed as the punctum satiens of the organic world, and then left it to itself to elaborate every organized being in the lapse of 'millions of millions' of ages, is a power of which we know nothing; and which never yet was heard of till expounded to us in the Theology * of Mr Darwin-or, if not by him, accepted by Sir C. Lyell. A deity of this sort is more absurd than that of the Epicureans, for they said of

* It is not clear that Mr Darwin admits the first organic being of his system, the spore, to be a result of creation. He scems rather to leavc its origin undctcrmined, and wisely enough, for as he rejccts spontaneous generation, there was but one other alternative in this delicate point of the Theory. In page 515 he quotes the opinion of ' a celebratcd divine and writcr,' sent to him as a private communication, and this opinion wonld attribute the first form to an act of creative power; but Mr Darwin does not inform us that he endorses that opinion. 
the Gods 'Magna curant, parva negligunt;' but of this deity we must say 'parva curat magna negligit.' He created the spore of the lowest algæ, and neglected all the rest of the great organic world. He either could not or would not do more than make a spore; after that he retired into darkness and never again was heard of, no, not in the appearance of man, for that was not a design of the creator, but was simply the natural development of an inferior animal.

There can be, then, no admission of the old language in this system, to save appearances. In the dispensation of Natural Selection there is no creation, and, by consequence, there is no creator; or if there be, then he is inferior to an ape, for an ape worked itself into a man, but the creator of this system could only fabricate a spore of a sea-weed, if, indeed, he did as much as that, which is doubtful, and which, if asserted, vitiates the logic of the Theory and militates with its essential principle.

In the preface to the tenth edition of the Principles of Geology, Sir C. Lyell speaks of 'the times entirely antecedent to the creation of man' (vii. dated Nov. 6, 1866). This may possibly be the use of a language of long habit, to be understood in the general sense of man's appearance; but if it be meant as an expression of the learned author's opinion of that great event, it must be met with a firm protest as most inaccurate, and entirely inadmissible in the system which he has adopted. We know well enough by this time what Natural Selection really is; we have secn that Sir C. Lyell has adopted it and written a book of which one object is to defend it; wo have seen what he himself has said of the formation of man, and with all this before us it is evident that in this quarter to talk of the 
creation of man is a flagrant abuse of terms. Mr Darwin, without circumlocution, denies that there is a design, in the existence of things, and here he keeps to the logic of his system; nor should any one that adopts it so mar its harmony as to talk of a design : if there is no design there is no designer, and thus the stage is left clear for Natural Selection to work without any interference; but if anything has been created it has been designed, and if man has been created, Natural Selection, either operating slowly or by ' a long leap,' has not been the agent-and the system 'tenues vanescit in auras.' But it was invented for another object, to get rid of the necessity of 'flashes into existence,' Mr Darwin's words for acts of creation. What, then, has been gained by this elaborate fabric if, after all, it began with one flash which contained in it all other flashes to the end of existence? If man was developed from an ape it was no 'flashing into existence,' it was the natural progress of events fostering and bringing to perfection ' $a$ favoured race.' 


\section{CHAP'TER XIII.}

THE ORGANIC SIMILARITY OF ANIMALS.

There is sufficient similarity in the general structure of animals, and of analogy in some of their parts, though in other respects the animals may be widely different in appearance and habits, to convince us that this is not accidental ; and, therefore, out of the School of Transmutation, it is said that there is a general plan which, on the whole, is sustained throughout the organic world. This plan seems to have been worked on a type with reference to a future advancement, and this advancement, in the opinion of many great physiologists, pointed towards the coming man, who was to be the crown and consummation of the vertebrated animals.

Agassiz, in his Principles of Zoology, has thus expressed it: "There is a manifest progress in the succession of beings on the surface of the earth. This progress consists in an increasing similarity of the living fauna and among the vertebrates, especially in their increasing resemblance to man. But this connection is not the consequence of a direct lineage between the faunas of different ages. There is nothing like parental descent connecting them. The fishes of the Palæozoic age are in no respect the ancestors of the reptiles of the Sccondary age, nor does man descend 
from the mammals which preceded him in the Tertiary age; the link by which they are connected is of a higher and immaterial nature; and their comnection is to be sought in the view of the Creator himself, whose aim in forming the earth, in allowing it to undergo the successive changes which geology has pointed out, and in creating successively all the different types of animals which have passed away, was to introduce man upon the surface of the earth. Man is the end towards which all the animal creation has tended from the first appearance of the first Palceozoic fishes.'

This is said, in substance, also by the illustrious Cuvier; and Professor Owen has expressed similar sentiments. 'The recognition of an ideal exemplar for the vertebrated animals proves that the knowledge of such a being as man must have existed before man appeared. For the Divine mind that planned the archetype also foreknew all its modifications. The archetypal idea was manifested in the flesh, under divers modifications upon this planet, long prior to the existence of those animal species that actually exemplify it.'

As a short illustration of this prophetic aspect of organic appearances, take the following remarks of Hugh Miller: ' Of the earliest known vertebrates, the placoidal fishes of the upper Silurian rocks, we possess only fragments, which, however, sufficiently indicate that they belonged to fishes furnished with the two pair of fins, now so gencrally recognized as the homologues of the fore and hinder limbs of quadrupeds.

'With the second earliest vertebrates, the ganoid fishes of the Old Red Sandstone, we are more directly acquainted, and know that they exhibited the true typical form-a verte- 
bral column terminating in a brain-protecting skull, and that in the acanth, celecanth, and dipterian families, they had the limb-like fins. In the upper part of the system, the earliest reptiles have the first-known traces of the typical foot, with its five digits. Higher still, in one of the deposits of the Trias, we are startled by what seems to be the impression of a human hand of an uncouth massive shape, but with thumbs apparently set in opposition, as in man, to the other fingers. We next trace the type upwards among the wonderfully developed reptiles of the Secondary periods. Then among the mammals of the Tertiary ages, higher and yet higher forms appear; the mute prophecies of the coming being will each approach clearer, fuller, more expressive, and at length receive their fulfilment in* the advent of man.'

All this of course is viewed in a very different light by the Transmutationists, with whom it is obviously essential to deny any plan in the general arrangements of the organic world. For if it be conceded that there is a plan, this would necessarily imply a presiding intelligent mind, able to arrange and carry out the plan; whereas the very essence of their system is that all living beings are the result of a non-intelligent sequence of events-of accidental circumstances benefiting and improving 'favoured' races, and leaving the rest to perish.

All these organic similarities and homologues of parts are with them evidences of descent. If the placoidal fishes of the upper Silurian have fins which were homologues of the fore and hinder limbs of quadrupeds, they interpret this that the fish is the ancestor of the quadruped, and that the quadruped derived his limbs from the fins of 
the fish. In the tail of the cow, giraffe, fox, horse, \&c., they see the tail of the fish ' worked up' for these different animals ; 'modified, and altered indeed, but still made out of the fish's tail : and thus similitudes and homologues are all family-marks, and all bespeak one ancestral origin.

'When several characters,' says Mr Darwin, 'Tet them be ever so trifling, occur together throughout the large group of beings having different habits, we may feel almost sure on the theory of descent, that the character has been inherited from a common ancestor' (458).

Mr Darwin might have said more than this, for 'on the Theory of Descent,' that is, taking for granted that that Theory is true, we may be quite sure that these 'characters ' have been inherited from a common ancestor. The postulate, however, is not conceded, and Mr Darwin has first to prove that his 'Theory is true.

However, thus more at length does he explain to us his views on this particular branch of his Theory :-

'We have seen that the members of the same class, independently of their habits of life, resemble each other in the general plan of their organization. This resemblance is often expressed by the term ' unity of type,' or by saying that the several parts and organs in the different species of the class are homologues. The whole subject is included under the term morphology. What can be more curious than that the hand of a man formed for grasping, that of a mole for digging, the leg of a horse, the paddle of the porpoise, and the wing of the bat, should all be constructed on the same pattern, and should include similar bones, in the same relative position? The parts may change to almost any extent in form and size, and yet they always remain connected together in the same order. 
We never find, for instance, the bones of the arm and forearm, or of the thigh and leg, transposed. Hence the same name can be given to the homologous bones in widely different animals.

'Nothing can be more hopeless than to attempt to explain this similarity of pattern in members of the same class, by utility, or by doctrine of final causes. On the ordinary view of the independent creation of each being we can only say that it is--that it has so pleased the Creator to construct each animal and plant.'

'The explanation is manifest on the theory of Natural Selection of successive slight modifications-in changes of this nature there will be little or no tendency to modify the original pattern, or to transpose parts--the bones of the limbs might be shortened or widened to any extent, and become gradually enveloped in thick membrane, so as to serve as a fin-or a webbed foot might have all its bones, or certain bones, lengthened to any extent, and the membrane connecting them increased to any extent, so as to serve as a wing, \&c. If we suppose that the ancient progenitor, the archetype as it may be called, of all mammals had its limbs constructed on the general pattern, for whatever portion they served, we can at once perceive the plain signification of the homologous construction of the limbs throughout the whole class,' \&c. (466-7).

This passage, which clearly explains the demands of the Theory on Morphology, shows also the necessary exclusion of creation from the system of the Transmutationists, who reject with disdain the idea of referring the commencement of life of an organized being to an operation and a power which our understanding cannot grasp. The whole reasoning, however, goes on the assumption that Natural 
Selection (or the sequence of Natural events) can perform these operations, and execute these transformations which seem so easy to $\mathrm{Mr}$ Darwin, that it can shorten or widen limbs to any extent, and cover them with membranes so as to turn them into a fin ; that a webbed foot can be metamorphosed into a wing, and that animals can be changed by this agency from fishes to quadrupeds, from quadrupeds to birds, \&c. \&c., ad libitum.

Let all this be granted, and the 'explanation is manifest;' but till it be proved, what is this but corroborating one assertion by another? And it is obvious that by taking for granted the thing to be proved any other hypothetical term might be substituted for Natural Selection, and might serve just as well for the argument. For instance, let the influence of the soil (the hypothesis of M. 'Trémaux) or the agency of the solar heat and light take the place of Natural Selection in the above passage, and it is obvious that either would do quite as well for Mr Darwin's explanation of morphology. Let us, argumenti gratiâ, say, That the solar influence has the power of changing the forms of organized beings, then 'on this Theory, in changes of this nature, there will be no tendency to change the original pattern,' for the agent must act on what it finds ready at hand.

But Mr Darwin tells us that it is hopeless to explain the homologues of morphology by the doctrine of utility and final causes; we therefore naturally suppose that he himself is able to explain these changes which, he affirms, are effected by Natural Selection. Will he then undertake to describe to us in accurate scientific language, the process by which the wing of a bat, the eye of an eagle, the proboscis of an elephant, the galvanic battery of an electrical fish, or the heart of a mammifer, were constructed; and 
that not in general vague terms of 'development, plastic tendencies, slight modifications, generative variability,' \&c., but in such clear anatomical, chemical, optical, or dynamic terms, as the case may require, so as to enable us to comprehend without any doubt how these marvellous structures were fabricated, and to know the whole process as satisfactorily as we know the structure of a watch or a steanıengine?

Now, unfortunately, Mr Darwin has in another part of his book said, 'it is most diffecult to conjecture by what transitions organs could have arrived at their present state' (213).

If even conjecture is at fault here, an instrument which in Mr Darwin's hands has done such ample service, it must be utterly hopeless to ask for certainty; and if even imagination can do nothing, how can we look for a scientific exegesis? In short, it is manifest not only by this confession, but by the very nature of the question itself, that the learned author of the 'Theory has here come to a dead-lock; and therefore we beg leave to turn his own language upon himself, and to say 'nothing can be more hopeless than to attempt to explain this similarity of pattern in members of the same class by Natural Selection and the Struggle for Life.'

But it seems that in our view of the case we can only say 'it pleased the Creator to construct each animal or plant.' In other words, we do not scruple to confess 'we do not know ;' we suppose we have reached the limits of knowledge when we come to a certain point, and there we stop; and we judge confessed ignorance to be far safer than pretended knowledge.

And what can be the ultimate advantage of attempting 
to force an entrance into the unapproachable? Are there not some things, may, very many, beyond the sphere of our intellect, even if it be taken for granted that there is no supreme Intelligent Mind, which has produced all the forms of life in this our planet, and in all the planets of all the systems in the Universe. If the Transmutationists complain that we check the spirit of discovery by taking refuge in a Deity, we reply that they too have their Deity, beyond whom they cannot advance. They have 'a power' incessantly watching to improve any modification for the benefit of the organic world.' This unquestionably is a Deity, and, moreover, it is one whose actions the great Master of the School declares it is impossible to explain even by conjecture. This, in other words, is the old language, ' his ways are past finding out.' We then claim our Deity, and that not an Allegory, a Metaphor, an illusion of words, but a Supreme Intelligent Power which always has watched to develope all possibilities of existence, and whose 'ways are past finding out.' We only ask that our. Deity may know as much, and be able to do as much, as Natural Selection-be as wise, as prescient, and as beneficent-and we are quite sure that all the mysteries of the organic world will then be explained up to a certain point. And what, we would ask, is the real difference if on the one hand it be said, that it pleased the Creator to make a plant or animal so and so, and leave it unexplained; or, on the other hand, to affirm that Natural Selection made a plant or animal so and so, and yet not be able even to conjecture by what means it was effected?

After all, then, it is a question between two Deities. Let the world judge whether it is wiser and better to be- 
lieve in these 'new gods newly come up,' or in Him who from everlasting to everlasting is the Almighty?

These sentiments it may be pleasing to see confirmed by the testimony of a distinguished physiologist.

"The unity of plan, which is visible through the whole animal kingdom, is nowlere more remarkable than in the function (of the heart) of which an outline has now been given. We have seen that, however apparently different, the essential character of the reproductive process is the same in the highest animal as in the lowest. It has been shown that the development of the highly-organized body of man conmences from the same starting-point with that of the meanest creature living; for even man, in all the pride of his philosophy, and all the splendour of his luxury, was once but a single cell, undistinguishable, by all human means of observation, from that which constitutes the entire fabric of one of the simplest plants. And when the physiologist is inclined to dwell unduly upon his capacity for penetrating the secrets of Nature, it may be salutary for him to reflect that, even when he has attained the farthest limit of science, by advancing to those general principles which tend to place it on the elevation which others have already reached, he yet knows nothing of those wondrous operations, which are the essential parts of every one of those complicated functions, by which the life of the body is sustained. Why one cell should absorb; why another, that seems exactly to resemble it, should assimilate; why a third should secrete; why a fourth should prepare the reproductive germs; and why of two germs that seem exactly similar, one should be developed into the meanest Zoophyte, and another into the complex fabric of man,--are questions that physiology is not likely ever to answer. 
'All our science is but the investigation of the mode or plan on which the Creator acts; the power which operates is infinite, and therefore inscrutable to our limited comprehension. But when man shall have passed through this embryo state, and shall have undergone that metamorphosis, by which everything whose purpose was temporary shall be thrown aside, and his permanent or immortal essence shall alone remain, then, we are encouraged to believe, his finite mind shall be raised more nearly to the character of the infinite; all his highest aspirations shall be gratified, and never-ending sources of delightful contemplation shall be continually opening to his view.

'The philosopher' who has attained the highest summit of mortal wisdom, is he who, if he use his mind aright, has the clearest perception of the limits of human knowledge, and the most earnest desires for the lifting of the veil that separates him from the unseen.'-Animal Physiology, by Dr Carpenter, p. 567.

But we pass on from general principles to details, to examine more particularly the theory of descent as proved by homologues, or by repetition of character, in groups of animals of different habits.

We are told that the 'number of the vertebræ forming the neck of the giraffe and the elephant, at once explain themselves on the theory of descent with slow and slight successive modifications.' 'This argument is of course applicable to the human form also, and we may therefore add man to the giraffe and elephant, so that the argument would be that the elephant, giraffe, and man are seen to be of the same descent by the number of their cervical vertebræ. 
But we are further informed, "on the principle of successive variations not always supervening at an early age, and being inherited at a corresponding not early period of life, we can clearly see why the embryos of mammals, birds, reptiles, and fishes, should be so closely alike, and should be so unlike the adult forms' (513).

This enigma of words requires explanation. Mr Darwin means to inform us that there is a principle by which variations, or great differences, do not make their appearance (supervene) in the beginning of their existence, but when they grow older these come on by inheritance. Or still plainer, a man is a fish at first, but his variation from the fish form does not 'supervene' at an early age, but is inherited later in life. $\mathrm{He}$ is in fact a varied or metamorphosed fish when he becomes a man. Why this 'principle' is delivered to us in the language of an obscure oracle with double negatives, is not apparent-but we may say of the principle that if the fact had been reversed it would have been more probable and more convincing-for if a man became like a fish as he grew older we should have a clearer evidence of his 'descent,' and it would be in accordance with what we see in animals, as it is well known that the apes (our near relation in the Theory) depart more and more from the human similitude as they grow older, and become more thoroughly and unmistakably the brute beast in the latest period of their lives.

But here there is a collision in the doctrine. Thus stands the argument, we are clearly of the same descent with other mammals, elephants, giraffes, \&c., as is proved by the number of our cervical vertebræ; but our embryonic state connects us closely with birds, for the order 
of our embryonic transition of similitude is the fish, reptile, bird, mammal. Now the bird has not ${ }^{*}$ the same number of vertebræ in the neck; and this, therefore, by Mr Darwin's own rule, would show that we are not of the same descent with the bird; for if the same number of cervical vertebræ identifies us in descent with mammals, a difference in the number must separate us from the bird, and show that we are not of the same descent. And yet the contrary is proved, according to Mr Darwin, by the evidence of the embryo !

Ifere, then, the Theory militates with itself, and confutes itself.

As a common descent of all organic beings is that on which the Theory depends, and as a family relationship is everything in this system, we need not be surprised to find that the learned author of the system should allow himself great latitude in tracing the genealogy. "We have no written pedigrees,' says he, 'we have to make out community of descent by resemblances of any kind. Therefore we choose those characters which, as far as we can judge, are the least likely to have been modified in relation to the conditions of life to which each species has been recently exposed. We care not how trifling a character may be, let it be the mere inflection of the angle of the jaw, the manner in which an insect's wing is folded, whether the skin be covered with hair or feathers-if it prevail throughont many and different species, especially those having very different habits of life, it assumes high value; for we can account for its presence in so many forms with such differ-

* No bird has so few as seven vertebræ in the neck: the eagle and the vulture have each 13 , the osprey 14, the blackbird 11, the crow 13 , the kingfisher 12 , the sparrow 9, the woodpecker 12 , the peacock 14, the ostrich 18 , the heron 18 , the stork 19 , the goose 15 , the swan 23 , \&c. 
ent habits, only by inheritance from a common parent' (457).

There is of course another way of accounting for this, the old way adopted by most physiologists, but as this cannot be admitted in the Theory, $\mathrm{Mr}$ Darwin does well to look out for another explanation, which, like every other part of the Theory, if it be accepted, must be accepted as a dogma without proof.

Let us look now at" similitudes and homologues of structure in a common-sense view of the subject, and see if it be so very difficult. First, however, we will take a statement of the subject from an approved author.

"The four component parts of the upper extremity, viz., the shoulder, arm, fore-arm, and hand, can be clearly shown to exist in the anterior extremities of all mammalia, howerer dissimilar they may appear on a superficial inspection, and however widely they may seem to deviate from the human structure. The wings of the bat, osteologically considered, are hands; the bony stretchers of the cutaneous membrane being the digital phalanges extremely elongated. The dolphin, porpoise, and all other whales have a fin on each side, just behind the head, consisting apparently of a single piece. But we find, under the integuments of this fin-like member, all the bones of an inferior extremity, flattened indeed, and hardly susceptible of motion on each other, but distinctly recognizable; these are a scapula, humerus, bones of the forearm, carpus, metacarpus, and five fingers. The fore-feet of the sea-otter, seal, walrus, and manati, form the connecting links between the anterior extremities of other mammalia and the pectoral fins of the whale kind. The bones are so covered and connected by integuments, as to 
constitute a part adapted to swimming; but these are much more developed than in the latter animal, and have free motion on each other. The bones of the wings of birds have a great and unexpected resemblance to those of the fore-feet of the mammalia; and the fin-like anterior member of the penguin, applicable only to swimming, contains within the integuments the same bones as the wings of other birds, which execute the very different office of flight.'**

So also, more particularly, another physiologist :-

'The fore-limbs of all species of animals are similar to one another in all respects save that of quantity, and this quantative difference is manifested chiefly upon the distal extremities. The obliteration of one or more parts of the distal organ renders it in the varying conditions of those forms to which we give the names of hands, paws, wings, palms, talons, hoofs, \&c. The same law of degradation is exercising on the distal extremes of the hind limb, and according to the quantative variety of these organs we characterize them by the like names. The hand and the foot are radically the same organ; not only in the same body but in all bodies.'-Maclise in Cyclopædia of Anatomy and Physiology, iv. 66.

This being the general state of the case by which the Transmutationist fortifies his Theory of a common ancestral descent of all animals, let us consider whether it may not much more justly be viewed in another light.

Let us suppose that a plan of creation had been adopted, with the object of producing a vast variety of forms of life, in beings organized for that purpose, with widely different habits, and destined to occupy certain positions for

* Lawrence's Lectures on Zoology, 48. 
different objects. First, the animal in the abstract is to be dealt with; what is it to be? It is to be a sentient being, connected through its senses with the outward world, in which it is to live and be perpetuated. It must have, then, organs to connect it with the outward world, in that portion of the world which is destined to be its theatre of life, and which may influence the amount of its requisite sensations, and its functions. If it has a lower position to take, or a confined theatre of existence, its wants will be fewer, and several parts will be omitted in its organization which may be required for a higher or more active sphere of existence. But let us take a specimen of a complete animal, one destined to enjoy life upon earth, and freely to move itself at liberty according to its wishes.

It must have organs to comnect it with the outer world, organs that will enable it to see, to hear, to feel, to smell, and to taste. These senses seem indispensable. Then it must have free powers of locomotion, and a structure to enable it to assimilate food and sustain life; and if, also, it is to be perpetuated, and not disappear from the scene, the faculty of reproduction is to be conferred on it, and that as an imperative principle.

'These are the functions of animal life, or those of relation, including sensation and voluntary motion, by which animals approach and perceive their fellow-creatures and objects around them, and bring them into relation with them : and next, the functions of vegetalle life, which are nutrition and reproduction; and which last are common to the animal and the vegetable.

Now, for the two distinguishing characteristics of animals, sensation and motion, two systems of organs are prepared, the nervous and muscular. 'The nervous, through which 
the impulses of the will are conveyed; and the muscular, which puts in motion the body according to the dictates of the will.

The monitors of the will are mainly in the senses, and it is in these that the intention of one plan is seen, as well as in the organs which execute the impulses of the will. The great illuminator of the will is the eye, that organ which is to acquaint the animal with the state of things around it, and so enable it to adapt its actions accordingly, by seeking what it wishes, or avoiding what it would reject or fear. The eye, therefore, is one of the most ancient of organs, far more ancient than a fin or a wing, for it is found in the early Silurian formation, as a very complicated optical instrument in the crustacean Trilobite, and constructed on true scientific principles. This organ having once been made, is adhered to, in the general plan, in every other instance in which it was expedient to place an animal in relation with the outward world by the visual faculty. The optic instrument may be varied, as it is greatly varied in numerous adaptations or modifications, but still it is essentially the same instrument in every case, and constructed on the same principle. It may, therefore, as much be deemed a homologue as any other organ of which physiology points out the less obvious relations.

The principle of creation, then, is to produce an organ which will answer for a general purpose, and not to make a new one, on a totally different principle, for that same purpose in organized beings of different characters. The eyes of the felidx and of the ruminants, of the owl and the eagle, of the diagon-fly and the bee, of man and of the log, are executed on one type, with modifications or addi- 
tions, but all are the design of one artist for one object on one plan.

It might have been possible on a very different principle to have conferred the faculty of vision on man; or at lenst we may suppose so; but why should a totally new instrument be invented when the optic machine already in use amongst all vertebrated animals had answered the purposes for which it was intended, and which it was certain would do for man all that was wanted, and by him be recognized as a most perfect organ?

And surely this adhering to one type argues skill in the Artist who could thus modify one instrument for thousands of different creatures, and yet make it perfect for all the varieties of habit and character by which those creatures were to be distinguished.

This principle then prevails through creation, to make one organ serve various purposes in various animals. The senses are admonished by similar organs to regulate the will, and the limbs are constructed on a similar plan to execute the impulses of the will.

Locomotion is one principle, but as it may be greatly varied in various sorts of motion in widely different habits of life, it will require limbs of different strength, size, and arrangement: so different, that if the problem had been proposed to the cleverest mechanician, he would have pronounced it to be clearly impossible to construct the organs of locomotion on one type. With locomotion is found very carly, and in full activity, a plan that has never been materially altered. The placoidal fish belong to the earliest specimens of their genus, but their two pairs of fins are generally recognized as the homologues of the fore 
and hinder limbs of quadrupeds. The legs of the horse were designed in futurity in the fins of the placoidal fish: and so, as we have seen, through all the ranks of animals, arms, legs, hands, palms, talons, hoofs, \&c., are considered radically the same.

The fact is conceded by all parties, the plan is contested by the Transmutationists; but taking it as a plan, shall we not be compelled to confess that if success is the test of excellence, here excellence must be recognized in the highest degree? And if we argue 'on the theory of creation' (these are Mr Darwin's words, not ours), does not this look very much as if the Supreme Intelligence, which directed creation, held all forms of life within its ken, and had them as it were within its grasp, so that the end was seen from the beginning, and from the beginning to the end one plan was sustained, as by one Mind, master of the whole work?

And if we compare this 'theory' with the Antitheos, Natural Selection, shall we not be constrained to confess that here is something vastly superior to that other system, which supposes organized beings to have been produced by empirical efforts, and the casting away of thousands and tens of thousands of patterns and experiments which were found to be imperfect?

The Deity of the 'Transmutationists, Natural Selection, makes an animal perfect by exterminating enormous numbers of experimental animals, not good for the purpose for which they had been elaborated. The workshop of this Deity is a vast sląughter-house* of incalculable carnage,

* Natural Selection may indeed be defined to be The Result of Destruction, for Mr Darwin has himself so stated it, 'Natural Selection results from the struggle for existence' (464). Thus a bat's wing or a horse's tail is the result of destruction! 
mountains of skeletons attest its blunders, according to the assertion of its votaries, if only these mountains could be found, but this they affirm, and are indeed obliged to affirm ; but as they believe this, how can they look upon Nature as a lovely scene, or see in it any beauty? must they not rather regard it as a great battle-field, in which every living creature has murdered its ancestors, and is preserving a precarious existence by exterminating every competitor, whilst its own life is nothing but a triumphant blunder?

This indeed is plainly affirmed by $\mathrm{Mr}$ Darwin in the most startling' passage of all his volume. 'By far the most important consideration is that the chief part of the organization of every being is simply due to juheritance; and consequently, though each being assuredly is well fitted for its place in Nature, many structures have now no direct relation to the habit of each species. We cannot believe that the similar bones in the arm of the monkey, in the fore-leg of the horse, in the wing of the bat, and in the flapper of the seal, are of special use to those animals. We may safely attribute those structures to inheritance' (220).

The best answer to this solemn trifling would be to take away those bones from 'those animals,' and to see how they would do without them. The bones in the fore-leg of a horse, though similar to those in the arm of a monkey, do somehow or other enable the horse to go full gallop, in the extremest speed of his race at the rate of nearly a mile a minute; and a monkey mounts a lofty tree with wonderful rapidity, or leaps from branch to branch in a progress almost resembling the flight of birds, with perfect success, though his bones may resemble those in the flapper of a seal ; and a seal progresses through the waters with all the speed he needs, though there may be a similarity in the 
structure of his flapper to the wings of a bat. No special use! then we must judge that a wiser structure might have been invented, by a more sagacious artist, for the benefit of 'those animals,' and that the works of Nature might be greatly improved.

This, however, must touch us very nearly, for as we are, according to the Theory, the nearest relations to the apes and monkeys, it cannot be but that the bones in our arm are of no special use to us; we have got them by inheritance, and if they were not advantageous to our ancestors the apes, they cannot be to us. This one would think is clear logic, but Mr Darwin states it differently, and affirms that they were of more use to our progenitors than they are to us.

'We may believe,' says he, 'that the progenitor of the seal had not a flipper, but a foot with five toes fitted for walking or grasping, and we may further venture to believe that the several bones in the limbs of the monkey, horse, or bat, which have been inherited from a common progenitor, were formerly of more special use to that progenitor, or its progenitors, than they now are to those animals having such widely diversified habits; every detail of structure in every living creature may be viewed, either as having been of some special use to some ancestral form, or as being now of special use to the descendants of this form, either directly or indirectly, through the complex laws of growth ' (220).

If the progenitor of the seal had a foot with five toes, fitted for walking or grasping, it must have been, according to any inference which Natural History would anthenticate, either a man or an ape, unless indeed it were the plantigrade bear, which has a tendency in the Theory to get into the ocean in a new form. But who can hold the eel of 
this science by the tail? for it can slip off into the preSilurian world, where there were 'swarms' of creatures 'totally unlike any existing animal,' and amongst some of those inexpressible vertebrated forms, the walking five-toed progenitor of the scal may have had his auspicious existence.

But at any rate if the bones of a monkey were formerly of more special service to its progenitor than to the monkey itsclf, the same must be predicated of us, the near relations of that tribe, and who have the homologue of our limbs in 'other animals of such widely diversified habits;' for the rule that is good for one genus is good for another, if indeed we be separated from the Simian race by so great a division as a genus.

We have then had a progenitor whose legs and arms were of more special use to him than to us his descendants, nay, 'every detail of our structure' had some special use in our ancestor in a higher degree than it has. in us. Our limbs are but an expectient, a tinkering and cobbling. of appendages, obsolete in our species, but of which $\mathrm{Na}$ tural Selection has made the best she could, finding them on her hands for work, and constrained as she was to turn to some account these inheritances from a better formed and better limbed progenitor.

The machinery of our bodies therefore has not been improving in the lapse of geological time, but deteriorating; and we are greatly mistaken if we suppose that the human limbs, their proportions and their uses, are the most advanced results of anatomical construction-if special use of limbs can be considered a proof of superior organization, then, by this doctrine, it is indisputable that a retrograde course of development is discernible in the formation of the 
human body-and that if we be indeed improved apes, we liave nevertheless deteriorated from our unknown ancestors, whose history is lost in the night of geological antiquity.

But this also demands observation, that with all this before us it is clear that the Theory must have been suspended in the instance of this ancient Incognito, for if his limbs were of more special use to him than they have been to his descendants, he ought to have been triumphant in the struggle for existence, as it is always the specially formed animal, possessing the greater advantages, that triumphs in the scuffle, and exterminates all other competitors. So, however, it happens that his specially serviceable limbs were of no avail in his case; the Theory was turned against him, the favoured animal was exterminated, and the inferior were perpetuated; and thus, instead of our non-pareil ancestor with his perfect limbs, we have had bats, seals, donkeys, apes, and men!

At the same time it is not to be forgotten that $\mathrm{Mr}$ Darwin has given another account of the progenitor of vertebrate animals, and therefore of our genus, as well as of the animals just named: 'An indefinite repetition of the same part or organ is the common characteristic of all low or little-modified forms, therefore we may readily belicve that the unknown progenitor of the vertebrata possessed many vertebræ' (469).

If this be the common progenitor of the horse, monkey, bat, seal, \&c., then to our surprise we now hear of him as 'a low and little.modified' form, whilst in the passage which we have just been examining his limbs are described as having been of more use to him than to his descendants. Here is a contradiction; but perhaps Mr Darwin may in- 
tercalate millions of ages between the progenitor of the horse, \&c., and the progenitor of the vertebrata, we know not; only on this subject we must repeat what we have already said, that this imaginary progenitor of the vertebrata ruins the whole system, for his appearance on the scene with many vertebræ, ready made, contradicts all that the learned author has inculcated with such careful repetition in his volume-that nature does nothing 'by leaps, and that every peculiar part of every animal is the result of Natural Selection's labours in an immense allowance of time.

- And from this there is no escape, for if the animal in question was The Progenitor of the vertebrata, he could have been preceded by no other vertebrated animal, he must have been the first; and yet he had a great many vertebræ all at once! In other words, he was so created, for Natural Selection could not produce such a phenomenon, and there is no other alternative possible for his first appearance, excepting spontaneous generation, which $\mathrm{Mr}$ Darwin rejects as inadmissible in science. So then, after all, the first vertebrated was really created! Here, then, we have the happiness to agree with Mr Darwin; and the only difference between us is that we beg leave to extend the rule to a vast many other cases. We have no doubt that the progenitor of a bird had many feathers, of a fish many scales, of an insect many facets in its compound eye, and so on throughout the animated world.

We need not tarry to inquire more particularly about this alleged progenitor of the vertebrata, but by this imperfect allusion to his form, it is most probable that he was a serpent, and a very long one too; for as he must have 
been parent of all serpents, we camnot doubt that he had more vertebræ than his descendants, in this case of descent, as well as in all the others.

The general plan of structure that seems to have been determined in the organization of animals, admits both of additions and omissions when the case requires; and by this fact teaches us that there must have been something more than inheritance at work, for inheritance can neither add nor leave out a part of the body.

Let us take a true insect, a bee for instance. The thorax is interposed between the head and the abdomen, and so far is analogous to that part in human anatomý, though it is but an analogy. To the thorax are attached the three pairs of legs ; the first pair may be compared with the pectoral extremities of the vertebrate animals, and the last to the pelvic members or hind legs, but to the middle pair of the insect's legs there is no analogue in the vertebrate serics. * These therefore are out of the rule and type of other animals.

So when we speak of the insect's eye, we say it is formed on the general principle, or rather, scientific theory of all other eyes, the optic nerve, the vitreous humour, the lens, and the retina; but the plan on which the principle is applied is greatly altered, and that which in the vertebrated animals is a single instrument is in insects a compound one, so as to contain some thousand facets, or corneæ, each a distinct instrument of vision in that compound hemispherical organ, which is popularly called the eye; each of these facets is of hexagonal form, and each has its peculiar

* Mr Darwin has observed that 'the anterior' and posterior limbs in each member of the vertebrate and articulate classes are plainly homologous' (468), but he has made no remark on the middle legs of the articulate class. 
double convex lens, iris and pupil, so as to be fully entitled to be considered a distinct instrument of vision, to be, in fact, an eye. Of * these we are told the common house-fly has 4000 ; some dragon-flies upwards of 12,000; and butterflies 17,855; whilst one of the Coleoptera, Mordella, possesses the astonishing number of 25,088 .

This apparatus of vision in the insect race is not then on the general plan of the eye of other animals; there has been a free choice and exercise of judgment in its arrangement, and the result is manifest, a separation in this respect, as in many others, from any imaginary line of descent.

Then if we look at the whale, we find indeed the anterior extremities converted into broad fins or paddles, and representing a large hand, whilst the pelvic extremities, the analogues of the hinder limbs of other vertebrata, are absolutely wanting. Now the whale is a placental mammifer, and suckles its young. Hence there is in it a community of organization and character with the higher animals, but it has no hinder limbs. They are omitted.

How is this by the Theory of inheritance? and more particularly may we be inquisitive on this subject, when the Theory furnishes us with the genealogy of the whale, and gives us the bear as its immediate ancestor. The bear has a well-formed proper foot, of which the heel, carpus, metacarpus, and phalanges rest flat on the ground. It was intended that he should walk, and make great use of his pelvic extremities; all is well and largely de-veloped in his body for that purpose--it is scarcely possible to have selected an ancestor more unlike his descendant, in this respect.

* Jones, Animal Kingdom, 277. 
If, then, omissions can take place in an alleged descent and additions to any amount be admitted, who can believe in such a law of heritage? Of what use is it to prove anything? and who can listen to its evidence, when it shows a rudimental transitory resemblance to a fish, or other lower animal, in the embryo of a vertebrate animal?

The serpent form, devoid both of the anterior and posterior limbs, may be taken as another instance. It is an animal apparently without the organs of loconotion, and if seen for the first time would be pronounced to be an immovable machine; but by other contrivances, which we certainly never should have imagined, with what rapidity can it move, and execute all its terrible designs! The artist of the animal form has not been circumscribed within the limits of our ideas, but has in thousands of instances proved to us that there may be something far beyond transmutation and the law of descent, in the mystery of organic structure.

But now we come to the bat, and its finger-stretched wing. It was not created a bat, we are told, but was worked out of some other form by Natural Selection, in the usual protracted operation carried on through multiplied ages. It had, however, some other wingless body before the operation began: it was some animal of some sort before the process of transformation commenced; and as there are several sorts of bats, and several sizes of them, some of them must have been as small as mice, and some as large as rabbits. If we were to concede that they used to live on insects before they acquired their wings - and there seems to be no other alternative-they must have been pinched with scanty fare in their first state, as they do not procure more than sufficient now with their very 
rapid flight. However, in due time the process of wingmaking began. Their fore feet or paws began to lengthen, but oh, how slowly! 'The hundredth part of an inch in a thousand years would be quick work with Natural Selection: but the bones lengthened. When they had been elongated to the fourth part of their present extension, what a miserable condition must the poor creatures have been in! they had lost their paws, which we cannot but suppose used to do them some service, and had got nothing as yet by the change. They could not run as they used, and they could not fly. But the Theory requires us to suppose that the Transmutation thus far advanced had been found advantageous, though it must certainly have been injurious: and we are further to suppose that all the unchanged animals, on whom this process had not been carried on, were dying off in the struggle for life, and that the quarter-bats were trimmphing. So they went on lengthening their bones, and exterminating all competitors till nothing was left but the perfect bat!

Now this seriously is the history of their formation according to the 'Theory. There can be no other' and this history may serve for all other transmutations, mutatis mutandis. It is, indeed, too ridiculous for the pages of $\mathrm{Na}$ tural History, and is worth only this, that it may convince the inquirer of the impossibility of these changes, as the intermediate state required in these transmutations could have no other effect than to exterminate the animals* pass-

* This has been noticed by Professor Owen in his Palæontology. IIo quotes Mr Darwin's imaginary ease of dogs preying on hares and rabbits -the rabbits beeome searce, and the hares increase; in this emergency the dog would endeavour to eateh more hares, and those individuals with slightly plastic limbs, longest legs, and best eye-sight, would be 'slightly favoured,' would tend to live longer, and survive when the food was scarcest. They would also rear more young, whieh would tend to inlierit 
ing through it, not those which the Theory supposes were destroyed as the consequence of their remaining stationary.

The case of the bat seems to puzzle even Mr Darwin, for he says, 'if it had been asked how an insectivorous quadruped could possibly have been converted into a flying bat, the question would have been far more difficult, and I could have given no answer' (198).

That is, the author of the Theory cannot explain the process of formation; and yet when we confess our inability to explain the first appearance of an animal in the theatre of life, and refer it to the act of a Creator, we are twitted with our ignorance, and our attempt to conceal it by such a reference. Here, however, Mr Darwin is precisely in the same position with us-c' he can give no answer.' Nescio is the explanation; and so it is with us, only we leave the matter where we are sure there is a power that is equal to all these difficulties. Mr Darwin leaves it with nothing, though he has in his hands Natural Selection, in which he assures us he 'has such confidence,' that 'he sees no difficulty in believing' anything he may ascribe to its opcration.

Having, however, thus candidly confessed to-a check-

the slight pecnliarities. The less fleet ones would be rigidly destroyed. 'I see no reason to doubt that these causes would in a thousand generations produce a marked effect, and adapt the form of the dog to catching hares.'

On this Professor Owen remarks: "Yet this condition of things, if followed out to its full consequences, seems only to tend to my original inferenee, viz. an extinction of species, for when the hares were all destroyed the long-legged dogs would perish-at most, there could but be a reversion to the first form and conditions' (435). We may add, that 'the slightly plastic limbs' is a gentle phrase for self-transforming, and is a covert assumption of the whole question. These short-legged dogs, however, would die in a very short time for want of food. One generation would see them all out: we need not speculate on a thousand.

'This imaginary case is strictly Lamarckian, it is based on the principle of appetency. 
mate, $\mathrm{Mr}$ Darwin adds these words: 'Yet I think such difficulties have little weight.' What then can have weight in such scales as these? a hundred-weight seems not to be reckoned so much as a scruple in the School of Transmutation. 


\title{
CHAPTER XIV.
}

\author{
ORGANIC DISTINCTIONS.
}

$\mathrm{W}_{\mathrm{E}}$ have been speaking of similaritics of organization, we have now to say something of the ordinations of division or distinction, by which certain animals, whatever may be the similarity of parts of their limbs or bodies, are arranged in broad manifest separation of distinct groups, so as to preclude the idea of any possible transition from one to the other.

In a popular view of the animal kingdom this would appear sufficiently plain in the most obvious examples, as, for instance, the distinction between the carnivora and the ruminants; for no one uninitiated in the mysteries of the Transmutationists could ever be brought to believe that a cow had, by any quantity of changes in her ancestors, proceeded from the stock which produced a tiger or a lion. But though this common-sense view of the question of Distinction of animals is really unanswerable, yet there are some other considerations of deeper moment that claim our attention.

Physiologists who have carefully studied organic beings, with a view to establish some fundamental system of arrangement, have observed these distinctions :- 
1. Creatures whose hearts are divided into four cavities, mammalia and birds.

2. 'Those having a heart consisting of three cavities, reptiles and amphibia.

3. Animals possessing a lieart with two cavities, fishes and most mollusca.

4. Animals whose heart consists of a single cavity, articulated animals, worms, and insects.

5. Creatures in which the functions both of stomach and heart are performed by the same organ, as Medusæ.

'This arrangement of the Animal Kingdom, in conformity with the structure of the heart, was proposed by the celebrated Hunter, and is here set before the reader that it may be perceived at a glance how formidable are the bar. riers which such divisions interpose to obstruct the scheme of Transmutation. In that theory there must have been a transference of life across these boundaries. If a reptile has, for instance, been converted, by Natural Selection and the Struggle for Life, into a bird, the animal with a heart of three cavities has, in its new form, assumed a heart of four; its circulation has been altered, and the corpuscules of its blood changed in form: so also the fish has changed its heart to become a reptile, \&c., \&c.

The functions of the heart are in the closest connection with the organization and power of the animal, with the whole apparatus of its life; a fish could not, for a few minutes, exist with a heart different from that which Nature has bestowed on it; nor could a bird be a bird with the heart of a fish or a reptile.

As the reptile is supposed, in the School of 'Iransmuta. tion, to be the antecedent and ancestor of the bird, we are to suppose that some time or other the change of structure 
in this particular was effected, and that the transformed or transforming animal acquired, ready made, this new centre of its circulation suited for its new position in life. There could be no formation by gradual mutation of ages in this point. The reptile must have its peculiar heart, and so must the bird. 'Slight modifications' are not admissible here. Life depends every minute on the action of the heart, there can be no empirical experiments here, no 'slightly plastic' attempts at a new machine; to suppose an animal living with an intermediate heart for a miliion of years, must be too desperate a venture for the most ardent admirers of Natural Selection. That dextrous metaphor may be 'always on the watch to take advantage of the slightest beneficial change,' but it would soon be discovered that no change at all could be made, without destroying life, and utterly ruining the attempt at metamorphosis.

Therefore we say that a transition from a reptile with a tripartite heart to a bird with its heart of four cavities is impossible; supposing we were to concede that the various genera and species of birds have slided into one another, that a blackbird may have had a common ancestor with a crow, and a goose have issued from a swan. This is not the question of the mutability of species, already discussed, but of a much wider separation, nature's grand organic distinctions in"which, by a few settled arrangements of internal organism, certain animals are totally separated from one another in the scheme of life; but which, nevertheless, Natural Selection is supposed to have surmounted by those who adopt the theory of Transmutation.

The distinction of the structure of the heart, an efficient rule for dissociation and sejunction, answers well for a negative purpose; but for classification something more 
precise is needed, and this has been effected by Cuvier, who looked more to the nervous system for an accurate distribution of the animal kingdom. Guided by this indicator he established his four divisions of Vertcbrata, Moliusca, Articulata, and Radiata, and though these divisions, with the exception of the first, are named from their cxternal appearance, the three first are defined by characters exclusively drawn from the internal organization. The nervous system is, in fact, 'the essence and prime distinction of the animal' (Owen); its mind, so to speak, depends on this; its peculiar character, the result of its sensibilities, is derived from the nervous centre and its ramifications; its body is constructed to suit the impulse of its will, and its will by the nervous system rules and directs the body.

The vertebrata rise in the comparative scale of existence through the peculiar arrangement of their nervous provision ; Mollusca (oysters, \&c., \&c.) are obviously creatures of a lower life than the vertebrated fishes. In the Mollusca* the centres of the nervous system are sometimes disposed irregularly through the general cavity of the body, sometimes aggregated round the gullet, sometimes arranged with more symmetry along the abdomen, yet seldom better cared for or protected than the neighbouring viscera.

This provision, inferior and imperfect as it appears, compared with the nervous furniture of the vertebrata, is fully adequate for the wants and habits of those lower animals; many of which can neither see nor hear, and have but little need of locomotion in the search for their food.

* "The nervous centres of the Mollusca consist of several detached nasses placed in different parts of the body, without regularity of distribution or symmetrical arrangenent.'-Jones, 4. 
When therefore life was to be exalted into a more vigorous manifestation, the vertebral column was formed, a case and protection for the nervous system, which as the spinal marrow, 'that mysterious albuminous electric pulp' (Owen), is there aggregated in force, and communicates with the citadel, the brain, shielded in another cavity, the skull.

'Two strongly-built cavities, the vertebral column and the skull, protecting the nervous system, characterize the vertebrated* class; and this is wanting in all the inferior invertebrated animals. This is one of those great organic distinctions which bar a translocation of life from one class to another; any pretended transmutation here would be simply fabulous, as much as to pretend that a rock was changed into a tree.

'There can be no doubt,' says Professor Rymer Jones, 'that the nervous system must be regarded as the very essence of being of all creatures, with which their sensations, volitions, and capability of action are inseparably connected; and such being the case it is a legitimate inference, that the capacities and powers of the several tribes are in immediate relation with the development and perfection of this supreme part of organization, and their entire structure must be in accordance with that of the nerrous apparatus which they possess. 'The nature of the limbs and the cxternal members, the existence or non-existence of certain senses, the capability of locomotion, and the means of procuring food, must be in strict correspondence with the powers centred in the nervous masses of the body, or in that arrangement of nervous particles which represents or replaces them.'

"Which consists of fishes, reptiles, birds, and manmals. The volume of the brain is proportionally larger as the animal occupies a more elevated scale in the rank of life. 
Now more than this need not be stated here, as our object is only to press the consideration of organic distinctions. The reader however will not forget that in the Theory of Transmutation it is held that there has been a gradual change from the lower forms up into the vertebrated class; indeed, without this supposition the Theory would be as much at a stand-still, as we have seen it to be at the starting-point, where Mr Darwin fairly acknowledged that he could not account for the first Transformations. In his Theory, however, creatures have been transformed from the first spore of a sea-weed into the lowest Protozoa, from the Protozoa to the Mollusca and crustacean-and then, by some happy leap, into the vertebrated animal. But to this we reply that an animal must either possess the vertebral column, or be without it; and that if it has the vertebral column it has the brain, and the whole nervous system in a new arrangement, and for higher purposes of life. If therefore the transmutation has ever taken place, it has been an immediate operation, that is, an operation without any intermediate delay, it has not been effected in millions of ages by Natural Selection, but it has been done at once. The vertebral column has been formed for the occasion; and this, in other words, is an act of creation.

Now in this particular point $\mathrm{Mr}$ Darwin has already met us, by acknowledging more than we ever could have expected from him, for he has told us that the common first ancestor of all vertebrated animals" had many vertebræ.

* In one passage Mr Darwin has deseribed our eommon prototype in a way to suggest the idea of the great sea-serpent. 'It may be inferred that all vertebrate animals having true lungs have deseended by ordinary generation from an ancient prototype, of which we lnow nothing, furnished with a floating apparatus or swim-bladder' (210); this eoupled with 'the 
There was therefore no violation of the distinction of organization laid down by nature in this case; the first vertebrated animal did not pass by slow degrees from the lower form of life into the higher, but was made or created the first ancestor of all vertebrated animals that have ever since existed.

The Transmutationists having made this concession must abide by the consequences.

The lacteal provision for the nurture of their young exhibited in the mammalia is a broad mark of distinction within the section of vertebrated animals. The reptiles are thus widely separated from the mammiferous animalsay a crocodile from a sow; and the whale, which suckles its young, from all the fishes of the sea. This, in fact, tells us a whale is not a fish. Earth, air, and water have their mammiferous animals; in the air we find them among the bats, and on the earth we see them everywhere. 'This provision is a physical and even moral advance in animated nature, for amongst the animals thus furnished man himself takes his place; and wherever the mother's breast is, there is there a strong parental affection for the offspring.

'The fishes and the reptiles * abandon their eggs and leave to nature their future destiny; the whale is passionately attached to its young, and will brave every danger

many vertebre' of the great prototype brings our venerable sire into close approximation with the sea-serpent. If this disputed creature should be caught some day, we may live to see the great prototype's skeleton in the British Museum.

* 'There are in the reptilia both viviparous and oviparous species, but the foetus in the former has no attachment to the womb, and the eggrs in the latter are hatched by extraneous warnth; the young, after exclusion, receive no parental care or tuition in any species of the class.'-Owen. 
for their protection. In the manifestation of this passion we see something that deeply interests us, we begin to feel that there is some communion between us and animals. The animal whose breasts bind it with ties of affection to its little ones, is, in a point that touches us nearly, very like ourselves.

Amongst select classes of the vertebrated animals the mother is supplied with milk, but amongst animals of a widely different character the parental affection is, nevertheless, elicited in strength, as amongst the birds and some of the insects. The structure of these creatures does not admit the foetal growth of the young and the corresponding secretion of milk; but by other ordinations of nature the young animals whose early existence requires aid and protection, find it in the affection of their parent, for if Nature does not herself nurture and educate the progeny, she arranges* that the parent animal shall administer to all the needs of the helpless offspring.

Now amongst the manmalia this great distinction is an obstacle to transition from the other vertebrated animals, obviously arranged by general plan and design. That an animal without milk and without care for its offspring,

* This is more markedly shown to us in the habits of the ostrieh. The young birds liatched in the torrid zone of Africa are left to take care of themselves, as the heat is suffieient for their growth, and they can find their own food; but towards the Cape, where the elimate is less warm, the mother ostrieh watehes over her young with the greatest care, and attends to their wants. 'Aussitôt que les jeunes autruehes sont éeloses, elles sont en état de mareher, et même de courir et de ehereher leur nouriture; en sorte que dans les zones torrides, où elles trouvent le degré de elıaleur qui leur convient, et la nourriture qui leur est propre, elles sont emaneipées en naissant, et sont abandonnées de leur mère, dont les soins leur sont inutiles: mais dans les pays moins ehauds, par exemple, au Cap de boune esperanee, la mère veille a ses petits tant que ses sceours leur sont nécessaires, et partout les soins sont proportionnés aux besoins.'--Buffon. 
should acquire milk and be attached to its young, is as impossible as to change the structure of its heart, or to alter the convolutions or proportions of the brain.

The general organic distinctions to be observed in the vertebrated animals cannot be better expressed than in the words of Cuvier:-

'Vertebrated animals offer four grand subdivisions or classes characterized by the sort or the force of their movements, which themselves depend on the quantity of their respiration-observing always that it is from respiration that the muscular fibres derive the energy of their irritability.

'The quantity of respiration depends on two factors: the first is the relative quantity of the blood which in any one instant is presented to the organ of respiration; the second is the relative quantity of oxygen which enters into the composition of the circulating fluid.

'The quantity of blood which is respired depends on the disposition of the organs of respiration and of those of circulation.

'The organs of circulation may be double, so that all the blood which arrives from the various parts by the veins should be obliged to go for circulation in the organ of respiration before it returns to the parts by the arteries; or they may be simple, so that one portion only of the blood which comes from the body should be obliged to pass by the organ of respiration, whilst the rest returns to the body without having gone for respiration.

'This last case is that of reptiles. Threir quantity of respiration, and all the qualities which depend on it, vary according to the proportion of the blood which is sent to the heart at cach pulsation. 
' Fishes have a double circulation, but their organ of respiration is formed for the medium of water, and their blood is not acted on except by the portion of oxygen dissolved or mixed in the water, so that the quantity of their respiration is, perhaps, still less than that of reptiles.

'In the mammifers, the circulation is double, and the respiration, which is that of the air, is simple-that is to say, it is effected by the lungs alone. Their quantity of respiration, then, is superior to that of reptiles, on account of the form of their organ of circulation; and superior to that of fishes, on account of the nature of the element which surrounds them.

'But the quantity of the respiration of birds is superior, again, to that of quadrupeds, because they not only have a double circulation, and respire the air ; ${ }^{*}$ but, again, because their respiration is by many other cavities besides the lungs, as the air penetrates through all their body, and bathes the branches of the aorta, or the artery of the body, as well as those of the pulmonary artery.

'From all this result four sorts of movements to which the four classes of vertebrated animals are more particularly destinated.

"The quadrupeds, with whom the quantity of respiration is moderate, are generally made for walking or running when they put forth their strength.

"The birds, with whom the respiration is greater, have vigour of muscles and lightness necessary for flight.

'The reptiles, whose respiration is weaker, are condemned to creep, and many of them pass a portion of their lives in a sort of torpor.

* That is, birds have a double advantage of respiration by the many cavities of their body filled with air, as well as their double circulation which they have in common with the mammifers. 
'And, lastly, the fishes in order to execute their movements have to be sustained in a liquid of almost the same specific weight as themselves.

'All the circumstances of organization proper to each of the four classes, and especially those which concern movement and the exterior sensations, are in necessary relation with those essential characters (of circulation and respiration).*

'Nevertheless the mammifers have peculiar characters in their viviparous production of their young, in the manner by which the foetus is nourished in the womb, by means of the placenta, and by the teats with which they nourish their young.

'On the contrary, all the other classes are oviparous; and if we compare them with the first class (quadrupeds), we find in them numerous resemblances, which reveal a special plan of organization for them, in the grand general plan of all the vertebrated animals.'

'This analysis of the various categories of the vertebrated classes is stated in the concentrated form of general principles, but in a more extended explanation it is observed that the animals which respire immediately and have a double circulation, and in which none of the venous blood can return to the various parts until after respiration, that

\footnotetext{
* 'Les quadrupeds, où la quantité de respiration est moderée, sont generalement faits pour marcher et courir en développant de la force ; les oiscaux, où elle est plus grande, ont la vigueur de muscles et la légéreté necessaires pour le vol; les reptiles, où elle est plus faible, sont condamnés a ramper, et plusicurs d'entre cux passent une partie de leur vic dans une sorte de torpeur: les poissons enfin ont besoin, pour executer leurs mouvements, d'être soutenus dans un liquide spécifiquement presque aussi pesant qu'eux.

'Toutes les circonstances d'organisation propres à chacune de ces quatre classes, ct nommément eelles qui concernent le mouvement et les sensations extéricures, sont en rapport néeessaire avee ces caractères essentiels.'
} 
is to say, birds and mammalia not only always live in the air and move in it with greater force than the other redblooded animals, but each of those classes enjoys the faculty of motion precisely in a degree corresponding to its quantity of respiration.

Birds which are always in the air are equally impregnated with that element both internally and externally. The cellular part of their lungs is not only very considerable, but these organs have sacs and appendices which are prolonged throughout the body.

Birds therefore consume within a given time a much greater quantity of air, in proportion to their bulk, than quadrupeds. It is owing to this circumstance that their fibres have an instantaneous force so very great, and which renders their flesh capable of becoming the moving power in machines which require actions so violent as to sustain them in the air by the simple vibration of their wings.

With respect to the force of their motion and quantity of respiration, the mammiferous animals seem to hold a middle place between birds and reptiles, which form the opposite extreme. With these, respiration appears to be only an accessory circumstance: they may dispense with it at pleasure. Their pulmonary vessels are merely branches of the great trunk. Their organs of motion reduce them to remain on the earth in obscure and close places, often amidst foul air; and their instinct frequently prompts them to shut themselves up in cavities in which the air cannot be renewed, or to bury themselves under water during a good portion of the year. Their motion is very slow, and they pass a great part of their life in complete repose.

The circulation of fishes is indeed double, like that of 
warm-blooded animals; but as it is air mixed with water which acts on their blood, it is necessary that the little activity of the element should be counterbalanced by the prompt return of the blood into the pulmonary organ. The velocity with which some of them swim must not mislead us in an estimate of their muscular force; for, as they are placed in an element as heavy as themselves, no force is requisite for their support.

In close connection with the respiration and circulation of those various classes of animals is the peculiarity of the blood. Reptiles and fishes are cold-blooded; but in the blood itself of various animals the form of the particles is very various.

The globules of the blood of all mammalia that have been examined are discs of a circular shape, and smaller than in any other class of animal; whilst in birds, fishes, and reptiles they are of an elliptical shape.

Among the invertebrate animals the globules of the blood are much less regular in their forms. Their surface is uneven and tuberculated like that of a raspberry; their contour is very variable, they change their figure with the greatest facility, and the size, by comparison, is considerable.

The blood of reptiles presents particles remarkable for' the large relative size, and 'the size increases in the ratio of the persistence of the branchial organs' (Owen). The blood-dises of the Siren can be discerned by the naked eye, and are very greatly larger than those in the human blood.

The red particles of the amphibia are the largest known. Those of a frog's blood being taken as a standand of com- 
parison, and observed under* the microscope side by side with those of other animals, it is found that those of birds are about one half the size of those of a frog; that the red particles of the salamander are not quite one-third larger than those of a frog, and rather more elongated: the bloodparticles of the lizard, compared with the same bodies from the frog, are about two-thirds the size; and the circular discs of human blood measure only one-fourth the long diameter of the elliptical particles of the frog's blood, and only one-twelfth the long diameter of the particles of the Siren. The circular particles of the musk-deer are exceedingly small, surpassed twenty times at least in size by those of the frog.

All this has been revealed to us by the microscope, and has taught us that which never could have been suspected, the systematic difference of the corpuscules of the blood, perceptible in different classes of animals; and has shown that the difference is not regulated by the bulk of the body, as it would be natural to conjecture, but rather in the direction of an inverse proportion, so that in most cases the larger animal has the smaller particle. In this way we might almost say that the fable of the ox and the frog is reversed, for if the frog could not with his utmost efforts inflate himself to the size of the ox, the ox could as little hope to equalize the minuter particles of his blood with those of the frog.

The cause of this difference in size and shape of the blood-particles will probably never be satisfactorily explained; it is, however, one of those fundamental distinctions of original structure which establish dissociation with

* Müller's Physiology. 
impassable obstruction; different bloods are differently constructed, and cannot be injected into veins of different animals without fatal consequences.

If the blood introduced into the veins of a living animal differs merely in the size, not in the form of its globules, a disturbance or derangement of the whole economy, more or less remarkable, supervenes: the pulse is increased in frequency, the temperature falls rapidly, the alvine secretions become tinged with blood, and death generally happens after the lapse of a few days. The effects produced by the injection of blood having circular globules into the veins of an animal the globules of whose blood are elliptical, or vice versâ, are still more remarkable; death then usually takes place amidst nervous symptoms of extreme violence, and comparable, in their rapidity, to those that follow the introduction of the most energetic poisons."

The application of these facts as an answer to the Theory of Transmutation is obvious, as the supposed change of animals would have to encounter this obstacle, and to admit into the veins of the transforming animal a stream of death in parting with its own proper original stream of life. In that Theory it is gravely suggested that the bird came out of the reptile, partly owing, it is to be presumed, to their contemporaneous appearance in geological record, and partly to some peculiarity of internal structure. We hear on good authority that 'the crocodile is the connecting link between Reptiles and Birds, and in almost every part of its body it presents a type of structure almost intermediate between the two. The stomach of this creature might, in fact, be almost mistaken for the gizzard of a rapacious bird. The

* Milne Edwards, who refers to the experiments of Messrs Prevost and Dimas. 
æsophagus terminates in a globular receptacle, the walls of which are very muscular, and the muscular fibres radiate from a central tendon precisely in the same manner as those of a bird, * \&c. This is quite enough for a Transmutationist; with this degree of similarity the next step to the change of the reptile into the bird would be very easy. In this school similitude, with sufficiont time intervening, is the same thing as metamorphose.

In a common-sense view of the subject such a transition must appear, of any that could be suggested, the least probable: for, taking reptiles as we fird them, and especially the crocodile, we should, without the revelations of anatomy, be unable to find in that animal any the most distant resemblance to a bird of prey, except in its rapacity and ferocity. Comparative anatomy, however, detects many unsuspected facts; but still, even with this evidence of comparative anatomy, we should say, in the supposition of such a change as this, that a cold-blooded animal had to be transformed into one of the warmest temperature; that a tripartite heart had to be changed into one of four cavitios; that an animal of the lowest respiration had to pass into a process of the highest; and to assume a blood of different-sized particles, thongh such a change is, as we have seen, decreed to be impossible by a law of Nature.

To these difficulties we should have to add the change of the animal's nature in the view of character. The reptile that leaves its progeny to chance, and is indifferent to its existence, would have to assume a disposition characterized by strong affection to the young brood, with a heart more changed in a moral aspect than the other physical change of the great pulsatory cavitics of circulation.

$$
\text { * Jones, Animal Kringdom, } 562 .
$$


In addition to all these considerations there would be the total change of the whole creature in its aspect, the use and destination of its limbs, the wonderful remodelling** of the limbs, its general habits, and all its relation to the external world. Comparative anatomy, therefore, helps the Transmutationists but little; on the contrary, it seems to increase their difficulties, by approximating animals in certain points, and bringing them as it were together, as if to make manifest the exceeding great difference and strong dissimilarity in general character and habit. It has done this in the instance of the man and the ape, and in Mr Darwin's favourite example, the horse and the tapir, and here we have it again in the reptile and the bird.

In the mean while, in spite of these similarities of comparative anatomy, there are organic distinctions, as we have seen, which interpose with a strong prohibition in the scheme of gradual change; and these distinctions are of

* 'The bones of birds, espeeially those of flight, present the opposite extreme of lightness; not but that the osseous tissue itself is more eompact than in most nammalia, but its quantity in any given bone is mueh less, the most admirable eeonony being traeeable throughout the skeleton of birds in the advantageous arrangement of the weighty material for the office it is destined to perform. Thus in the long bones, the cavities, analogous to the medullary in mammals, are more extensive, and the solid walls of the bone mueh thinner. A large aperture ealled the foramen pmeumaticum, near one or both ends of the bone, communieates with its interior, and an air-eell or prolongation of the lung is eontinued into and lines the eavity of the bone, which is thus filled with rarefied air instead of marrow. The extremities of the bone, instead of being oeeupied by a spongy diploë, present a light open network, slender eolumns shooting across in different directions from wall to wall, and these columns are likewise hollow. The vastly-expanded beak, with its hornlike process, in the Hornbill, forms one great air-eell, with thin bony parietes: and in this bird, in the Swifts, and the Humming Birds, every bone of the skeleton, down to the phalanges of the claws, is pneumatie.'-Owen.

We eannot but admire the great ability, scienee, and skill exhibited by Mr Darwin's 'Sequenee of events as observed by us,' in produeing such a strueture, and the more so as it has been produeed without object, ain, or lesign. In Mr Darwin's theory the bones of a bird are a lucky hit, one of the best throws in the gane of chance ever recorded. 
greater weight in the scale of life than the anatomical analogies.

Mr Darwin, who does not tell us from what antecedent animal a bird was formed, seems to think that the only difficult point in the manufacturing of birds was making a pair of wings, just, we may presume, as Dædalus supposed, when he fabricated wings for his ill-fated son : but everything in the bird, if elaborated out of some other animal, had to be changed,--many important points of its internal structure, the circulation of its blood, its lungs, its respiration, the form of its bones, the texture of its bones, its skeleton, its muscles, the arrangements and number of its nerves, the mould and texture of its eye, * its mind and its will; and all changed simultaneously, if ever such a dream was realized as the mutating a wingless animal into one that could soar into the air with plumed body and wings.

'It might require a long succession of ages,' says $\mathrm{Mr}$ Darwin, 'to adapt an organism to some new and peculiar' line of life, for instance, to fly through the air, and consequently the transitional forms would often long remain confined to some one region: but when this adaptation had once been effected, and a few species had thus acquired a great advantage over other organisms, a comparatively short time would be necessary to produce many

* Cuvier's description of the cye of the bird deserves attention : 'L'œil des oiscaux est disposé de manière à distinguer également bien les objets de loin et de près; une membrane vaseuleuse et plissé, qui se rend du fond du globe au bord du cristallin, y contribue probablement en deplacant cette lentille. La face anterieure du globe est d'ailleurs renforće par un cercle de pièces osseuses; et, outre les deux paupières ordinaires, il y en a toujours une troisième placée à l'angle interne, et qui, au moyen d'un appareil musculaire remarquable, peut couvrir le devant de l'œil comme un rideau. La cornée est très convexe, mais le cristallin est plat, et le vitré petit.' 
divergent forms, whieh would be able to spread rapidly and widely throughout the world' (328).

From this passage we learn a eurious history of birds: it required a long suceession of ages to adapt the organisms to this 'new and peeuliar line of life'-doubtless, very long- - that is, it required the lapse of untold ages to make the first bird; the process was going on eonfined to some one region on the faee of the earth; intermediate forms between the first attempt and the last, amounting to an enormous number of experiments, were eoming into existenee, and undergoing extermination, always, however, in the direction of the true bird; and at last, after a hundred or two hundred million of ages, more or less, a real bonâ fide bird, eock and hen, eame forth trimmphant, out of the slaughter of innumerable aneestors.

What sort of bird this might be we are not informed, it might be an eagle or it might be a dove; and perhaps the dove was the more probable form, as the prey has to be made before the bird of prey. At any rate 'the new and peeuliar line of life' was secured, and after that, the process of bird-making went on with suecess, eomparatively in a short time; nay, more than this, "many divergent forms spread rapidly.'

This comparatively short time and this rapidity are, indeed, violent invasions of the. fundamental law of the system, for Mr Darwin has repeatedly laid it down that 'Natural Seleetion always acts very slowly' (114); but in this history of birds thcre was mueh to aeeount for, as the feathered tribe is rich in orders, families, genera, speeies, and sub-speeies, and to eoneede the usual measure of time which the Theory requires, for each distinct species, would be making too large a demand even on the millions of 
ages with which this Theory has made us familiar. Thus the process had to be hastened, for when 'the adaptation had been once effected,' a facility of change hastened the process of mutation, and the winged tribes found comparatively little difficulty in producing new orders and families, as circumstances seemed to encourage the 'plastic tendencies' of their organizations.

But though Natural Selection was thus accelerating matters for the emergency, the other principle, extermination, was by no means dormant, for we are informed that ' extinction has played an important part in defining and widening the intervals between the several groups in each class. We may thus account even for the distinctness of whole classes from each other-for instance, of birds from all other vertebrate animals - by the belief that many unusual forms of life have been utterly lost, through which the early progenitors of the birds were formerly connected with the early progenitors of the other vertebrate classes' (463).

'Thus, by the process of 'believing' as a substitute for' proof, we are to understand that such was the process. Many 'unusual forms' in the progress of bird-making have been utterly lost: these forms nust indeed have been by myriads to account for the distinction at last effected, when, 'in a long succession of ages,' the real bird was at last produced, to say nothing of the countless experiments lost in comnecting the various orders and species of birds. All these unusual forms, exterminated in the Struggle for Life, have disappeared, and can nowhere be found, and so it is that we see the bird separated from all vertebrated animals by an apparently vast chasm, and all the fanilies of birds separated from one another. This 
presents an appearance to us of a design, as if birds had been created as we see them-but this is an illusion, simply owing to the loss of all the intermediate animals of unusual form, which 'we are to believe' would make one unbroken chain of connected organization, if only the links could be discovered.

Such, then, is the history of the origin of birds according to the doctrine of Transmutation; whether it presents to our apprehension a wiser, less improbable, and less miraculous contrivance than that which is usually understood by creation, the reader must judge.

After such lucubrations as these it is a real pleasure to turn to the instructions of one of Nature's most successful interpreters, the illustrious Cuvier. On the great subject of Organic distinctions he has, in an admirable manner, pointed out to us the intimate conuection which exists between the whole organization of an animal and its destinies in life. 'Every organized being,' says he, 'forms a whole, an unique and perfect system, the parts of which mutually correspond, and concur in the same definitive action by a reciprocal reaction. None of these parts can change without the whole changing, and consequently each of them, separately considered, points out and marks all the others. Thus, if the intestines of an animal are so organized as only to digest flesh, and that in a fresh state, it follows that its jaws must be constructed to devour prey, its claws to seize and tear it, its teeth to cut and divide it; the whole structure of the organs of motion such as to pursue and catch it; its perceptive organs to discern it at a distance: Nature must even have placed in the brain the nccessary instincts to know how to conceal itself and lay snares for its victims. 'That the jaw may be enabled to seize it must have a cer- 
tain-shaped prominence for the articulation, a certain relation between the position of the resisting power and that of the strength employed with the fulcrum; a certain volume in the temporal muscle, requiring an equivalent extent in the hollow which receives it, and a certain conyexity of the zygomatic arch under which it passes; this zygomatic arch must also possess a certain strength to give strength to the masseter muscle.

' That an animal may carry off his prey a certain strength is requisite in the muscles which raise the head; whence results a determinate formation in the vertebræ or the muscles attached, and in the occiput where they are inserted.

"That the teeth may cut the flesh they must be sharp; and they must be more or less so according as they will have, more or less exclusively, flesh to cut. Their roots should be more solid as they have more and larger bones to break. All these circumstances will, in like manner, influence the development of those parts which serve to move the jaw.

'That the claws may seize the prey they must have a certain mobility in the talons, a certain strength in the nails, whence will result determinate formations in all the claws, and the necessary distribution of muscles and tendons : it will be necessary that the forearm have a certain facility of turning, whence again will result determinate formation in the bones which compose it ; but the bones of the forearm articulating in the shoulder-bone cannot change its structure without this latter also changes.

'In a word, the formation of the tooth bespeaks the structure of the articulation of the jaw; that of the scapula indicates that of the claws; just as the equation of a curve involves all its properties; and in taking each property separately, as the basis of a particular equation, we should 
find again both the ordinary equation and all the other certain properties; so, the claw, the scapula, the articulation of the jaw, the thigh-bone, and all the other bones, separately considered, require the certain tooth, or the tooth requires them reciprocally; and, beginning with any one, he who possessed a knowledge of the laws of organic economy would detect the whole animal.

'We see, for instance, very plainly, that hoofed animals must all be herbivorous, since they have no means of seizing on their prey. We see, also, that having no further use for their forefeet than to support their bodies, they have no occasion for so powerfully-framed a shoulder; whence we may account for the absence of the clavicle and acromion, and the straightness of the scapula. Not having any occasion to turn their foreleg, their radius will be solidly united to their ulna, or, at least, articulated by a hinge-joint, and not by a ball and socket, with the humerus. 'Their herbaceous diet will require teeth with a broad surface to crush seeds and herbs; this breadth must be irregular, and for this reason the enamel parts must alternate with the osseous parts. This sort of surface compelling horizontal motion, or the grinding of the food to pieces, the articulation of the jaw cannot form a hinge so close as in carnivorous animals: it must be flattened, and correspond with the facing of thic temporal bones, more or less flattened. This temporal cavity will only contain a very small muscle, - will be small and shallow.

'We have no difficulty, then, in understanding that an animal is a complete machine, with harmonies and correspondent provisions in every part of its organization: that the whole creature, in the integrity of its being, recognizes its own character, and executes its orn will by the concur- 
rent aid and perfect agreement of every distinct portion of its body: that there is nothing empirical in its structure, nothing mutable or fluctuating in its system; and that no cliange, in the true meaning of change, could take place in any of its parts without impairing the whole, which is perfect in the consentaneous perfection of all its members, directed to one object and operating with one aim, to fulfil the preordained destinies of the animal's life.'

Every animal that exists is, for the purposes of its existence, as perfect as it can be; and is as far out of the reach of ideal improvement, and 'beneficial changes in a slight degree,' as the sun itself, whose light and heat sustain the existence of every organic being. 


\section{CHAPTER XV.}

\section{THE ARGUMENT OF DESIGN.}

AfTER these multiplied considerations of the Theory before us, we approach the concluding question which involves the whole argument, is there a dosign in the existence of plants and animals? Have they been brought into being for a special purpose according to a preconceived plan? or is their appearance the uninfluenced result of circumstances, and a natural sequence of events without any specific design or particular object?

The Theory of course denies any idea of design, and that too in precise words, as well as in the general discussion; and, in this respect, whenever the question seems to incline towards the notion of creation, it is uniform in its statements. Mr Darwin has carefully considered all the vulner, able parts of his Theory in the presence of a creative design, and has guarded them from that quarter where danger is most apparent, to the best of his abilities. Nevertheless, the Theory is not invulnerable, for as the heel of the infant Achilles was covered by his mother's hand when she plunged him in the waters of Lethe, so this Theory has not, in every portion, been thoroughly imbued with Atheism, as its parent has kept one little spot untouched-the 
breathing of life into the primordial spore-an exception which leaves the whole theory open to a death-wound.

But though Mr Darwin, with this one exception, which he apparently could not avoid, has been so watchful in warding off creation; he has without scruple admitted a designing and contriving power of his own invention, which he invests with the most marked attributes of the creator, and in such large terms as he would certainly consider superstitious and credulous if applied to the interposition of a Divine Power. We have seen a good deal of this already, we shall see more of it presently.

But truly he must be a courageous man who can contemplate all the forms of life in this our globe, all the structure of animals and plants, all the habits of different animals and the parts they sustain in Nature, and all the vast variety of their tribes constituted to enjoy life in certain special climates, removed from which they*. could not live,

* We must suppose that when the author of nature creates an animal or a plant, all the possible circumstances in which its descendants are destined to live are foreseen, and that an organization is conferred upon it which will enable the species to perpetuate itself, and survive under all the varying circumstances to which it must be inevitably exposed. Now the range of variation of circumstances will differ essentially in almost every case. Let us take, for example, any one of the most influential conditions of existence, such as temperature. In some extensive districts near the equator, the thermometer might never vary through several thousand centuries, for more than $20^{\circ}$ Fahrenhcit; so that if a plant or animal be provided with an organization fitting it to endure such a range, it may continue on the globe for that immense period, although every individual might be liable at once to be cut off by the least possible excess of heat or cold beyond the determinate degree. But if a species be placed in one of the temperate zones, and have a constitution conferred on it capable of supporting a similar range of temperature only, it will inevitably perish before a single year has passed away.'--Principles of Geology, ii. p. 351, 3rd edition.

These sentiments it is to be presumed Sir Charles Lyell must now repudiate, under the influence of the Lamarckian system of which he has become the advocate. If he is faithful to his new creed, the crcator and the plan of creation inust of necessity be repudiated. 
and yet in the face of all this shall deliberately say there has been no design here, and no superior intellect ordaining what we see. IIe that says this has to believe that when different forms of life answer to one another perfectly, it is a mere accident; and that when certain creatures have special habits and characters with all their organization corresponding with their habits and instincts, that it is a mere accident,-that all the instincts of animals either as private individuals or as members of a society are accidental,- - and that whatever has hitherto been noticed as a plain proof of design, is on the contrary nothing but 'the sequence of events as ascertained by us.' He has to believe that a spider was not made to catch insects, and that the art of making its web was not imparted to it for that purpose; that no carnivorous animals, on land or in the waters or in the air, were designed to keep down the redundancy of those animals which constitute their prey; that certain birds and other animals were not made to live in the trees; that fishes were not designed for the water, nor winged creatures to soar in the air; that the various modes of rearing the young of animals are accidental; that milk was not prepared for the mother's breast; that insects were not framed for any of the functions they perform, that their extra-fœtal transformations are fortuitous and not regulated by any plan; that the products of the earth were not intended to support animal life. In one word, that all these things, if they be beneficial and answer useful purposes, are the unintentional result of blind matter pushing its way in the world at random, withont any definite object, and after innumerable and incalculable instances of failure, at last hitting on the arrangement which has turned out to be right. 
In vain is it that to the advocates of this system you present the most striking instances of adaptation of parts for a function, the most marvellous instances of instinct, the most curious habits and contrivances of certain animals kept up from time immemorial as the sacred traditions of their race, the arts, the architecture, the expedients, the inventions, the economies, the precautions of thousands of creatures in their sphere of life. To all these examples the answer is, "True, this is a very curious result, and has the appearance of a plan; but it never was intended that by any of these arrangements any particular object should be secured. Natural Selection has indeed at last effected that the most beneficial organization should, after innumerable failures, be the characteristic of the animal that has survived, and has outlived the extermination of its predecessors ; and because its organization suits its mode of life, it is now an established member of the animal kingdom; but this is not a design-it is the mere sequence of events : and there is nothing more wonderful in those phenomena which are called the contrivances of Nature than in the fact that water should freeze at a low temperature, or that sugar should melt when thrown into water.'

Neither in this system can beauty either in colour or in form, or in the execution of any intricate contrivance, be admitted as any part of a plan of Nature. If the landscape is beautiful; if the heavens are glorious to behold; if all the wealth of Nature's wardrobe shines in gorgeous show; if Solomon in all his glory was not arrayed like one of the lilies of the field; if the animals are of surpassing beanty in

* It must be remembered that Mr. Darwin has said, 'some naturalists belicve that very many structures have becn created for beanty in the cycs of man, or for mere varicty. This doctrine, if true, would be absolutely falal in my theory' (219). 
their forms, their colours, their clothing, and the grace of their movements; if the song of birds is sweet, and every country sound charming to the observant mind; none of these varieties of the beautiful were intended to please or to produce admiration; they are an accident. We must take them as we find them, but never confound a rigorous sequence of events with a studied plan. We have seen that the beauty of male birds is attributed to the coquetry of the females, preferring the accidental distinction of a new feather in certain males. These males, more favoured than others of their sex, owing to the new feather in their plumage, were selected partners in the breeding senson; and so by degrees new feathers coming more and more into favour, in thousands of ages, a bird with the splendid plumage of the tropics was finally established.

This is the theory to account for beanty of plumage that a great Physiologist has had* the courage to propound; and this is the theory which other Plyysiologists have been able to digest! to such miserable puerilities has the severe and cautious study of Nature descended in this School.

It may cheer us for a moment after hearing such sentiments to listen to an opposite expression of thought suggested by a contemplation of Nature.

' Tlower's may be regarded not only as the last, but the

* 'I see no good reason to doubt that female birds by selecting during thousands of generations the inost melodious or beautiful males, according to their standard of beauty, might produce a marked effect' (91).

It would appear therefore that the beauty of male birds is not according to any real standard of beanty, nor is it the arrangement and painting of that master mind from which all beauty is derived, but is simply an expression of the feeling of the hens! We cannot be too thankful to the hens for the taste they have thus manifested; we may, however, presume that the result may be accepted as conpletely successful, as it is thus moved that hens and not creation were the inventors. There can be no objection in the Theory to praise the taste of a hen. 
most elaborated organs of the vegetable system. Whether we contemplate the beauty of their forms, the splendour of their colours, or the delicious fragrance they everywhere breathe around us; or whether with a physiological eye we survey the delicacy of their structure, and investigate the peculiar functions they perform; we cannot but feel the greatest admiration of the skill with which, in a compass so small, and by means apparently so simple, such a series of actions, terminating in results so varied and important, can be at once combined and regulated.'*

But if the difficulties in the denial of design in Nature is great in these instances of external appearance, immeasurably greater are they when we approach the profound teachings of comparative anatomy, and consider, in the great though imperfect light of modern discoveries, the structure of the animal frame, the parts prepared for the animal's peculiar life and habits, and those which relate to the circulation of its blood, its respiration, nutrition, and reproduction. We have seen something of this in the last chapter, and of course many more chapters might be written on such a theme without exhausting the subject. But whatever anatomy reveals to us of the surprising provisions in the animal frame, whatever is intricate and perfect in adaptation, and whatever moreover is not yet understood in the functions of all the parts is, in this system, to be attributed solely to the Sequence of ascertained events: they are events the result of time, and of matter working itself into certain conditions; mind and forethought have had no part whatever in planning and constructing them.

If we speak according to Mr Darwin's more serious in-

Supplement, Encyclopredia Britannica, Article, "Vegetable Physiology. 
terpretation of his meaning, then the formation of an eye on optical principles is simply an event; it is so because it is so, but it never was designed to secure the faculty of sight by an eye. If, however, we make use of his more favourite language, and nount with lim his hobby, then Natural Selection made the first eye; and this we shall presently see he describes as a fact in entlusiastic language. In the same way Natural Selection constructed the first stomach, the first intestines, the first biliary duct, the first heart, and the veins and the arteries, and the whole apparatus of respiration.

The curious part of this system is, that though its author tells us he has such confidence in his metaphor, as to attribute to its operation alone all the most admired contrivances discoverable in Nature, yet he seems to feel no difficulty whatever in attributing to Ignorance and Impotence all that has hitherto been considered inseparable from Wisdom and Power. In the question of transforming a low grade of animal life into a higher, of improving its organization, there is nothing to undertake the process that has any intellect. Let us suppose the case of the promotion of a toad, or a worm, in the scale of life, there is nothing to begin the move but the animal's orrn body; and if we were to concede that a toad wished to improve his organization, the creature could think of nothing better, nor make the slightest move, we will not say, in the right direction, but in any direction whatever towards a change. But the trinsmutations nevertheless take place, the anatomical structure is altered, and changes involving an intuitive knowledge of all the profoundest secrets of Physiology, in all its branches, are duly effected when there is no intellect at all employed in the change, nor any definite plan or ob- 
ject for which the change is made. Thus it comes out that perfect Ignorance and perfect Helplessness produce the wisest, the most complete, and the most wonderful objects in Nature. Give Inability, Ignorance, and Nothingness only time enough, and they will be able to accomplish anything. It is not wisdom and power that create wonders, but Ignorance and Inability. If anything is really admirable in nature it has come to be so by blundering; you see at last the success, but you do not see the hundred thousand or the million blunders by which the success has been obtained. It is blundering and not wisdom that has filled the world with wonders of art and beauty.

Now, that it is only a question of time for Non-Intellect to do everything will be apparent in the following passage. Mr Darwin first asks to be allowed to personify nature, when he really means 'the natural preservation of varying and favoured Individuals during the Struggle for Existence'- -in other words, Natural Selection: he then adds, 'How fleeting are the wishes and efforts of man, how short is his time! and consequently how poor will be his products compared with those accumulated by nature (Natural Selection) during whole geological periods. Can we wonder, then, that her productions should be far truer in character than man's productions, that they should be infinitely better adapted to the more complex conditions of life, and should plainly bear the stamp of far higher workmanstipp' (Ss).

So then, only allow Non-Intellect sufficient geological time, and great will be the result! We must here, however, observe how systematically Mr Darwin deceives himself by metaphorical language; he tells us that "her works bear the stamp of a far higher workmanship' -when we 
inquire what this precisely means, we find that Nature is Natural Selection; and then we discover that Natural Selection is the Sequence of Events! and thus events are turned into workmen, and results into artificers!

As, however, there is another light in which the workmanship can be contemplated, the light which common sense and right reason afford, we will, in this other exhibition of it, see what effect can be produced by the report of a faithful witness. Valentin, in the first pages of his Text Book of Human Physiology, makes the following excellent remarks :-

'The capacities of self-preservation and propagation recur in every kind of living being. As it was necessary that the order of the organic world should maintain itself without external and supplementary support-as it was necessary that the individual should be able to accommodate itself to internal and external change, and preserve the species in spite of the destruction of the individualboth of these capacities were indispensably called for. At the same time, they constitute the characteristic means of distinguishing the organic creation from those contrivances which are the result of human handywork.

'Every such apparatus requires a physical or chemical stimulus - a food as we may call it - to maintain the activity of its machinery, and thus bring about the intended effect. In this way the clock-weight conditionates the movement of the clock, the steam that of the steam-engine, and the combustion of its constituents the light of the candlewick. The like phenomenon recurs in living creatures. 'Their manifestations of force are always connected with a change of molecular proportion, or with a chemical inter- 
change of substance. In this way particular combinations are produced, which leave the body, and which must therefore be replaced by others, in order that it may subsist.

'But the food thus needed not merely serves to compensate these unavoidable losses, its surplus is frequently applied to the formation of new organs, to the perfection of old ones, and to the restoration of lost parts. And while in the case of our artificial contrivances, all these changes can only be induced through the instrumentality of the mind and hand of a human being foreign to the machine, organic bodies accomplish them by their own inherent forces, so that the living being fulfils at one and the same time the different functions of machine, attendant, and architect.

..... The organic being which possesses the capacity of applying the food it receives, not only to the nutrition of existing parts, but also to the construction of new organs, and which can defray unavoidable expenses or necessary restorations from the already existing structures of the body-presents an embryo as an additional product of nutrition. This embryo includes a certain sum of parts, which only require a particular food, in order that limb should arrange itself on limb, after a definite plan, until a new and independent being is created. But since the parent organisms only attain the capacities necessary for generation after a certain duration of life, the parents and their progeny are separated by an interval of time, the continual repetition of which secures the genera and species.'

Here, then, indeed the superiority of the works of nature is fully acknowledged, but they are spoken of as con- 
trivances, and as arranged after 'a definite plan,' implying that a power superior to any which man can bring into play ordained the original structure.

Thus, again, when the author is speaking of the composition of the skeleton, he says, "The proper mixture of cartilage with salts of lime, of compact with cancellated tissue, of rounded with angular forms, of uniformly contiguous segments with numerons elevations, depressions, enlargements, and processes-all this results in making the pieces of the skeleton hard levers, bases of support, and protective textures, such as the artifice of man * could never imitate' (24). And this, it appears to us, is the right way of stating the case, not so as to bring down the Supreme Intellect to a level with human skill, which is frequently the course pursued by popular writers, but to point out rather how inadequately man can imitate the contrivances observable in nature. The small modicum of our highest art and knowledge can scarcely be put in any degree of

* There is an exeellent deseription of the wing of the bird in Professor Phillip's 'Life on the Earth,' which, however, is too long to give here. The concluding sentences correspond with the general observations of Valentin :-

'This is exactly the arrangement indicated by the experiments of engineers, and the theories of inechanicians.... . but no human hands could make an apparatus embodying so perfectly the abstract truths of mechanical science, nor conld the luman mind with the materials given have predicted by any theory the arrangement which is found to be so complete. .....

'The scheme of feather, structure, and arrangement is altered in the tails of birds to suit the very different mechanieal purposes of that instrument-altered in the construction of the individnal feathers-in the direction of their planes, in the resultant of their strength. Henee the resemblance of the steering tails of the swift Falconidx, and Hirundines, and Sternidæ-in contrast with the stiff prop of the Picidie, and the almost extinction of the apparatus and suppression of the function in the acuminated tails of the Diving-birds. Every feather is altered when the work is different' (39). 
comparison with the absolute science and supreme art which have presided over the works of creation.

But in the Theory with which we have to deal, Absolute Ignorance is the artificer, so that we may enunciate as the fundamental principle of the whole system, that IN ORDER TO MAKE A PERFECT AND BEAUTITUI MACHINE IT IS NOT REQUISITE TO KNOW HOW TO MAKE IT. This proposition will be found, on a careful examination, to express in a condensed form the essential purport of the Theory, and to express in a few words all Mr Darwin's meaning; who, by a strange inversion of reasoning, seems to think Absolute Ignorance fully qualified to take the place of Absolute Wisdom in all the achievements of creative skill.

We, however, who do not accede to this fundamental principle, will select amidst the myriad-designed productions in Nature's vast storehouse one intimately connected with the animal structure, which, in its numerous complications and adaptations, argues antecedent knowledge, and a manifest intention to produce certain effects such as that prescience demanded. In the contrivances for the circulation of the blood this is everywhere apparent, and in considering all that has been brought into play for effecting this function, we affirm that a profound knowledge of the whole mystery of life, as far as it is at present understood, and very far beyond, must have been the foundation on which the whole proceeds, and that Intellect can only have been the originator of such a system.

Now, as the circulation, in various modifications, extends to almost the whole animal kingdom, though it is seen in its highest arrangement in the class of mammalia, the argument, if it can be established, will apply to the 
whole animal kingdom, and therefore will everywhere confute the doctrine of Transmutation.

The circulation starts from the first principle that life must be sustained as a continually moving power-as a vortex in which new materials must be unceasingly entering, and old and used ones incessantly departing. It supposes the known requisite for organic existence to be an unremitting change; that every part of the animal frame must be taking in new substance and giving out waste; that parts unseen as well as those seen--the firmest as well as the tenderest portions of the fabric, have need of renewal; that the brain and the bones, the fat and the muscles, must yield up the older particles to make way for others of a more recent formation; and that the stability of the whole is to be secured by its constant renovation.

Let us suppose now that, anterior to the appearance of any living animal, this method of existence had been proposed as indispensable, and that, with this problem to solve, and inert matter to work on, without any further aid or information, the solution had been left to luman ingenuity and powers of invention. Who could have grasped the problem, or who could have encountered this Sphinx, with her incomprehensible enigma? But we need not suppose this problem to have been proposed before the existence of animal life, for it is but as yesterday that the general principle lias been understood. For ages wise men had been poudering on the mystery of life without ascertaining the machinery with which it is sustained; so recondite are the designs that prevail in Nature's works, and so deep the wisdom that arranged them.

'The method to secure a constant renovation of all parts of the body has been by providing a fluid which should 
continually be visiting every part of the frame, and conveying in its progress the materials for the formation and nutrition of every part. For this three provisions are indispensable: the source which is to sustain the fluid in its requisite quantity; the proper quality of the fluid; and the motive power which is to keep it in continual progress. This fluid is the blood, supplied by the lymphatic and absorbent vessels, and some of the smaller veins communicating with the food taken into the body. The animal takes nutriment into its stomach that it may live; thus life depends on the digestive apparatus treating the food received in a peculiar manner, and after chylification, with other intermediate processes, converting into blood the solids and liquids that had been received for food.

'This fluid-aptly called 'the stream of life,' having the appearance to the naked eye of a homogeneous and uncompounded liquid of a uniform brilliant colour-contains many substances, detected, for the most part, by chemical analysis of a modern date. We hear of water, albumen, fibrine, fatty crystallizable matter, salt, soda, chloruret of potassium, alkaline sub-carbonates, phosphate of lime, of magnesia, of iron, peroxide of iron, \&c., \&c., carbonic acid gas, azote, oxygen, \&c. And, in addition to this list, it is believed by eminent* physiologists, that several other substances may yet be discovered. The albumen furnishes the base of a great number of tissues, fibrine is the constituent principle of the muscles, the salts are found in the bones; and so of the other secretions requisite for different parts of the body

* 'Cette complication tonte grande qu'elle peut nous paraitre, est encore au dessous de la réalité, et si nos moyens d'analyse étaient plus parfaites, ou decouvrerait dans le sang d'autres substanees encore qui $y$ existent bien eertainement, mais ne s'y trouvent qu'en quantités trop petites pour que le chemiste puisse les saisir.'-Milne Edwards. 
the requisite materials, in minutest particles, are diffused through the blood.

Now, thus far having advanced, we pause to observe that a very complicated machine, such as the digestion exhibits, was needed to keep up the supply of the blood; that the fluid destined to circulate in all parts of the body is an elaborately compound substance; that many materials, to which we give artificial names, enter into its composition, and that it would not be what it is, and therefore would not answer for the purposes for which it is intended, unless the internal apparatus of digestion, modification, and absorption had been in proper place and order to elaborate its formation.

So far we have got to be quite sure that, to secure all this, there must have pre-existed the highest degree of knowledge to foresee and to arrange all things requisite for the production of the blood,--a knowledge that by thousands of years anticipated the discoveries of modern science, and that has, in these arrangements, other intentions and objects also in view, which are not yet fully understood by the ablest physiologists, as is manifest by the various interpretations which they propose.

The universally permenting liquid having been thus provided, the next requisite was to secure its motion, by some propelling power which could effectually drive the stream through every part of the system, and keep up a circle of movement which was never to relax. The recurrent flow, without any point of stoppage, was as indispensable as the accurate composition and proper elements of the moving stream itself.

To ensure all this a contrivance analogous to a forcingengine was placed in a central position of the body. This 
machine, the heart-the centre or chief agent of the function, drives the blood in the peripheric or centrifugal direction within special conduits, the arteries. It receives the blood again by the apparatus of the veins, by means of which the fluid returns with a centripetal course. Where the arteries and the veins meet there is a fine net-work of capillary vessels, forming a transitional structure between the two kinds of conduits; that is, between the arteries that carry out the blood from the heart, and the veins which convey it to the heart.

The heart is a hollow muscular organ, a sort of bag or sack, divided into the left and right partition, which have no direct communication with one another: there is a strong wall of separation between them. Each of the partitions has an upper and lower chamber or cavity. The upper chamber is called the auricle, the lower the ventricle.

In the floor between the upper and lower chamber there is a valve for communication, which will allow the blood to descend, but closes against any effort it may make to reascend.

The valves, composed of fibrous membrane, are attached at their lower extremities to the walls of the heart by little tendinous cords, termed corde tendinece, otherwise they would flap through into the auricle, offering no resistance to the rush of blood when, pressed by the contraction of the lower chamber, it is urged through the tubes for its proper course. The blood, therefore, is destined to enter the ventricle, or lower chamber, from the auricle, or upper chamber, but careful provision is made that it is not to return the way it came into the auricle, and this is by the provision of the valves.

The auricle, then, in each partition of the heart receives 
the blood, and the ventricle sends it out. The upper chamber receives, and the lower propels.

But this propulsion, on which indeed everything depends, is effected by an alternate process of contraction and dilation of the heart, independent of the will, and is the power which urges the whole stream through the body.

The right auricle contracts and propels the blood into the right ventricle through the valve (tricuspid valve) which opens to receive it. At the same time the ventricle * dilates to receive the blood forced into it.

Then, as soon as it has received the blood, the right ventricle contracts and drives the blood through the pulmonary conduit into the lungs, where it is to be aërated by communication with the atmosphere introduced into the lungs through the process of respiration.

The aërated blood, or revitalized blood, returns by the four pulmonary veins to the left auricle, or upper chamber of the left side of the heart: the auricle now contracts, and urges the blood through its valve (the mitral valve) into the ventricle below which dilates to receive it. Then the ventricle contracts, and by that contraction urges the blood it has received through the great aorta (a conduit which enters into the ventricle) and sends it on its centrifugal course all through the body.

This contraction, as it is in fact the momentary squeezing of the ventricle, would urge the blood up again into the auricle from which it had descended, but the valve or

* This, which is called dilation, is probably the return of the ventricle to its normal state after contraction. It is a comparative dilation. These two actions of contraction and dilation are called Systole and Diastole$\sigma v \sigma \tau o \lambda \dot{\eta}$, contractio, coarctatio, from $\sigma v \sigma \tau \varepsilon \lambda \lambda \omega$, contraho- $\delta \iota a \sigma \tau o \lambda \dot{\eta}$, divisio. 
floodgate closes, and that danger is prevented. Thus the blood has no other exit but through the aorta.

The action of the right side, then, of the heart is to send the venous blood to the lungs to be aërated through respiration ; the action of the left side is to drive the purified or aërated blood in its centrifugal course to visit the general system.

Now how this action of the heart, its contraction and dilation, is effected is a disputed point, and is not yet explained : here we have only to record the fact, and that it is said that the heart contracts four thousand times in one hour, in which time about fourteen thousand ounces of blood pass through it ; and that in a life of eighty years' duration it propels not less than half a million of tons through its chambers; and has in that time made not less than three liundred million beats or contractions. If the propelling action were to be arrested but a few moments the stream of life would stand still, and move no more. On such apparently perilous eventualities does life seem to depend.

We have referred to the sending out of the blood from the right side of the heart to the lungs to be aerrated. The whole of the arterial blood, which, setting out from the left side through the aorta, had served the purposes of nutrition, and had performed all the offices required of it, returns to the heart through the veins in an impure state, and unfitted for the repair of tissues, and the support of life, and highly charged with carbonic acid gas: it therefore has again to visit the heart by the right auricle, to descend from it into the right ventricle, and by a contraction of the ventricle to be propelled to the lungs, and 
spread out in excecdingly minute vessels to a very extensive surface of air.

Thus, in every inspiration of the breath the pure atmosphere enters the lungs, and at every expiration the vitiated air, charged with carbonic acid gas, escapes.

By this arrangement the venous blood receives the oxygen from the air which exercises its purifying influence on it, and thus as renewed, oxygenated, and arterial blood, it returns back to the heart to be propelled through the left auricle and left ventricle into the great aorta, on its renewed journey of general nutrition.

Having thus traced the progress of the blood in its circuit, it may be requisite to point out the immense importance of its visit to the lungs, by the wonderful provision that is there made for diffusing it in an extended space. There are in the lungs labyrinths of cavities, which are called lobules; one of these lobules is composed of about 18,000 minutest cells, they communicate freely with one another, are bounded by a delicate transparent web, and have lying between them thousands of exquisitely slender capillary blood-vessels. It has been computed that of these air-cells there are in the human lungs not less than ${ }^{*}$ six hundred millions, and Valentin estimates that 300 ounces of blood may pass through the lungs of a strong man every minute. Life therefore is thus provided for by a communication of large design with the atmosphere; by contrivances, far beyond our thoughts, the blood is thus continually bathed in air, and the vital properties which it possesses are thus communicated to the whole body through the instrumentality which we have been describing:

* Lawson's Popular Physiology, 71. 
Here, then, we take our stand, and say this is our life, and the life, with modifications, of all animals. It is a plan which pervades the animal kingdom; it is found on a gigantic scale amidst the hugest of creatures in the depths of ocean, in whose bodies the mighty heart, through an aorta' a foot in diameter, throws out from ten to fifteen gallons of blood at each pulsation; it is seen in the delicate and aery forms of insects with distinct arterial and venous currents flowing in a simple circle, and not fluctuating from side to side as in the higher forms, but impelled forwards by the dorsal current towards the head, and returning in the opposite direction through the body, to enter again the dorsal vessel. Neither is the circular current wanting in the rotatoria, and other minutest animals, as described by Ehrenberg, though, with them, the flow is not dependent on the action of a heart, but seems to be the result of ciliary motion.

"Thus in varied arrangements it extends through the animal kingdom; and that it is the result of a deep design, arranged in profound wisdom, and executed with a skill which we can only admire at a distance, who can doubt that has not delivered up his understanding a holocaust to the shrine of Transmutation? That such a plan has required transcendant knowledge to imagine it, is as cvident as the result is wonderful. Something has already been said about the scientific prescience requisite in the formation of the blood; as much might be said with reference to the provisions for purifying the blood by communication with the air. It is acknowledged on all hands that the object of this communication is to seize on the oxygen, one of the component parts of the air we breathe. Who could have told us anything about oxygen the early part of last 
century? who knew that there was such an element, or who understood its action and qualities? We would not, indeed, urge that the author of the circulation of the blood must have been acquainted with oxygen, as that would be elevating our lately-acquired knowledge on a very lofty pedestal, for of oxygen itself, to which we have appended a name of no good significance, we can give but a very poor account, as we know not what it is, and can only verify some of its actions; but it is certain that the component parts of the atmosphere have been understood in their very essence before the experiment of animal life was submitted to it, and it is more than probable that the atmosphere has been compounded exactly as it is, for the express purpose of sustaining animal life.

Well, then, we repeat that if there has been this elaborate provision in the circulation to send the blood to the lungs, and this elaborate provision in the lungs to enable the blood to seize the oxygen in the air, it must have been known before the beginning of animal life that the air had this element in it, and the circulation of the blood was devised according to that knowledge. This is not a sequence of events, but life began with the event of circulation and could not have begun without it; wherever therefore we turn in the animal kingdom we find a certain proof of design, and in every living animal on the face of the earth we see a confutation of the Theory of the Transmutationists.

But again, we have to remember that the respiration of fishes is arranged for the water and not for the air. The circulation of the blood of these animals is carried on by the assistance of a heart of two cavities only, which receives the vitiated blood after it has coursed through the system, and propels it through the branchia, or gills, where 
it is exposed to the influence of the oxygen contained in the surrounding medium. Now here, again, the knowledge of the constituent parts of water was a pre-requisite for such an arrangernent. It must have been known that oxygen which is in the air, is in the water also; otherwise the branchiæ of the fishes would not have been prepared for extracting it.

In describing the heart the valves have been mentioned, a design for a special object if ever there was one. This design is carried out also in the hearts of fishes, and in some instances* more markedly than in other animals. In certain veins also of the human body there are valves all opening towards the heart, which is the destined course of the blood in the venous tubes, but closing immediately if any force should urge the blood the reverse way. "Those veins which are exposed to the pressure of muscles have pouch-like valves, which prevent the backward passage of the blood towards the capillaries; consequently any pressure on the veins, instead of interrupting, favours the flow of the blood to the heart. In the veins of parts protected from extcrnal pressure the valves do not exist.' -Müller.

Now any one finding these valves, and considering their use, would as naturally conclude that they had been devised for the purpose of allowing the blood to flow one way only, as any of us would conclude on finding flood-gates in a stream flowing to a tidal river, that they had been contrived to regulate the flow. To this common-sense view of the valves of the veins we owe in a great measure the discovery of the circulation of the blood.

* In the shark there are several rows of semilunar valves so clisposed as most efficiently to prerent the blood being drawn back into the rentricle. Perhaps this may be a provision to resist the pressure of the enorunous gorging of that ravenous creature. 
Mr Boyle in his Tract on Final Causes gives us this wellknown anecdote :-

' I remember that when I asked our famous Harvey, in the only discourse I had with him, which was but a little before he died, what were the things that induced him to think of a circulation of the blood, he answered me, that when he took notice that the valves in the veins of many parts of the body were so placed that they gave free passage to the blood towards the heart, but opposed the passage of the venal blood the contrary way, he was inclined to imagine that so provident a cause as Nature had not placed so many valves without design, and no design seemed more probable than that since the blood could not well, because of the interposing valves, be sent by the veins to the limbs, it should be sent through the arteries, and return through the veins, whose valves did not oppose its course that way.'

We see, then, how Harrey came to those conclusions which have made his name so celebrated. Had he been a disciple of Mr Darwin's school he could not have reasoned in this way, as in that school a design in the works of Nature is inadmissible; and we may add that the circulation of the blood could never, by such reasoning, have been discovered by Mr Darwin, unless indeed he had, for the occasion, attributed the invention of the valves in the veins to his Metaphor, as he has not scrupled to assign to it the formation of the eye. This is, however, a renunciation of the Theory, as it is the introduction of a design and an artificer in a masquerade dress, for an emergency.

On all these considerations, then, $\mathrm{Mr}$ Darwin must either admit that there was antecedent knowledge, by which the structure of organized beings has been arranged in many complex contrivances, or that in the formation of a perfect 
and beautiful machine it is not requisite to know how to make it. There is no escape from one of these alternatives. Mr Darwin must make his choice.

This subject, however, is not to be dismissed without observing that, as in the circulation of the blood the contraction of the heart is the primum mobile, on which everything depends, the whole apparatus of circulation must have been prepared with a reference to this main-spring of the machine. To have arranged arteries, veins, capillaries, auricles, and ventricles, without this foreseen power to be exercised by the heart, would have been only to construct a dead image. Therefore there was a knowledge somewhere, that the heart would, by contraction, continue to propel the blood, as long as life lasts; and upon this knowledge the contrivance of circulation was set a-going. But how was this known? and who knew it? For we are ignorant of the canse of the contraction of the heart, and with all our anxious conjectures on the subject, have not yet reached the explanation of that which will, perhaps, for ever remain unexplained.

But yet, somewhere the mystery was, and is, understood. Did Natural Selection know the cause? Can the 'Sequence of Events, as ascertained by us,' favour us with an explanation? Can Mr Darwin himself, the father of Natural Selection, help us in this difficulty?

And thus, in thousands of instances, we find proofs of knowledge which we cannot reach; and in all these instances we cannot doubt that Supreme Intellect has ordained and disposed those concurrent circumstances which we admire but cannot explain.

The proof of design has been argued here on a general principle pervading animal life. There is another general 
principle as much involved in its origin which must now be adduced.

The appearance of the sexes, that on which animal life depends, must for ever baffle the advocates of the Theory of Transmutation.

Life, they assure us, began from a simple primordial spore. New forms of life emanated from the spore, and, at last, that which we can recognize as an animal springing from the union of the sexes, came into being. Now we ask, how was this formation of the two sexes accomplished? Mr Darwin derides the idea of an unborn man, the first of his race, but we ask him to account for the appearance of the sexes in his system.

If two animals, male and female, qualified for the reproduction of their race, were produced by 'the Sequence of Events, as ascertained by us,' this must have been by design. 'This is the general proposition; it is impossible to deny it.

The male and the female must have been produced at the same time; there could have been no intervening time between their production more than a very few years, and if this took place in the case of some of the lower animals, only a few days.

But if the male was produced before the female he would have perished in the course of nature before reproduction could have commenced; or, vice versâ, a similar catastrophe would have taken place if the female appeared before the male.

In either of these cases there would have been an end of the sexes, and things would have returned to the state of the primordial spore. Thus animal life would, in no instance, have originated in the union of the sexes. But if the two sexes had been produced simultaneously, which to 
sccure perpetuity of race is necessary to suppose, then they came on the scene for a purpose, for an object, by a design. They were made for one another in that case-they were created.

Moreover, the appearance of either male or female must be a proof of positive design, for as there had been in the Theory another form of life without the sexes, this change could not have been without an object.

The male is made for the female, and the female for the male. This cannot be disputed: but yet if they are indeed made for one another the Theory is at end!

Observe, moreover, that though the male and female are widely dissimilar in that which distinguishes them, they are yet perfectly adapted and designed for one another, and their union perpetuates their race, by the production of new animals in all respects similar to their parents.

In this union of male and female, a vast number of provisions are involved in complicated design, and if any one of them failed, all would fail-and there would be no perpetuation of the race.

'Therefore it is certain that all this was provided for when the first male and female came into being.

Natural Selection introduced here would be more than usually senscless jargon, for it is not a question of an individual acquiring a beneficial modification in a million of ages-elaborating a wing, or working out a tail,-but the absolute necessity for two individuals appearing at the same time, perfectly adapted and prepared for one another. In this preparation there was intelligence presiding over a plan, and a plan of that sort that its great result, the reproduction of a germ of life, is well described as 'the mystery of mysterics' (Cuvier). 
Now in this question there is another circumstance to be considered, another mystery to be accounted for, the propelling principle which pervades all animals, and which is clearly a design to secure reproduction by an imperious mandate of Nature. Animals were not to be left to their choice in this matter, they were ordained to increase and multiply; and consequently a principle was interwoven in their own structure, to manifest itself periodically, and so secure the lasting traditions of all forms of life.

Now a general principle to the power of which myriads of different species are compelled to submit argues a sovereign disposing mind. It tells so plainly of one Master, that all the decrees ever issued by a king could never so clearly prove his existence, his will, and his power, as this universal mandate which all are obliged to obey shows the authority from which it emanated.

In the great field of the designs of nature we have selected two examples which refer to animal life in general, but the numerous instances of particular contrivance which at any turn may be found in creation, we pretermit: many of these the reader will have seen well stated by able anthors, and any of those examples, if carefully considered, are sufficient for the purpose.

It must now be our task to show how Mr Darwin, who closes the door against design in the hands of a Creator, opens it very wide for the skill and wisdom of his Metaphor, and that in terms of such large expression as have rarely been used, even by an inconsiderate writer, with regard to a Divine Agent.

Many are the instances in which $\mathrm{Mr}$ Darwin speaks of 'beautiful contrivances,' though, of course, in his system there is no Contriver, and therefore nothing can be contrived 
in it ; but the following passage, as entering fully into the question, will best show his mode of treating the subject.

The subject which Mr Darwin is discussing is the formation of the eye. After a brief sketch of the various forms of eyes, the first of which he affirms is a rudimentary eye, 'which can distinguish light from darkness, but nothing else,' he says there is an advance towards perfection, ascending to converging lenses in the structure of compound eyes, \&c. : and so sums up with the usual formulary of a creed, in which he is wont to deliver his doctrine- ' With these facts, and bearing in mind how small the number of living animals is in proportion to those which have become extinct, I can see no very great diffculty in believing that Natural Selection has converted the simple apparatus of an optic nerve merely coated with pigment, and invested by transparent membrane, into an optical instrument as perfect as possessed by any member of the Articulate Class (Insects),' (207).

First let us observe here, that the number of extinct animals referred to is an allusion to the supposed millions of experiments of those intermediate animals exterminated in the Struggle for Life, which are required in Mr Darwin's system. We need not say that this is quietly assuming an important point which remains to be proved. Next, it is passed over quite as an ordinary circumstance demanding no explanation or observation, that 'a simple rudimentary eye' should have been the first formed, capable of ' distinguishing light from darkness, but nothing else.'

Now in this simple rudimentary eye there was first needed an intention to make it. If we 'start' from that, it was the first eye; therefore it was made for the simple animal that first had it. It was the first animal with an 
eye, or else we cannot 'start' from it. Well, then, an animal there was that had the first eye. It could only distinguish light from darkness, we are informed-which is certainly more than $\mathrm{Mr}$ Darwin can prove,-but if as much as that could be discerned by the eye, it was for a definite object. It was to see light, either to seek it or to avoid it. It was to see with. There must, therefore, have been some nerves of sensation, and some of apprehension. If the animal had a simple eye to see light, it certainly was to understand that there was light. Here then, simple as we may call this eye, was something which we are utterly unable to imitate; and as long as the world lasts never will human skill be able to make a machine which shall be able to discern between light and darkness.

The very starting-point is, in principle, as wonderful as the formation of the eagle's eye, to which Mr Darwin next introduces us. Mr Darwin has not told us how Natural Selection made the first simple eye. We ask him, was that eye made for the object of discerning between light and darkness? Did Natural Selection make it for that purpose? 'These are questions not to be evaded. If $\mathrm{Na}$ tural Selection made the first eye for the purpose of seeing, then Natural Selection is the Creator, neither more nor less.

$\mathrm{Mr}$ Darwin continues, "He who will go thus far ought not to hesitate to go farther, and to admit that a structure even as perfect as the eye of an eagle might be formed by Natural Selection, although in this case he does not know any of the transitional grades. His reason ought to conquer his imagination; though I have felt the difficulty far too keenly to be surprised at any degree of hesitation in extending the principle of Natural Selection to sUCH STAR'TLING LENGTHS.' 
Truly this is an amazing passage; let us, however, examine it. If we have indeed gone thus far, we are in for it, and ought not to hesitate to go farther. But we have not gone so far, and have given our reasons for not accompanying $\mathrm{Mr}$ Darwin in his visionary progress. We do not start with him, and therefore we do not advance with him. But it seems that we ought to go the whole length, and allow our reason to conquer our imagination. So, when we believe that an eye was made by creative skill, we are following the illusions of imagination, and when we believe that the sequence of events made an eagle's eye it is allowing our reason to get the victory! Surely a more curious metastasis of terms was never yet met with. Does $\mathrm{Mr}$ Darwin really belicve as he here expresses himself? We doubt it. The confession, however, of his keenly feeling the difficulties of such preposterous excesses of spcculation is quite affecting-it tells us plainly enough that a great mind, though voluntarily surrendered to a false system, occasionally wakens to the sense of its situation, occasionally perceives its captivity, and when compelled by the laws of logic to feel the weight of the absurdities to which it is chained, is amazed that it ever can have gone to such startling longths, and therefore does not wonder that others should hesitate to plunge into a similar position.

Mr Darwin, however, gives us the history of the cye: 'If we must compare the eye to an optical instrument, we ought in imagination to take a thick layer of transparent tissue, with spaces filled with fluid, and with a nerve sensitive to light beneath, and then suppose every part of this layer to be continually changing slowly in density so as to separate into layers of different densitios and thick- 
nesses, placed at different distances from each other, and with surfaces of each layer slowly changing in form. Farther, we may suppose that there is a power, Natural Selection, always intently watching each slight accidental alteration in transparent layers; and carefully selecting each alteration which, under varied circumstances, may in any way, in any degree, tend to produce a distincter image. We may suppose each new state of the instrument to be multiplied by the million; and each to be preserved till a better be produced, and then the old ones to be destroyed. In living bodies, variation will cause the slight alterations, generally will multiply them almost infinitely, and Natural Selection will pick out with unerring skill each improvement. Let this process go on for millions on millions of years; and during each year on millions of individuals of many kinds, and may we not believe that a living optical instrument might thus be formed as superior to one of glass as the works of the Creator are to those of man?' (208).

This portentous statement, which, for its wildness, almost defies criticism, must, nevertheless, be sifted, that it may be reduced to its real value, as it is the most precise exposition of an act of auto-plastic creation with which $\mathrm{Mr}$ Darwin has favoured us.

Mr Darwin commences with giving us a receipt for making an eye: 'take a thick layer of transparent tissue,' \&c. But we ask why in this Theory should such a process be commenced at all? was there any intention to produce an animal that could see? and from what quarter were we to take these thick layers of transparent tissue? How did they originate? and how came it that the materials for eye-making were at hand, and in the right place? 'These 
we are to take in imagination; as, however, we were not there when this process began, who was it that took and manipulated the thick layers of transparent tissue? and. why were these tissues, filled with fluid, selected for the occasion? Mr Darwin here evidently presupposes a knowledge of the formation of the eye as a dioptric instrument, with fiuids of a denser medium to refract through lenses rays of light in certain angles, but who knew this before the first eye was made? and where was the nerve to be had that was sensitive to light? A nerve sensitive to light! this is as coolly demanded as if it were as easy to make and to find it as a piece of pack-thread. It amounts to this-'take one of the senses, and put it under a thick layer of transparent tissue.'

Then we are to suppose every part of the tissue to be 'continually changing,'-but how changing? what was to make it change? and for what object or in what direction should it change?

If such a process were going on in a living animal that could already see, its vision would be sadly disturbed-a transition eye in a living creature would be truly disastrous. However, the process went on, be it remembered, without any definite object or intention. There was no design to produce an eye. There happened to be a nerve sensitive to light in the proper place in the head, and there happened to be 'spaces filled with fiuid' in the same position, not put there for an object-and there accidentally was a repetition of these accidents on each side of the head, and so the process advanced! But, in the mean time, there was a powen INTExTLY watchisg what was going on. We need not say that this was the great Goddess Natural Sclection, who, floating on a lotus on the 
ocean of dreams for millions of billions of ages, was determined to make an eye. She intently watched each slight 'accidental' alteration in the transparent tissues, and when one of these aggregation of layers and spaces filled with fluid began to produce a distinct image on the nerve sensitive to light, then she took advantage of it, by forthwith exterminating all the animals that had not yet acquired the power of observing an image so distinctly. Whether this encouraged the survivors must be left to conjecture; but the changes in the densities never ceasedthe 'accidental' changes - in millions of millions of instances, every one of which changes was marked by the infinite carnage of all that lagged behind in the art of seeing. And so in 'millions of millions' of ages, and with slaughter of millions of millions of bunglers, every year, at last the eagle's eye was brought to perfection, to the infinite credit of the vast abilities of the great Goddess.

Mr Darwin, who speaks as a true devotee in profound admiration of 'the uncrring skill ' of his Goddess, does not however mean us to understand that she herself changed anything in this process of eye-making, for it is not her office to construct anything; her sole attribute is to knock on the head those that do not make use of the right thing. Her ' unerring skill' consisted in giving the coup-de-grace in the right place. She watched the animals that could see the best in however slight a degree: those she allowed to live, till others arose that could see better; but, in the mean time, she unmercifully cxterminated the poor creatures that had not taken advantage of the latest improvements.

All this being supposed, "we may believe that a living optical instrument was thus formed as superior to one of glass as the works of the Creator are to those of man.' 
This last most startling sentence immediately suggests the inquiry, why, after a narrative so strictly atheistic, and so obviously invented to exclude the idea of creation, the sacred name is here introduced? What can it mean but an irony, unless, peradventure, Natural Selection is to be considered the Creator? 'The expression is most inopportune and most incongruous ; it militates with all Mr Darwin's system, and it could not have been more out of place than in the above passage. Let the learned gentleman keep his own ground, which is very intelligible; but as his system is as far apart from Natural Theology as the east is from the west, he must forego the usage of terms which it is the main object of all his doctrine to render for ever obsolete.

We cannot dismiss the above passage without observing that the whole process of producing instruments of vision for the animal world is described as a series of accidents, 'Natural Selection was intently watching cach ACCIDENTAL alteration.'

It was therefore a fortuitous process. There was no exercise of intellect aiming to bestow the gift of vision on animals, nor was there any premeditated design to produce an instrument of sight. Everything that we observe in the formation of the eye was an accident, and the eye itself is a series of accidents accumulated in millions of millions of ages.

The arrangement of this camera obscura, which, instead of a space filled with air, is entirely occupied by special refractile substances, in three separate humours of different densities-the black choroid of the internal shell, corresponding to the darkened sides of the cumerce obscura, and the retina on which the mirrored images are portray- 
ed: the erystalline lens with its anterior and posterior surfaces acting as different mirrors, and the whole arranged and devised for the purposes of refraction of light-the same lens having more refraetibility than the cornea and the aqueous humour-its stratified structure of several layers of different densities, or different refraetibility, constituting it a polyzonal* lens in which the refractive power inereases continually from the surfaee towards the nueleus; these and numerous other provisions-- the lachrymal gland to wash the eye, or the nictitatory gland in birds to sweep it clean-the muscles that move the eye, and the nerves that conneet it with the brain, eonstituting it the ehief informer and monitor of the mind,-all these are 'aecidental alter. ations' which have been preserved for our benefit by extermination. No esmment is needed on all this, we leave it with the reader that he may draw his own conclusions.

In the mean time, all this will confirm that which we have already said of the fundamental principle of the system-that in order to make a perfect and beautiful machine, it is not requisite to know how to make it. 'The account which $\mathrm{Mr}$ Darwin has given us of the origin of the eye proves this abundantly. We now understand his creative mystery : it is a 'lrimurti of three prineiples, Aecident, Absolute Ignoranee, and Extermination, eonstituting the creative quorum of the school of Transmutation. These are the Bramah, Vishnu, and Sevah of the system. Ex-

* 'The true object of the polyzonal structure of the lens can hardly be explained as a mere increase of the index of refraction ; for nature might easily have attained this purpose in a much simpler way. On the contrary, it is far more probable that the chief purpose of this peculiar arrangement is to secure certain collateral advantages which are revealed by optical considerations. And especially the amount of spherical aberration is thus diminished.'-Valentin (444). 
termination is the Sevah, and the multiplied millions of ages are the great periods of its Shasters.

That the first manifestation of a living instrument for sight was in an animal of the lowest form, and that the first eye that made its appearance was of the simplest possible construction, enabling it 'merely to distinguish light from darkness,' is indeed a statement such as this 'Theory demands, which is based on the principle of progressional development; but the testimony of palæontology authenticates no such statement; on the contrary, there is abundant evidence that perfect eyes of a complex nature existed in creatures of the earliest date, nor can we doubt that each animal came into being at once with its power of vision precisely adapted for the line of life assigned to it. Some visual organs therefore would be of a simpler structure than others, but in the very dawn of life there were organisms which required a large power of vision, and everything requisite to meet that need was abundantly provided. Of the Trilobite we have already spoken ; it was a crustacean that existed in the early Silurian period, and the structure of that animal's eye, owing to the elaborate contrivances which distinguished it, has much attracted the notice of geologists.

Let us take Professor Ansted's statement. 'The form of the eye of the trilobite is generally that of the frustrum of a cone, incomplete on the side which is directly opposite to the corresponding part of the other eye. In this way the exterior of each ranges round three-fourths of a circle, and is made up of a number of distinct spherical lenses, fixed in separate compartments on the surface of the cornea. The form of the cornea is such that the animal is enabled to see distinctly in all directions horizontally. 
The species of Trilobite, called Asaphus caudatus, is admirably adapted in this way for extended and perfect vision; each eye containing not less than four hundred spherical lenses. This species is found most abundantly in the upper beds of the Silurian series, and is one of those which we believe to have been amongst the earliest of created beings' (Ansted's Geology, i. 130).

Of the Trilobite family Professor Owen says that it is entirely confined to the Palæozoic age, and of the fifty genera into which it has been grouped forty-six are Silurian, and thirteen Lower Silurian. It therefore goes back to the geological commencement. He also says that of this family the Asaphus Caudatus has 400 facets to each eye; and in the great Asaphus Tyrannus each is computed to lave 6000. "The exterior of each eye, like a circular bastion, ranges nearly round three-fourths of a circle, each commanding so much of the horizon, that where the distant vision of one eye ceases that of the other begins, so that in the horizontal direction (the only direction required by an animal living in the bottom of the water) the combined range of both eyes was panoramic. Thus we find in these animals an optical instrument of most curious construction adapted to produce vision of a particular kind, created in the fulness of perfection, and fitted for the uses and conditions of the class of creatures to which this kind of eye ever has been and is still appropriate.'-Buckland, quoted by Ansted.

Here, then, we have in the earliest page of this earth's history an animal, amongst the very first that can be traced, appearing with an optical instrument of elaborate construction, ' as periect as possessed by any of the articulate class,' to use Mr Darwin's own words. 
This, in all ordinary reasoning, would be driving his Theory up to a wall, and there annihilating it; for as $\mathrm{Mr}$ Darwin has required his millions of millions of ages, and millions of millions of acts of extermination, to produce a perfect eye, and we know not how many hundreds of millions to produce any eye at all; we have in this instance of the Trilobite confronted him with a perfect complex eye appearing at the very beginning of things: but the fox, not thus to be caught, will take cover in the PreSilurian world, and having escaped into that realm of mists, will conceal itself behind billions of billions of great periods, and innumerable destructions, before the Trilobite's eye was brought to perfection.

Mr Darwin's Theory, when pressed hard, can always glide away where pursuit is impossible; and as indeed the pursuit would not be that of truth and science, but of fiction and illusions, we leave the Theory in its appropriate home.

But we have to produce still further proof that Mr Darwin largely admits design for the furtherance of his Theory, though he professes to discard it. Take the following passage: "In the case of a gigantic tree covered with innumerable flowers, it may be objected that pollen could seldom be carried from tree to tree, and at most only from flower to flower on the same tree, and that flowers on the same tree can be considered as distinct individuals only in a limited sense. I believe this objection to be valid, but Nature* has largely provided against it by giving to trees

* Again, "How, then, does Nature act? she has endowed these plants with sensitiveness, and with the remarkable power of forcibly ejecting their pollinia to a distance.'-Orchids, 212.

'Hence it would appear as if Nature were so economical as to save even superfluous elasticity.'-Id. 56. 
a strong tendency to bear flowers with separated sexes. When the sexes are separated, although the male and female flowers may be produced on the same tree, we can see that pollen must be regularly carried from flower to flower, and this will give a better chance of pollen being occasionally carried from tree to tree' (105).

These observations are to establish a point which need not be contested, that occasional intercrossing with distinct individuals tends to the vigour and fertility of all organized beings. How $\mathrm{Mr}$ Darwin meets this in the case of great trees with innumerable flowers we see, but the main point to observe is that this provision for intercrossing is by a premeditated arrangement of Nature.'Nature has largely provided' - this of course means Natural Selection; but whatever it might be, we find, according to this statement, that there is a large provision to secure the intercrossing by giving to trees a tendency to bear flowers with separate sexes.

Had we said as much as this of a design of creative wisdom there can be little doubt how it would have been received by the 'Transmutationists, but when the manifest intent of this 'provision' is attributed to that which is understood not to be creation, it passes as advanced philosophy. This, however, is certain, that if anything of this sort has really taken place, if there has been a large provision for a certain object, by giving certain trees this peculiarity, there must have been an Intellect to provide and a Power to give; and if so, the fact would be fatal to the Theory.

Again we hear it stated still stronger: 'In many cases there are special contrivances which effectually prevent the 
stigma receiving pollen from its own flower; for instance, in Lobelia fulgens, ${ }^{*}$ there is really a beautiful and elaborate contrivance by which all the infinitely numerous pollengranules are swept out of the conjoined anthers of each flower, before the stigma of that individual flower is ready to receive them' (103).

'This 'contrivance' is to prevent self-fertilization, and to necessitate crossing with another plant. And the contrivance is 'beautiful and elaborate;' nevertheless, in this system there is no design and nothing that can contrive. A system that has to be upheld by such flagrant contradictions as these must indeed be tottering to its fall.

But a still more curious statement is contained in the following passage: "The tubes of the corollas of the common red and incarnate clovers do not, on a hasty glance, appear to differ in length; yet the hive-bee can easily suck the nectar out of the incarnate clover, but not out of the common red clover, which is visited by humble-bees alone, so that whole fields of the red clover offer in vain an abundant supply of precious nectar to the hive-bees . . . . . if humble-bees were to become rare in any country, it might be a great advantage to the red clover to have a shorter or more deeply divided tube in its corolla, so that

* Compare with this, passages in the 'Fertilization of Orchids' :-

'To save this waste and exhaustion special and admirable contrivances were necessary for safely placing the pollen-masses on the stigma-and thus we can partially understand why Orchids have been made more highly endowed in this respect than other plants' (356).

'The simple fact that some Malaxer have only a single pollen-mass necessitates that extraordinary pains should have been taken in their fertilization, otherwise the plants would have been barren' (Id.).

It is truly marvellous that with such thoughts and such language $\mathrm{Mr}$ Darwin can have persuaded himself that blind matter, without an agrent, can have cxccuted these 'admirable contrivances.' 
the hive-bee should visit its flowers. 'Thus I can understand how a flower and a bee might slowly become, either simultaneously, or one after another, modified and adapted in the most perfect manner to each other, by the continual preservation of individuals presenting mutual and slightly favourable deviations of structure' (100).

One would think that this passage must, even to its author, appear a reductio ad absurdum of the system. Red clover finding itself in a state of hopeless celibacy, owing to the absence of humble-bees, begins slightly modifying its structure to meet a prospective slight modification of the structure of the hive-bee. The hive-bee, with great good nature, begins to alter its own organization in order to meet the inclinations of the red clover; and thus by this simultaneous process of slow modification on the part of the flower and the insect, they become "perfectly modified and adapted to one another.' A profitable arrangement to both parties, as the bee gets the honey, and the red clover fertility!' But this of course is not accomplished without the usual slaughter on both sides, for it is by the ' continual preservation of individuals presenting mutual and slightly favourable deviations of structure,' that is, some millions of races of bees, and some millions of crops of improving red clover, are continually undergoing extermination, till at the end of a million or more of years red clover and hive-bees are perfectly adapted to one another.

One cannot but admire, in this picture, the spirit of self-sacrifice in the hive-bees, for as they get on very well with the present arrangement, and have done since the beginning of things, without the red clover, one can see no 
reason why they should give themselves up to extermination for a million of years, to obtain that which they do not want. It is, moreover, to be remembered that the breed of improving bees must depend on the queen, the sole mother of the hive. She, therefore, who never gathers honey herself and never visits any flower, must have resolved to lay eggs, which shall produce insects kindly intentioned to the red clover, \&c., \&c., \&c.

And this is the system 'which is to banish the belief of the creation of new organic beings, or of any great and sudden modification of their structure' (101).

These specimens of the mode of reasoning by which the Theory is upheld will be sufficient, though there is no lack of many similar statements if it were requisite to adduce them. We have seen enongh to convince us that the argument of design, which it is in many quarters now the fashion to deride as puerile and obsolete, is largely used where it is least of all admissible, in the dogmas of that school which pretends to have mapped* out creation on an atheistic plan; and that the leaders of that school are continually talking of contrivancest without a contriver, of plans and adaptations without intellect to devise them, and of beauty and skill in organized structures, though they declare that premeditated beauty and skill would be fatal to their theory. The attributes of power and wisdom, hitherto considered inseparable from the Creator, they

* Mr Darwin speaks of 'Nature worked out by Natural Selection.'Orchids, 278.

+ 'No one who advanced so far in philosophy as to have thought of one thing in relation to another, will ever be satisfied with laws which had no author, works which had no maker, and co-ordinations which lad no designer.'-Phillips' Life on the Earth, 43. 
ignore; and invent another power which is but an allegory, and has only a verbal existence, and yet they scruple not to say that "they can see no limit to THIs power (Natural Selection) in slowly and beautifully adapting each form to the most complex relations of life' (502).**

This advantage, then, at any rate, we have in arguing with $\mathrm{Mr}$ Darwin, that we believe there really is a Power that can, and has done, all these things, by supreme exercise of intellect and will ; Mr Darwin does not believe this, and yet he continually is making use of language implying that he does believe it.

The explanation of this is, that he feels by the force of reason that to be necessary and indispensable which his Theory condemns.

This great question of design brings us ultimately to the beginning of life, which Mr Darwin calls the Origin of Species, and which it is the professed object of his book to explain. In this, as we have scen, he has failed, as he has only explained up to a certain point, which does not reach the origin. He tells us of a primordial spore of the lowest algæ from which all animal and vegetable life was evolved, but the origin of the great parent he leaves untouched.

It is, however, a remarkable circumstance that in the edition of his work of the year 1859, from which Professor Phillips has made his quotations, and from which many

" Every naturalist who has dissected some of the beings as now ranked very low in the scale, must have been struck with their really wondrous and beautiful organization (135).

'Whenever the period of activity comes on, the adaptation of the larvæ to its conditions of life is just as perfect und becutiful as in the adult animal' (472). 
others have made theirs, there was some further information on this subject which has been since withdrawn. In the edition of 1859 we read it thus: 'All living things have much in common in their chemical composition, \&c. ; therefore I should infer from analogy that the organic beings which have ever lived on this earth have descended from some one primordial form into which life was first breathed.' All the words from 'therefore' to the end of the sentence, have been suppressed in the subsequent editions; and in addition to this a long paragraph ending with this sentence, "there is grandeur in this view of life, with its several powers having been originally breathed into a few forms or one; and that whilst this planet has gone cycling on according to the fixed law of gravity, from so simple a beginning endless forms, most beautiful and most wonderful, have been, and are being evolved.'

With this statement we should inquire, of course, how was life breathed into the first forms: surely, in a point of the system of such transcendent importance, $\mathrm{Mr}$ Darwin cannot here also be talking allegorically - he must have meant what he says, that life was breathed from a source that had power to give it. Whether there was an allusion here to the language of the Scripture, must be left to surmise, but certain it is that the whole paragraph is cancelled, and that, we now read the important sentence thus: "Therefore on the principle of Natural Selection with divergence of character, it does not seem incredible, that from some such low and intermediate form, as the lower algæx, both animals and plants may have been developed-and if we admit this, we must admit that all organic beings which have ever lived on this earth may have descended from some one primordial form' (519). 
Now all this is very curious as showing how the author of this Theory is unsettled on the main point, the Origin of Species. At first, as he saw the necessity of an original mover and a real commencement of life, we were informed that life was 'breathed' into the first forms ; but subsequently, and in consequence perhaps of perceiving that this statement was a virtual contradiction of the Theory, we are told that all life descended from one form-leaving that one form to acquire life as best it might.

The Theory, therefore, is in a more consistent dress at present, and does not contradict itself at starting; but it is far more absurd, for we now see the origin of all things traced to a sea-weed, which of course sprung from another sea-weed, and so on backwards for millions of millions of ages, for sea-weeds either sprung from some other form, and therefore they cannot be the first themselves, or they existed for ever without beginning, or they were created.

There is, however, another alternative-and it is that of spontaneous generation. M. Pouchet-who is a Transmutationist of the School of Lamarck-pure, and without admixture, openly defies* the scientific world to find any other alternative ; either creation, says he, which is a miracle, or 'successive evolution of Lamarck.' Now this successive evolution is from spontaneous generation, and of this doctrine M. Pouchet is a conspicuous advocate. Nevertheless, he is quite right in his logic, that there is no other alternative. Mr Darwin, $\nmid$ however, does not accept spon-

* 'Nous defions qu'on sorte de cette alternative, ou la création instantanée et miraculeuse d'un certain nombre d'animaux parfaits, ou l'évolution successive, c'est ì dire l'idée de Lamarck, modifiée dams le sens des connaissances nouvelles que resument ì notre époque, d'un coté la geologie, et de l'autre l'anatomie philosophique.'-Ponchet, La pluralité des races liumaines, 182.'

+ 'Lamarck was led to suppose that new and simple forms were con- 
taneous generation, and therefore has no origin for his system. His elephant stands upon a tortoise, and the tortoise upon nothing.

tinually being produced by spontaneous generation! I need hardly say that science in her present state does not countenance the belief that living creatures are now ever produced from inorganic matter' (135). 


\section{CHAP'IER XVI.}

THE CONCLUSION.

$W_{\mathrm{E}}$ have thus touched on the most important points of Mr Darwin's Theory, though it would have required a largely extended work to meet the numerous secondary arguments and collateral disquisitions in the 'Or:gin of Species.' 'The reader will remember that the main propositions of this Theory are:

1. That no organic being has been created.

2. That every plant and animal has been made by accidental minute changes taking place in the organization of antecedent forms.

3. That these changes, beneficial in result, but not in intention, have given the possessor an advantage in the struggle for life. The organized being with the advantageous accidental change has been enabled to live; the plant or animal not so favoured has been exterminated.

4. No plant or animal has been designed for any particular object or place in nature, but all have taken such a place as was open to them, and have maintained themselves as well as they can in their position.

5. Every existing plant or animal is struggling to maintain its place in nature. If others, near them in habits, 
should arise, better organized, they would have to succumb and yield to the law of extermination.

6. 'This operation is called Natural Selection: it does not really construct or design anything; it only, by exterminating unimproved animals, preserves new improvements in organized beings.

7. Natural Selection, when correctly stated, is 'the Sequence of Events as ascertained by us.'

S. Facts or events having followed one another in an ascertained sequence explain the existence of things. Organized beings have become what they are, because they are so. Existence is an absolute fact without a cause.

9. There is no such thing as Species: there is no fixed and permanent division amongst plants and animals.

10. All varieties are in the act of becoming* species. New forms of plants and animals are now in the progress of evolving out of existing forms, by accidental beneficial changes, and the process of extermination.

11. Beauty in the works of Nature has not been produced by an intentional arrangement. If any plant or animal is beautiful it is an accident.

12. All organized beings are slowly advancing towards perfection. There will be a period when there will be no more change; that is, when all plants and animals will have obtained absolute perfection.

This creed, of which perhaps the last article is the most surprising, is nevertheless well-considered as a whole. The first point of advantage to gain was, of course, by an attack on the fixedness of Nature's works, without which

* Here, then, is a contradiction between the 9 th and 10 th proposition, for if there be no species in nature, varieties cannot of course be advancing towards species. This contradiction lias been seen more at large in the third chapter. 
the Theory could not advance one inch; and for this reason we have the elaborate special pleading against Species, in which $\mathrm{Mr}$ Darwin has as frequently asserted as he has denied the point he was combating. It is against Species that all the Transmutationists begin, for unless this obstacle can be removed they can do nothing. Lamarck, the author of Vestiges, Pouchet, Trémaux, \&c., all turn the tide of their logic against Species-and the most vehement of them all, Mr Darwin-but Species still remains unmoved as firm as the everlasting hills, and all the impetus of this sophistry expends itself in froth and foam, without accomplishing anything.

However, this is the beginning of the Theory, to talk down Species if possible; and then, having made a clear stage, to go on with transformations and metamorphoses, without restraint. But then the question would arise, what is to be the end of all this continual move in the forms of life? What are they all to come to at last? Will there be dragons, centaurs, mermaids, and satyrs again? Is mutation to go on for ever, elaborating we know not what? To this inquiry Mr Darwin has given an answer by settling a terminus to which everything is tendingthis terminus to be reached, in an unknown series of ages, is absolute perfection. When organized beings shall have arrived at that point, Nature will have reached her Sabbath, Natural Selection will cease from her work of carnage; after the extermination of infinite millions of organized beings, more numerous than the figures of arithmetic can express, she will retire from the scene to take her great reward in the Paradise of Metaphors. Every plant will be perfect, and every animal perfect, though, whether animals will feed on plants or on one another as they do at present, 
the author of this prophecy has not revealed to us. Neither do we know whether there will be distinction between carnivorous and graminivorous animals; nor whether men will have wings, and animals will talk: in short, we do not know how animals are to be more perfect than they are.

Here, however, as usual in this 'Theory, a great designthe greatest indeed that can possibly be imagined-is to be effected without a designer and without the execution of a plan. But as Mr Darwin has, throughout his system, been well content to affirm that perfect works have been made without a maker, and without the exercise of intellect, he can have no difficulty in bringing everything to an imaginary perfection by the same non-means. It is indeed a sequence of Transmutation logic that it should be so.

Mr Darwin feels that the most advanced organization is that of man, and therefore he seems to hint that in the great and final palingenesy of his system, animals will have a chance of becoming men, or at any rate very like them.

To this, however, the allusion is in brief and guarded terms*-intellect and an approach in structure to man 'clearly come into play' - clearly come into play! if $\mathrm{Mr}$ Darwin would have made this most important point a little more 'clear' it would have been much to the satisfaction of his readers. There is scarcely anything that he has told us more interesting than this, as it turns on the future destiny of animals; and yet, all that we can learn

* 'The ultimate result will be that each creature will tend to become more and more improved in relation to its conditions of life. This improvement will, I think, inevitably lead to the gradual advancement of the organization of the greater number of living beings throughout the world. But here we enter on a very intricate subject, for naturalists have not defined to each other's satisfaction what is meant by advance in organization. Among the vertebrata the degree of intellect and an approach in structure to man clearly come into play' (131). 
is condensed in these oracular words, selected, as we suspect, for the vagueness of their import. So vague are they that any commentary on them seems hazardous; nevertheless, we may venture to offer this interpretation, that in the advance of organization towards improvement in animals the intellect and the structure of man is the point at which they will either arrive, or to which they will approximate.

There is, however, involved in this a question which $\mathrm{Mr}$ Darwin does not like to handle, the origin and the first appearance of man. Of course in this system man was not created; he was gradually unfolded out of another form, less perfect; from some of the thousands of exterminated creatures, intermediate between the ape and the man. 'The human character and form are the result of changes brought on by insensible degrees, and carried on during an immense period of time. The intellect, conscience, virtues, imagination, taste, wit, skill, reflection, and religion of man are accidental beneficial accumulations carefully preserved by Natural Selection, who killed off the less complete semi-men, not endowed with these attributes. Man was no more designed for his place in nature, than 'the incrustations* of carbonate of lime on the inside of a kettle.' Accidental improvements, preserved in advancing: apes, produced the intellect of man, and the whole of his organization corresponding to his intellectual cliaracter. His mind and character are the result of molecules of matter put into new shapes and places, and as he was not created, but evolved, or developed, he is not a creature accountable to his maker, for, indeed, he has no maker, nor can a sense of right or wrong, or any moral feeling in man, be considered anything but the motions of cerebral im-

* Professor Sedgrwick on the Studies of the University of Cambridge. 
pulse, or some yet unexplained action of galvanism or chemical power.

With such an origin of the sense of duty, how can he be certain that his ethical determinations are based on any firm foundation? or that they are more than temporary impressions on the brain, which may have to undergo further changes, and so be brought to entertain new apprehensions of things? If the rationale of morals depends on a correct anatomy of the human mind, and an intimate acquaintance with the affections, passions, and sentiments of the human heart; and if the human mind has been produced not long ago (speaking geologically) by its altered anatomy, how is it possible to be certain of the rectitude of moral precepts, as they are at present accepted, unless it be also mathematically certain that the human anatomy is to change no more? But it is by no means certain that the intellectual, moral, and physical qualities of man are stationary. They may change according to this theory, so that a future advanced man may be as far above the present man in his organization and mental apparatus as the negro is above the gorilla.

Therefore we are not justified in affirming that the susceptibilities of moral emotion, in consequence of which actions of a moral character are regarded with powerful feelings of approval or condemnation, are permanent qualities of the human mind. Moreover, it is certain that the mind of man has not been formed for the object of discerning what is right and approving it. If it does so it is an accidental circumstance, it is merely a Sequence of Events as ascertained by us, and therefore other events taking place in the general arrangements of the human organization may alter altogether the mental impressions, and produce other moral conceptions of an entirely new character. 
Now, as man is the standard of intellect and virtue, and as man is not created, but developed out of unintelligent antecedent matter, without any superintending design, it is clear that intellect proceeds from non-intellect, and that virtue is the result of blind matter put into certain shapes, positions, and relations by chemical or mechanical action.

Moral rectitude is a mere result of a modification of matter, analogous to the growth of mould in a cheese : let the organization that produces it be re-modified, and the result will be different.

Mr Darwin, indeed, anticipates that his system will introduce an entirely new era of psychology. "In the distant future I see open fields for far more important researches. Psychology will be based on a new foundation, that of the necessary acquirements of each mental power and capacity by gradution. Light will be thrown on the origin of man and his history' (523).

Whether this brief account of the moral attributes of man, as logically deduced from the Theory, may be a fore. shadowing of the new psychology we will not venture to say, but that it is a true history of man's origin in the genesis of the Transmutationists is indisputable. Psychology, nevertheless, seems to be a word but ill-fitted to the doctrine of this school; a soul cannot be developed from the changed flesh and bones of an ape; somatology, therefore, is the more appropriate term for this system-as the organization has changed by 'gradations,' so has the character of the animal man changed by gradations : and perhaps many thousands of experimental species of men were exterminated before man was produced with his present faculties. 
But in this Theory what shall we say of virtue and moral excellency as the crowning attributes of man? How have they made their appearance in the human animal, slowly transformed into his present nature from the baboon? That these qualities have not been pre-ordained as a distinguishing plan for the race, is quite certain in the philosophy of Natural Selection; for if man had been designed to be a creature that should appreciate virtue, then he nuust have been the product of a creative will, operating antecedently to his existence. Man, therefore, by this system, must have attained his moral peculiarities just as all other animals have become possessed of the instincts or characters of their races, by additions and mutations from other antecedent forms; and if he be an animal striving after moral superiority, it is the result of the sequence of events, and not of intention or design. We must, therefore, place virtue in this 'Theory precisely on the same footing with every other attribute of every other animal, and account for its existence in the same way: that is, we must say that when the first virtuous men, or men with a capacity to appreciate virtue, were accidentally elaborated, it gave them a decided advantage over all their congener's who did not share with them in the new quality, and so enabled them to keep their place in the struggle for life, whilst their competitors were exterminated by that rigorous law which knows no exception. In one word, the men endowed with virtue exterminated all those who lacked that endowment.

If this should be a startling history of the origin of moral excellence, and if it should be contradicted by all the records of our race, we must, nevertheless, beticve that 
it was so, for the Theory imperatively demands it, and cannot subsist without the supposition.

But we return to the text of all these remarks, and observe on it that it contains three statements. 1. That each creature will tend to become more and more improved in relation to its conditions of life; 2. The greater number of animals throughout the world will be advanced in organization; 3 . That amongst the vertebrata this advance has a reference to the intellect and structure of man.

Now the vertebrata begin with the fishes: there will be therefore advancement in the depths of the sea, and great things will take place amongst the finny tribes. Much might we speculate on the intellectual improvement of the whale, who, as belonging to the mammalia, would have the first claim to advancement amongst animals in the waters -and much of every species of fish-but this may be omitted, and we now proceed to observe that in this prospective advancement of lower forms there is a contradiction in the Theory.

It has been urged against it that if all organic beings tend to rise in the scale, as we are taught has always been the case, how is it that throughout the world a multitude of the lowest forms still exist?

$\mathrm{Mr}$ Darwin has noticed this objection, and has told us that 'Lamarck, who believed in an innate and inevitable tendency towards perfection in all organic beings, seems to have felt this difficulty so strongly that he was led to suppose that new and simple forms were continually produced by spontancous generation' (135). 'This of course, by help of a bold figment, was a solution of the difficulty; Lamarck, by affirming that all the lower forms were continually coming into existence by spontaneous generation, 
could account for their not having as yet been transformed into higher grades of life. But how does Mr Darwin, who repudiates the solution of Lamarck, surmount the difficulty?

His method is this, he turns against his own statements, and undertakes to show that it is not requisite that the lower forms should be advanced. He asks us 'what advantage would it be to an infusorial animalcule, to an intestinal worm, or even an earth-worm, to be highly organized? If it were no advantage these forms would be left by Natural Selection unimproved' (135).

This very unexpected answer is in fact a confutation of the Theory.

'How do we know it would be any advantage for the lower forms to be more highly organized?'

How, indeed, do we know? This is precisely the question we put in every case of Mr Darwin's alleged metamorphoses. We do not confine it to earth-worms, but in the case of tapirs, ostriches, logger-headed ducks, bears, \&c., we ask precisely the same question? how do we know it would be for their advantage to be changed?

Mr Darwin tells us that these changes have taken placa by accidental beneficial modifications; but we ask him how any animal can be benefited by a change? All animals below man are of the lower forms, and all, according to the Theory, have been changed, because it would be to their advantage. But let him name any animal that is to be changed; and how can he venture to affirm that any change whatever would be for the advantage of that animal ? To change a frog into an eagle would be no benefit to the frog, for he is in his own department of life perfect; and so of every creature, however humble it may 
appenr to us - the infusoria, the rhizopoda, \&c., are for their destination perfect. Mr Darwin himself has told us that "every naturalist who has dissected some of these beings now ranked as very low in the scale, has been struck with their really wondrous and beautiful organization.' Is it not then a monstrous idea to set about improving ' woncrous and beautiful organizations;' and is it not a sort of madness to think of making an animal something else than what it actually is?

In this matter, therefore, we repeat it, Mr Darwin has completely answered himself, "How do we know that it would be any advantage for the lower forms to be more highly organized?'

Nevertheless, from him, this question is most strange; for the answer would be that in this Theory the benefit of an advancing change would be everything.

Would it not be an advantage, according to the representations of this Theory, for an intestinal worm to be advanced into the owner of the intestine, who might be a grand Lama, a king, or a pope? and would it not be a glorious promotion for an oyster to be promoted into an alderman who devours the oysters? and why condemn the carthworms to perpetual humiliation? If a form is low in the scale of organization, Mr Darwin takes it for granted, in his scheme of Natural Selection, that it would be an advantage to promote it into one of superior grade: on this the whole theory of metamorphose proceeds, how then can he thus turn round upon us, and ask what advantage it would be for an earth-worm to be highly organized?

We know very well, that in the truth of nature such changes would not be advantageous, but Mr Darwin always reasons on this subject the other way, and judges of 
the feelings and interests of animals as if he himself were one of them, and were therefore anxious for promotion. It is quite true that in our opinion, and with our human feelings, it would be more agreeable, as well as more dignified, to be a race-horse than an earth-worm; but worms do not reason and feel as we do, and if a choice of change were offered to the worm he would not have the slightest inclination to quit his native clod and run for the Derby.

According to nature and the established laws of life it certainly would be no advantage to advance any animal into a higher form, it would on the contrary be as disastrous as it is impossible; but according to the Theory it would be most desirable, it would be gaining a point in that progress of animal life which it is the object of the system to establish. We cannot do better than to finish these remarks with Mr Darwin's own words, self-immolating as they are to the learned gentleman. "Who can pretend that he knows the Natural History of any organic being sufficiently well to say whether any particular change would be to its advantage? ?* (137.)

* Ve have seen in the last chapter Mr Darwin's reveries on the correlation of change possible between the hive-bec and the red clover, and yet, behold ! thus does he write against himself in another passage :-

'It las been objected, if Natural Selection be so powerful, why has not this or that organ been recently modified and improved. Why has not the proboscis of the hive-bee been lengthened so as to reach the nectar in the flowers of the red clover? but can we feel sure that a long proboscis would not be a disadvantage to the hive-bee in sucking the innumerable small flowers which it frequents? Can we feel sure that a long proboscis would not, by corrclation of growth, almost necessarily give increased size to other parts of the mouth, perhaps interfering with the delicate cellconstructing work' (139).

Who can wite so effectually against Mr Darwin as Mr Darwin hinself? And who, when facing Nature, in a candid spirit and free from the contagrion of paradox, can so acutely observe and so ably apply the observations he has made? 
Yet this is the very thing which Mr Darwin has asserted again and again in every chapter, that it lias been for the advantage of the lower animals that they should be changed, and, moreover, he predicts that this system of mutation will go on amongst them till it reaches perfection.

Here, then, is the contradiction, Mr Darwin meets the objection of the lower animals remaining as yet unchanged by telling us it would not be to their advantage that they should be changed; and yet he predicts that 'each creature will tend to become more and more improved in relation to its condition of life.' In short, he writes for and against the advance of the lower animals; and his own confutation of himself is unanswerable.

In the mean while we may rest satisfied that the Theory is visibly confuted by the existence of innumerable lower forms remaining unchanged; and by the palpable fact that the lower forms have not been exterminated by the higher. This may be noticed anywhere; moreover, we see numbers of species closely allied to one another living together, that is, occupying the same regions, without the slightest tendency to this imaginary extermination. The horse, it will be said, is an improvement on the ass; these creatures are so nearly allied that a mixed progeny can be produced between them, and yet there is no tendency in the horse to exterminate the ass in a state of nature; and so in thousands of other instances. If indeed we could bring ourselves to doubt that which is so evident, $\mathrm{Mr}$ Darwin's perplexity of reasoning and his contradictions on this topic would be amply sufficient to convince us of the real state of the case. And here, to dismiss this subject of Natural Selection by extermination, this need only be 
added to foregoing remarks- - that this operation imagined by $\mathrm{Mr}$ Darwin is merely an expedient to account for the total want of intermediate links, " necessary to connect the transformation of one animal into another. Where are all these intermediate forms, which in some cases Mr Darwin says, in general terms, may have been ten thousand; where are they, in what depariment of nature shall we find them? The reply to this is, they have all been exterminated, they could not keep their places in the competition for life, and, therefore, all have been swept away into oblivion by Natural Selection.

But where is the evidence of this extermination? how comes it that when Geology has preserved such multitudes of extinct animals, it has preserved none of these intermediate forms? In very many cases this slanghter must have taken place amongst large quadrupeds, but of all the ten thousand links connecting the tapir with the horse, in which of the geological formations shall we find one?

To this Mr Darwin answers, 'what geological research lias not revealed in the former existence of infinitely numerous gradations, as fine as existing varieties connecting $\uparrow$ all known species?' (324).

Then how can we accept this bold assertion, involving a whole system of nature, without any proof? Has any

* "We may thus aeeount even for the distinctuess of whole classes from each other, for instance, of birds from all other vertebrate animals, by this belief that many ancient forms of life have been utterly lost, through which the early progenitors of birds were formerly eonnected with the early progenitor's of the other vertebrate classes' (463).

To believe in these many aneient forms of life which no one can describe to us, and of the existence of which no evidence can possibly be obtained, is asking more of us than to believe in Griffins and Centaurs, of which there are many delineations and many descriptions.

$\dagger$ And, again, 'The number of intermediate and transitional links hetween all living and extinct species must have been inconceivably great. But assurclly, if this Theory be true, such have lived upon earth' (305). 
branch of science been established by assertions only? is not a proof, such as the senses can appreciate, requisite in every step of legitimate science? has not geology taken its place amongst the noblest of the sciences by an appeal to facts, have not chemistry, astronomy, clectricity, all advanced by rigid proof; and must we accept your system not by the process of proof but of special pleading? To all this Mr Darwin has one answer, we must believe. 'I see no difficulty in believing;' he has told us in scores of instances. If my Theory be true, it must be so: but my Theory is true, therefore it is so.*

This is a compendious statement of the expedient, on which everything depends. It is the body and soul of the whole system, but geology, with all the rocks of the world, annihilates it; all the series of strata from the most modern down to the Silurian formations overwhelm it with confutation, and though Nature be ransacked in all her corners, not a vestige of proof to corroborate this bascless 'Iheory, can anywhere be discovered.

Mr Darwin has given us a text for our contemplation of Nature: 'Every organized being is trying to livet where it

* 'If my Theory be true, it is indisputable that before the lowest Silurian stratum was deposited, long periods elapsed, as long as, or probably far longer than, the whole interval from the Silurian age to the present day, and that during these vast, yet quite unknown periods of time, the world swarmed with living creatures' (333).

And this most wild suggestion has been endorsed by Sir C. Lyell: 'The oldest fossiliferous strata kuown to us, IIAY BE the last of a long series of antecedent formations, which once contained organic beings.'Antiquity of Man, 470.

When these learued gentlemen can fix their sheet-anchor in no firmer ground than this, that a conjecture may not be impossible, they must not be surprised if they suffer shipwreck. Professor Sedgwick lias well observed, 'A theory is worse than nothing if it reflect not back the present condition of our knowledge. If it tell of laws neither proved nor suggested by the lessons of experiment and observation, it is nothing better than imposture.'-Studies of Cambridge, 71.

$\dagger$ And, again, "Most of the animals and plants which live close round 
can live' (224). Everywhere, according to him, there is a struggle, a scuffle, a vehement contention for life: plants and animals are driving and pushing in unceasing competition to maintain their existence; and Natural Selection is looking on with her murderous eyes to cut off the weakest. But what a dream is this! who ever suspected all this tumultuous tragedy in the serenity of Nature's appearances? every returning season introduces us again to our old friends, in the same places; Spring comes and brings with her the violet, the primrose, the cowslip quietly shining in their old haunts; the hyacinths and the orchises carpet the woods as usual; all the sweet flowers smile upon us with their 'quaint enamelled eyes' as thicy did on our forefathers; the little birds build their beautiful nests as of old, and the cuckoo tolls his bell in the groves as he did in the days of the Saxon Heptarchy. We can reckon on all the forms of life reappearing with certainty, in every country and every climate. We hear of no scuffle, we see no extermination; creatures most like one another seem to know nothing of this competition. Even the venomous snakes live in peace in the same regions with their* non-venomous congeners, and where the dangerous serpents abound others also abound that are comparatively innocuous. There are indeed the car-

ally sinall piece of ground may be said to be striving to the utmost to live there' (120). And, again, 'All organie beings are striving to seize on each place in the econoiny of nature' (107).

* 'In all cases the new and improved forms of life tend to supplant the old and unimproved forms' (304). The serpents with venom-fangs have received a most marked distinetion amongst all the serpent tribe. 'This, in the Theory, has been effected by Natural Selection, who must have known much more than modern chemists, as they cannot give us an analysis of that fatal venom, nor tell us of what it is composed. But the serpents which had obtained this advantage ought to have exterminated all other serpents, not so endowed. This, indeed, they were well qualified to do, but nothing of the sort has taken place. 
nivorous animals seeking their prey, but this arrangement is not on a design of extermination but of repression : and, however the hawks and other rapacious birds may prevail, we may be quite sure they will not exterminate the thrushes and the blackbirds; nor have we the slightest apprehension that the goldnnch, the robin red-breast, or the little wren will disappear, notwithstanding the terrors of Natural Selection.

In bidding farewell, then, to this subject we have examined Natural Selection with sufficient care to understand that it represents nothing, and is a mere play of words. The only real part of the Theory is Accidental Change and Extermination. There is no other agency. There is nothing that can select; no power, intellect, or existence of any sort, that can make any choice, or discriminate between the useful and the inexpedient.

The animal is represented as changing its organization spontaneously, and by slow degrees; the animal that does not change is exterminated. This is the whole machinery by which organized beings have been produced.

The term 'Natural Selection,' therefore, is superfiuous, it is an illusion, an allegorical phantasy devoid of real meaning, and representing no fact. It ought to be entirely banished from the system, and from the title-page of Mr Darwin's book where it is offered as an alternative: 'Origin of Species, by means of Natural Sclcction; or, the preservation of favoured races in the Struggle for Life.' 'That is, we may take our choice between these two statements, which are proposed as equivalent. But the first is a misrepresentation, for species cannot derive their origin from that which has no real existence; and the second contains two errors: 1. 'The favoured races;' favoured by 
whom, or by what? this expression implies selection and has a reference to the first part of the title. 2. "The Struggle for Life' is a metaphor, which Mr Darwin cannot pretend is to be taken literally. Thus the title of the book has three metaphorical expressions, as an carnest of all that was to follow.

'The production of species by accident and extermination' would have expressed more correctly and truthfully the gist of the Treatise.

Mr Darwin has himself told us that Natural Selection is a metaphor, and yet on this basis has he argued all through his book, without even once availing himself of that definition which he assures conveys the real meaning of the term. That there has been an object in this we can scarcely doubt, it has been intended to induce the reader, by continual usage of the words, to suppose that there is really a power of selection and of choice in this dispensation of metamorphoses. Very numerous are the passages in which Natural Selection is personified, and represented as a vigilant inspector and improver of the forms of life, and as endowed with transcendent skill and wisdom in her multiplied operations. Several of these passages the reader has seen, and that this inexcusable language has produced its effect on the converts to the system is more than probable. But as a corrective to this illusion we propose this experiment. Let the reader, in every instance in which the word Natural Selection occurs, substitute * the real

* Take the following instance of a sentenec thus corrected: 'Under changing conditions of life, there is no logical impossibility in the acquirement of any conceivable perfection through-the Sequenec of Events as ascertained by us' (224).

And arain: "The Sequence of Events as ascertained by us, is a power" incessantly ready for action; and is as inumeasumably superior to man's fecble efforts, as the works of Nature are to those of Art' (65). 
meaning of the term, 'the Sequence of Events as ascertained by us,' and it will then be seen how soon the bubble bursts. We recommend this experiment to all the converts of Transmutation.

It is, however, a dangerous practice to trifle with words, and more especially in a scientific treatise; for whilst we are thus misleading others we not unfrequently mislead ourselves; and that $\mathrm{Mr}$ Darwin has done this in not a few instances, but especially in the following passage, is sufficiently evident.

'If this relation, on the one hand, between the viscid matter requiring some little time to set hard, and the nectar being so lodged that moths are delayed in getting it; and, on the other liand, between the viscid matter be. ing at first as viscid as ever it will become, and the nectar lying all ready for rapid suction, be accidental, it is a fortunate accident for the plant. If not accidental, AND I CANNOT BELTEVE IT TO BE ACCIDENTAL, WHAT A SINGULAR CASE OF ADAPTATION.-Orchids, 53.

Now, these last words are precisely such as Paley would have used in the case in point, and indeed he has frequently expressed himself in not dissimilar language, in his explanation of the contrivances and adaptations of the structure of organic beings. With him, whose reasoning is avowedly directed to attribute all that is wise, beneficial, and beautiful in nature to the Creator, such language is

-And in this magnificent sentence :

'I ean sce no limit to the anount of change, to the beauty and infinite complexity of the co-adaptations between all organic beings, one with another and with their physieal conditions of life, whieh may be effeeted in the long course of time by - the Sequenee of Events as aseertained by us' (113).

The cpitome of all this may be taken in these words: 'I can belicve that anything nay have becn effected without a causc.' 
natural, but with Mr Darwin, whose whole system is aimed against the idea of creation, nothing can be more inappropriate-nothing more self-convicting. It is the result of an habitual abuse of words. The learned author of the system has so continually spoken of Natural Selection, as a real existence, and an Intelligent Power in Nature, that he has at last, in his moments of inattention, come to think that the phantasy is indeed a real substance, and he has, in consequence, made use of expressions which stultify all his 'Theory. If the arrangements of which he speaks were not accidental, they certainly were intentional, they were the result of a design, they were, as he says, a singular case of adaptation, and were devised and planned to produce the effect which he so much admires.

All this is true, but then it annililates the Theory.

Wherever we turn in our inspection of this Theory we find that ingenuity has been taxed to produce imaginary beings, events, and circumstances, which liave no existence but in the magisterial affirmation of the inventor ; and that the whole system from beginning to end is based on assumption without proof. Every step of the argument is wanting in that exact evidence which Science dcmands even in the most ordinary case, but which in a Theory such as this would require more than usual scrutiny. We have a profusion of pliysiological learning, abstract reasoning, and ingenious speculations, but the plain direct facts which are indispensable for establishing the main points are wanting. Probabilities and possibilities abound, and it is a favourite cxpression with the learned author that 'he sees no great difficulty in believing' some strange proposition adduced in the course of his argument. We 
have analogies and presumptions, and all the expedients of able special pleading-we have questionable propositions taken for principles, but the evidence which should establish them wholly omitted; and we meet with the freest flights of the imagination in asserting circumstances as facts, which have no more claim to our credence than the mythical allegories of the Hindoo Cosmogony.

Locke, in his 20th chapter, on the Causes of Error, has placed amongst the first, want of proofs; and these pages will have shown the reader that the instances are numerous in which we have met with assertions unsupported by proof.

Let us now in recapitulation look at a few of the most striking instances.

In the matter of species, the primum mobile of the Theory, Mr Darwin acknowledges that his scheme is an assumption. He tells us that varieties in process of time become species, then, after a long interval, they vary again, and so ultimately make another species.

'That varieties more or less different from the parent stock occasionally arise, few will deny, that the process of variation should be thus indefinitely prolonged (i.e. that they should become species) is an assumption, the truth of which must be judged of by how far the hypothesis accords with and explains the general phenomena of Nature' (89).

Now this process of variations becoming what Mr Darwin calls 'good species,' is an assumption for an liypothesis. This we learn from the best authority; and this be it remembered is the great point of the Theory, the Mutability of Species.

Again, we hear that 'new forms are continually and 
slowly being produced' (1 1.5). What evidence has $\mathrm{Mr}$ Darwin for this assertion? where are his proofs? the answer is that historical time is as nothing for such a process ; five or six thousand years, the utmost reach of history, are a trifle for Natural Selection. The slowness is that of geological time. Be it so, but still the process is an assertion without a proof.

Again: 'As new forms are continually and slowly being' produced, unless we believe that the number of specific forms goes on perpetually and almost indefinitely increasing, numbers must inevitably become extinct. That the number of specific forms has not indefinitely increased geology* tells us plainly' (89).

This, as a specimen of Mr Darwin's reasoning, deserves more than passing attention.

First he lays it down as an established fact-as an axiom - that 'new forms are continually and slowly being produced,' and then, on this assertion, the logic of the rest of the sentence is constructed.

New forms are continually being produced.

But if so, the number of them must indefinitely increase :

But geology teaches us that they do not indefinitely increase,

Therefore the new forms are exterminated.-Q. E. D.

Again : varieties are frequently called 'incipient species ;' an assertion without proof (131).

Here again geology is admitted as an unanswerable witness whose testimony must settle the question : and that on the very point of the greatest importance to $\mathrm{Mr}$ Darwin. It is a question of the indefinite increase of specific forms. The evidence which geology offers on this question is here taken as decisive: but when we ask for the evidence of his exterminated intermediate forms in the records of geology, he tells us that the extreme imperfection of the record fails in proving that on which his theory depends. Thus geology is good evidence against the indefinite increase of forms, because it does not produce them; but for the cxtermination of an indefinite number of forms it is a bad witness for the same reason, because it does not produce them. 
Again: 'When a part has been developed in an extraordinary manner in any one species, compared with the other species of the same genus, we may conclude that the part has undergone an extraordinary amount of modification since the period when the species branched off from the common progenitor of the genus' (171).

Here are three assumptions: 1. That parts of organizations have undergone modification. 2. That the species branched off. 3. That there is a common progenitor of a genus. No proof is offered for any of these propositions.

Again: the retrogression of animals, and their degradation into a lower form, is entirely hypothetical. There is no proof of this in nature, and Mr Darwin offers nothing to confirm it but his simple assertion.

All the particular cases of metamorphose, as a bustard into an ostrich, a tapir into a horse, \&c., \&c., are purely visionary. No proof of these pretended changes is mentioned.

The account of the formation of the eye-of the tails of animals —of the beautiful plumage of birds, and other parts of animal organization, is in every instance given to us without an attempt at proof.

The gradual advance of organized beings towards perfection is visionary, proof indeed could not be given of such a prediction.

The assertion that the animals of lower form have not been advanced to the higher, because it would not be for their benefit, as it is altogether visionary, and incapable of proof, has been propounded merely to parry an unanswerable argument against the Theory.

The doctrine of Natural Selection by extermination is an assertion without proof. It is, however, disproved by 
the testimony of geology, and this Mr Darwin acknowledges to be a most serious difficulty. We ask for the intermediate forms swept off by millions through Natural Selection. Where are they to be found? And why not found when so many forms of distinct organization have been discovered in all parts of the world? All the distinct forms, or great numbers of them, have been discovered, but the intermediates are as if they had never existedthey are invisible.* And an Edinburgh Reviewer has well said " that Geology, not seen through the mist of any theory, but taken as a plain succession of monuments and facts, offers one firm cumulative argument against the hypothesis.'

Finally, the pretended origin of all plants and animals from one primordial form-a spore of one of the lowest algæ, is visionary: No proof can be adduced of such a proposition, which surely may bear the palm amongst pre. posterous conjectures.

Thus all the main parts of the Theory are assertions without proof. It is not a system established by inductive reasoning, but by conjecture, assumption, and invention. Now all natural knowledge is based on inductive reasoning. We have learnt to comprehend the mechanical movement of the heavens by first learning the laws of motion upon the earth. In like manner we have learnt to speculate securely on the functions of organized beings during the old conditions of the earth, by first studying the laws of organic life among the phenomena of living nature. In every instance we must begin with what is known and

* Cependant on peut leur repondre, dans leur propre systême, que si les espèces ont changé par degrés, on devroit trouver des traces de ces modifications graduelles;-pourquoi les entrailles de la terre n'ont elles point conservé les monuments d'une généalogie si curieuse.'-Cuvier, Discours Preliminaire (74). 
present to us, before we can speculate about what is unknown and remote. To this rule we know of no exception.

But in an hypothesis based on assumption, such as $\mathrm{Mr}$ Darwin himself acknowledges his account of species to be -which is the same thing as confessing that it is devoid of proof-how can its author demand as his right the assent of those to whom it is addressed? But the assent of the reason is a sort of right which every writer may demand who is conscious that his statements are supported by accuracy of proof. Harvey, Cuvier, Hunter, de Candolle, Müller, Valentine, Owen, and other great names, take it for granted that the evidence of their statements must produce conviction, and they advance from step to step in their doctrine in perfect security of their position.

But with Mr Darwin a new principle is continually evoked, it is not the assent of the understanding, but it is faith:- 'we must believe'-and the number of instances in which this is urged, or in which Mr Darwin says that 'he sees no great difficulty in believing' such or such a conjecture, is truly astonishing. 'It is necessary to believe that when a variety has once arisen it again varies, and that these varieties are preserved' (i. e. become 'good and distinct species' (\$9), and so on continually. Here a fundamental principle of the Theory is proposed as an article of faith: it is not proved to us, but we must believe it. Many such examples have already been laid before the reader, and therefore they will not be repeated. In the note* references will be found to some remarkable

* See pages $89,91,99,115,152,199,207,209,211,212,213,220,221$, $225,229,256,258,259,265,329,336,332,333,463,469,519$, \&c.

These references are to the thind edition. 
passages where this occurs, but by careful search the number might be considerably increased.

We may say generally that Mr Darwin's Theory is expressed in the form of a creed.

Now surely this is instructive, and must convince us that in order to avoid the miraculous, by seeking for a new method in the interpretation of nature, the end is not only not obtained, but the result is exactly opposite to our expectations. In the old method the great physiologists take it for granted that their researches can only reach a certain point, beyond which they cannot penetrate, there they come to the inexplicable, and they believe that barrier to be the Creator's power, which they leave at a respectful distance. This, according to the feelings of the ancients, was 'the veil of nature which no mortal hand had ever withdrawn,' and as they approached it, they felt and spoke of it with reverence.

Now the new method is to discard the belief in a Creator, to reject the omniscience and omnipotence of a Maker of ail things - to speak of the act* of creation with scorn-to charge us who believe in it with endeavouring to conceal our ignorance by an imposing form of words; and to undertake to explain the origin of all forms of life by another and a totally different hypothesis. What, then, is the result? a long list of new and doubtful assertions, some of them of surpassing novelty and wildness, and all of them unaccompanied by proof, but proposed as points of belief. The marvellous in the old method is in

* Mr Darwin not unfrequently speaks of creation as a Theory :-

'How inexplicable, on the Theory of Creation, is the variable appearance of stripes on the shoulders and legs of the several species of the horsegenus, and in their liybrids' (506), and other passages. 
one point only, and that for the most part more implied than expressed, the belief in a paramount Intellect ordaining life and providing for its success. The marvellous in the new way is a vast assemblage of prodigies, strange and unheard-of events and circumstances that cannot be confirmed by any authentic evidence, and which, indeed, are out of the reach of evidence-a throng of aerry dreams and phantasies, evoked by the imagination, which we are called on to belicve as realities, as it is impossible to prove that they are so.

Therefore we affirm that if it were for nothing else than to get clear of the marvellous, it would be far wiser and more prudent to adhere to the old method, since the credulity demanded in the School of Transmutation, as essential for discipleship, very greatly exceeds any acts of faith habitual to the old way of thinking.

Mr Darwin, indeed, seems to think that he has opened a way for the augmentation of knowledge hitherto unknown, and that by the aid of his system he is to be the pioneer of immense discoveries. 'We shall never probably disentangle the inextricable web of affinities, but when we have a distinct object in view, "and do not look to some unknown plan of creation, we may hope to make slow but sure progress' (4.64).

Is not, then, the progress that has hitherto been made sure? Have not the great naturalists, who have preceded Mr Darwin, or who have been his contemporaries, paid large tribute into the treasury of science? is all that they have taught uncertain, vacillating, and questionable? and has the progress which knowledge has made been so very slow this century? Has everything been at a stand-still, and were we all groping in the dark till this new light of 
Transmutation blazed upon us? and will the discoveries of the Transmutationists be more sure than those by which Science has already been enriched? When wẹ hear that it has taken a long time to acquire a pair of wings, certainly the progress of that phenomenon must liave been slow enough, but that it is more sure than a long list of physiological discoveries effected in this century is not quite so obvious.

Mr Darwin seems, in the zeal of his new creed, to think that a belief in the plan of creation has hitherto been the chief hindrance to the advance of science; truly a strange opinion to have adopted. We know how the world is indebted to the discoveries of Harvey, and we also know low, directed by the conviction that there is a plan in the works of creation, he made those discoveries. If we refer to Newton, the great sun of the scientific world, we know full well his sentiments on this subject, and we remember that he interwove his creed in the text of his immortal Principia. The sentiments of Cuvier on this head are no secret, and it is quite evident that his strong. belief in the design of creation greatly influenced his scientific labours, and contributed in no small measure to their triumphant result. Even Laplace has shown us, by the doctrine of probabilities, ${ }^{*}$ that the machinery of the heavens must have been devised by an original or first

* Laplace has shown by the calculus of probabilities that it is above four millions to one in favour of the forty-three motions from west to east (including rotation as well as revolution, and the motion of the rings as well as of the planets and satellites) having been directed by an original or first cause. And by the same calculation he has shown the probability of the sun's rising again on the moment of any given day, to be not much more than 1,800,000 to one; or in other words, that the rising of the sun is two million times less probable than the truth of the proposition that the motions in our system were designed by one first cause. 
cruse; and long indeed would be the list of men of distinguished intellect, who, in all departments of science, have felt that there is a plan in creation, and that the wisdom and beauty of its design prove the divine power of its Author.

The name of Mr Darwin himself might, thirty years ago, have been placed in this list. Was he at that time groping in the thick fog of error and ignorance? we might almost suppose he thinks so, by the following words: ' when we no longer look at an organic being as a savage looks at a ship, as at something wholly beyond his comprehension, how far more interesting-I speak from experience-will the study of Natural History become' (521).

What then! do naturalists and anatomists of repute look at an organic being as a savage looks at a ship ? can they not explain a large portion of the design of that organization, though they be not adherents of Mr Darwin's sect? and are all men of science in the civilized world staring at Nature like ignorant savages, because their eyes are not purged with the collyrium of Lamarck's prescription?

Mr Darwin may indeed feel deeply interested in looking at his own organization as the result of twenty thousand improving apes, exterminated to bring him to perfection, but others, to whom the orang-outang genealogy is less attractive, and who have always believed that the first sire of their race was of the highest origin, will be not less satisfied with the ancient opinions regarding the history of their existence. But now that all things are to be made so clear by the bright morning light of Transmutation we may inquire whether Mr Darwin has himself advanced the knowledge of organization by his new method? Not the least; 
for though he twits us with* our ill-disguised ignorance, yet when it comes to the point where the real difficulty lies, and where the explanation is wanting, he is just as ignorant as we are, and plainly confesses that he can neither account for the first beginning of life, nor for the mode in which the alleged mutations are effected.

He uses very strong language in some instances, and tells us that 'it is impossible to conceive by what steps these wondrous organs have been produced' (p. 818).

He acknowledges, not merely once or twice, that these things pass his knowledge-the unknown quantity of the problem he cannot discover, he is fairly baffled, and he tells us so.

As then he is not, by virtue of his new method, one inch in advance of other physiologists in the exposition of the secrets of Nature, he must be content to be, in that respect, as we are-and if we are 'looking at organized beings as a savage looks at a ship,' he is in the same predicament, as true a savage as ever was tattooed in full cannibal decoration. All that we can do, savages as we are, is to be looking still closer, to be continually recording the facts we discover, and for which we can show our proofs, and thus by slow degrees we may perhaps learn more, in the prescribed labours of patient observation.

But we do not repudiate this charge of ignorance; we

" "It is so easy to hide our ignorance under such expressions as the "plan of creation," "unity of design," \&c., and to think that we give an explanation when we only re-state a fact. Any one whose disposition leads him to attach more weight to unexplained difficulties than to the explanation of a number of facts will certainly reject my theory' '(516).

Here Mr Darwin plainly sets himself up as the great interpreter of the difficulties of nature, and tells us that those whose disposition leads them to prefer ignorance (for that is the meaning of the words) will reject his theory. After this it is amusing to see him clicck-mated over and over again when he comes to these very difficultics. 
know that we are ignorant, we are sure that there are limits for the utmost reach of our knowledge, and we know full well we are, as yet, at a vast distance from those limits, but if ever we should reach them we know that further progress will be impossible. We see the fiery sword turning every way to guard the way of the tree of life. = We shall be able to describe life in the forms in which it is presented to us, but life itself, its essence, the secret of reproduction, and the profound and awful mystery of our creation, we shall never touch.

We believe that infinite wisdom was united to infinite power to effect this first construction and arrangement of all things; and as there we come to a light that dazzles us we turn away, for to press onward against dazzling light would only produce blindness.

But Mr Darwin in a better mood has himself confessed the greatness of our conmon ignorance, which he does not seem to think will be much diminished even by his new method. 'It deserves a special notice that the more important objections relate to questions in which we are confessedly ignorant, NOR DO WE KNOW HOW IGNORAN'T WE $\Lambda \mathrm{RE}^{\prime}(499)$.

These last words of deep import open a wide field for reflection, and remind us of a sentence uttered by Laplace in his last moments, 'our ignorance is immense.' The height to which a superior intellect can ascend only increases the horizon of things that have yet to be discovered, the more we know the more we shall have to know, and at the same time it is important to remember, and to some minds of the utmost consequence never to forget, that there are many things, which, though it is tempting to examine, 
we never can explain. Unfortunately, however, Mr Darwin himself forgets his own wise words, and though he confesses that our ignorance is deeper than we suppose, he nevertheless ignores the possibility of an intellect superior to that of man, to whom, nevertheless, he has attributed no very intellectual origin. Hence he plainly declares that he cannot believe in the works of creation.

'Almost every part of every organic being, at least with animals, is so beautifully related to its complex condition of life, that it seems as improbable that any part should have been suddenly produced perfect, as that a complex machine should have been invented by man in a perfect state' (46).

This reasoning takes for granted that there is nothing wiser or more skilful than man; if man is not able to make a complex machine perfect without a long time for its preparation, how can the limb of an animal have been suddenly made perfect?

Certainly the atheistic sentiment was never more broadly stated, though it contains a latent argument against the very Theory it is intended to support. For it is clear that the passage has this import, the complex machinery of men requires a long time for design and construction, therefore a much more complex and wonderful machine must require much more time for the design and construction to bring it to perfection. But as this would be a proposition opposed to the Theory, Mr Darwin's meaning probably is this, as a human machine cannot be made by design and skill suddenly, an infinitely more intricate machine can only be made by long-protracted ignorance and inability.

Now that a dissimilar deduction would be suggested by 
common sense, and assented to even by those who allow themselves great freedom of thought and language, we may see in these words of Voltaire :*

'In perceiving by the mind the infinite relations that are in all things, I suspect a Workman of infinite ability.' And indeed the questions have ramifications not acknowledged in the theory, for the argument would, if fully stated, set in against it from many a quarter besides that of organization; as it is abundantly clear that the earth itself, with its diurnal revolution, the length of clay, its atmosphere; the ministrations of the sea, its tides and currents; the birth of the clouds, the winds; the diversities of the seasons, the range of climates, the balancing of temperature, the partition of light and solar heat, the main properties of light, its refraction and reflection; the laws of electricity, its relation to air and moisture, the fluidity, density, and elasticity of the ether, by means of which its vibrations produce light, the composition of the atmosphere-these and a vast many other arrangements slow plainly enough a preparation and a design for life, and lead us to expect something answerable to such wonderful and complicated dispositions. When therefore we find life in all its myriad forms of enjoyment, when we see the senses by elaborate organs cnabled to apprehend and reap the benefit of these preparations, we understand the object of the work, and see it brought to perfection in the organic beings adapted for all climates.

If therefore we deny the will and the work of a Creator in the existence of organized beings, we must deny it in the cosmical arrangements also: re must carry out the

* 'En appercevant par la pensée des rapports infinis dans toutes les choses, je soupçonne un ouvrier infiniment habile.'-Lettre à Diderot. 
theory of Natural Selection to the earth itself, and the whole machinery of the solar system. We must not mince the matter, but must be prepared to affirm that the world itself is the result of Natural Selection, and that myriads of globes were exterminated before this actual sphere with the density of its mass, its size, its peculiar shape, the inclination of its axis of rotation to the plane of the ecliptic, its climates, its distance from the sun, and its rate of motion in its orbit, were brought to that condition which constitute it a theatre for the life of animals and plants.

'To allow that the earth was arranged as it is, by design, but to deny that organic life on the earth is the production of design, would be to allow the greater miracle and deny the smaller. If Natural Selection be a true theory, it must embrace the whole heavens. If an artificer and a design can be discovered anywhere in the universe, they will be acknowledged everywhere. If a supreme Intelligence created all worlds, the same power beyond all doubt created intelligent man who is able to scrutinize all the phenomena of the celestial orbs. There is no breaking the chain of this argument; if there is creation at the beginning, there is creation at the end, and vice versit.

We have just seen that Mr Darwin cannot believe that the perfect parts of organized beings liave been made perfect suddenly, we must now contemplate lim finding fault with Nature, and for the purpose of reminding us that where there are such faults, we can scarcely admit them to have been produced by an act of creation. 'We ought not to marvel if all the contrivances in nature be not, as far as we can judge, absolutely perfect, and if some of them be abhorrent to our ideas of fitness. We need not marvel at the sting of the bee causing the bee's own death, or drones 
being produced in such vast numbers for one single act, with the great majority slaughtered by their sterile sisters ; at the astonishing waste of the pollen of our fir trees; at the instinctive hatred of the queen-bee for her own fertile daughters, at ichneumonidæ feeding within the live bodies of caterpillars, and at such other cases' (505).

On this quarrel with Nature we observe first, that one of these instances is simply an example of the system of repression, by check and counter-check, which seems absolutely indispensable in the general plan of the exuberance of life. The Ichmeumonidæ take possession of the body of the caterpillar, as recipients for their eggs, that the larvæ when hatched may destroy the caterpillars. The caterpillar's, feeding on some vegetable, are not to be left to infinite reproduction, and therefore this is a check provided to keep down the excess of their numbers. Of such arrangements there is no end, and if we have determined that there ought not to be any destruction in nature, then of course this particular instance must be abhorrent to our ideas of fitness. When a leopard destroys an antelope, or a wolf worries an innocent lamb, or a tiger dines on a wise and virtuous man, this may be abhorrent to our feelings of fitness - except when we perpetrate the like crimes ourselves. When we sit down to a quarter of lamb, with mint sance, we never disturb ourselves about the conscience of the grim butcher who is making a sanguinary fortune by our cyclopian appetites. It is not at all abhorrent to our ideas of fitness to do that ourselves, which we hear of with such horror when perpetrated by a wolf or a lion. If a dog eats a sheep we have him hanged forthwith; but if a thousand sheep are cut up next morning and sold in the London market, we 
think it a most encouraging circumstance, and a blessed proof the prosperity of the landed interest.

These considerations may perhaps tend to cool the heart of our indignation against the Ichneumonidx.

The poor bees, with whom Mr Darwin seems to have a settled feud, are not quite so guilty as he would have us think. In the first place Mr Darwin may learn that when he is next stung by a bee, if he will not fight with the insect, but allow it sufficient time, it will extract its sting without destroying itself by the operation. It is the strugyling to escape when struck at that causes it to pull its sting out by the roots.

Then, again, there is a reason for the great number of drones over and above the well-known object of their existence. It is intended that they should contribute to keep up the warmth of the hive when the bees are at work, as a high temperature is indispensable for the rearing of the young. When the harvest of flowers is over, or nearly so, they are killed off on a utilitarian principle, to get rid of the number of useless mouths in a season of short-commons; just as we, in a close siege, take steps to get rid of the non-fighting inlabitants, and to lessen as much as possible the number of consumers. This, perhaps, is not very amiable, it is moreover cruel; but it seems a strange idea to judge a hive of bees by the 'l'en Commandments or Paley's Moral Philosophy.

The queen-bee kills the young queens, or is killed by one of them in duel; as monarchy, in the strictest sense of the word, is indispensable in that polity. One only queen can be allowed a place in a hive of honey-bees. These jealousies of the reigning sovereign are certainly not amiable, but according to our own usagges not unnatural, for what 
is so common as that Eastern princes should slay their brothers and nephews. The Grand Sultan limself is said, to this day, to imitate the morals of the queen-bee. Why did Natural Selection make grand sultans and Eastern despots? An Eastern prince commits a crime when he destroys his brother, but the queen-bee has not a code of morals and a conscience to direct her in the government of the hive.

We need not, therefore, say more in answer to these not very profound objections. Mr Darwin, however, need not disturb'himself about the imperfections of Nature, for he may rest assured it is much too perfect for his Theory.*

Having thus traversed this system with hasty steps, we take a parting view of all that we have gone through, to recognize in what we have found in it but a modern name given to very ancient speculations. The Theory of Transmutation differs but little from the Epicurean doctrine, which itself was but a new dress for kindred opinions of an earlier date. And, indeed, it is impossible it should be otherwise, for they who deny a first mover and an intelligent cause of unintelligent matter when arranged in organic living forms, must agree in the great point of all, the fundamental negation. Anything that may be added to this is comparatively unimportant, but everything that has been added in any age and in any quarter amounts in substance to the same thing. Democritus, Leucippus, Protagoras, and Epicurus might each have variations of machinery to account for contrivances in nature on the atheistic principle, but the machinery of all differs much more in names than

* 'La nature a des perfections, pour montrer qu'elle est l'image de Dieu ; et des défauts, pour montrer qu'elle n'en est que l'image.'-Pensées de Pascal, 87. 
in realities. The slanting atoms of Epicurus acquired the greatest vogue, and became the most popular tenet with the opponents of creation; but the jargon of all those doctors was much the same-original molecules of matter, rough or smooth or hooked, placed in different modifications, by affinities or repulsion-philia and neikos - a plastic force of nature, and whatever else can be imagined of grandiloquent phrase to conceal profound ignorance.

The modern expedient of the school has been by imaginary spontaneous generation-a power of development-or Natural Selection; but all these teachers, from Democritus down to $\mathrm{Mr}$ Darwin, have one system, that unintelligent matter can put itself into advantageous and improving forms of existence, and that matter, leit to itself, can execute perfect works, and at last, by its own operation and out of its own substance, produce the highest qualities of intellect, with which we are acquainted. Mr Darwin's system seems to be a reflection of that of Strato Physicus, ${ }^{*}$ who thought that all Divine Power was placed in Nature, which contains in itself the causes of generation, increase, or diminution-but is wholly devoid of sense.

A senseless, self-creating, plastic nature is the sole agent of $\mathrm{Mr}$ Darwin's Theory, which differs in nothing essential from that of Strato; though we may be pretty certain that neither Lamarck nor Mr Darwin has been influenced by the opinions of Strato, or of any of the ancients. It is, nevertheless, obvious that by having selected the very path in which the old philosophers were bewildered, the Transmutationists find themselves face to face with

* 'Nec audiendus Strato qui Physicus appellatur, qui omnem vim divinam in naturâ sitam esse censet, qux causas gignendi, augendi, minuendique liabeat, sed careat omni sensu.'-Cicero de Nat. Deor. 1. 13. 
their predecessors at last, and are constrained to adopt their ideas, and to make use of their language.

The remarks of Aristotle on such speculations, as they apply to a general principle, are as pertinent for these days as they were for his own. "Though all * generation and dissolution be never so much made out of something, whether it is one material or more, yet the question still is by what means this takes place, and what is the cause? because that which is the subject-matter cannot change itself. I mean this, neither timber nor brass is the cause that either of them are changed, for timber alone does not make a bed, nor brass a statue, but there must be something else the cause of the change, and to inquire after this is to inquire after another principle besides matter, which we would call that from which matter springs - or the cause of motion.'

On the whole, then, Lucretius, the celebrated exponent of the Epicurean system, has well expressed, in the interests of atheism, a pandenic creed for all times, which it will be found embraces some main points of the School of Transmutation-an absence of design in nature-and plenty of time and absolute ignorance as the only causes of all the phenomena and all the forms of life.

'But in what ways the concourse of atoms founded earth, and heaven, and the deeps of the sea, and the courses of the sun and moon, I will next declare. For, truly, not by design, did the beginnings of things station themselves each in its right place by keen-sighted intelligence, nor did they agree which motions each should assume; but because the first beginnings of things, many in number, and

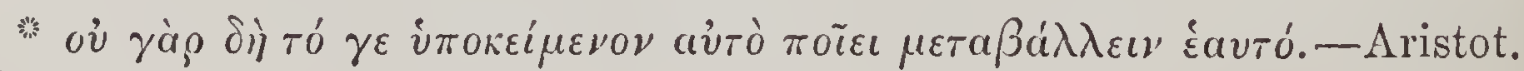
Met. i. 3. 
in many ways impelled by blows for infinite ages back, and kept in motion by their own weights, were carried along and united in all manner of ways, thoroughly to test every kind of production possible by their mutual combinations-therefore it is, that spread abroad through a vast period of time, after trying unions and motions of every kind, they at length meet together in those masses, which, brought together suddenly, become often the rudiments of great things, of earth, and sea, and the heavens, and the races of living animals. "*

One more remark then only remains, that allowing this school unquestioned freedom for their opinions, we have a right to protest against their interfering with our sentiments, for strange to say some of the Chiefs of the School have undertaken to read us a lesson of Theology, and to point out in what way we may still retain some remnants of the old faith tacked on to the grander creed of 'Iransmutation. This will be best seen in the words of Sir C. Lyell.

' Dr Asa Grey has pointed out that there is no tendency in the doctrine of Variation and Natural Selection to

* Sed quibus ille modis conjectus materiai

Fundârit terram et colum pontique profunda,

Solis, lunai eursus, ex ordine ponam.

Nan certe neque eonsilio primordia rerum

Ordine se quaque atque sagaci mente locarunt:

Nec quos quæque darent motns pepigêre profecto,

Sed yuia multa modis multis prinordia rerum

Ex infinito jam tempore percita plagis,

Ponderibusque suis consuerunt eoncita ferri,

Onnimodisque coire, atque ommia pertentare,

Qua cunque inter se possent congressa creare:

Propterea fit, uti magnum volgata per avum,

Omnigenos coetus et motus experiundo,

Tandem ea eonveniant, quro ut convenîre, repente

Magnarum rerum fiant exordia sxpe,

Terrai, maris, et coli, generisque animantum.-v. 417 
weaken the foundations of Natural Theology, for consistently with the derivative hypothesis of species, we may hold any of the popular views respecting the manner in which the changes of the natural world are brought about. We may imagine that events and operations in general go on in virtue simply of forces communicated at the first, and without any subsequent interference-or we may hold that now and then, and only now and then, there is a direct interposition of the Deity-or, lastly, we may suppose that all the changes are carried on by the immediate orderly and constant, however infinitely diversified, action of the intelligent efficient Cause.'-- (Antiquity of Man, 506.)

Thus Professor Asa Grey, seconded by Sir Charles Lyell, in condescension to our wcakness, gives us a choice of religions, neat varieties of faith, ticketed and docketed, and tidily stowed in the pigeon-holes of the learned Professor's study. However, with this free choice so liberally allowed us, and with these methods which ' we may imagine' to keep things decent, it is to be feared we shall not find one of the religious packets that will suit Mr Darwin's Theory; we have by this time become so thoronghly acquainted with his views, and so periectly understand his opinion of those who adopt 'the Theory of Creation,' that we are certain it will be impossible to find any theological varnish which can be made to adhere to his system.

Whatever our creed may be, we are not ignorant of the atributes of the Deity proposed for our worship by Sir C. Lyell and Professor Asa Grey ; an imaginary being of impotence and indolence, who having some hundred thousand million years ago created a sea-weed, retired from his demi- 
urgic labours, and has never been heard of any more. Hc has not troubled the world again "with any subsequent, intcrference,' to use the more dainty phrases of the learned Professor; and Mrr Darwin farther gives us an insight into his faculties, as we lcarn from him that it would have been impossible to create the limb of an animal, because it is so complex and beautiful a specimen of organization. This god of sea-wceds, therefore, who is less clever and efficient than the sea-weed which he made (for the sea-wced has done that which the maker of the sea-weed could not accomplish), may abide in the distance where these loarned gentlemen have placed him. Those who feel inclined may worship that deity, but we certainly shall not be of the number.

In the mean whilc those who join the School of Transmutation should make up their minds to adopt the system pure. Let not thcir courage oozc out at thcir finger-ends, when they find themselves confronted with a majority who may entertain different sentiments; but if they conscientiously believe thesc things let them profess them, and take the consequences, whatever they may be. The world will not be deceived by a masquerade of dissimulation, nor will they respect those who adopt it. Transmutation can have no creed. That is ccriain, and all the quibbles in the world will not alter this fact.

At the same time we would assert the right of all to profess thcir opinions, when not urged in a spirit of offence and insult; and we should vehemently deprecate the application of popular clamour and vulgar intolerance to cry down any opinions which we ourselves do not approve. Let the trith be canvassed freely; we have no misgivings re- 
garding its ultimate victory, nor have we the least fear of its succumbing ultimately to popular names, whatever temporary success those names may impart to a cause which we are persuaded is based on false principles.

Mr Darwin has been fortunate in the conjuncture in which his book is offered to the public attention, as it is an era of change, and, perhaps, of not far distant revolution. In such a period, a work of the peculiar tendencies which are conspicuous in 'The Origin of Species' is sure to be acceptable, as it will be recognized as a valuable coadjutor for that thorough license of speculation which such an era always demands. In the mean while it is said that the success has been great, and that the disciples are numerous, so that Mr Darwin need not now connine his hopes of acceptance to 'a few* naturalists, endowed with much fiexibility of mind,' or look with confidence only 'to young and rising naturalists.' 'The flexible naturalists and the juvenile philosophers have indeed joined his ranks, and others, too, whose character and calling might have been considered a safeguard against such a movement. On the whole, however, this is such an event as need not create surprise, as it is evident that fashionable opinions of the day, novelty, and exaggeration, have more general influence at present than sober thought, deep-based convictions, and patient inquiry. We are in an age of exaggeration, both in politics, literature, and science. We are sowing the wind, and we must reap

* 'A few naturalists, endowed with much flexibility of unind, and who have already began to doubt on the immutability of species, may be influenced by this volume; but I look with confidence to the future, to young and rising naturalists' (516). It is to be hoped that the flexibility of these naturalists does not extend to their bodies also, as in that case we inight, according to the Theory, expect to see them changed into strange animals - centaurs or pterodactyles, or some other alarming creatures. 
the whirlwind. After a season of unsettlement, and its inevitable consequences, there will be a rcaction in the right direction, and it will be generally felt and acknowledged that all excess of sentiment is as much to be deprecated as excess of action.

FINIS. 


\section{APPENDIX A.}

Thi direct tendeney of the physiologieal systern which has been examined in the preeeding pares is, for the most part, left by its authors as an inferenee; the principles of the Sehool are laid down, but the corollaries are left to be deduced by those who aeeept the principles.

An energetie labourer in this Sehool, Dr Carl Vogt, Professor of Natural History in the University of Geneva, in his 'Lectures on Man, his place in Creation, and in the History of the Earth,' has stated this clearly enough. Thus does he expound the doctrine of the School :-

'There can be no doubt Mr Darwin's Theory ignores a personal Creator, and his direet interferenee in the transformation and ereation of Speeies, there being no sphere of action for such a Being. Given the first startingpoint-the first organism, all existing organisms are subsequently, by $\mathrm{Na}$ tural Selection, developed from it in a continuous manner throngh all greolugical periods, by the simple laws of transmission. Every man is neither a distinct ereature, forned in a speeial manner, and differently from all other aninals, nor provided with a special soul, and endowed with a divine breath of life. He is only the highest product of a progressive Natural Selection, and descends from the Simious group standing next to man.

'Darwin, it must be stated, has nowhere in his work touehed upon these sequences, so that, from the richness of materials, and the logieal treatnent of the leading idea, the work met at first with a very fuvourable reception in England,-a eountry so much attached to Biblieal traditions. But when it was pereeived upon what base the Theory rests, the storm broke forth from all quarters of the eompass; - nor has the agitation as yet subsided. But we inust not be disconeerted by attacks of this kind.'

Dr Vogt, who accepts the theory of Mr. Darwin as far as it is in opposition with a belief in a Creator, has his own partieular views, whicl do not always aecord with the dictations of the great Corypliæus, but he eoncludes his Leetures with the following passacre:-

'The lancentation over the destruction of all faith, morality, and virtue, the woeful ery about the endangered existence of society, is by this time heard in the French tongue. The pulpits of the orthodox churches, the platforms of the missions, the chairs of the consistories, resound with the pretended attacks on the foundations of human existenee made by Materialism and Darwinism. 
'Let them rage! They require the fear of punishment-the hope of reward in a dreant-of-beyond, to keep in the right path; for us suffices the consciousncss of being men amongst men, and the acknowledgrnent of their equal rights. We have no other hope than that of receiving the acknowledgments of our fellow men; no other fear than that of seeing our luman dignity violated-a dignity we value the nore since it has been concuered with the greatest labours by us and our ancestors, DOW TO THE $\triangle P E '(469)$.

This sensitiveness for the dignity of humanity, which the learned Professor traces directly to the ape, here distinctly named as the first anthopuidal ancestor of man, is a curious phenomenon. It is as a fanily feeling, and as such may clain our forbearance; for if some are tremblingly alive to the honour of their Anglo-Saxon descent, and others to their Nornan origin, why should these philosophers be debarred the satisfaction of tracing their families up to orang-outangs and apes with blue tails? There may be motives of private consciousness prompting them to contend for this genealogy with which we would not interfere.

A considerable portion of Professor Vogt's lectures is dedicated to the proof of the connection between inan and the ape, and yet there are some strange admissions in the progress of this inquiry, some of which onght to be the groundwork of deduetions but little according with the learned Professor's theory.

"This organ (the foot of the ape-chimpanzee), compared with the human foot, is a real hand-the thumbs thicker and larger than in the anterior haud; but still it is a hand, with a flat lower surfaee, well-separated, movable, drawn-out fingers, with opposable thunb, and a long, furrowed palnn. On comparing a sketeh of this hand with that of a human foot, we perceive that Burmeister was right in designating the foot the specific character of leumanity' (155).

Now this is yielding a much-contested point, and aeceding to the definition that the ape is a quadrumanous animal; thus separating the ape altogether from man.

However, the conclusion of the whole matter is thus:-_'If, in different regions of the globe, anthropoid apes may issue from different stocks, we cannot see why these different stocks should be denied the further development into the human type, and that only one stock should possess the privilege; in short, we camot see why the American raees of man may not be derived from American apes, Negroes from African apes, or Negritos from Asiatic apes' (466).

As Professor Vugt advocates a plurality of races of man, he, of course, derives these races from a phurality of apes; but he has not told us from which of the four-handed worthies of the forest the European race of nan is sprung; so that, in contending for. 'liuman dignity,' lest by some calumny it should be 'violated,' we are at a loss to know which of the Sinian tribe clains our particular respect, as the source from which we liave derived our position in socicty.

Proiessor Vogt, whose system differs in many points from that of $\mathrm{M}$ Darwin, is in complete opposition to it on the origin of different organic buings, for where Mr Darwin traces tlem all to one primal furm, Iroficssor 
Yogt offers cogent reasons for the impossibility of this plan:-'From the Vertehrata to the Invertebrata,' says he, 'I can find no guide, nor have I any idea by what adaptation or intermixture intermediate forms can arise, which may lead from the Mollusca and Articulata to the Vertebrata. It is, moreover, well known that the lowest Vertebrate we are acquainted with, the Amphioxus Lanceolatus, is, as regards the development of all its organs, so far behind that of the higher Mollusca and Articulata, that the transition from one of these better-developed types into that of this Vertebrate would include a series of retrogressions from which, nevertheless, is said (by Darwin) to have issued the beginning of a structure capable of the highest development. In other words, I see here the Vcrtebrate type, with man as its highest development, commencing with an animal which, as regards the perfection of its organs, is excelled by most worms, and nluch more so by the Mollusca and Articulata, which, in some instances, attain the highest development of which the structural plan of the Articulata is capable. I should thus find myself face to face with an insoluble enigma, if I were not permitted to recur to the conclusion I have arrived at, namely, the assumption of an original difference in the primary germs from which the animal kingdom has been developed' (460).

This reasoning is both intelligible and convincing; but if it drives the learned Professor to 'assume' that there were various primary germs, from which the various divisions of the animal kingdom must have sprung, it amounts to the supposition of an original plan, and to the acknowledgment that there existed primary germs differently constituted for different oljccts, to say nothing of the origin of these germs, of which this system gives no account. Professor Vogt thus escapes indeed from the enormous absurdity of retrogressive formations, adopted by Darwin and Lyell,--an absurdity which supposes that certain animals have gone backwards through old forms in order to start better in a new; but he docs not escape from the necessity of acknowledging a design of Creation, by the plan which he proposes.

It is, however, curious to hear the Professor energetically protest against the one primordial gern. 'Not only,' says he, ' do organisms that stand in an intermediate position between animals and plants consist of different kinds of cells; not only are those cells developed in a different mode, so that we are able to distinguish different species of these organisms; but also those egg-cells from which the more compound organisms are developed, show, from the beginning, a fundamental difference, both of form and subsequent development. The attempt, therefore, to reduce the whole organic world to one fundamental form, so to speak-one primordial cell, from which all organisms have been devcloped in different directions, is as futile as the assumption of those Naturalists who consider that the whole organic creation has been developed from an elementary plastic matter-the so-called primordial slime' (445).

From whence then came the varied germs of Professor Vogt's theory? From the soil! This we are told distinctly; but we are not told how the soil produced them.

'If it be difficult to conceive how the great diversity of organic types could have been dereloped from a common soil it can, on the other hand, 
not be denied that an intrinsic difference in the constitution of this soil may have given rise to the diversity of the types springing from it ' (446). Thus, then, after all we come back to the old thing, to the Mother Earth of Lucretius, and of the first speculators in the mystery of Creation, when science had no existence, and when the imagination undertook to settle that which experiment, analysis, and induction can alone establish.

\section{THE LEPORIDES.}

Sone time ago there was a good deal of talk about the Leporides, or crosses between hares and rabbits, that were alleged to be raised in considerable quantities by an enterprising Frenchman. Dr Pigeaux, writing in the Bulletin de la Société Imperiale Zoologique d'Acclimation, observes, 'To sum up, therefore, we would affirm that Leprovides exist, undoubtedly, under both forms, with predominance of the hare or the rabbit; but as a Species, or even as a Variety, we cannot admit them, since, like all other crosses, they have only an accidental productiveness.' He adds that their flesh has neither the whiteness of the rabbit nor the flavour of the hare.From the Intellectual Observer, August, 1867. 


\section{APPENDIX B.}

Wincs these sheets are going through the press another writer of the Transmutation School has published his opinions, in a book of which the title is 'The Geographical Distribution of Manmals, by Andrew II urray.' This work, excepting the theoretical part, is a valuable contribution to Natural History, and is ilinstrated throughout by useful maps to show the habitat of the animals properly belonging to the author's plan. Unfortunately, however, the author has not confined himself to facts, but following the fashion of the day has propounded a Theory of the Origin of Species, which has its peculiarities, and accords with that of $\mathrm{Mr}$ Darwin only in the principle of excluding creation, - in the mode of exclusion these learned gentlemen do not agree.

'In some respects,' says the anthor, 'I have come nearer to Mr Darwin's views, but in others I still differ from him. It is not, lowever, by way of opposition that I offer my views; mine are rather of the nature of a sequel to his, or an attempt to work out the truth by the light of his previous labours.' He informs us that 'species are not modelled or produced by independent creation, but that under the operation of a general law the germs of organisms produce new forms different from themselves, when particular circumstances call the law into action.'

He inclines to 'the involution 'Theory of Bonnet and Priestly, that all the germs of future plants, organical bodies of all kinds, and the reproducible parts of them, are really contained in the first germ. This appears to me to furnish a satisfactory explanation of the homologies in structure, and the relationships between species, which are everywhere apparent through the organized world.'

This system of Bonnet, long ago exploded on the continent, and thoroughly decrié by the French physiologists, annong whom it first made its appearance, is by them called the systen of 'cmboitement' from the resemblance it offers of a series of boxes enclosing one another. For as all species have sprung from germs, there must have been germs within grerms for future transformations to an unlimited extent; and for aught we know to the contrary, as we spring from germs contained within apes, there may be germs within us for the development of other animals, as soon as our present 'inertia' shall change to a more active state. In this way the monkey himself sprung from some antecedent other animal, the horse from the germ within an ass or a quigga, and so of all the equine germs. 
'If in the concurrence of particular circumstances a law comes into action effecting an alteration in the yerm which is about to be developed, it follows that in those points where the law has not affected the germ, it should have the same form as the parent; and on those points where it lias affected the germ, it unst produce the alteration, not by a creation of new parts, but by an alteration of those already existing' (5).

After stating that, he does not dispute 'Mr. Darwin's existence of the struggle of life, and that that influence cleared away the weakly and left the strongly endowed,' $\mathrm{Mr}$. Murray adds, 'I have not succeeded in bringing my mind to accept the possibility of a new species being eliminciled (sic) out of any amount of gradual variation, hybridization, or str'ugrgle for life, taken either singly or in continuation.'

Mr Murray informs us that in the developinent of a germ into a new forn, 'if fins were wanted where legs were before, they obtained not by the creation of a new organ, but by alteration of the parts of the leg, hence the existence of homologies between them.'

If fins were wanted! thus then it would appear that some terrestrial animal had within itself the germ of a future fish, that in process of time the germ awoke, and recognized its wants, and that to gratily its wishes, the leg which it had inherited from its parent 'by the operation of a general law,' turned into a fin by the process of 'alteration,' other parts we presume turning into a tail, gilis, \&c.

Here, of course, Mr Murray agrees with Mr Darwin that the animal changed, but neither of these profound expositors of Nature's secrets give us any information as to the condition of the animal whilst the change was going on. Half a fin and half a leg would not suit either land or water ; it would only verify the old saying, 'neither' fish, nor flesh, nor good red herrings.'

If we inquire of the first movement of the enclosed germ, and how it comes at last, after ages of contented quiescence, to show an inclination to change-or if we ask how in this system the stability of Nature is not continually in a state of jeopardy, we have this answer: 'I imagine that the law which secures the stability of species is INERTIA-so long as they are not meduled with they stand still; but subject them to change, whether it comes to them, or they go to it-give them an impulse of any kind, and variation conmences. Some receive the impulse more easily than others. What may be felt by one may not be felt by another. Constitutions differ (!), hence the greater range of some species than otirers ; but wherever the change makes itself felt, there I apprehend modification commences.'

'The result of this exposition then amounts to this, that animals have no disposition to change, and that if they are let alone they remain. as they were. The grerm within keeps quiet till it is put into circumstances to desire a change. The proposition that 'if the germ is subjected to change variation will commence,' wonld scarcely be contested, as little as that ' when change malies itsclf felt modification will commence.' 'These profonnd remarks will pass undisputed, but the difficulty is in subjecting the germ to change, and in making the change felt. If things change, they do change; no dorbt of that, but the effecting the mutation is the thing to 
be proved. If the sky were to fall we should catch larks. These IFs are the cloud-pillars of many a beautiful fabric of the imagination, but when the rays of truth penetrate them they melt away into aëry dreams.

It is a singular part of this Theory that changes take place not in individuals only, but in masses of organized beings, many thousands of the same species changing at the same time. 'One essential element in my Theory is that the change is effected through the medium of not single individuals, but of a multitude of individuals; a whole nation of the same species' (8).

As, then, we are informed that 'man cannot be regarded as more widely separated from the apes than the different families of them from each other' (73), which amounts to this, that man is a species of the ape genus, and as no species is created, we must understand that the germ of the human species began to break through its inertia which it had maintained within the ape for ages, and to make a stir for a new form-the human. This stir was not in a solitary individual, not in Sir C. Lyell's one superior ape, but in a whole nation of apes at once, and thus some thousands of men and women were contemporaneously 'developed' out of some thousands of male and female apes.

$\mathrm{Mr}$ Murray is careful to inform us that 'the process of change is obviously gradnal and imperceptible, and extends over a greater space of time than we have had the opportunity of observing' (8), and of this there can be no doubt.

IIow far this prudent remark is in keeping with the following statement the reader must judge:

'The adaptation of species to the conditions in which they are to pass their lives, as of tree kangaroos to a life in trees, is a phenomenon which does not come within the scope of this inquiry. I offer no opinion here upon the subject. Only of one thing I may say I feel as sure as I can be of anything which $\mathrm{I}$ do not know, and that is, that it is not by the process supposed by Mr Darwin, namely, by Nature trying an infinity of experinents, and rejecting them till she hit upon the right one. Nature never makes chips. When the occasion for a tree hangaroo arose we may be sure that the tree langaroo appeared perfect at the first attempt. There was no failure of myriads of kangaroos in other directions created or developed but to die, until by chance one in this direction appeared. This $I$ feel, but I cannot prove it. It is only my feeling, and therefore of no use to any one but myself' (13).

Mr Murray inust excuse us. This 'feeling' is of very great use to us all,- it is the feeling of common sense breaking down the barriers of dogmatism and paradox; it is the force of that great gift bestowed on us all, plain reason, vindicating its liberty and casting off the trammels of inagisterial hypothesis; and forcing a man to acknowledge, that which it is most difficult to disbelieve even for a short time, that a superior power created animals perfect at once, for the part that was chalked out for thein in the domain of creation.

Mr Murray wishes to be in the mode, and to build up an atheistic system, but common sense breaks out in this passage, and sweeps away 
not only Mr Darwin's laborious extravagances but Mr Murray's germs, and imaginary laws of nature, and labulous ' developments.'

With Mr Murray's reasons for not assenting to Mr Darwin's machinery of change, as expressed in the following words, we shall all be disposed to agree.

"What impressed me more than anything else was the absence of any transitional form or geological evidence in support of this idea. I argued that if such transition really existed, it ought to have been seen or to have left traces of its having been, but no form has as yet been discovered ainong fossil remains, which can be fairly adduced, as showing a gradation of form passing, during the course of time, from one species to another,' \&c., \&c. (5).

Thus, then, even the Transmutationists hurl the rocks against Mr Darwin, and overwhelm him with the mountains. There is intestine war amongst the Giants themselves. They would scale the heavens, but they cannot agree amongst themselves. The labourers in this great Babel have different languages and cannot act in harmony. Their tongues have been confounded. There is division in the camp, and with division hopeless and irremediable discomfiture. Nevertheless, though each of these teachers of the School of Transinutation has his own Theory, and though no two of them agree, yet in one particular there is harmony annongst them, in the usage of a vague language for the furtherance of their Theories, an unsubstantial dialect, with which it is impossible to grapple.

The favourite phrase with the School, in which indeed some of them mask their whole Theory, is 'developinent;' and of this we have said more in another page. In Mr Muray's system it is indeed everything. When he wants to produce a new animal out of a dormant germ, the germ has been 'developed.' He tells us with much gravity that the whales of the arctic and antarctic species were 'developed' in the Meiocene period (212).

The developing of a whale must have been no trifling matter, and we ought to hear something of the process, as from what it was developed, and by what particular mode. But this is left unexplained, and 'development' is made to act as a sort of thimble-rig of physiological conjurers, and to produce the required change under the hat of mystery. A herring, perhaps, is put under the hat-presto!-the hat is removel, and lo! a whale!

The whale, indeed, seems to be the great bait to catch the philosophers of this School. We know its success in Mr Darwin's case, and its attractions have been irresistible for Mr Murray." But seriously, all this

* That this is a proeess seriously contemplated by the author we sce in the following passige, which, if professedly written to ridicule the 'lransmitationists, night be thought too broad a earieature:-

"The origin of marine animals by deseent, in other words, their derivation or parentage, has always appeared to me one of the most diffieult problems to solve. How a terrestrial animal eould ever give birth to a scal or a whale-how it could ever nurse or feed it, naturally milkes us pause and wonder. 'The very first and most essential qualification of a co:amon medium in which to live scems wanting; when we cone, 
affords a most instructive lesson to us, that when learned physiologists forsake the legitinate path of facts, to indulge in the pursuit of hypothesis, they fall into mistakes palpable even to the illiterate. Curious, indeed, it is to observe that these interpreters of nature, whose sceptical logic will not admit the idea of a Creator, can, with such perfect self-complacency, indulge in a language which represents no recognized fact, and expresses nothing but a coinage of the imagination to conceal unacknowledged ignorance.

'Development-germs-the operation of a general law-Natural Selection,' \&c., \&c., \&c. Assertions like these, resting on no proof, and incapable of being proved, are quietly assumed as the solid materials for their hypothesis. They argne on them as if they were realities, and seen to persuade themselves that they liave by their instrumentality produced a new system, which is to be a substitute for the received opinions and firm belief of all the common sense of mankind; and thus, to use the caustic language of $\mathrm{Dr}$. Jolinson, 'these persons are weary of the oldfashione 3 practice of milking the cow, and su they go to milk the bull.'

however, to think of the steps and processes by whieh this creation (sie) may have been effeeted, we find ourselves wholly at sea without eompass or rudder. We do not even know at whieh end to eommence our speenlation. Were the aquatie animals deseended from the terrestrial or the terrestrial from the aquatie? although the probabilities seem in favour of the former, there is no faet known whieh shuts out the possibility of the seals having been in existence before the earnivora. The latter is the most natural theory, beeause it seems to stand to reason that the exceptional form should be derived from the normal rather than the reverse; although if pressed for a reason why one should be eonsidered more normal than the other, I ninst candidly confess that I have none to give, exeept the revy lame one that now the one is more numerous than the other' (123).

After some more musings on this deep question, the learned author inclines to think that the bear was the lineal aneestor of the seal (125). "What amphibious carnirora have we then of bulk approaehing to the seal? none but the bear.'

So bulk earries it, and the bear produced a germ whieh produced a seal.

If we were students of this sort of genealogy, we should be disposed to enjecture that the seal produeed the bear, for this simple reasen, that the polar bear nostly feeds on seals, and indeed eonld not exist withont them. The food necessary for its existence must have preceded its existenee, and this it will eome to pass that the bear eats his an eestors.

The reader will remember that in Mr Darwin's system the bear is progenitor of the whale; so that altogether bears and whales seem destined to be pierres d'achoppement for the learned Protessors of the School of Transmutation. 


\section{APPENDIX C.}

\section{Professor Gïppert on the Darvinian Theory.}

Is the Angust month of the Journal of Botany is an interesting paper by Professor H. R. Güppert, translated from the Nova Acta of the Imperial German Academy Naturæ Curiosorum.

The title of this essay is 'On Aphyllostachys, a new genus of fossil plants of the Calamites group, and on the relation of the Fossil Flora to Darwin's Theory of Transmutation.'

The learned Professor first notices Dr Hooker, who, in his 'Tasmanian Flora,' lias adopted the Theory of the Transmutationists. Neverthcless, Dr Hooker, it seems, does not find much to encourage him in his floral studies. 'He holds that, regarded from the classificatory point of view, the geological history of plants is not so favourable to the Theory of progressive development as that of animals, because the earliest ascertaincd types arc of such large and complex organization, and because there are no known fossil plants which can certainly assume to belong to a nonexisting class, or even family, and none that are ascertained to be intermediate in affinity between recent classes and families.'

Dr Hooker also acknowledges the absence of genuine monocotyledonous plants in the ancient flora, and all this from an advocate is a scrious admission.

Professor Göppert holds that 'our knowledge of fossil plants is amply sufficient to supply decided proofs' that there are no genetic rclations in the geological history of plants such as the Transmutationists would require. He urges also that a high importance must be accorded to those species of plants, and to the more numerous animals, which have passed from the Tertiary period to our own time, and still more to those which liave existed unaltered through theree periods, as the Nenropteris Lostici, which ranges from the lower coal formation, through the upper to the Permian. 'If we add to this,' says the Professor, 'the numerous families and genera which have remained unitured since their first appearance, so that the same charactcrs can be used for the definition of the different specics that occur in all the geological periods, it is difficult to perceice where the mutations are to be found, which the different species are said to have undergone.'

The Professor then urges 'that in the very earliest times of the land Flora certain groups of plants, for instance, the Ferns, appear in a degrce of perfection, previous to the gradual development of which an cnormously long range of time, and numberless antctypes (which, howcver, are cntirely wanting) would be required in the Darwinian Theory.' Bcsides this some groups become extinct at very early geological periors, leaving 
to subsequent periods only faint remnants or indications of their former degree of perfection.

A few orders and families attain, on their first appearance, a high degree of development, and retain this down to the present time; this applies to the oldest fumily, the Algre. Other orders, as, for instance, the Coniferæ, which began with the Abietineæ, as early as the Palæozoic period appeared in such diversity of form, and high internal structure, as in no subsequent period.

The Cycader also, of the Permian formation, attained an organism of a ligher stage of development than is observed in any Cyead before or since that time.

Quite isolated are the Sigillaria, and even without any further evidence they are quite sufficient, says the Professor, to support the dictum that certain forms were created only once, in eertain geological periods, without the ereative power being solicitous, as Darwin everywhere assumes, to ensure their further development.

He then observes that the vegetation of our globe commenced with Algæe, "but one would make a mistake in supposing that the lowest forms appeared first and isolated.' 'T!his is by no means the ease, for with the lowest unicellular Algæ, the higher Florideæ co-existed, and even a Callithamnion.

The Fungi are of a lower grade than the Algæ, and we meet with them first on Ferns of the coal period. The other eellular plants are entirely wanting in Palæozoie strata, they make their appearance only in the Tertiary period, and perhaps they have not existed earlier.

'In a strict succession, aeeording to the Theory of Progressive Development, there is here a serions break-down.'

All the lower stages of the vegetable kingdom, cellular plants, higher Cryptogams, Monocotyledons, and even Gynosperms, already existed in the Palieozoic period, but the appearance of genuine Dicotyledons has still to be discovered. In the Cretaceous formation, however, genuine leafDicotyledons appear, and there is from that time a eonstantly increasing approximation towards the Flora of the present time; and this proceeds, until, in the Tertiary period, the balance is turned, and the living forms predominate.

'If, as I believe, notling can be said against the correctness of these views-based as they are, not upon conjecture or mere examination of external appearances (most deceptive in fossil plants), but upon internal structural differences-one is at a loss to eomprehend how all these very different forms ean have descended in a direct line from eaeh other, and, as a necessary consequence of sueh a theory, from one prinordial form; or low they ean have been developed into the present diversified form of life by undergoing a constant nutation of hereditary peculiarities, by individual variations, by struggles for existence, and by Natural Selectionthe principal dogmas of the Darwinian Theory.

'Under these circumstances, it will be granted that the doctrine of Transmutation receives no more support from the fossil flora, than it does (as Reuss has shown most convincingly) from the fossil fauna.' 


\section{APPENDIX D.}

\section{MIMICRY IN NATURE.}

\section{From the Athencum.}

' Oxford, Dec. 4, 1866.

'IN every division of animated nature, even of comparatively limited extent, are to be found species which, although agrceing in all their ehief structural characters with the types of sueh groups, exhibit in their general form and appcarance so great a rescmblance to the members of some other group, that by ordinary observers they are at onee regarded as belonging to the latter, and not to their own legitimate group. Thus, an eel resembles a snake more than a fish, a euckoo resembles a hawk, a humming-bird hawk-moth so nearly resembles a lumming-bird that a person who had seen the Trochilidæ in their American haunts eould not be brought to believe that one of the moths which he happened to have noticed in Oxfordshire was an insect. This kind of external resemblanee has been termed Analogy, and was greatly used by M'Leay and Swainson in the development of their respective "Systems of Nature." More recently this resemblanee has been termed "Mimiery," and some very remarkable instanecs of it have been described and figured by $\mathrm{Mr}$ Bates, occurring in certain speeies of butterflies whieh frequent the banks of the river Amazon and other parts of South America in vast numbers, both of speeies and individuals, forming a separate family, the Heliconiidx, distinguished by their very peeuliar elongated wings, as well as by their distinct styles of colouring. These butterflics are, it appears, accompanied in their flight by eertain other species of butterflies, which so eloscly resemble them in gencral form and colour as to be scarcely distinguishable from them, although belonging to a totally different family, the Pieride, of which our eommon white butterfly, Pieris brassice, is the type. Aceording to Mr Bates, the Melieonians emit a disagreeable scent, which renders them distasteful to insectivorous birds, and so preserves them in the "battle of life;" and he moreover assumes that their minics, the Picridans, have, by a long proeess of devclopment from the old typieal white, broad-winged form of their own family, attained that of the well-todo Helieonians, and have thereby been enabled to improve their condition and maintain their existence in nature. 
'It may, I think, fairly be doubted whether' this system of minicry has been benefieial to these Pieridan butterfies, and that their evolution from white progenitors is in the highest degree problematical,-1st, Beeause the mimicking species barely exist, mueh less flourish, in the eountry where the Heliconiida abound, "not more than one in a thousand" individuals having been found by Mr Bates. 2nd, Because there still oceur: numerons species of white Pieridx in the comntry of the Heliconiida in a flourishing condition. 3rd, Beeause there are numerous other groups and speeies of butterflies in Brazil, equally suljeet to the attaeks of birds with the Pierida, whieh have never attempted to assume the forms of the dominant group, Heliconiidæ. 4th, Beeause there are numerous instanees of mimiery between the different species of Helieoniida then:selves, which, therefore, needed not the indueement to mimiery attributed to the Pieridre. 5th, Because there are eertain speeies of Pieridxe of whieh only one sex mimies the Heliconiidx. It would require a wide stretch of imagination to suppose that Natural Selection could have led to the assumption of such mimiery ly the individuals of only one of the sexes of a species. (Papilio Ceneus earries this mimiery still further, the male resembling Danais Echeria, and the female Danais Chrysippus.) 6th, Because the Theory assumes that the Heliconiida existed before the attempt at mimiery commeneed on the part of the Pierida, whereas Mr Bates's statements would lead to the inferenee that the Helieoniidx are so unstable a group that the manufacture of species is still going on amongst them. 7th, Beeause, according to the doctrine of ehances, it is in the highest degree improbable that a easual variation of any given species of Pierida should by constant modification, assisted by hereditary deseent, gradually assume the form, and eolours, and markings of another species, especially of so remarkable a type as the Helieoniidse. But for an entire group to be simultaneously engaged in sueh a process, each species tending towards distinet and equally peeuliar species, would, by a logician, be pronounced impossible. The admission' that the God of Nature created these speeies in their present mimetic condition for some wise, but hidden, purpose, disposes of all diffieulty.

J. O. WESTWOOD.' 


\section{APPENDIX E.}

Bremser, on the Revolutions of Life on the Globe:-'I believe as little that the cedar of Lebanon was originally moss or lichen, as that the elephant owes his origin to an oyster or zoophyte, even had he passed through a thousand gradations; and still less do I allow that man was originally a fish, or an animal covered with scales, as some modern naturalists (Lamarck) endeavour to make it appear. If things had proceeded in this manner, then similar progressive metamorphoses, or rather gradual formation of new beings, and others more and more perfect, whether among plants or animals, would be taking place daily under our observation. But to speak only of man: nothing proves that there is any progress in his physical and moral organization, to indicate an ulterior development. He remains always the same, such as he was thousands of years since. The influence which government, education, and soil have upon some nations cannot be taken into consideration; there existed in the most remote times just what we see in the present daynen endowed with elevated intellect, and men of narrow capacities.

'The intestinal worns, which are engendered daily under our own notice, furuish a proof adverse to such a progressive transformation of animals of an inferior degree to those of a lighlier class. In fict, if that took place, the least perfect worms would always be the first formed, and the most perfect would be developed afterwards; but no observation warrants us in believing that ascarida, for instance, draw their origin from a liydatide or tæuia. In this hypothesis it is presumed, as may be seen, that the greatest perfection would consist in the greatest and most raried composition, and that imperfection would be in direct relation to simplicity. What I have just said would happen, however, even upon the contrary supposition.'-Quoted in the Notes on Bertrand's Revolution of the Globc. 1835. 
$\gamma$ 

. 
